\title{
Pleasure, pain and pornography: A gendered analysis of the influence of contemporary pornography on the lives of New Zealand emerging adults
}

By

Samantha Maree Keene

A thesis

submitted to the Victoria University of Wellington in fulfilment of the requirements for the degree of Doctor of Philosophy in Criminology

Social and Cultural Studies

Victoria University of Wellington

2019 


\begin{abstract}
Historically, concerns have been raised about violence in pornography and the influence that such portrayals may have on levels of violence against women and children. Today, pornography is pervasively available on the internet and viewed by both men and women in ever-increasing numbers. In New Zealand, violence against women and children remains at alarmingly high levels, and concerns about pornography's influence on gendered violence are a common refrain. Research remains inconclusive about the impacts of pornography on viewers' sexual scripts, behaviours and attitudes, yet the voices of those most affected by pornography - viewers and their partners - are often omitted from pornography studies.
\end{abstract}

Few New Zealand studies employ a gendered analysis of men's and women's experiences with pornography. To provide research specific to New Zealand about these experiences, this thesis explores the reported influences of mainstream pornography on the lives of a self-selecting sample of (primarily) heterosexual New Zealanders between the ages of 18 and 30. It adopts a uniquely gendered analysis and critically interrogates both men's and women's experiences with pornography in the digital age.

The findings of this research suggest that pornography research necessitates a gendered appraisal both in terms of how pornography is experienced individually, but also within intimate relationships. For instance, whilst both men and women suggested that mainstream pornography was often aggressive, demeaning and degrading, the way that aggression was perceived and understood differed between the genders. Some women spoke of 'rough sex' having some sexual appeal, however, they also felt conflicted about feeling aroused by pornography in which actresses appeared potentially in pain or distress.

Conversely, several men spoke of aggression in pornography as commonplace but something they might avoid rather than denounce, leaving the door open for other men to engage with as a matter of individual 'choice'. Further, men's worries about pornography concerned their compulsive need to use it, which differs substantially from women's concerns. This research also suggests that gender is a critical factor in considering pornography's impact in intimate relationships, particularly regarding pornography addiction and the perceived influence of pornography on partners' 
behaviours and sexual scripts. These findings are a testament to the gendered way that pornography is experienced, understood and interpreted in the digital age.

Overall, this thesis provides a platform for future research into pornography in New Zealand. It provides a comprehensive and nuanced understanding of how online pornography affects the lives of every day New Zealanders, and highlights the need for more critical, gendered analyses within this space. Further, the findings also indicate the importance of providing young people with the media literacy skills needed to appraise how mainstream pornography reinforces stereotypical gendered representations of men, women, and heterosexual sex. 


\section{Acknowledgements}

As I write these acknowledgements, I am reminded of just how much of a rollercoaster this journey has been. There have been so many highs, a fair share of lows, and the process from start to finish has been a painstaking labour of love. There have been so many people that have supported me in this journey, which has been both academic and immensely personal, and it's impossible to thank everyone individually.

Talking about pornography is challenging, so opening up to a stranger about one of the most personal aspects of their lives is undoubtedly a difficult task. I want to thank the participants who took the time to share their stories and experiences with me. I was immensely privileged to hear them, and I will be forever grateful. Without your stories, this research would not have been possible.

This thesis would not have got to the finish line without the continued support and guidance of my incredible supervisors, Professor Jan Jordan and Dr Carol Harrington. I struggle to find the words to express how thankful I am for everything you have done throughout this thesis journey. Jan - working with you for my entire postgraduate life has been an absolute joy. There are few people in this world that inspire us, challenge us, support us and guide us through both research and life's obstacles. You really are one in a million. Carol - thank you so much for your critical insight and feedback, for keeping me focused and for always offering a unique perspective. Talking about sex toys at supervision meetings has been one of the most unique aspects of a doctoral project on pornography, and I would not have wanted those conversations with anyone else! I hope you are both pleased with the final product.

The list of everyone else that supported and guided me through this research is almost a mile long. My family - Mum, Rachel, Ashleigh, Grandma - thank you for believing in me, listening to me, and for always being there when things were rough. My friends - Poppy, Woody, Eli, Toni, Jordan, Sally, Sophie, Shannon - thank you for your support and for listening to the trials and tribulations of both life and thesis. Finally, it's time to celebrate! Lastly, to Gill - I'm not sure how I'm going to survive without our daily debriefs, laughs and occasional cries. Thank you for always managing to keep me grounded during the chaos. 
The staff in the criminology department also deserve a massive thank you, as well as the administrative staff in the school and the wider postgraduate community. Thank you for always making me feel supported, welcome and part of the school.

Finally, I'd like to thank the Royal Society of New Zealand for providing the financial support for this research. Without the scholarship offered through Jan Jordan's Marsden Grant, this research would not have existed. Further, Victoria University's Doctoral Submission Scholarship was instrumental in the final three months of completion. 


\section{Table of Contents}

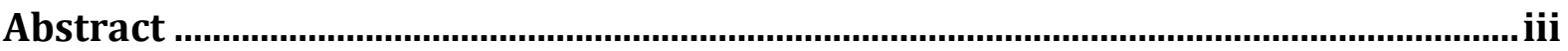

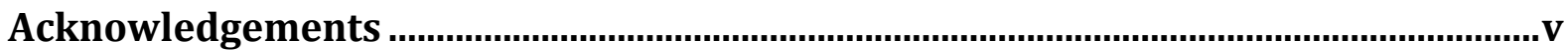

Table of Contents................................................................................................................. vii

Chapter One: Why study pornography? ........................................................................ 1

Why study pornography? A background to the research....................................................... 2

Pornography or porn: a note on terminology ........................................................................... 3

The contemporary New Zealand pornographic landscape................................................... 7

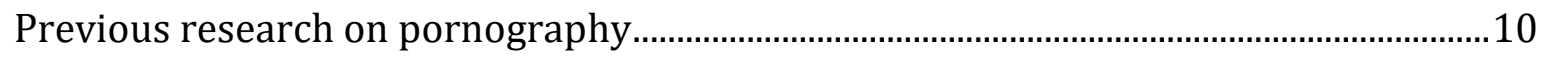

Thesis aims and key findings ............................................................................................11

Chapter Two: Mapping the terrain of the pornographic research landscape .........15

The 'sex wars': conflicting feminist perspectives on pornography ....................................15

The shifting content of pornography: from Playboy to Pornhub ........................................18

From the shelves to the bedroom: the content of pornographic magazines...............18

Plugging in and switched on: pornography in VHS/DVD formats .................................19

A click away: the content of contemporary internet pornography ..................................20

The pornographic audience: consumer engagement and experiences with sexually

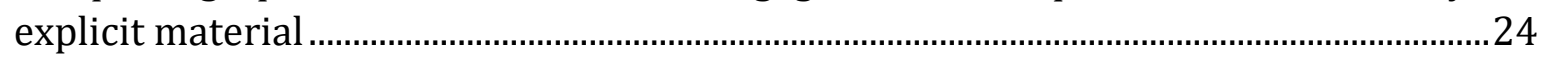

Overexposed? Young people and internet pornography ……........................................24

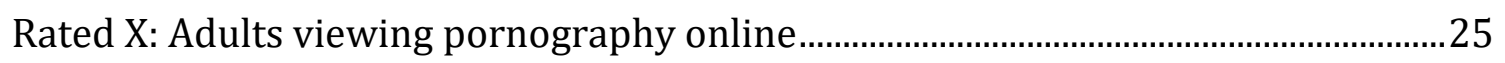

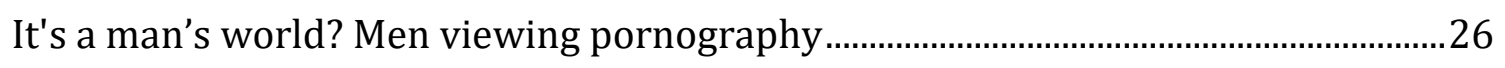

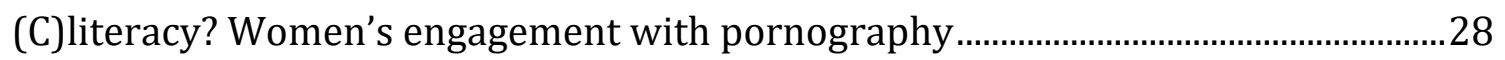

Pornography as the 'third' person in a relationship? Pornography's location in

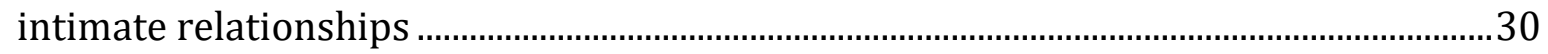

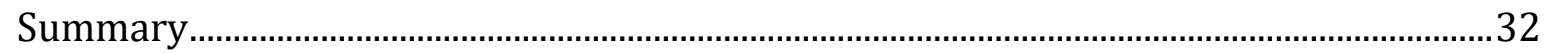

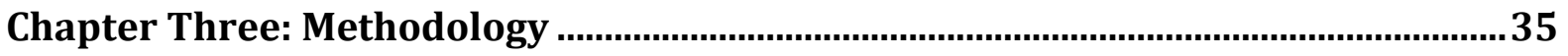

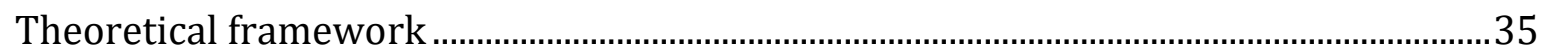

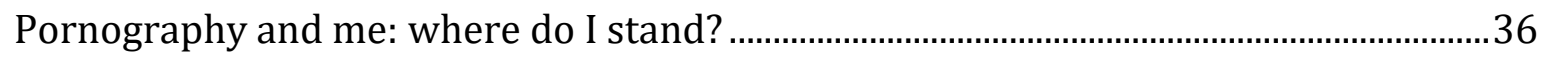

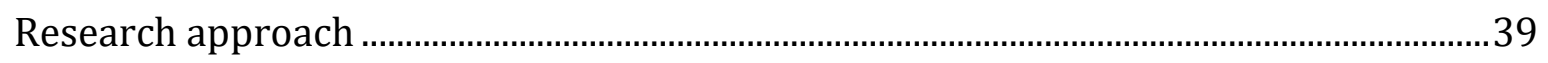

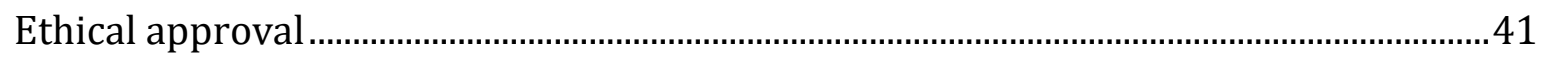

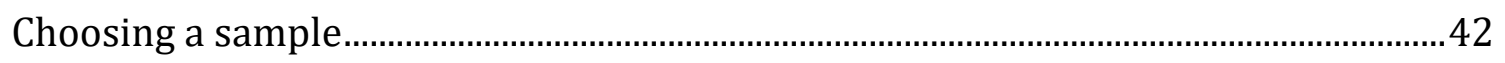

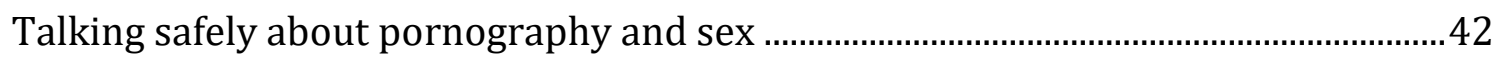

Managing conversations about criminal behaviours .........................................................43

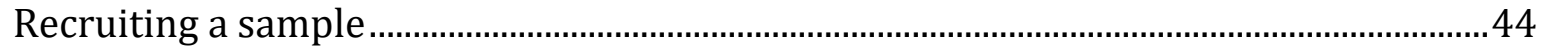

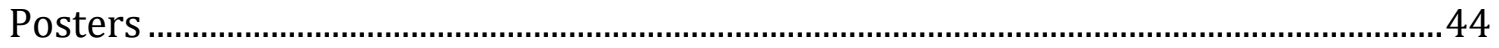


Social media. 45

Collecting data 48

Talking about private(s) in public 48

Talking about porn with strangers: building a comfortable environment .50

The participants .51

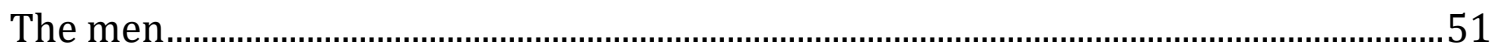

The women

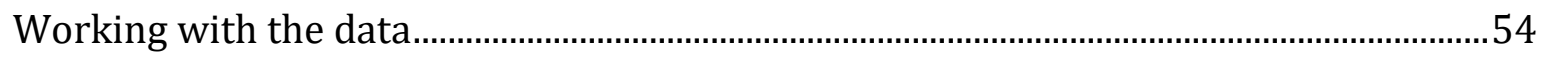

Emotional involvement and the challenges in 'sexing up' the academy............................55

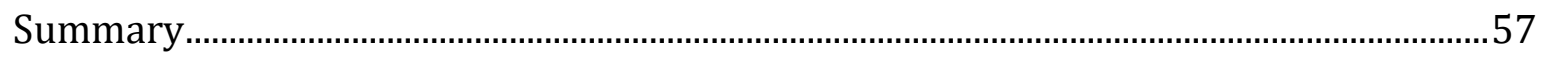

\section{Chapter Four: Porn sex versus real sex? Defining the mainstream of pornography}

The pornographication of the mainstream. .59

Defining the contours of mainstream pornography ...........................................................6

"Mainly Pornhub": Accessing mainstream pornographic content......................................62

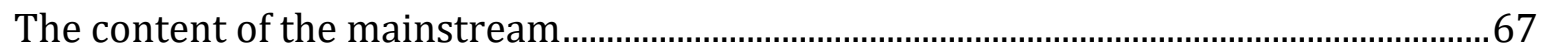

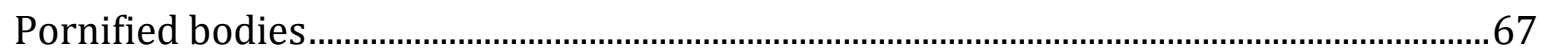

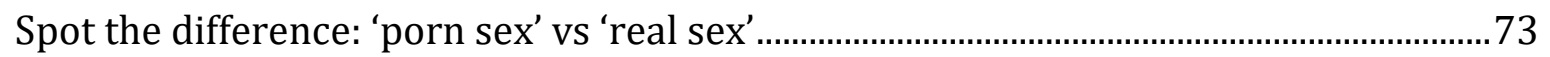

Intimacy vs dominance? Gendered roles in pornography ..................................................76

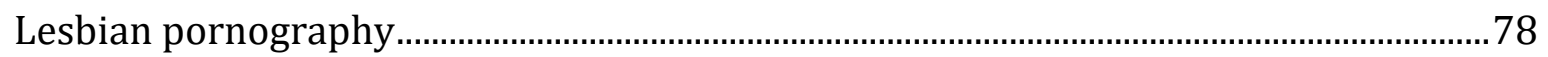

Female-friendly pornography: What do women really want? ……....................................80

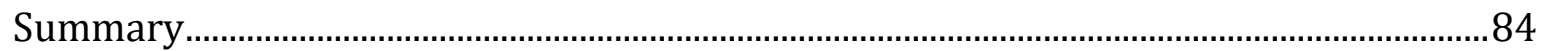

Chapter Five: The "hidden part of our culture": Stigma, pornography and New Zealanders.

Talking dirty with me: interview environments and pornographic conversations......87

Asking for help: men talking about pornography addiction ...............................................94

X-rated chat with the ladies: facing judgment .................................................................... 101

A different kind of judgment: women experiencing blame for their partner's abuse of

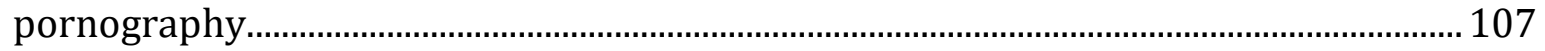

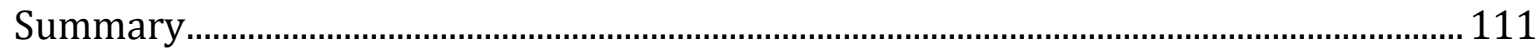

Chapter Six: Women and pornography: navigating roughness and aggression in

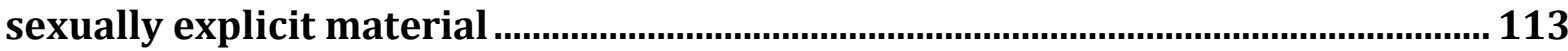

What women see: encountering aggression in mainstream pornography.................... 113

Conceptualising rough sex................................................................................................. 117

A fine line between pleasure and pain? Women's conflicted feelings about

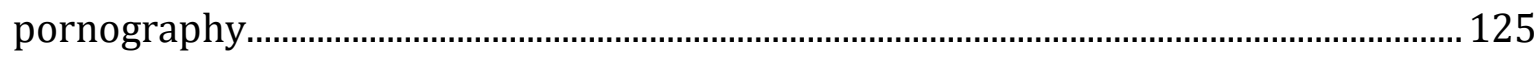


The perils of porn 127

Summary 136

Chapter Seven: Men on pornography. 137

The appeal and allure of sexually explicit material 137

Deciphering women's authentic sexual pleasure in pornography. 139

Distant engagements: men navigating aggression in pornography ....... 142

Tuning in or tuning out? Responding to aggression in pornography 146

Going down the 'rabbit hole' of pornographic content. 151

The influence of pornography: men open up about the role of pornography in their lives. 153

Encountering addiction: men's experiences of addiction to pornography. 159 Summary. 164

Chapter Eight: Pornography and partners 167

Partners and pornography: couples viewing erotic material together. 167

Pornography and coercive sexual practice: women on male partners using pornography to shape sexual interactions. 174

Men's thoughts about how their pornography use affects their partners ..................... 177

Women's understandings of how men view their use of pornography .......................... 180

Women's perspectives on men's use of pornography in intimate relationships ........ 181

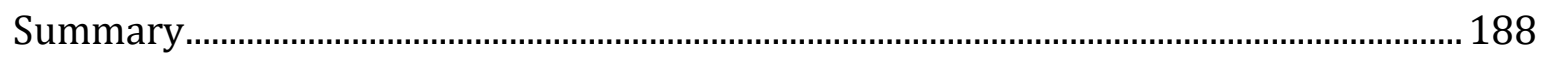

Chapter Nine: Why we need to talk more about pornography .............................. 189

Bringing the audience into conversations about pornography ...................................... 189

Mainstream pornography: misogynistic and mostly male................................................. 192

Consensually rough: women on aggression and 'roughness' in pornography............. 195

It's just not for me: men navigating aggression in pornography ..................................... 200

Pornography as an addictive, but gendered experience .................................................... 203

The gendered nature of pornography in intimate relationships ..................................... 207

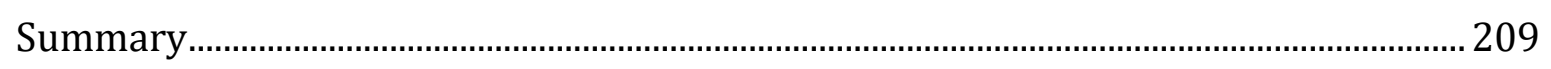

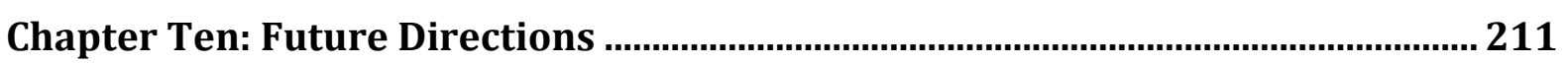

Thinking ahead: A focus on gender in contemporary pornography research ............ 212

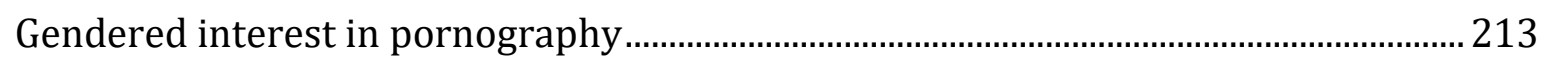

Gendered understandings of aggression in sex and pornography ................................. 213

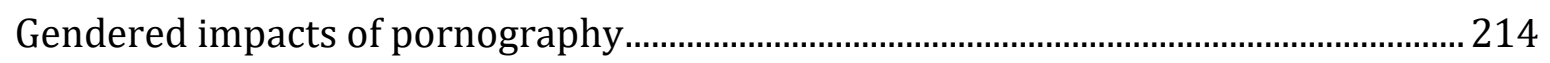

Pornography as a critical inclusion in education.............................................................. 215

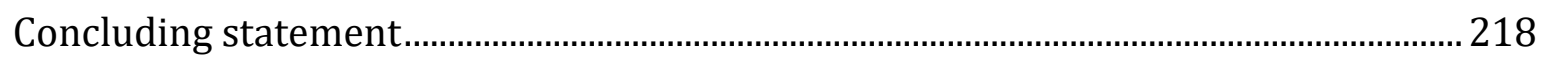




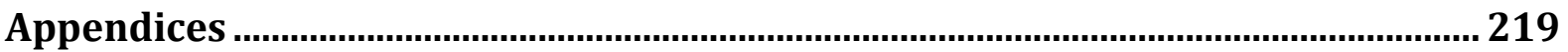

Appendix A: Memorandum of Ethical Approval................................................................. 219

Appendix B: Support Services Sheet....................................................................................... 220

Appendix C: Participant Information Sheet ...................................................................221

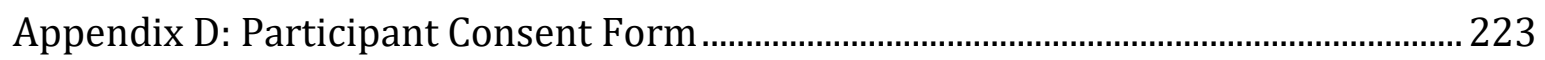

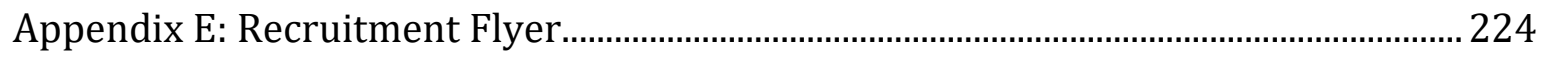

Reference List ........................................................................................................ 225 


\section{Chapter One: Why study pornography?}

Pornography is a contentious topic, and research in this field is often imbued with moralistic evaluations and strong personal opinions (Böhm, Franz, Dekker, \& Matthiesen, 2015). As a practice, however, pornography remains distinctly private and shrouded in secrecy. Over the last forty years, researchers have constructed an impressive body of scholarship which highlights and attests to the potential, or realised, harms of pornography (Cawston, 2018; DeKeseredy \& Corsianos, 2016; DeKeseredy \& HallSanchez, 2016; Dines, Jensen, \& Russo, 1998; Jensen, 2016), yet the popularity of pornography continues to grow on a massive scale. The rise of pornographic 'tube' sites, ${ }^{1}$ such as Pornhub, has seen an unprecedented increase in access to hardcore pornography. In 2018 alone, Pornhub reported 33 billion site visits - an increase of 5 billion visits from 2017 figures (Pornhub, 2018a). The stunning presence of pornography on the internet makes it hard to envision a world without it, so critical investigations of its complexities are more important than ever.

New Zealanders' engagement with pornography is high for its relatively small size, and while men continue to be the majority of viewers, New Zealand women make up 35\% of Pornhub's New Zealand audience (Pornhub, 2015). Further, recent data suggest that nearly $15 \%$ of New Zealander's under the age of 18 are regularly engaging with pornography online (Office of Film and Literature Classification, 2018). Despite New Zealanders' keen engagement with pornography, there remains a paucity of research which examines how the audience understands, interprets and navigates sexually explicit material. The exclusion of the audience of pornography from research about its effects is not unique to New Zealand (Klein, 2006; McKee, 2005a), but it seems disconcerting that the audience is excluded when such significant claims are made about its harms (Hardy, 1998), and when regulatory changes are underway to control access to pornography. For instance, legislative change is taking place in the United Kingdom to regulate and control young people's access to internet pornography through age verification on pornography websites (Matthews-King, 2018; Rotherham, 2018). New Zealand is observing this

\footnotetext{
1 Pornographic tube sites follow a similar platform to websites such as Youtube, where content can be uploaded and engaged with by viewers all around the world. On pornographic tube sites, much of the pornographic content is pirated (Tarrant, 2016).
} 
process closely, with the Children's Minister keen to see similar changes implemented in our own backyard (New Zealand Herald, 2018).

This introductory chapter contextualises the thesis and outlines the aims of the research. I begin this chapter with a background to the project and discuss my interest in the study of pornography. I then briefly define pornography for the purposes of this research; however, this is critically explored in more depth later in the thesis. Moving on, I explore the place of pornography on the public agenda in New Zealand, which is followed by a discussion of the research aims. I situate this research within the pornography literature base and highlight how it bridges the gap in knowledge about pornography in New Zealand by providing an in-depth examination of the influence of pornography on the lives of heterosexual emerging adults. ${ }^{2}$ This chapter is rounded off by an outline of what each chapter covers.

\section{Why study pornography? A background to the research}

My academic interests have always been in areas that others consider challenging or confronting. My previous Master's research explored women's experiences of sexual victimisation in tertiary accommodation and came with its fair share of challenges and obstacles. My decision to study pornography, however, has raised many eyebrows. My early interest in pornography came about during my undergraduate study, but it peaked about five years ago as I assisted with a funding application for a project on rape, silencing and objectification - a project which would later fund this research. I still remember telling my supervisor what I had discovered; I spoke of how my friends described pornography as a normative aspect of both men's and women's lives. It was intriguing, fascinating and I wanted to know more.

I experienced a disconnect between conversations with friends and what I read in academic literature on pornography. Much of the literature theorised pornography as misogynistic, sexist, aggressive, and detrimental to women and young people (Antevska \& Gavey, 2015; Boyle, 2000; 2010; Bridges, Wosnitzer, Scharrer, Sun, \& Liberman, 2010; DeKeseredy \& Corsianos, 2016; DeKeseredy \& Hall-Sanchez, 2016; Dines et al., 1998; Dworkin, 1981; Flood, 2010; Jensen, 2007; Kappeler, 1986; Long, 2012; Tyler, 2010; Whisnant, 2016b). If pornography was really all of these things, why did my friends

\footnotetext{
2 Emerging adulthood is the developmental period between the late teens and through the twenties. It is characterised as a unique time of maturation, particularly with regard to love and sex (Arnett, 2000).
} 
neglect to mention this? Why would they engage with such material? I also encountered material which celebrated the transgressive potential of pornography (Attwood, 2005; Liberman, 2015; McKee, 2005b; McKee, 2007; McKee, Albury, \& Lumby, 2008; Smith, Barker, \& Attwood, 2015; Taormino, Shimizu, Penley, \& Miller-Young, 2013). Was this the perspective that my friends held? Is this why they engaged with pornography? Essentially, I wondered what people thought about pornography, and whether they felt it had influenced their lives.

\section{Pornography or porn: a note on terminology}

"I shall not today attempt further to define the kinds of material I understand to be [pornography]; and perhaps I could never succeed in intelligibly doing so. But I know it when I see it" - Justice Potter Stewart's opinion on defining pornography, as cited in Gewirtz (1996, p. 1024).

The origins of the word 'pornography' stem from the Ancient Greek word porne, meaning woman for sale or female prostitute, and graphos, which is understood as writing. McKee et al. (2008) suggest that the term was first used, in the way that we now understand it, by "nineteenth century art historians to describe the erotic paintings and statues found by the archaeologists who unearthed Pompeii and Herculaneum from the volcanic ashes that buried them in AD 79" (p. 5). But what does pornography mean in 2019?

At first glance, it can seem odd to be asking what pornography 'is' because it sounds so obvious. As a young woman who has grown up in a generation with relatively unbridled access to internet pornography, my mind jumps to hardcore depictions of sex on sites such as Pornhub. I struggle to narrow down what type of content 'pornography' may explicitly refer to, but I know what pornography is to me when I see it. West (1987) suggests that we demarcate our understandings of pornography through "traditional conceptions," which are not based on definitions of pornography, but are made up of

broadly stated and widely believed inductive generalizations, which are in turn based on a multitude of common and shared experiences with pornographic materials... it still dominates our sense of what is and is not pornographic and our arguments about the value of pornography (p. 681).

The traditional conception of pornography in 1987 likely differs from conceptions of pornography today, and the pervasiveness of pornography in the digital age has surely contributed to this shift. Whilst traditional conceptions of pornography may well continue to operate, my own understandings of what constitutes pornography may be a distant relative to the views held by others, perhaps even your own. When you think of 
pornography, what comes to mind? Is it sexual videos on tube sites? Is it a woman draped over a motorbike in a lad's mag? Is it Ariana Grande's music videos? Is it all of these things or something else entirely?

Defining pornography is further complicated by its highly political nature, so separating pornography from the personal and the political makes defining pornography seem an almost futile task. Tarrant (2016) usefully sums up the challenge involved in defining pornography in the digital age:

One person's pornography may seem like hate speech to the next person or like nothing at all to a third. What arouses a plushy, for instance, may go unnoticed by someone without a sexual interest in cute stuffed animals. Whereas some think of the Victoria's Secret catalogue as reference information about lingerie and sale prices, others find it a rich source of masturbatory material. Depending on one's political perspective, some may even think that music videos, romance novels, or fiction such as Fifty Shades of Grey are pornographic (p. 4).

In essence, “one person's smut is another person's sensuality" (Peakman, 20003, p. 5), so it's unsurprising that pornography continues to provoke intense debate. Despite more than four decades of pornography scholarship, defining pornography remains a slippery task (Boyle, 2018) within a remarkably "weedy field" (Williams, 2014, p. 24). As Kendrick (1987) has argued, pornography is more often than not used to describe an argument rather than a thing, making pornography the name of a "cultural battle zone" rather than a definable object or subject (Hunt, 1996, p. 13).

Williams (2014) contends that the term 'pornography' is often, although not exclusively, used by scholars who are disapproving of the genre, lending itself neatly to antipornography positions. The anti-pornography position orients around the harms of pornography, particularly to women and children, and has a long history within feminist circles (Cawston, 2018). Radical feminist literature in the 1970s and 80s located pornography, and the associated sex industry as a whole, as situated within a patriarchal structure of men's violence and control of women (Brownmiller, 1975; Dworkin, 1981; Dworkin \& MacKinnon, 1988; Long, 2012; MacKinnon, 1993; 2005; MacKinnon, 1989). In 1975, Brownmiller's ground-breaking book on rape identified pornography as instrumental in the development of a rape culture - a culture which maintains, perpetuates, and condones sexual violence against women (Brownmiller, 1975; Buchwald, Fletcher, \& Roth, 1993). Shortly after, Andrea Dworkin's seminal text 
Pornography: Men Possessing Women assertively identified pornography's role in reinforcing male power and dominance. Dworkin (1981) identified male power as intrinsic to pornography:

The ways and means of pornography are the ways and means of male power... the valuation of women in pornography is a secondary theme in that the degradation of women exists in order to postulate, exercise, and celebrate male power (pp. 25-26).

The anti-pornography position endorsed the censorship of pornography, seeing it as "the preferred solution to the pornography problem" (Bronstein, 2011, p. 328). Legislative efforts were made in 1983, when feminist activists Catharine MacKinnon and Andrea Dworkin drafted an ordinance for the city of Minneapolis which would establish pornography as a violation of women's civil rights, and allow pornography to be considered a form of sex discrimination (Baldwin, 1984; Duggan, Hunter, \& Vance, 1995; Easton, 2005). The draft proposal was rooted in a feminist understanding of the harms of pornography to women, which defined pornography as:

The graphic, sexually explicit subordination of women through pictures or words, that also includes women dehumanised as sexual objects, things or commodities, enjoying pain or humiliation or rape, being tied up, cut up, mutilated, bruised or physically hurt, in postures of sexual submission or servility on display, reduced to body parts, penetrated by objects or animals, or presented in scenarios of degradation, injury, torture, shown as filthy or inferior, bleeding, bruised, or hurt in a context that makes these conditions sexual (MacKinnon, 2005, p. 503).

In considering pornography as a form of sex discrimination, the ordinance provided a range of remedies and actions for those who felt that pornography had breached their civil rights (Spaulding, 1988). The Minneapolis City Council passed the ordinance twice, which was heralded as a major victory for anti-pornography feminism and a new day for women's equality (Dworkin \& MacKinnon, 1988). However, the ordinances were vetoed by the mayor both times, and a similar version of the ordinance was passed in Indianapolis, but later overruled as unconstitutional (Long, 2012).

Some anti-pornography feminists have pointed to the etymology of the word 'pornography' as symbolic of its reality. Long (2012) suggests that whilst dictionary definitions frame pornography "in terms of 'explicit' sexual content and aesthetic value, the etymology of the word is illuminating regarding the sexual politics that inhere in the term, since the terms refer to writing about prostituted women" (p. 56). Further, Dworkin (1981) famously wrote that the ancient Greek roots of pornography demonstrated its 
social realities, as porne refers to the literal, written depiction of "the lowest class of whore... the brothel slut available to all male citizens" (p. 199). Through this radical feminist lens, pornography is firmly planted in the political, and a focus on the etymology of the word is "a useful reminder that pornography as a concept does not originate in notions of individual expression or erotic fantasy, but in relation to representations produced within specific, material conditions of inequality between women and men" (Long, 2012, p. 57). The anti-pornography standpoint remains a dominant position in pornography studies today, with many scholars continuing to write about pornography from this perspective (DeKeseredy, 2015; DeKeseredy \& Corsianos, 2016; Dines et al., 1998; Jensen, 2007).

Whilst the Minneapolis Ordinance may have initially been considered an overwhelming win in the struggle against pornography, not all feminists advocated for, or supported, the anti-pornography position. On the other side of the coin, the term 'porn' is perhaps likely adopted by those who may be sympathetic to viewing pornography from a positive lens. The anti-censorship, or 'pro-porn' position arose amid the 'sex wars', whereby feminists became split over the issue of pornography. Calls for pornography to be censored or banned were met with strong opposition from feminists who saw the censorship of pornography as the suppression of women's sexuality. In critiquing the anti-pornography position, Vance (1984) stated that the anti-pornography movement

restates the main premises of the old gender system: the dominant cultural ideology elaborates the threat of sexual danger, so the anti-pornography movement responds by pushing for sexual safety via the control of public expression of male sexuality. Although this would seem in certain respects a decisive break with an oppressive system - sexual danger is being directly challenged - in other respects the focus continues unchanged in that sexual pleasure for women is still minimized and the exploration of women's pleasurable experience remains slight (p. 6).

Reflecting on the sex wars and the division of feminists on pornography, Duggan (1995) suggests that the anti-censorship position set out to "counter antiporn accounts of 'pornography' as a unified (patriarchal) discourse with a singular (misogynistic) impact" (p. 7). Collectively, the critique of anti-pornography politics used an anti-censorship rhetoric which disputed the claim that "pornography's narratives construct gender as male domination/female subordination through sex, as in the repeated story 'she says no but she really means yes'” (Duggan, 1995, p. 8). Anti-censorship supporters cautioned that the anti-pornography movement itself "promoted gender stereotypes and repressive 
sexual ideas that served right wing interests", making them antithetical to feminist goals of equality for women (Bronstein, 2011, p. 280). In essence, the anti-censorship position held that if "feminists define pornography, per se, as the enemy, the result will be to make a lot of woman ashamed of their sexual feelings and afraid to be honest about them" (Willis, 1993, p. 352).

Throughout this thesis, I have debated whether to use the word 'pornography' or 'porn' when talking about sexually explicit material. I was concerned that being cognisant of the harms of pornography would somehow label me 'anti-porn', and therefore somehow 'anti-sex'. Would using the full term 'pornography' suggest I was adhering to an antipornography position? I reflect in more detail on my own positionality in Chapter Three, but I believe that the full term 'pornography' is most appropriate for this research. Williams (2014) suggests that the full term signals a "more scholarly, distanced and critical approach" (p. 34) and I follow this line of thought. This thesis uses data from interviews with men and women in emerging adulthood about how they felt pornography had influenced their lives. The full term 'pornography' has been used throughout, except in interview extracts where data has been presented verbatim.

I left it up to participants to define pornography for the purposes of this research, and overwhelmingly they suggested that pornography referred to visual depictions. This will be discussed later in more detail, but in the interests of setting the scene, it's important to contextualise that when I am referring to pornography, it is primarily in relation to visual material. For these reasons, I find Tarrant's (2016) definition of pornography most helpful:

Pornography refers to visual depictions that are intended to sexually arouse the viewer, such as still photos, magazines, adult cable television channels, or VHS movies. Today, pornography is more likely to mean online video; and in the future, technological changes may again shift how these visual depictions are delivered to the consumer (p. 3, emphasis in original).

\section{The contemporary New Zealand pornographic landscape}

Concerns about the harms of pornography to women and children saw pornography become the focus of numerous international inquiries. The two decades between the mid1960s and the mid-1980s were considered "the Era of the Pornography Commissions" (Hawkins \& Zimring, 1988, p. 3). In the United States in 1970, the Johnson Commission provided an "unexpected government seal of approval" for pornography whereby the 
Commission's report declared "that the latest scientific research had found no proof of a link to violent or antisocial behavior" (Bronstein, 2011, p. 70). Following this, the US Attorney General's Commission on Pornography (otherwise known as the Meese Commission) was established as a response to the earlier Johnson Commission. Issued in 1986, the Meese Commission filed its final report which condemned violent pornography and provided support to the anti-pornography position (Bronstein, 2011).

The American Commissions inspired efforts in the United Kingdom (1979), Canada (1986), and New Zealand (1989), however New Zealand's inquiry appears to have had little relevance to international debates (Bynum, 1991). As New Zealand's Committee of Inquiry progressed, they received over 700 written submissions, including "many divisions of opinion about pornography and related matters" but traditional, morallyimbued positions were "overwhelmed numerically by submissions from women's groups with their varied but predominantly feminist stances" (Department of Justice, 1989, p. 13). The report made a total of 202 recommendations for change, including legislative change, classification guidelines, future research efforts surrounding consumer habits, and societal education efforts around sexual education, including the provision of funding to sexual abuse and domestic violence support agencies to deliver educational material about pornography in their programmes (Department of Justice, 1989).

Some of the recommendations of the Inquiry were implemented, such as legislative reform which created the Films, Videos and Publications Act 1993, however calls for adequate societal education efforts in response to pornography are still being made today. In 2017, a petition containing 22,000 signatures was lodged by conservative lobby group Family First which sought an investigation of the public and societal health impacts of pornography by way of an expert panel. In their submission to the Government Administration Select Committee, they referenced a substantial body of academic scholarship on pornography and suggested that an expert panel was warranted to ensure both a legal/policy response, as well as a wider societal response to pornography as a social and health issue. ${ }^{3}$

Their research summary suggested that pornography has strong impacts on sexual violence and exploitation, damaging effects on adolescents, and causes harm to adult

\footnotetext{
3 The full submission to the inquiry can be found at http://porninquiry.nz/wp-
} content/uploads/2017/08/SUBMISSION-Petition-of-Bob-McCoskrie-and-22334-others.pdf 
women, men and intimate relationships. Further, they suggest that pornography has harmful impacts on neural pathways in the brain, contributing to pornography addiction. The Porn Inquiry spotlighted pornography and its potential public health implications for the government. The report of the Government Administration Select Committee tasked with responding to the petition has not been released at the time of writing, but it does not appear that an expert panel is to be appointed.

In August 2018, the Minister for Internal Affairs and Minister for Children, Tracey Martin, expressed concern about young people's access to hardcore internet pornography (New Zealand Herald, 2018). These concerns prompted her to consider calls for regulating online pornography, in a similar way to the British response mentioned earlier in this chapter. The Minister's comments were made in response to the commencement of a major piece of research by the Office of Film and Literature Classification regarding young people's online pornography habits. The key findings of the NZ Youth and Porn report suggest that many young people in New Zealand have seen pornography prior to the age of 18 , and whilst many accidentally encounter pornography, a number of young people are regularly viewing it. Further, young people indicated that pornography was a site of sexual learning and influenced their offline sexual lives. Importantly, however, many young people were aware that pornography negatively affected them, and they were concerned that it promoted false expectations of sex and relationships, as well as normalising violence and aggression (Office of Film and Literature Classification, 2018).

Calls are also being made for a more comprehensive, nuanced and contemporary delivery of sexuality education in New Zealand. In a recent review of sexuality education in schools, the Education Review Office highlighted an urgent need for discussions about pornography, consent and more comprehensive sexual education due to the changing social and technological lives that young people are living (Education Review Office, 2018). They found that less than half of secondary schools visited were covering sexual violence and pornography, thereby leaving a significant gap with regard to a more comprehensive understanding of sex and sexuality in the digital age (Education Review Office, 2018). It seems, therefore, that we need to know more about pornography in order to appropriately and effectively equip young people with critical media literacy skills through their school-based education. 


\section{Previous research on pornography}

Research on pornography is regularly concerned with its effects, and often utilises sexual script theory as an overarching framework to demonstrate them. Sexual script theory originated in the 1970s (Gagnon \& Simon, 1974) and has been highly influential in sex research (Bridges, Sun, Ezzell, \& Johnson, 2016; Frith \& Kitzinger, 2001; Fritz \& Paul, 2017; Graham, 2017; Kimmel, 2007; Simon \& Gagnon, 1986; Sun, Bridges, Johnson, \& Ezzell, 2016; Wiederman, 2015). Frith and Kitzinger (2001) define sexual scripts as “culturally available messages that define what 'counts' as sex, how to recognize sexual situations, and what to do in a sexual encounter" (p. 230) and pornography as a genre has been theorised as a key site for influencing sexual scripts, particularly for young people (Braithwaite, Coulson, Keddington, \& Fincham, 2015b; Bridges et al., 2016; Sun et al., 2016). Understanding the 'pornoscript' is important "as it has been suggested that the behaviors enacted in pornography reinforce a specialized sexual script, designed to maximize arousal, rather than simply reflecting what is typical in heterosexual encounters" (Vannier, Currie, \& O'Sullivan, 2014, p. 262). As the next chapter will show, much pornography research is concerned with the influence of pornography on the development and acquisition of sexual scripts. It is an important area of consideration, and indeed informs some of the forthcoming analyses in later chapters.

From a criminological perspective, there is little research in this field which examines adult pornography (DeKeseredy, 2015), which seems a surprising omission given the location of much pornography research within a harms-based paradigm. That said, a small number of studies have included participants' perspectives on pornography in New Zealand and are important to consider from a criminological lens (Allen, 2006; Antevska, 2012; Antevska \& Gavey, 2015; Kingi \& Poppelwell, 2005; Kingi, Poppelwell, \& Paulin, 2004; Martin, 2016; Office of Film and Literature Classification, 2018). Further, a number of international studies have used the audience of pornography as a starting point for understanding its influence on the lives of consumers (Attwood, Smith, \& Barker, 2018b; Beggan \& Allison, 2003; Benjamin \& Tlusten, 2010; Bridges, Bergner, \& Hesson-McInnis, 2003; Chadwick, Raisanen, Goldey, \& van Anders, 2018; Chowkhani, 2016; Ciclitira, 2004; Crutcher, 2015; DeKeseredy \& Hall-Sanchez, 2016; Gurevich et al., 2017; Hardy, 1998; Lofgren-Martenson \& Mansson, 2015; Loftus, 2002; Marston \& Lewis, 2014; Mattebo, Larsson, Tyden, Olsson, \& Haggstrom-Nordin, 2012; McKee et al., 2008; Parvez, 2006; 
Smith et al., 2015; Wong \& Yau, 2014). The qualitative literature base on pornography will be examined more thoroughly in the literature review. This will show that there are few studies which adopt a gendered lens for understanding heterosexual men's and women's experiences of adult pornography, so this research is a unique contribution to both criminological inquiry and pornography studies more generally.

As aforementioned, this research spawned from my interest in the ways that pornography is understood, interpreted and experienced by emerging adults in New Zealand. Given the pervasiveness of pornography in the digital age, in conjunction with the paucity of qualitative research from the perspectives of those most affected by pornography - the audience - this thesis is an exploratory investigation into the realities of pornography for heterosexual emerging adults in New Zealand. This research adopts a gendered lens for understanding how pornography is experienced, arguing that contemporary understandings of pornography require a gendered focus as pornography is experienced in profoundly gendered ways.

\section{Thesis aims and key findings}

The broad aim of this research was to identify how emerging adults in New Zealand understand, experience and interpret pornography in their everyday lives. As a young, feminist woman myself with a complicated relationship to pornography, I wanted to explore the complexities involved in others' perspectives. As this thesis will demonstrate, the realities of pornography in the digital era are anything but simple, straightforward or ordinary. Specifically, this research set out to:

- Examine what emerging adults in New Zealand consider to be pornography and how they engaged with it

- Consider the ways that emerging adults perceived pornography to have influenced their lives, if at all, in positive and/or negative ways

- Consider the gendered implications of pornography consumption for emerging adults

- Provide a foundation for future research in a contemporary, rapidly changing area of study

In response to these research questions, data obtained from interviews with emerging adults suggested that when they think of pornography, what they think of is sexually 
explicit material on pornography tube sites such as Pornhub. Both men and women identified pornography's misogynistic tendencies, and how it was primarily designed by men, for a heterosexual male audience. Further, they acknowledged that the aggression that is fused with sex in pornography was remarkably gendered, with women as the targets and men as the enforcers of aggressive behaviours.

Aggression was a key theme which emerged from the data, and understanding aggression was a gendered phenomenon. Many of the women's understandings of aggression were complicated, and at times, confusing. Several women suggested that 'rough' sex had appeal, but their understandings of what constituted rough sex was bound to consensual sexual interactions and is not a simple mirroring of rough or aggressive sexual interactions in pornography. This framing of rough sex is considered through the lens of postfeminist thought, particularly regarding the pressure women encounter to adopt and conform to an 'up for it' sexuality, and will be discussed in more depth in later chapters (Gill, 2008). Conversely, men increasingly framed aggression in pornography as omnipresent, but were hesitant to denounce aggression in pornography entirely. Instead, men distanced themselves from the type of man that enjoyed aggression in pornography, opting to understand other men's interest in aggressive sexual material as one of 'user preference'. This finding has implications for understanding aggression in pornography and showcases the importance of a gendered lens when discussing pornography with emerging adults.

In speaking to the impacts of pornography on both men and women in this research, it was impossible to ignore their gendered nature. A substantial number of men included in this research identified the addictive nature of pornography, and many had experienced pornography addiction in their lives. Conversely, this was less of an issue with women, with only one woman reporting a similar experience. Importantly, however, a number of women in this research experienced difficulties with their partner's use of pornography. For some, this was related to their partner's abuse of pornography, with two women feeling blamed for their partner's addiction and how it caused significant negative impacts on their intimate relationships. For others, they identified how their partner's use of pornography had influenced their sexual behaviours and expectations, which included experiences of sexual coercion and violence. 
Ultimately, this thesis argues that the gendered nature of pornography is a critical starting point for understanding the ways pornography is understood and experienced by its audience. It illuminates both the pleasures and pains of pornography in the digital age and situates participants' perspectives at the forefront of the analysis, thereby helping fill an omission in pornography research to date. It provides a platform for future research on pornography and affirms the importance of applying a gendered lens. Lastly, the findings of this research suggest the need for ensuring young people are equipped with critical media literacy skills to help them navigate and appraise the depictions of sex, gender and bodies in contemporary pornography. 


\section{Chapter Two: Mapping the terrain of the pornographic research landscape}

Research on pornography yields a diverse yet contentious literature field. Much of this literature is focused on the 'effects' of pornography on viewers within a quantitative paradigm. Concerns have been voiced about the nature and extent of these effects, particularly for women and children, and research in this area remains inconclusive. Whilst the literature on pornography is expansive, this chapter presents a review of the literature in this field, particularly of a qualitative nature, in order to situate my research with emerging adults in New Zealand within a comparative context.

First, I explore how the sex wars have been instrumental in dividing feminist research in this space, contributing to a somewhat hazy literature landscape today. The next section of this review is concerned with the content of pornography, and documents how this has shifted across three media formats: magazines, VHS/DVDs and most recently, the internet. In documenting this shift, I draw primarily from content analytical literature which showcases how pornography has drastically shifted in its representation. Following this, I then explore research which includes the audience of pornography (adolescents, men and women) and how it is understood, interpreted and experienced from their perspective. In this realm, there is a massive body of research from an experimental/psychological approach which is often located within a 'cause/effect' dichotomy. As my research is qualitative in nature, I have chosen to review mainly qualitative literature which offers rich, detailed accounts of the way pornography is experienced. Lastly, this review explores qualitative research on the role of pornography in intimate relationships, exploring the gendered ways that pornography use in relationships can be experienced and understood.

The review concludes by outlining the gaps in research on the influence of pornography on men's and women's lives in New Zealand. This review identifies how my research provides both an exploratory account of the influence of pornography on the lives of a sample of New Zealand adults, but also a foundation for future research about the complex and nuanced ways that pornography is experienced across gendered lines.

\section{The 'sex wars': conflicting feminist perspectives on pornography}

As aforementioned in the introduction, the sex wars have divided feminists on the issue of pornography, and the legacy of the sex wars continues to have relevance today. Long 
(2012) summarises the history of anti-pornography feminism as "brave, turbulent and deeply instructive" (p. 12), and the voices of feminist scholars in the anti-pornography movement continue to be heard strongly (Boyle, 2010; Dines et al., 1998; Jensen, 1995; Jensen, 2016; Tyler, 2010; 2015). Whisnant (2010, p. 114) argues that "in contemporary mainstream pornography marketed to heterosexual men, hostile and humiliating acts against women are commonplace," whilst Dines (2006) suggests that mainstream pornography is

populated with what the male performers call "cum buckets," "sluts," and "cunts" who love pounding anal, oral, and vaginal sex... threaded throughout all these movies is an overt hatred for women that is evidenced in the dialogue and fascination with body-punishing sex (p. 286).

From a critical criminological perspective, DeKeseredy (2015) suggests that violence against women is a common theme in contemporary pornography, with videos routinely depicting "painful anal penetration as well as brutal gang rape and men slapping or choking women or pulling their hair while they penetrate them orally, vaginally, and anally (p. 6). Further, Whisnant (2004) suggests that pornography has become the "ultimate cool", with pop culture teaching women that men's use of pornography is legitimate, acceptable and normalised. In being "a cool, modern, liberated woman" (Whisnant, 2004, p. 16), women must tolerate, participate in, and embrace other women's degradation in pornography to fit in.

Today, feminist debates about 'agency' and 'choice' are a key site for discussions about women's objectification and subjectification in a 'postfeminist' world (Gill, 2008; 2012a; Gill, 2007b; McRobbie, 2004; 2008). There is a growing trend whereby women's bodily practices, surveillances and sexual engagements are shaped through a discourse of empowerment (Gill, 2008; 2012a), and "the dynamics of regulation and control are less about what young women ought not to do, and more about what they can do" (McRobbie, 2008, p. 54). Women are expected to be sexually adventurous and presenting an 'up for it' sexuality (Gill, 2009; Harvey \& Gill, 2014) under the guise of 'empowerment', yet women's empowered 'choices' continue to be made within a patriarchal system plagued with sexual double standards (Gill, 2007b).

On the flipside, a chorus of scholars remain critical of the anti-pornography perspective (McKee, 2005a; McKee et al., 2008; Paasonen, 2014; Segal, 1998). They argue that antipornography rhetoric "tends towards the thrilling and titillating" which therefore draws 
on discourses of sex as inherently dangerous (Attwood, Maina, \& Smith, 2018a, p. 1). Further, they are concerned that academic voices informing public debate are limited to discussions of the harms of pornography, typically in line with an anti-pornography position (Smith \& Attwood, 2014). The idea that pornography has the potential to be liberating and transgressive is the key concept underpinning the perspectives of those who propose a 'feminist' pornography. Given the heteronormativity present within much mainstream sexually explicit material, feminist pornography is a project of using "sexually explicit imagery to contest and complicate dominant representations of gender, sexuality, race, ethnicity, class, ability, age, body type, and other identities (Taormino et al., 2013, p. 9). Ultimately, then, one of the goals of feminist pornography is to "chang[e] the game of the 'market'" (Mondin, 2014, p. 189) by both the production of pornographic works and its commitment to social justice and gender equality as manifested in the finished product through both its content and how it is represented (Eaton, 2017).

The climate that feminist pornography is produced in is said to be a space where performers are encouraged to negotiate the type of sex that they want to have on screen, thereby creating a more ethical working environment that situates performer safety and consent at the forefront of production, thus promoting sexual subjectivity (Liberman, 2015). Further, feminist pornography is not just about making pornography for women, or showcasing femininity, rather it "uses aesthetics and filmmaking styles that empower the performers who make it and the people who watch it" (Tarrant, 2016, p. 168). However, feminist pornography as a genre continues to be critiqued by the antipornography position. DeKeseredy and Corsianos (2016) contend that "some selfdefined feminist pornographers depict women who are hog-tied while having sex that looks painful, or women who are suspended from the ceiling while men penetrate them" (p. 81). Further, Whisnant (2016a) interrogates the work of Tristan Taormino and argues that it fails to achieve the 'feminist' ideals that it promotes because it depicts behaviours such as anal sex and aggression. Such a critique neglects to appreciate that women can, and do, consume pornography which contains such elements, and may actually reduce the agency of the performers and their ability to consent to sexual acts with their own bodies. 


\section{The shifting content of pornography: from Playboy to Pornhub}

The content of pornography has been extensively examined, yet research remains conflicting, especially regarding aggression. The methodological disagreements involved in defining and interpreting aggression in pornography are many and there is remarkable inconsistency between studies and researchers about what constitutes aggression or violence in pornographic material (Bridges et al., 2010; Bridges, 2010; McKee, 2005b; 2015). This review explores the changing content of pornography across magazines, videos and contemporary internet pornography. The review of magazines and video pornography is substantially shorter than the review of internet pornography because the internet is now the dominant modality for accessing pornography.

\section{From the shelves to the bedroom: the content of pornographic magazines}

Traditionally, pornographic magazines such as Playboy, Penthouse and Hustler have been immensely popular avenues for viewing pornography. Despite the glossy nude photographs of women in Playboy seeming "risqué to some observers, and downright scandalous to others" (Fraterrigo, 2016, p. 196), pornographic magazines such as Playboy became mainstream by the early 1970s, with Playboy alone recording circulation rates of 7 million copies in 1972 (Gunelius, 2009). Dines (1998) suggests that competition between pornographic magazines such as Playboy, Penthouse and Hustler changed the mainstream pornography industry by "pushing the limits of what was deemed as acceptable, both legally and culturally" (p. 51) and contributed to a desire and push for more extreme content.

Concerns about pornography's influence on the perpetration of violence against women inspired analyses of the content of pornographic magazines. Early research suggested that sexual and physical violence against women was a commonly depicted theme (Malamuth \& Spinner, 1980; Matacin \& Burger, 1987), however this was not universally agreed upon. Others suggested that depictions of sexual violence were less common (Scott \& Cuvelier, 1987; 1993), and that the explicitness of pornographic images tapered off in the 1980s, perhaps suggesting a ceiling effect whereby the limits of sexual explicitness may have somewhat peaked (Bogaert, Turkovich, \& Hafer, 1993). Pornographic magazine circulation rates are minimal today compared to their peak in the 1970s. Circulation rates are so low, perhaps, that it may have been the driving force 
behind Playboy magazine's decision to no longer print nude models in their magazines from March 2016 (Donatelli, 2015). This decision was reversed within a year, with nude images reappearing in their March/April 2017 editions, and the creative director of Playboy called the decision to remove nudes a 'mistake' (British Broadcasting Corporation, 2017).

Dines (1998) wrote in the late 1990s of the dynamic evolution of the pornography industry and how it was fast becoming obsolete due to an "exploding video market (and a growing CD-ROM market), which appear[ed] to be following a somewhat similar path to the one blazed by Hugh Hefner's Playboy magazine" (p. 59). Given the pervasiveness of online forms of pornography today, however, such a statement itself is nearly obsolete, but it speaks to how pornographic magazines have been virtually surpassed - perhaps even buried - by the very industry and culture they inspired to develop.

\section{Plugging in and switched on: pornography in VHS/DVD formats}

Dines (1998) observes that the video pornography industry "generated $\$ 3.1$ billion in rental and sales in 1995, up from $\$ 2.5$ billion in 1994 and $\$ 1.2$ billion in 1991" (p. 59). Pornography in video form was easier and cheaper to make, which Whisnant (2004) observes opened up a "huge amateur market" for pornographic material (p. 15). Debates persist about what is actually being depicted in video pornography and how such depictions should be interpreted, particularly regarding aggression. Williams (1989) posits that the general stereotype of film pornography focuses on its deviance and abnormality which emanates from "what has traditionally been defined as typical or 'normal' in heterosexual male sexuality: it's phallic 'hardness' and aggression" (p. 7).

Methodological differences in definitions of aggression have inevitably contributed to divisiveness in the literature, as the study of pornography is remarkably influenced by the definitions employed, as well as the overall position of the researcher(s) (Bridges, 2010; McKee, 2015). The idea that video pornography routinely depicts sexual violence and/or sexual inequality has been reported (Cowan, Lee, Levy, \& Snyder, 1988; Dines et al., 1998), and this has been demonstrated as closely related to race and social inequalities in pornographic depictions (Cowan \& Campbell, 1994). Dines (2006) suggests that race is a key site of analysis for understanding how pornography operates as a discourse, and that "while there is little doubt that most heterosexual pornography 
categorically defines men as the 'fuckers' and women as the 'fuckees,' this has very different meanings and consequences for white men and black men" (p. 284).

Research on the social and sexual realities of contemporary video pornography suggests movies continue to spotlight the sexual prowess and pleasure of men, with women consistently portrayed as sexually willing and available (Brosius, Weaver, \& Staab, 1993). More recently, an oft-cited content analytical study of the 50 most popular pornographic videos demonstrated that over $88 \%$ of scenes contained physical aggression which was overwhelmingly targeted at women. Women typically responded either neutrally or positively to acts of aggression in pornography, which could be seen as contributing to a culture of permissible violence against women as willing participants (Bridges et al., 2010). Contrary to these findings, other studies suggest that extreme sexual violence is uncommon in popular video pornography and claims about pornography's hostile, sexist approach are seen as less concerning (McKee, 2005b; McKee et al., 2008; Monk-Turner \& Purcell, 1999). Such scholarly division culminates in a divided research landscape about the content of video pornography, but what about pornography available on the internet?

\section{A click away: the content of contemporary internet pornography}

Technological advances have changed the way that pornography is accessed, with most pornography now accessed via 'tube' sites (Smith et al., 2015). Much of what is available on tube sites is what is described as 'mainstream' pornographic content, but academic definitions of the mainstream differ substantially. Some scholars suggest that it is the contextual factors surrounding pornography that make it mainstream (Sostar \& Sullivan, 2015), whilst others focus on the content (Corsianos, 2007; DeKeseredy \& Corsianos, 2016; Dines, 2006). Casting definitional dilemmas aside, a number of scholars have observed how technological advances have contributed to an immense shift in the content of mainstream pornography (DeKeseredy \& Corsianos, 2016; Tyler, 2010). As Katz (2006) contends,

mainstream pornography has changed a lot in the past couple of decades. People of a certain age who still associate heterosexual porn with "girlie magazines" and air-brushed photos of big-breasted women shot in soft light on luxurious beds with big pillows would be shocked by the brutality, outright contempt for women, and racism that is common in today's product (pp. 186187). 
Contemporary internet pornography is the subject of a growing body of content analytical research, and research in this area dates back nearly 20 years. In their early analysis of pornographic media across three media platforms, Barron and Kimmel (2000) observed that depictions of violence against women were increasing in online newsgroups, and they attributed this increasing violence to the climate and environment that such newsgroups fostered. They argued that Usenet groups were "the closest things to the all-male locker room that exist in the pornographic world" (p. 166). These rooms provided men with a sense of homosociality, whereby men could communicate with others and jockey for position, using violence against women as a form of currency to do so. Shortly after, Gossett and Byrne (2002) presented their analysis of internet rape pornography websites. They argued that the iconography strongly emphasised the depiction of female victims as extremely powerless, and concluded that the accessibility of images depicting such misogyny, in conjunction with the increased interactivity of internet websites, "foregrounds the need to examine the effects of viewing Internet rape, particularly when it concerns power differentials among women and men and depictions of man-on-woman violence" (p. 704).

Internet pornography is a display of excessive gender differences and centres female agency as decidedly limited. Paasonen (2006) suggests that it does this through the display of "fantasy scenarios that are difficult to draw apart from gendered relations of power: male dominance and female willingness to serve are featured from the point of view of male protagonists and male pleasure" (p. 416). Internet pornography also increasingly adheres to a 'pornoscript' which prioritises masculine sexual pleasure and structures the way that sexual pleasure is enacted and visualised, perpetuating an "essentialist gender ideology" (van Doorn, 2010, p. 426). Gorman, Monk-Turner, and Fish (2010) find similarly: they observed that in free internet pornography, men were more likely depicted in sexually dominant positions, and the images "continued to focus on male pleasure, thereby upholding asymmetrical gender relations within a cybersex internet landscape" (p. 142).

Content analytical work has also focused on particular categories of pornography found on internet websites. According to Pornhub Insights data, 'teen' pornography is one of the 
most popular pornography categories (Pornhub, 2018a). In analysing teen and 'MILF'4 pornography, Vannier et al. (2014) found that "male actors were depicted more often as in control of the pace/direction of sexual activity, and female actors were portrayed more often as the victims of exploitation" (p. 260). Whilst they acknowledged that exploitation was uncommon overall, the majority of exploitation tended to occur in teen videos, primarily videos in the "casting couch" genre (p. 261). Casting couch refers to a specific subgenre of pornography where young women are portrayed as

being interviewed by a male talent agent who tells her that he is recruiting actors for adult films. According to the text at the start of the video, the talent agent is fake and the young woman is tricked into engaging in sexual activity on film under the pretense of creating an audition tape (Vannier et al., 2014, p. 260).

In a similar analysis of internet teen pornography, Peters, Morrison, McDermott, Bishop, and Kiss (2014) examined the cues used to construct illusions of youth. Their findings suggested that content which implied the female performer was underage was consistently found in a subsample of videos, however "behavioural and textual cues that conveyed the loss of virginity or sexual inexperience were relatively uncommon" (p. 542). In light of the irregularity of sexual inexperience being depicted in teen pornography, the authors posit that what makes the genre attractive is "the contrast between their youth and sexual prowess, which becomes evident as a given scene progresses" (p. 542).

Other content analyses are concerned with representations of gender inequality, violence and aggression in pornographic material. Klaassen and Peter (2015) contend that gender inequality in mainstream pornography "is complex and requires a nuanced application in media effects research" (p. 730). In their analysis of internet pornography videos, their findings suggested that women were often instrumentalised and depicted as sexually subordinate and dominated by men. In contrast to the traditional feminist critique, however, they found that women were not generally dehumanised and with the exception of spanking and gagging, violence was not a frequent feature in their sample.

As previously mentioned, the ethos of feminist pornography is a more equal, balanced representation of sexual activity produced under ethical circumstances (Taormino et al., 2013), so considerations have also been given to whether feminist pornography differs

\footnotetext{
${ }^{4}$ MILF is a type of pornography that eroticises mature women. The acronym stands for 'Mother I'd Like to Fuck'.
} 
in the type of material it presents. Fritz and Paul (2017) analysed the agentic and objectifying sexual scripts across feminist, for women, and mainstream pornography categories. Their analysis suggested that mainstream pornography contained significantly more depictions of female sexual objectification and physical aggression, suggesting that women were presented systematically as the "normalized target of aggression" (p. 648). Analysis of the 'for women' and 'feminist' categories suggested that the 'for women' category had "significantly more indicators of objectification than Feminist pornography" (p. 648), and queer feminist pornography contained more indicators of women's sexual agency. Interestingly, however, this was not the case for heterosexual feminist pornography. The authors suggest that heterosexual feminist pornography still encompasses "strong gendered sexual scripts about whose pleasure is prioritized whereas queer pornography may be able to break free from these normalized gender roles, allowing for more female pleasure and perhaps sexual agency" (p. 649). In sum, the authors concluded that mainstream "heterosexual pornography is not providing women with scripts of sexual agency and empowerment" (p. 650).

Most recently, content analyses of internet pornography have examined whether mainstream pornography is becoming "harder". Shor and Seida's (2018) analysis of videos uploaded to Pornhub in the last decade suggested that there was no consistent uptick in aggressive content, videos showed shortened segments of aggression, and aggressive content received less views and less positive appraisal. They concluded that viewers preferred pornography where women clearly performed pleasure and indicated that "at least some mainstream viewers are gradually moving away from prevalent depictions of aggression and degradation, and in particular from videos that include long sequences of such practices and from videos that depict non-consensual aggression" ( $p$. 9). Other areas of concern for recent analyses have centred on the way that race and gender combine in the conformation of stereotypical derogatory assumptions about ethnicity and sexuality (Shor \& Golriz, 2018; Zhou \& Paul, 2016); the uneven representation and distribution of orgasm and pleasure across gendered lines (Seguin, Rodrigue, \& Lavigne, 2018); and the nature of the relationships between performers, as pornography rarely promotes sexual connections between intimately connected relational partners (Rasmussen, Millar, \& Trenchuk, 2018). 


\section{The pornographic audience: consumer engagement and experiences with sexually explicit material}

As mentioned in Chapter One, rates of internet pornography consumption are massive, yet stereotypes persist about the type of person who watches pornography. In detailing the history of the pornography consumer, Attwood (2007) cites Kendrick's (1996) work on the shifting characteristics of the porn consumer over time, moving from the innocent child exposed to pornography to the figure of the addicted male. Attwood (2007) argues that a figure who has remained constant is women as "victims' of pornography who must be rescued" (p. 5), and goes on to demonstrate the dangers of such stereotypes, especially in the panics around pornography on the internet, such as the 'child-victim' and 'cyberporn addict', which are not completely representative of the perspectives of consumers themselves. McKee (2006b) writes similarly, suggesting that "there is a systematic "othering" of pornography consumers in academic research and in public debate about the genre. They cannot know themselves; they cannot speak for themselves; they must be represented" (p. 3). In light of this othering of pornography viewers, this review now explores young people's, men's and women's engagements with sexually explicit material, with a particular focus on qualitative research.

\section{Overexposed? Young people and internet pornography}

Children and young people's engagement with pornography is situated as a particularly concerning social problem, and whilst children and young people often encounter pornography online (Owens, Behun, Manning, \& Reid, 2012; Peter \& Valkenburg, 2016), some scholars suggest that their exposure to, and accessing of, pornography is perhaps more limited than popular media outlets suggest. Attwood et al. (2018b) contend that

the theme of young people's 'exposure' to pornography is a recurring refrain in much of the research which is drawn on in policy debates, implying that young people in their millions are constantly stumbling upon porn - a problem made all the more urgent by the availability of handheld devices giving children unfettered access to the web (p. 3753).

However, they go on to comment on the difficulties around young people's encounters with online pornography and how this is reported in the media. They argue that:

the issue of where young people encounter sexually explicit media is increasingly vexed... young people learn about sex from a wide variety of media and the wide use of social media by young people has made it increasingly difficult to decipher what encountering 'online pornography' might mean" (Attwood et al., 2018b, p. 3754). 
For children and young adolescents, much of their viewing of pornography is accidental or unintentional (Baker, 2016; Flood, 2007; Nash et al., 2015; Ybarra \& Mitchell, 2005), and research with young people suggests that some young people are distressed by pornographic content they have seen online (Green, Brady, Holloway, Staksrud, \& Olafsson, 2013; Livingstone, Haddon, Gorzig, \& Olafsson, 2011; Smith, 2012), or concerned about the impacts of pornography for their friends (Walker, Temple-Smith, Higgs, \& Sanci, 2015). That said, young people experience and negotiate pornography in a multitude of ways, and their interactions with pornography online are not always unintentional, nor are they always viewed as distressing and/or harmful by young people themselves (Attwood et al., 2018b; Mulholland, 2013; Rothman, Kaczmarsky, Burke, Jansen, \& Baughman, 2015; Smith, 2012). This is the case in New Zealand, where recent data suggests that a small, yet significant, number of young people regularly engage with internet pornography (Office of Film and Literature Classification, 2018). However, young New Zealander's were also concerned about the negative influence of pornography on their lives, suggesting they hold some critical appraisal of contemporary content.

\section{Rated X: Adults viewing pornography online}

Whilst significant concern exists about young people's viewing of pornography, adults constitute the primary audience of pornography consumers (Smith et al., 2015). People in emerging adulthood form the largest group of viewers, yet perspectives from consumers are notably absent in wider debates about pornography and its effects (Attwood, 2007; Hardy, 1998; McKee, 2006a; Mowlabocus \& Wood, 2015). Klein (2006) argues

there's something almost always missing from the common critiques of pornography: the voices of actual consumers... the main cultural narrative about pornography almost exclusively involves its alleged victims (identified, variously, as porn actresses; wives; all women; pathetic male consumers; atrisk children; the entire society). These critiques omit (in fact, contradict) the experiences of tens of millions of satisfied, repeat customers (p. 245)

Arguably, the most appropriate way to include insights into consumer experiences is through qualitative methods (Hardy, 2004). This thesis positions the experiences of 13 men and 11 women who use pornography, or their partners do, at the forefront of analysis. This review now turns to explore the qualitative work on men's and women's engagements with pornography. 


\section{It's a man's world? Men viewing pornography}

Much of the empirical work with men about pornography comes from a quantitative paradigm, and whilst this review is by no means exhaustive, concerns have been focused on men's development of hostile attitudes or sexually aggressive behaviours towards women (Hald, Malamuth, \& Yuen, 2010; Hald, Malamuth, \& Lange, 2013; Malamuth, Addison, \& Koss, 2000; Malamuth, Hald, \& Koss, 2012), gender role conflict (Szymanski \& Stewart-Richardson, 2014), the influence of pornography on men's sexual scripts (Sun et al., 2016; Wright, Sun, Steffen, \& Tokunaga, 2015), and the detrimental impact on men's body image (Tylka, 2015). However, as with all research in pornography studies, researchers report oppositional findings in this space (Ferguson \& Hartley, 2009), and some research suggests that men who view pornography may actually hold more gender egalitarian perspectives towards women (Kohut, Baer, \& Watts, 2015).

In recent years, concerns have been raised about the addictive nature of internet pornography. Pornography addiction, or self-perceived problematic pornography use, has seen increasing scholarly attention paid to primarily men's compulsive or problematic use of internet pornography (Duffy, Dawson, \& das Nair, 2016; Sniewski, Farvid, \& Carter, 2018), particularly from a neuroscientific perspective (Love, Laier, Brand, Hatch, \& Hajela, 2015). There is also an abundance of work written from a selfhelp perspective (Struthers, 2008; Wilson, 2015), as well as a dedicated online community called 'No Fap' to assist men in recovering from pornography addiction (Taylor \& Jackson, 2018). Although not codified as an official diagnosis in the Diagnostic and Statistical Manual of Mental Disorders, pornography addiction remains a powerful media label lacking defined contours, and has become a key driver for considering pornography a public health crisis (Ley, 2018; Ley, Prause, \& Finn, 2014).

Although men form the primary audience of pornography, there remains scant qualitative literature conducted with men about their subjective experiences with the genre (Attwood, 2005; Hardy, 1998). Of the recent qualitative research with men, there is an increasing body of research exploring non-straight men's experiences with sexually explicit material (Elder, Morrow, \& Brooks, 2015; McCormack \& Wignall, 2016), yet there is little qualitative exploration of heterosexual men's experiences with pornography, despite their dominance as pornography's audience. 
In an early review of literature on men's experiences with pornography, Attwood (2005) points to the Hite Report on male sexuality as one of the first qualitative explorations. The report itself contains a detailed account of men's experiences with sex and sexuality, including a dedicated section on pornography which explores what men see and feel when they engage with it (Hite, 1981). Nearly two decades later, Loftus (2002) explored the way that men respond to pornography, suggesting that men were more critical of pornography than anti-pornography feminist discourse would lead us to believe. In a more in-depth and critical engagement with men's engagement with pornography, Hardy (1998) detailed the way men's engagement changed over the lifespan, identifying early adolescent engagement as a form of social use, whereas later use of pornography when in relationships with women was a more reconciled form of engagement.

In a qualitative analysis of readers' self-reports of why they viewed Playboy, Beggan and Allison (2003) explored men's self-reported engagement with Playboy and the possible ways that Playboy worked as a socialising mechanism for boys transitioning to manhood. Further, qualitative research with men has documented the way that men assume a "culturally conferred right to evaluate the female nude" (Eck, 2003, p. 697) and that the way that men look at pornography - by gazing at women and not gazing at men - affirms their heterosexual masculinity. More recently, it has been reported that men's discussions about pornography acknowledge the pervasiveness and normalised place of pornography in their everyday lives (Antevska \& Gavey, 2015; Haggstrom-Nordin, Sandberg, Hanson, \& Tyden, 2006; Lofgren-Martenson \& Mansson, 2015; Mattebo et al., 2012).

Research suggests that some young men do have critical media literacy skills and are cognisant of the idealised representations of bodies in pornography and how pornography depicts a distorted sexual reality (Mattebo et al., 2012). Further, research suggests that some men are consciously aware of the fictional representation of men in pornography and reject its representation as 'artificial' (Potts, 2002). That said, some research has substantiated concerns about pornography's potential influence on sexuality, with young men reporting that a primary reason for engaging in anal sex is to replicate what they view in pornography (Marston \& Lewis, 2014).

In-depth interviews with New Zealand men have demonstrated the way that they understand and interpret the gendered dynamics of internet pornography (Antevska \& 
Gavey, 2015). Further, interviews with men have interrogated men's interest in degrading practices that are commonplace in pornography (Sun, Ezzell, \& Kendall, 2017). Antevska and Gavey (2015) identified the way that men normalised gendered positionalities in pornography and presented a detached way of engaging with erotic material online. Men were clearly not expected to account for the appeal of pornography, with these questions eliciting an 'it just is' response. Further, Sun et al. (2017) highlighted the ways that men were influenced by degrading practices in pornography and how it functioned as a powerful sexual script that encouraged them to want to partake in practices such as ejaculating on a woman's face, despite knowing that most women would not enjoy it or find the same pleasure in the practice. In sum, qualitative research with men about how they understand and interpret pornographic material is a sparse literature field, despite men's heavy presence and engagement with pornography, necessitating further investigation into the way that men understand and engage with particular types of pornography.

\section{(C)literacy? Women's engagement with pornography}

Attwood (2005) argues that "if studies of male consumers of pornography are scarce, research that focuses on women as active users of pornography are practically nonexistent" (p. 72). Despite women being involved in both the production and consumption of pornography, their experiences have received considerably less attention than men in the field of pornography studies (Ashton, McDonald, \& Kirkman, 2017; Attwood, 2005; Mowlabocus \& Wood, 2015; Parvez, 2006; Shaw, 1999). This may be unsurprising, given that women have been frequently identified as using pornography at lesser rates than men (Maas \& Dewey, 2018), however recent research suggests that this may be attributable to a generational shift, in that younger women between the ages of 18 and 25 may be more likely to view pornography than older women (Smith et al., 2015). Specifically for Kiwi women, data from Pornhub suggests they are a significant proportion of the audience of pornography for New Zealand as a whole, and engage with internet pornography at rates higher than the global average (Pornhub, 2015).

Women's experiences with pornography are remarkably complex and varied (Attwood, 2005; Boynton, 1999; Parvez, 2006; Senn, 1993). In Senn's early research with women about pornography, she argued that “women's experiences and attitudes toward pornography cannot be collapsed into a unitary category of female. All women do not 
think about pornography in the same way nor have they had the same or similar experiences" (Senn, 1993, pp. 337, emphasis in original). What does seem to be conclusive within the literature, however, is that many women often report quite mixed feelings about pornography, simultaneously experiencing it in both positive and negative ways depending on context (Gurevich et al., 2017; Haggstrom-Nordin et al., 2006; Lofgren-Martenson \& Mansson, 2015; Parvez, 2006).

Chowkhani (2016) notes that women can experience danger and risk as consumers of pornographic material, but their reading of pornography also speaks to the pleasures of viewing female bodies in pleasure. This is a similar finding to the work by Gurevich et al. (2017) who identify pornography as a 'contested arousal tool', whereby pornography is simultaneously arousing but also a potential site for pain. More recently, research suggests that some women are acutely aware of the potential for pornography to appear with negative content "which could derail their arousal or cause disinterest or discomfort" (Chadwick et al., 2018, p. 1858). This awareness meant they employed strategies to try and contain their encounters with such content, such as by viewing pornography they deemed to be 'safe', altering its content, or choosing non-visual forms of pornography which provide a higher measure of control.

Women's ambivalent perspectives about pornography are a departure from the divisive perspectives that flood the academic literature in pornography studies. However, research suggests that some women often report feeling that their use of pornography conflicts with their own feminist ideals and values, contributing to a sense of uncertainty about pornography, yet it continues to induce feelings of sexual arousal and enjoyment (Ciclitira, 2004; Gurevich et al., 2017). Not only do some women report feeling internally concerned and conflicted, but their concerns are also outward facing, in that women's reading of, and empathising with, other women's discomfort in pornography has been repeatedly identified (Boynton, 1999; Chadwick et al., 2018; Shaw, 1999). This concern extends beyond the women on screen, with concerns cited about men's use of pornography and their adoption of problematic or unattainable expectations of women's bodies and sexual selves (Gurevich et al., 2017; Mattebo et al., 2012; Shaw, 1999). Not all women are interested in pornography, however, and many women choose not to view pornographic material (Ciclitira, 2004; Kohut et al., 2017). Women's disinterest in pornography has been reported, with some women suggesting that the way women are 
presented in pornography is incongruent with real women and real bodies, meaning women struggle to relate to these stereotypical depictions (Lofgren-Martenson \& Mansson, 2015; Mattebo et al., 2012; Wong \& Yau, 2014).

In terms of pornography's influence on female sexuality, research suggests that some women report men's normalisation of heterosexual anal sex following watching pornography (Fahs \& Gonzalez, 2014), and how pornography can be a source of education and inspiration in their sexual relationships (McKeown, Parry, \& Penny Light, 2018). In speaking to experiences of abuse, research has also detailed women's attribution of their male partner's use of pornography to their experiences of sexual and physical violence in intimate relationships (Bergen \& Bogle, 2000; DeKeseredy \& HallSanchez, 2016). Ultimately, then, research with women about pornography suggests a complex and gendered experience which warrants further ongoing investigation.

\section{Pornography as the 'third' person in a relationship? Pornography's location in intimate relationships}

Research surrounding the impact of pornography on intimate relationships has been a key point of concern for academic scholarship, however research in this area is often quantitative in nature, contentious and conflicting (Daneback, Træen, \& Mansson, 2009; Grov, Gillespie, Royce, \& Lever, 2011; Maddox, Rhoades, \& Markman, 2011; Manning, 2006). For example, some research suggests that some pornography viewing in the presence of a partner is not related to negative relationship functioning (Maddox et al., 2011; Manning, 2006) and that using pornography together may increase opportunities for open sexual communication in intimate relationships (Daneback et al., 2009). Conversely, research reports that pornography consumption can be related to weakened commitment to a romantic partner and greater levels of infidelity (Lambert, Negash, Stillman, Olmstead, \& Fincham, 2012).

Whilst some women may watch pornography with their male partners, it is not always because "they want to watch it or they enjoy watching it" (Resch \& Alderson, 2014, p. 420), and this has been reported elsewhere (Wong \& Yau, 2014). From a gendered perspective, research with young adult women suggests that their understandings of their male partner's level of pornography consumption can be associated with negative relationship quality, as well as having impacts on women's self-esteem and sexual satisfaction (Stewart \& Szymanski, 2012; Tylka \& Kroon Van Diest, 2015) Some research 
with emerging adults suggests a degree of acceptance around expectations of pornography use in relationships, with many people reporting some level of conditional use of pornography acceptable by their intimate partner (Olmstead, Negash, Pasley, \& Fincham, 2013), but this is especially related to women's use which is often understood and interpreted in a positive way in dyadic relationships (Bridges \& Morokoff, 2011).

Early research on the influence or effect of pornography on intimate relationships tended to focus on women's relational experiences with men who used pornography. An analysis of letters written online by women in relationships with men who used pornography heavily suggested that their experiences in these relationships were overwhelmingly negative. These women reported that their male partner's use of pornography negatively affected intimacy, self-esteem and their overall view of the relationship and satisfaction (Bergner \& Bridges, 2002). The impact of men's use of pornography on women's feelings of trust and security in the relationship has also been reported as significant for women (Bergner \& Bridges, 2002; Bridges et al., 2003; Schneider, 2000; Shaw, 1999). In their survey of 100 women in relationships with men who used pornography, Bridges et al. (2003) reported that one third of women

ascribed highly negative meanings to, and experienced considerable distress over, their partner's use of pornography. They saw it as constituting a kind of infidelity, as damaging to the sexual and other intimacy in their relationships, as indicative of their partner being a sick and lesser man than they had previously supposed him, and as damaging to their own self-esteem (p. 13).

Ultimately, then, these women's discovery of their partner's use of pornography "radically altered the way that these women perceived their relationships, themselves and their partners" (p. 12).

Contemporary qualitative research on the relational impacts of pornography is limited, and critics argue that continually producing research from a harms-based paradigm limits the possibilities for diverse research findings (Montgomery-Graham, Kohut, Fisher, \& Campbell, 2015). Some research suggests that women can feel pressured to embrace pornography in intimate relationships (Benjamin \& Tlusten, 2010; Resch \& Alderson, 2014; Wong \& Yau, 2014), however this is often to please male partners (Wong \& Yau, 2014). That said, pornography can provide a source of sexual exploration and inspiration for intimate relationships (Kohut, Fisher, \& Campbell, 2017; McKeown et al., 2018). 
Further, large-scale research by Kohut et al. (2017) has identified the multitude of ways that pornography can, and does, function in intimate relationships. In their sample of 430 partnered men and women, they identified that a great number of participants reported no negative effects of pornography on their relationships and that pornography had the potential to contribute positively to sexual experimentation. At the same time, they recognised other common themes such as personal insecurity, decreased interest in sex with a partner, and that pornography contributed to unrealistic expectations within the relationship, cementing a contradictory and conflicting research platform. This necessitates a more open-minded approach regarding pornography and its role in intimate relationships, particularly regarding the gendered differences in men's and women's reported understandings and experiences.

\section{Summary}

This review has briefly explored the key historical debates about pornography and shown how 'sex wars' continue to divide feminist researchers in contemporary times. The legacy of the sex wars ultimately lives on, then, and the anti-pornography feminist position remains a dominant one. However, research on both sides of the anti/propornography spectrum would benefit from moving beyond emotive positions and exploring perspectives from consumers of pornography themselves as their lack of inclusion in research on pornography is a striking omission. Such a position does not necessitate an objective, disembodied approach, but has the potential to present a more, balanced, nuanced account of the realities of pornography in the digital age.

This review has highlighted the significant literature gaps that exist regarding men's and women's critical engagements with pornography, including in their intimate relationships. My research provides a qualitative, exploratory insight into the myriad ways that a sample of emerging adults in New Zealand experience contemporary pornography. It situates participant perspectives at the forefront of the discussion, and presents their perspectives rather than 'representing' them (McKee, 2006b). To my knowledge, this research is the first of its kind in New Zealand to present the perspectives of both genders about how they understand, interpret and relate to pornography in the digital age. It addresses this literature gap by providing rich, detailed accounts on a topic which is typically shrouded in secrecy. Further, it provides a platform for future research 
from participant perspectives and positions. Fundamentally, it encourages future research with people about pornography rather than on them. 


\section{Chapter Three: Methodology}

This chapter documents the methods used for data collection in this research and the theories underpinning the overall research approach. It provides an insight into how the data was gathered and a critical reflection of the difficulties faced throughout the project. This chapter begins by providing an overview of the theoretical framework utilised to explore the research aims, as outlined in Chapter One. It then outlines my positionality as a researcher in an area which is plagued with ambiguity, conflict and uncertainty. The next section details the research approach, including the methods used for the study and the difficulties involved in obtaining ethical approval. Following this, the chapter details the recruitment methods used to locate a sample, introduces the participants, describes the interview experience and then the data analysis process. Lastly, this chapter turns to a critical reflection of the challenges involved in sex research.

\section{Theoretical framework}

Theoretically, this research is informed by an interpretivist approach which is influenced by feminist perspectives. Feminist research "positions gender as the categorical center of inquiry and the research process" (Hesse-Biber, 2014, p. 3). Feminist methodologies have broadened from concerns only for women's lived experiences and offer a broad vision of praxis that can analyse both men's and women's lives in the pursuit of social change (Brinton Lykes \& Crosby, 2014). A feminist methodology is important for this research given the gendered differences present within pornography itself, as well as the way it is experienced by both men and women. Feminist research, and particularly feminist research methods, are more about the ways research is conducted and the methods used throughout the research process (Reinharz, 1992). Mason and Stubbs (2012) contend that "there is no orthodoxy to feminist research methods in criminology" (p. 486), however one of the core components of feminist research is the inclusion of reflexive practice. The questions of power and experience that feminism explores extend further than just that of participants, and these questions encourage feminist researchers to examine their own positionality in the research process (Hesse-Biber, 2014; Renzetti, 2013).

Wodda and Panfil (2018) describe a vision for a feminist sex-positive criminology and suggest several ways that feminist criminologists could incorporate a sex-positive focus 
into their research and praxis. They suggest that sex-positive feminists should be concerned with the criminalization of teen sexting given the potential for discussions around reducing harm, public health and the continuation of comprehensive sexuality education. Fundamentally, their sex-positive stance aligns with a “don't 'yuck' anyone's 'yum'” mantra (Wodda \& Panfil, 2018, p. 589), provided such 'yums' fit within the realm of consensual sex. Ultimately, they suggest that "feminist criminologists could fruitfully explore the notion of a more nuanced "sexual universe" that avoids the binary formulation of sexual assault verses sex-positivity" (Wodda \& Panfil, 2018, p. 593). As I read this piece, I saw the appeal for considering pornography and its pleasures within this remit, but I felt that such a position ignored discussions about the pains. It is for these reasons that I prefer to consider this project as conducted from a position on a continuum whereby pornography as pleasurable sits on one end, and pornography as painful is positioned on the other, with my own position somewhere in the middle, but leaning left or right of centre depending on the perspective I am presenting from participants. I have continually reminded myself that people's experiences with pornography are shaped over time and space and are heavily reliant on context. By consciously inserting myself into the research process and being as reflexive as possible about my involvement in the process, I hope that this produces a more honest and balanced form of knowledge.

\section{Pornography and me: where do I stand?}

It has been suggested that sex researchers should disclose their own sexual preferences when conducting research, due to their influence on the development and progression of the project (Thomas \& Williams, 2016). Whilst I agree that one's own preferences can influence the direction of a project, my own lived experience with pornography affects this as well. Although writing about my experiences with pornography makes me feel somewhat naked - and potentially runs the risk of coming across as remarkably selfindulgent! - I believe doing so is a critical inclusion in this study. My experiences with pornography provide a backdrop for my understanding and interpretation of the narratives which form the backbone of this research.

As a child, I spent seven years living in New Zealand's largest city before moving to a rural township when my parents separated. My Mum's decision to leave an abusive relationship was undoubtedly difficult, and my childhood experiences in that environment have fundamentally shaped my perspective on the world. During my high 
school years, several friends disclosed their experiences of childhood sexual abuse and violence, with many of them saying that nobody listened to them when they disclosed or attempted to stop it from happening. I questioned why or how people could hurt the people I cared about, and I wanted to know how this could be prevented in the future.

Fast forward to my first year of tertiary study: at 17, I naively thought everyone working in the legal profession felt the way I did about justice. I admired the few law students I encountered that stood up for victims' rights, yet I loathed the idea that I would have to represent people who had perpetrated harm. Upon reflection, my understanding of this issue was anything but nuanced, and I faced a crisis of identity in the process. I dropped out of law and enrolled in criminology. For the first time I found a subject that made sense. I began engaging with academic literature which tackled issues such as racism, discrimination, violence and the inadequacies of the New Zealand criminal justice system. I was engaging with material which helped me understand why people trivialised violence, and how these views continued to be perpetuated despite increasing societal recognition in New Zealand of the realities of intimate partner abuse. I was finally understanding complex issues and questions were finally being answered. Everything seemed to be making sense, except pornography.

My first memories of pornography are clear, but my understanding of them as 'pornographic' were limited. At about age four I recalled looking at one of my father's 'boobs on bikes' magazines and felt a sense of confusion about what I was seeing. A few years later, my first memory of encountering something I understood as pornography was when it was shown to me by a relative's male international exchange student, about ten years my senior. He invited me into his room where he had clearly been watching pornography for his own arousal. Some years later, in my early teenage years, my female cousin and I watched pornography together which we found on a laptop. As we watched it, we laughed at the ridiculousness of the videos, the accents of the performers, and it was anything but erotic.

It was not until my first adolescent relationship that I started to develop an opinion about pornography. My boyfriend at the time had pornography pictures plastered all over his bedroom wall and roof. I used to spend most of the night staring at these beautiful, thin, naked women above me. When my requests for the images to be removed were ignored, 
I started to wonder if this was what my boyfriend wanted me to look like. The images had stories written alongside them and when I focussed on those, I felt that these women were somehow more human - less plastic, more real, more like me. I grew to despise pornography and felt like I could never compete with the women in these images, a feeling which continued in my next serious relationship. When I discovered he was secretly using pornography, it felt like a form of infidelity. I felt inadequate. In my mind, if my boyfriend had to look at pornography, it was because he did not want to look at me.

Academically, I confronted pornography for the first time in a third-year criminology paper. A male student spoke up during a tutorial about how wonderful pornography was and how it was his 'right' to view pornography and masturbate to it. I vocalised how strongly I disagreed with this statement and how I felt it showed no regard for the way other people - namely me - felt about pornography. There was a resounding silence from much of the female class during this exchange, but a number of women supported his view and believed that watching pornography was normal for men. Some even disclosed their own use of pornography. How could people have such open and accepting views about something I felt so strongly about?

Upon starting my PhD, I immersed myself in pornography scholarship and struggled to comprehend the ferocity of the 'sex wars'. The more I read, the less I knew; the academic debates about pornography seemed black and white, but I was feeling decidedly grey. I was troubled by this because what would this uncertainty mean for my data? For the project overall? Now, I see not picking a 'side', but picking a coherent and substantiated position somewhere in the middle of these debates, has been beneficial for this research. My own changes in perspective about pornography have meant that I can in some ways understand the ways that my participants have also experienced changes in their positions. My position on pornography is still neither strictly for or against, however I am consciously aware that pornography - particularly mainstream content - tends to depict a rigid type of sexuality which prioritises male pleasure and presents sex in a scripted, fragmented sense of reality. That said, I recognise the potential pains of pornography alongside its potential pleasures, and I hope that thinking about pornography in this way provides a nuanced lens for considering participants' perspectives. 


\section{Research approach}

This research explores the influence of pornography on the lives of a self-selected sample of heterosexual New Zealanders between the ages of 18 and 30. I chose to include participants between the ages of 18 and 30 as they form a generation who has grown up with increasing access to the internet, but who are also likely to have experiences with pornography outside of the digital realm. I was curious why the concerns raised about youth pornography use were not similarly raised about adults, especially as they are the largest group of viewers. I was especially interested in exploring the gendered differences in experiences with pornography, so both men's and women's experiences form the basis of this project.

I chose to limit this study to self-identifying heterosexuals, however a small number of participants identified as bisexual during interviews. I understand that limiting this project to heterosexual-identifying participants inevitably limits the scope of the project, and the decision to limit to heterosexual-identifying persons was not a decision made lightly. That said, as a heterosexual-identifying cisgender woman myself, alongside my interest in mainstream heterosexual representations, limiting the scope of the study best met my aims in this project.

Participants in this project were all aged between 18 and 30 years of age. Commonly referred to as emerging adulthood, this developmental period is characterised by exploration of life in a variety of ways, especially romantic love (Arnett, 2015), and the frequent use of pornography (Coyne, Padilla-Walker, \& Howard, 2015; Olmstead et al., 2013; Rasmussen, Ortiz, \& White, 2015). Thus, concerns have been raised about the susceptibility of emerging adults to the influences of sexually explicit material (Braithwaite et al., 2015b; Carroll et al., 2008), and these concerns were influential in the decision to isolate this study to emerging adulthood.

Overall, then, this research is limited to exploring the experiences and perceptions of a small sample of heterosexual men and women living in New Zealand. Having a small sample who discuss such a diverse array of perspectives makes it near impossible to draw generalised conclusions from the data, but it was never my intention to generalise. Instead, my goal in this project has been to accurately present the diverse, complex and nuanced experiences with pornography which were relayed to me by my participants. 
Positivist approaches have a long history in criminological inquiry, and neatly align with quantitative methodologies. The exploratory nature of this project meant that I needed to be constantly open to the possibility of new ideas or ways of asking questions, necessitating an engaged and reflexive approach which is in opposition to the positivist paradigm. Positivist approaches encourage an objective, unemotionally engaged positionality, as well as the pursuit of an absolute 'truth'. Whilst this might be a suitable foundation for research in some disciplines, it is a concept I dispute regarding social scientific research. The pursuit of a single truth ignores the potential for unveiling complex and subjective experiences, promoting a superiority of generalised labels to experience rather than highlighting the nuances in individualised accounts. I anticipated a variance in experiences to be reported by participants. I did not set out to find out the exact 'way' that pornography is experienced, and I do not believe that there is one single truth which is reflective of people's feelings and engagements with sexually explicit material.

I opted to use qualitative research techniques, specifically semi-structured interviewing, for this research. The essence of qualitative inquiry is it provides researchers with a way of "understanding, describing, explaining, unraveling, documenting, illuminating, chronicling, and documenting social life" (Leavy, 2014, p. 1). Qualitative research asks the why questions (Wertz et al., 2011) and it is both a way of learning about social reality, but also an acknowledgement of the active role that individuals have in the construction of their own social realities (Boeije, 2010). The strength of qualitative techniques lies in their ability to facilitate access to deeper meanings and insights, allowing for the capture of richer, more nuanced accounts of lived experiences (Marshall \& Rossman, 2011; Miller \& Glassner, 2016). The fluidity of qualitative techniques allows for the development of strong trust and rapport relationships with participants, which, in the hands of a skilled interviewer, can permit access to deeper, more complex discussions with participants (Braun \& Clarke, 2013; Liamputtong, 2007; Rubin \& Babbie, 2010). More broadly, qualitative research is also described as a "creative process" where researchers are able to "experiment, play, adapt, learn, and grow along the way" (Leavy, 2014, p. 6). It therefore lends itself neatly to the doctoral process which is an ever-evolving process of adaptation and growth. 
There were a number of changes throughout the development of this project. Initially, I proposed a mixed-methods project incorporating both one-on-one semi-structured interviews and a series of online focus groups. In-depth interviewing has a long history in sensitive research (Dickson-Swift, James, Kippen, \& Liamputtong, 2009; Liamputtong, 2007), however focus groups have also been employed in sex-based research. Frith (2000) considers focus groups appropriate for sex research as they allow insight into under-researched topics and provide conditions where participants feel comfortable talking about sensitive topics. Focus groups have been specifically used in research on pornography (Crutcher, 2015; Liberman, 2015; Lofgren-Martenson \& Mansson, 2015; Scarcelli, 2015), and the ubiquity of pornography on the internet encouraged me to consider online focus groups as a method. I decided later that using semi-structured interviewing would be the most appropriate method for the project in its entirety. My preliminary assessments of the data obtained in one-on-one interviews indicated that there could be difficulties involved with managing some of the disclosures made in an online forum. I was concerned about my ability to identify how participants were feeling about the discussions as they progressed, and their safety was paramount. In the interests of participant safety, I chose to discard online focus groups as a method and progress with interviewing on a one-on-one basis. However, the process of actually getting to the interviewing stage was plagued with difficulties, particularly around gaining ethical approval for the project. This chapter now discusses the difficulties involved in obtaining ethical approval for sex-related research.

\section{Ethical approval}

As with all research involving human subjects, this study required careful consideration of ethical issues. Whilst research on sensitive topics has the potential to cause distress or harm, this may be especially so with research on pornography as the eliciting of powerful emotional responses about a topic can be detrimental for participants. Further, pornography research has the potential to cause distress to the researcher, as qualitative research on sensitive topics can be a remarkably embodied experience (Dickson-Swift et al., 2009; Fahs, Plante, \& McClelland, 2017). Ethical approval was sought from the Victoria University of Wellington Human Ethics Committee. The approval process took a total of three months, and the memorandum of approval can be found in Appendix A. 
I anticipated obtaining ethical approval for this project may be challenging, and concerns have been discussed about the role of research ethics boards in assessing researcher risk and safety in the context of sexuality research (Webber \& Brunger, 2018). It is important to detail the challenges faced in gaining ethical approval for pornography scholarship in the New Zealand context, given the urgent need for future research in this space, and this chapter addresses this next.

\section{Choosing a sample}

Initially, I proposed to include 17-year olds as participants in this study. Prior research on pornography and/or sex from a qualitative perspective has included people of this age (Attwood et al., 2018b; Marston \& Lewis, 2014; Rothman et al., 2015). The ethics committee requested I reconsider including 17-year olds due to the age restrictions on pornography consumption. In New Zealand, it is considered illegal for under-18s to view pornography, and given the other issues raised with the ethics application, I agreed to limit my sample to participants between the ages of 18 and 30 .

\section{Talking safely about pornography and sex}

Safety is always a critical consideration in qualitative research, which extends to both participants and researchers (Hammersley \& Traianou, 2012; Wiles, 2013). All participants were provided with a list of support services that they could contact if they required assistance or counselling following the interview (copy in Appendix B). I had also considered the emotional impact of researching in this area, so included details about how those issues would be managed. In response, the committee highlighted their concerns about my own physical safety when conducting interviews and asked me to "seriously consider having a second researcher present as a transcriber to protect you." I was troubled by the use of the word 'protect' as I felt it drew upon dominant narratives of pornography viewers - usually men - as deviant individuals (Attwood, 2007; Klein, 2006). Further, it also drew on wider narratives of women as passive 'victims' in pornography (Attwood, 2007; Kendrick, 1987), removing their capacity as agentic consumers, but also assuming I was somehow naïve and in need of protection as a researcher. This commentary felt solely related to my gender and I wonder whether such concerns would have been raised if my research was isolated to women's perspectives, or if I was a male researcher. 
I assured the committee that the location for interviews had been considered extensively and I rejected the idea that a second researcher be present for the interview. The presence of a third person alters the power relationship in the interview - a position already weighted towards me as the researcher - and their presence may also make participants feel threatened or uncomfortable. Further, the presence of a transcriber raises further questions about risk and safety, as their emotional involvement in the project may necessitate further consideration.

\section{Managing conversations about criminal behaviours}

The most significant concern raised by the committee was around disclosures of criminal behaviour in relation to pornographic material. It was suggested that I

"specifically warn against criminal disclosure in the information sheets and in the starting introduction to the session. Any disclosures of criminal behaviour of this nature must be disclosed to your supervisor and in consultation with them, the Police. Any such disclos[ure] must lead to immediate ejection from the project".

On the one hand, I appreciated the stance of the committee and understood their concern about disclosures of involvement in illegal materials and the legal issues this could raise. The legal and ethical considerations involved in research with child pornography offenders are many (Ray, Kimonis, \& Donoghue, 2010), but I also felt that this cautioning had the potential to limit the conversations I could have. If I were to follow the recommendation that I disclose the use of illicit or objectionable material to my supervisor or the Police, it could mean that anyone watching pornography which uses violence or coercion may necessitate disclosure as it could be considered objectionable. However, what counts as violent or coercive is difficult to assess without viewing the material that participants are describing. For example, a participant may disclose that they engage with pornography which shows men as dominant and women as submissive, with elements of spanking, gagging, and choking in the scenes. Such material - identified as mainstream and routine by some researchers (Bridges et al., 2010) - could be interpreted as violent or coercive. Alternatively, it may sound simply like a BDSM ${ }^{5}$ scene

\footnotetext{
${ }^{5}$ BDSM is an amalgamation of acronyms that refer to a particular set of sexual practices that individuals may be interested in, such as "domination/submission, pain or sensation play, power exchange, leathersex, role-playing, and fetishes." The letters in BDSM stand for "B \& D (bondage and discipline), D/s (domination/submission), and SM (sadomasochism)" (Weiss, 2011, p. vii).
} 
involving consenting individuals. How was I expected to make a judgment call on a description provided to me by a participant?

In response, I noted that research is often done with people involved in illicit behaviours - such as drug use - and I felt that pornography consumers, even if the material was objectionable, should not be excluded. However, if someone was involved in the creation or distribution of objectionable pornography then this could be managed differently. My parallel between objectionable pornography and drug use was not shared, as

"people taking illicit drugs are harming themselves but there is no direct third party harm involved. In the case of at least some of the pornography you describe, there are third parties who are being abused - of course this is likely to relate mainly to children and animals but could involved (sic) exploitation of some adults as well."

I agree that third parties are undoubtedly repeatedly abused by the ongoing viewing of material. However, I highlighted that some research shows that pornographic videos routinely depict violence and aggression aimed at women (Bridges et al., 2010). I concluded that I would be clear in my information sheet and consent forms (Appendices $\mathrm{C}$ and $\mathrm{D}$ ) that disclosures of behaviour that may contribute to the offline perpetration of harm to either themselves or others may be disclosed to authorities, and approval was subsequently granted.

\section{Recruiting a sample}

This project consists of a self-selecting sample of 24 participants who were recruited through a combination of both online and offline methods. This chapter now details the methods used to recruit the final sample.

\section{Posters}

Using posters in bathroom stalls had been a successful recruitment method in previous projects, and I opted to use this method again as I felt that the privacy afforded would allow potential participants to consider the project in isolation. Recruitment posters were designed and printed by me and can be found in Appendix E. Most poster placements were made around my university campus in the evenings. This allowed me to enter the men's bathrooms to place posters and limit the possibility of encountering men in their private space. I always had another person with me when I did this who stood outside the stall and told people who may enter that I was in the bathroom. Participants often 
mentioned that they had seen the posters in bathrooms on campus, and some participants mentioned that these posters were shared through the social media channels of friends, indicating the reach was further than just toilet stalls.

\section{Social media}

As well as posting in bathroom stalls, I used both Facebook and Twitter as sites for recruitment. I created a Facebook page titled 'The Porn Study' which received 69 'likes'.6 I paid to 'boost' two of the posts to a targeted audience of men and women living in the Wellington region.

Posts on the page between October 2016 and March 2017 reached 581 people. On the 7th of March 2017 I shared a news article from 1 News to The Porn Study page. I added some of my own commentary when I shared the post, which can be seen in the image below:

\section{This image has been redacted. Please see print version for the full image.}

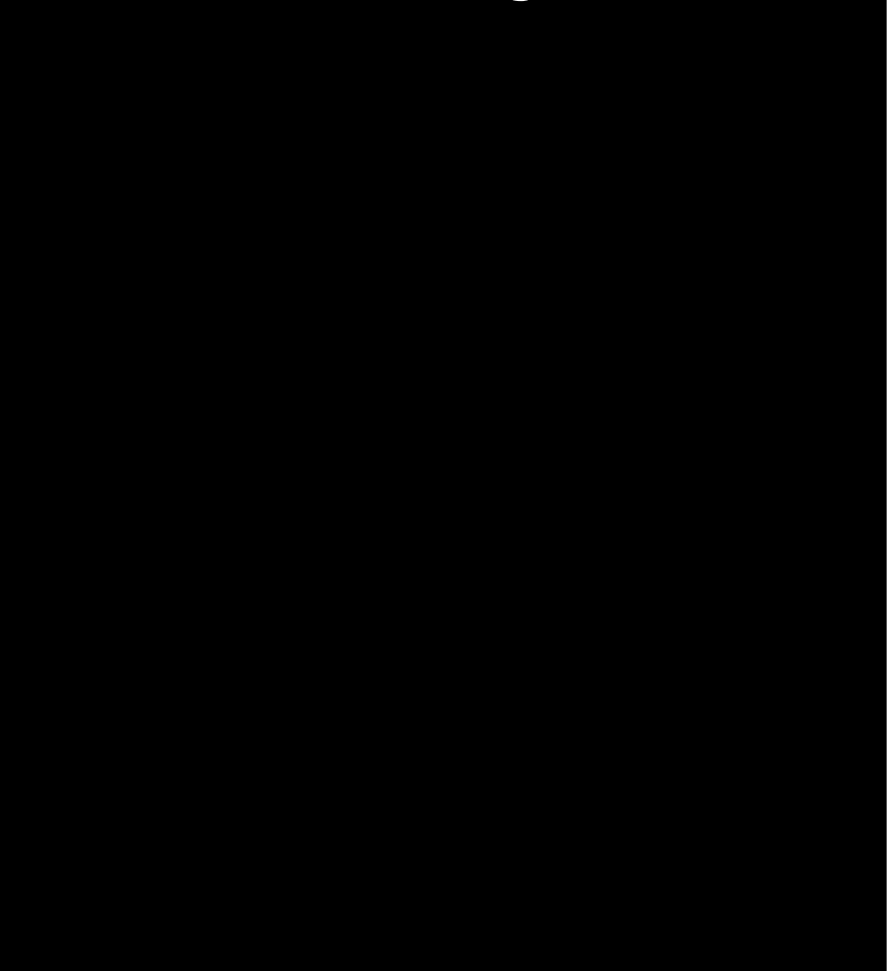

Figure 1: screenshot from The Porn Study Facebook page

\footnotetext{
${ }^{6}$ Liking things on Facebook means a user of Facebook pushes the 'like' button underneath a comment posted by another user. This functions as a way of one user demonstrating to the other that they like the comment this person has provided.
} 
This post reached 1,177 people and six people commented on it. Three of these comments were people tagging their friends in the post which is often done to draw their attention to the post/subject. The other three were more in-depth and showed how strongly people felt about pornography:

Comment One: "Family First and their alliance of Christian fundamentalist groups are calling for a Government inquiry. There, I fixed your head line. If you're going to report this stupid story then at least make sure the headline is accurate."

Comment Two: "It only a health crisis when I wait till everyone is at church on a Sunday and I go out front of the church and turn porn on really loud. They all come running out cause they head (sic) oh god oh god thinking someone is praying, only to get a shock of a life time. Good times good times."

Comment Three: "experts"? since when was fucking family first an "expert" in any fucking study? Those are the guys who wanted to ban abortions and let us hit our kids. You wanna take us back to the stoineage (sic), and you're using pseudoscience to do it. There's absolutely no evidence that porn is harmful. I think you're just another christian fundamentalist trying to find reasons to ban porn. If it isn't illegal, let the people have their fun in private."

My reply: Hi [name], thank you for your commentary. I certainly do not personally align with any religious view about pornography, and the study itself is primarily concerned with people's experiences with pornography, whether they be positive or negative, and to identify the meanings of pornography for a sample of New Zealanders. Further, I shared the link from mainstream news media here as pornography is receiving a lot of media attention currently, not to say that I endorse this sentiment from the article. In fact, I think reporting on this issue should be more balanced than it is.

On the $27^{\text {th }}$ March 2017 I shared an article from NewstalkZB which reached 1,121 people, received five likes and one comment. The comment was provided from the same person who made comment three on the previous post:

Comment One: “It really isn't a problem. You and the christian fundamentalist groups you clearly support need to get that through your head. Stop interfering in peoples personal lives. This isn't a PhD study, it's a joke."

My response: "Hi [name], thank you for your commentary. As I posted on your other comment, I simply shared the article as pornography is getting airtime at the moment. As for the study, I am certainly interested in speaking with and have done! - people who express similar views and feel that porn has had a positive effect on their lives, and I am keen to get a diverse array of perspectives included. Thanks!"

A total of 2,937 people were reached by posts from The Porn Study page. The page also provided a mechanism for private messaging, whereby potential participants could 
contact me directly and find out more about the project. Five people used the private messaging function to contact me, and of those five, three resulted in interviews. When I had completed interviews, I made the page invisible on Facebook so it could not receive any new likes or interactions.

I also shared my recruitment posters on my own personal Facebook page, thus making my friends aware of the project. These posts were public so that my friends could share to their own social networks. This proved beneficial as it allowed me to engage with people who had questions about the project on those posts, and I was asked numerous times about why the study was limited to heterosexuality. As the posts were on Facebook, I was not limited by a small character limit and could write a considered response to these queries. However, using Facebook as a recruitment tool opened up a space for some people to make comments about the links between pornography and masturbation, which could make people wanting to take part in the project feel uneasy or uncomfortable. I certainly did not want to appear to endorse such comments, so I monitored them closely and removed the ones I felt were inappropriate or could be shaming for some people.

I also created a Twitter account for the project called @ThePornStudy. @ThePornStudy only amassed a total of 35 followers, however I connected it directly to my personal Twitter account which has 600+ followers. My first tweet about the project received 701 impressions by people on Twitter, and had 11 total engagements, including one retweet. ${ }^{7}$ Whilst this may seem like a lot of engagement with a single tweet, it's difficult to gauge the audience that received it as there was little engagement with @ThePornStudy page. As recruitment progressed, I found I received much more engagement with the project when tweeting off my personal account.

Comments on Twitter about the project tended to focus on the confines of the study to heterosexuals, which was queried several times by people who thought heterosexuality did not exist, or that the scope of the study erased the experiences of queer individuals.

\footnotetext{
${ }^{7}$ Activity associated with a specific tweet is easily located on Twitter. Impressions refers to the number of times a user is served the tweet in their own timeline or in search results. Engagements refers to the total number of times the tweet was interacted with by Twitter users. Retweets are when a user decides to share the tweet to everyone on their own Twitter timeline. Further information about Twitter functions can be found here: https://support.twitter.com/articles/20171990
} 
In response to this feedback, I mentioned that whilst this study was focused on heterosexuality, that did not mean that important work with queer people about pornography should not be conducted and pointed to research that already existed. All up, posting on Twitter resulted in 6,751 impressions, 285 total engagements, 21 retweets and 14 likes.

\section{Collecting data}

Interviews began in October 2016 and were completed by April 2017. Interviews were scheduled after discussion either via Facebook or text message/phone call to address any questions that interviewees may have. I met with interviewees in a range of locations including cafes, private meeting rooms or hotel restaurants/bars. To facilitate a relaxed and comfortable environment for participants, I offered to buy coffee, food or a drink for participants, or provided biscuits and coffee if the interview was held in a private meeting room and there were no cafes nearby.

All participants were given the opportunity to read through the information sheet prior to the interview and I made sure that participants were able to ask any questions from the information sheet, and verbally summarised the information sheet before the consent form was signed. All participants were required to sign the consent form prior to the interview commencing to confirm they understood the conditions of the study and agreed to take part. Participants were given the opportunity to choose a pseudonym to be referred to in the project. and the application of pseudonyms for participants is common in qualitative research to ensure participant confidentiality (Saldana, 2011).

\section{Talking about private(s) in public}

Talking about pornography can be difficult in a public place. In cafes, I was concerned that people may overhear our conversations which could make others feel uncomfortable. When conducting interviews in cafes, I selected areas that were as far away from others to afford as much privacy as possible. I also told some participants that I was good at understanding code, so if they felt uncomfortable using the word pornography, for example, they could just use the letter ' $P$ '. I was careful to let participants know that there were procedures in place that could be considered if someone were to approach us that knew either myself or the participant. For example, I would mention that if someone were to come over and ask what we were doing, I would say that we were having a chat about the media, implying that it was more a journalist-type study than anything else. 
There was one situation in a café where the barista asked why there was a Dictaphone on the table. I mentioned that we were having a chat about gender and the media and it was a private conversation, to which he asked if I was a spy. The participant and I laughed and agreed that obviously this was 'super spy-type' work. There were two other instances where privacy presented as an issue. During one interview, people sat very close to us at a nearby table. We were in the middle of an in-depth conversation about pornography and sex, so we decided to move to another part of the café at that time to afford more privacy. In the second situation, we were sitting outside a local café and it was clear that people sitting near us were hearing our conversation. This interview was at times quite humorous and we both spoke freely about pornography and sex. During the course of the interview two groups of people moved from their seats. Thankfully, this participant saw the humour in the situation, and it coincided with our discussions about the difficulties involved in talking about pornography generally.

All participants agreed to the interview being digitally recorded. I assured participants that only myself and my supervisors would have access to the digital recordings and that interviews would be transcribed verbatim by me. My consent form also provided an option for participants to have the digital file returned to them, however none requested this. As per the consent form, audio recordings will be destroyed within five years of completion of the study. At the conclusion of each interview, participants were provided with a copy of a support sheet detailing the services available if they felt they needed to follow up after their interview.

Participants were also advised that they could request a copy of an interview summary or transcript as per the consent form and could withdraw from the research at any time before a specific date. Some participants requested either an interview transcript or summary which was sent through to them via email after I had checked that the email was still in use and it was okay to send through to that address. Only one participant had amendments to her transcript to make, and she also sent through some annotations to her transcript which she advised could be included in the data as they helped to contextualise her perspectives. No participants indicated that they wished to withdraw from the study. Interviews ranged between 36 minutes and 103 minutes with an average length of 60 minutes exactly. 
All participants who took part in the study were provided with a koha of $\$ 20$ value. Financial support to cover the cost of giving koha to participants was provided through a grant from the university. The giving of koha to participants was well-received, with most participants feeling surprised that they were offered anything at all. Food - such as coffee, cake and biscuits - was covered at my expense. Payments to participants for taking part in social research have been criticised as 'inducing' and fundamentally changing the power relationship between the researcher and participant (King \& Horrocks, 2010). However, I felt it was important to provide participants with payment as it shows I valued their involvement in the research.

\section{Talking about porn with strangers: building a comfortable environment}

I was initially concerned that I may struggle to find participants who were willing to speak freely about pornography. In practice, participants were remarkably open, honest and frank in their conversations. Interviews were semi-structured and allowed participants to decide upon the direction of the interview. During the interview, I did my best to ensure that participants did not feel judged about their views on, or experiences with, pornography. I also let participants know that they were free to ask questions at any time, and I often offered up information about myself and my own experiences with pornography which I felt helped build rapport. Often when I relayed a personal experience, participants opened up about their own memories or experiences in similar or different veins.

Language and terminology was also important during interviews. I found in the interviews I did - particularly with men - they tried to use rather sanitised language at the outset of the interview. For example, they would use the word 'penis' or 'masturbation', but there would be a clear pause before they said the word. A number of times I made it clear that it was fine to use the language they felt most comfortable using or assured them it was okay to swear. Some participants audibly sighed relief at being able to use language they were familiar with which also contributed to helping them feel more relaxed and comfortable. I also tried to use the same language that participants used throughout the interview. For example, if someone continually used the word 'porn', I tried to use that instead of 'pornography' throughout. I felt that this helped show that I was actively listening and taking on board what the participant was saying. 


\section{The participants}

A total of 24 men and women took part in this research. Participants were aged between 18 years and 30 years of age and came from a variety of backgrounds. In total, I interviewed 13 men and 11 women who volunteered to participate in the study. It is important to note that the sample for this research was self-selecting, so it was more likely that participants may report issues with pornography. As will be discussed in the forthcoming analysis chapters, many of the participants in this research had strong views about pornography or reported significant issues with pornography. In this sense, they may not be a typical sample of everyday pornography users. Further, participants were mostly recruited from the Wellington region for convenience, but online recruitment methods meant that participants were also included from further afield. Each of the participants is now introduced below and is referred to by their pseudonym throughout this thesis.

\section{The men}

\begin{tabular}{cl}
\hline Name & \multicolumn{1}{c}{ Who they are } \\
\hline Bill & Bill is a 26-year-old bisexual male who identifies as \\
White. He was in a relationship with a female partner at \\
the time of interview. \\
\hline Cameron is a 24-year-old heterosexual male who \\
identifies as New Zealand European/Pākehā. He lives in \\
the Wellington region and was a student at the time of \\
interview. He is currently in a relationship. \\
\hline Chris \\
Pākehā. He lives in the Wellington region and was single \\
at the time of interview. Chris had not had sex at the time \\
of interview, but chose to spoke about experiences with \\
addiction to pornography/masturbation during the \\
interview. \\
\hline Derek is a 25-year-old heterosexual male who identifies \\
as Caucasian. He lives in the Lower North Island region \\
and is in a long-term relationship with his partner. \\
\hline Ethan & Ethan is a 23-year-old heterosexual male who identifies \\
& as Pākehā. He lives in the Wellington region, was a \\
student at the time of interview and was engaged to his \\
partner at the time of interview, however he \\
acknowledged this was likely to end. Ethan reported \\
having experienced issues with pornography addiction \\
earlier in his life. \\
George is a 25-year-old heterosexual male who identifies \\
as New Zealand European/Māori. He lives in the \\
Wellington region and was single at the time of interview.
\end{tabular}




\begin{tabular}{cl}
\hline & George identifies strongly with his religious faith and had \\
experienced issues with pornography addiction \\
throughout his life and was currently abstaining from \\
pornography. \\
Jack is a 21-year-old heterosexual male who identifies as \\
Pākehā. He lives in the Wellington region, was single at \\
the time of interview and also a current student. Jack \\
mentioned that he had experienced issues with \\
pornography addiction throughout his life and was \\
currently abstaining from pornography. \\
\hline Kevin is a 25-year-old heterosexual male who identifies \\
as New Zealand Pākehā/Māori. He lives in the Wellington \\
region and was in a relationship at the time of interview. \\
\hline Luke is a 28-year-old heterosexual male who identifies as \\
Caucasian/Māori. He lives in the Wellington region and \\
was not in a monogamous relationship at the time. \\
\hline Matt is a 19-year-old heterosexual who identifies as New \\
Zealand European/Pākehā. He lives in the Wellington \\
region, was single at the time of interview and a current \\
student. \\
\hline Nathan is a 28-year-old heterosexual male who identifies \\
as New Zealand Māori. He lives in the Wellington region \\
and was a student. Nathan was also single at the time of \\
interview.
\end{tabular}


The women

\begin{tabular}{|c|c|}
\hline Name & Who they are \\
\hline Carly & $\begin{array}{l}\text { Carly is a 24-year-old heterosexual woman who identifies } \\
\text { as Italian and New Zealand European. She lives in the } \\
\text { Wellington region and is a current student. Carly was in a } \\
\text { relationship at the time of interview. }\end{array}$ \\
\hline Holly & $\begin{array}{l}\text { Holly is a } 25 \text {-year-old woman who identified herself as } \\
\text { being of mixed-descent. She identifies as bisexual and } \\
\text { lives in the Wellington region. She was in a relationship at } \\
\text { the time of interview and had previously worked in the } \\
\text { sex industry. }\end{array}$ \\
\hline Izzy & $\begin{array}{l}\text { Izzy is a } 30 \text {-year-old heterosexual woman who identifies } \\
\text { as Pākehā. She lives in the Wellington region, is in full- } \\
\text { time employment and was married at the time of } \\
\text { interview. Her partner had experienced issues with the } \\
\text { problematic viewing of pornography. }\end{array}$ \\
\hline Jasmine & $\begin{array}{l}\text { Jasmine is an 18-year-old heterosexual woman who } \\
\text { identifies as New Zealand European. She lives in the } \\
\text { Wellington region and is currently single. }\end{array}$ \\
\hline Lilith & $\begin{array}{l}\text { Lilith is a } 23 \text {-year-old heterosexual woman who identifies } \\
\text { as Chinese. She lives in the Wellington region and was in } \\
\text { a relationship at the time of interview. }\end{array}$ \\
\hline Miranda & $\begin{array}{l}\text { Miranda is a 28-year-old heterosexual woman who } \\
\text { identifies as European. She lives in the Wellington region, } \\
\text { and is married. }\end{array}$ \\
\hline Nadia & $\begin{array}{l}\text { Nadia is a 26-year-old heterosexual female who identifies } \\
\text { as White. She lives in the Wellington region and was in a } \\
\text { casual sexual relationship at the time of interview. }\end{array}$ \\
\hline Naomi & $\begin{array}{l}\text { Naomi is a 26-year-old heterosexual woman who } \\
\text { identifies as New Zealand European/Pākehā. She lives in } \\
\text { the Wellington region and was in a relationship at the } \\
\text { time of interview. Naomi had previously been in a } \\
\text { relationship where her partner used pornography } \\
\text { coercively. }\end{array}$ \\
\hline Rach & $\begin{array}{l}\text { Rach is a 27-year-old woman who identifies as Pākehā. } \\
\text { She identifies as bisexual and lives in the Wellington } \\
\text { region. She had been in a relationship with a male partner } \\
\text { who was a self-described pornography 'addict' and was } \\
\text { living with him at the time of interview. }\end{array}$ \\
\hline Tara & $\begin{array}{l}\text { Tara is a } 20 \text {-year-old heterosexual woman who identifies } \\
\text { as New Zealand European. She lives in the Wellington } \\
\text { region and was a student. She was in a relationship at the } \\
\text { time of interview. }\end{array}$ \\
\hline Tina & $\begin{array}{l}\text { Tina is a 21-year-old heterosexual woman who identifies } \\
\text { as New Zealand Māori. She lives in the Wellington region } \\
\text { and is a current tertiary student. She was in a relationship } \\
\text { at the time of interview. }\end{array}$ \\
\hline
\end{tabular}




\section{Working with the data}

All interviews were transcribed verbatim as soon as possible after the interview. This was an involved and time-consuming process but familiarised me with my data as the research developed. I made sure to note any initial thoughts I had during transcribing, and I took my time during this process. Some of the data that I was working with was difficult, and at times it felt that I was 'transported' back to the interviews. Whilst all part of the process, my previous transcribing experience with sensitive research ensured that I employed techniques of self-care throughout the process, which most importantly included regular breaks.

After transcripts had been reviewed for accuracy and completeness, they were returned electronically to participants who had requested them on their consent forms. Once transcripts had been electronically returned to participants, they were loaded into Nvivo for data analysis. Having previously used Nvivo for prior research, I was keen to employ it again for this project. Nvivo software "provides a range of tools for handling rich data records and information about them for browsing and enriching text, coding it visually or at categories, annotating and gaining accessed data records accurately and swiftly" (Richards, 1999, p. 4). Using Nvivo meant that I was able to effectively arrange, analyse and organise the complex data I had gathered during interviews. Being familiar with Nvivo meant that this process was far less daunting than my earlier experiences with it, even as a technologically savvy young person!

Using Nvivo meant that continuous, in-depth involvement and analysis of the data was possible. Interviews were labelled individually in Nvivo and separated into male and female interview categories. Each interview was coded individually to commence identifying themes. This was primarily done on a line-by-line basis to avoid missing important nuances in the data. Thematic analysis was employed for this project, and as a method, is flexible, accessible and easy to use for qualitative researchers, making it a useful starting position (Braun \& Clarke, 2013). As themes were identified, they were created as codes which allowed for easy identification of common patterns across the transcripts. It also allowed for an individualised approach to specific accounts in transcripts, which will be discussed throughout this research in later chapters. 


\section{Emotional involvement and the challenges in 'sexing up' the academy}

Researchers are often silent about their emotional involvement in research, despite such discussions having the ability to enhance research by giving a more comprehensive account of the fieldwork process (Blackman, 2007). However, there is increasing interest in understanding the impacts that research can have on researchers as "research is emotional work and may have emotional outcomes" (emerald \& Carpenter, 2015, p. 746). Thus it is expected that researchers in sensitive fields may well be affected by the work they are involved in (Dickson-Swift et al., 2009; Fahs et al., 2017; Webber \& Brunger, 2018).

I grappled with whether I should write about the emotional impacts involved in researching pornography as there is a delicate balance to strike when declaring our own vulnerability. Whilst it can "add another dimension to the examination of social issues", it also has the potential to "bore the reader with personal information that is uninteresting or irrelevant, takes the focus off the topic, and may seem simply selfindulgent" (emerald \& Carpenter, 2015, p. 744). I feel it is important to declare our own vulnerability to enhance the dimensionality of the project. Choosing to do so provides an outlet to "develop a relationship with the reader, help the reader develop some sort of relationship with the observed, and move the reader at a profound level" (emerald \& Carpenter, 2015, p. 746). I now detail some of the challenges I faced whilst completing this project and the strategies I employed to manage them.

When I first started this project, I was aware that telling people that I studied pornography could make me the butt of all jokes, so to speak. I expected constant sexual banter and jokes, and I laughed about the title 'Porn Queen' which I was ever-so-quickly gifted. I, too, laughed at the irony of studying pornography in my office at university, and informally named it the Porn Hub. I expected curiosity about the topic, and I was aware that it had the potential to make people feel uncomfortable or uneasy. What I discovered, however, was that studying pornography meant that the way many people behaved around me - and treated me - would fundamentally change.

Upon hearing about my research, people would openly tell me about their own experiences with pornography - particularly men - who would then boast about the types of pornography that they viewed whilst they sat alongside their partners. I also 
encountered situations where people clearly felt uncomfortable at the topic being raised. I expected this, but I did not expect to be called a 'slut' or a 'skank' for doing sex-related research, nor did I expect that some women would place their hands on their male partners whenever the topic arose, implying that I was somehow a threat to their relationship.

These experiences are by no means a full account of the challenges I faced throughout this research, yet I had not expected studying pornography to have been as difficult as it was. I had read that people struggled for legitimacy in the academic realm, but the mere mention of my topic was met with raised eyebrows and fundamentally changed assumptions about who I was as a person. I had no idea about the best way to manage these issues. I tried telling my friends that I was tired and bored of talking about pornography all the time. However, I never felt that I was truly listened to, or my friends appreciated quite how draining thinking about porn all day could be. The 'Porn Queen' title felt glued to my forehead.

Ironically, the concerns that the ethics committee raised about my 'safety' in the interview environment were perhaps misguided. In reality, it was situations outside of the interview context that were perhaps more dangerous or unsafe. For example, in the second year of my research, I attended a party in another city. I only knew two or three people there, and one of my friends announced to the group that I studied pornography. I was bombarded with questions, which I answered, but I tried to steer the conversation away from the topic. Later in the evening, I was in a garage and was suddenly in the company of five to six men and my friend had gone elsewhere. One of the men stood up, locked the door, and they proceeded to ask me very sensitive questions about my research. I felt particularly uncomfortable, and when I tried to change the topic, one of the men told me to "shut up" because all he could imagine when I spoke was a "big cock down my throat." I managed to leave the situation but ended up stranded at the party and had to stay the night. I awoke a couple of hours later and my face had been drawn on with permanent marker. As I looked in the mirror, I saw multiple ejaculating penises drawn on my face, aimed at my mouth. If whoever drew on my face did not know I studied pornography, I doubt that this would have happened. 
emerald and Carpenter (2015) argue that whilst graduate educational systems may provide some supports, students and researchers are largely "left to fend for themselves" (p. 744) when managing the emotional work involved in research. Outside of the administrative boundaries of the ethical approval process - where I specifically mentioned that I was aware of the personal impacts involved in researching sex and would consider clinical debriefing - there are few provisions for ensuring staff and student wellbeing and safety when it comes to emotional work. That said, my supervisor has always been open and honest about the emotional involvement by us as researchers in the research process. We had regular, open and honest conversations about the social implications of my pornography study. She encouraged me to meet with a counsellor or clinical psychologist for clinical debriefing to discuss some of the issues. I regularly met with my General Practitioner and had debriefing sessions with her. I also wrote personal diaries about my experiences during the research process as a form of personal reflection. These diaries were raw, emotional and detailed exactly how I was feeling at the time it was written. As I reflect on these pieces, it's difficult to remember feeling as isolated, insecure, angry or as frustrated as I clearly was. However, these personal accounts were another outlet for letting off steam and helping me to verbalise how I was feeling. They read as if I'm yelling into an echo chamber, but I did not want these reflections heard. They functioned solely as a regurgitation of my feelings onto paper and now stand as an important piece of my own personal self, documenting my transformation(s) throughout the research process.

\section{Summary}

This chapter has detailed the theoretical foundations of this research, and the methods employed to gather data. Alongside this, I have provided some insight into the experience of doing sensitive research in New Zealand, and how the politics of pornographic inquiry have a gendered basis. As data were collected for this research, it become a constant and iterative process of learning. I learnt to appreciate the subjective, gendered ways that pornography was experienced by men and women in New Zealand. I discovered that people had conflicting views on pornography, and I shared many of their perspectives. In many ways, this fieldwork has been a constant site of personal growth and development. The following chapter begins by examining participant perspectives on pornography in 
New Zealand. It outlines the contours of the 'mainstream' and documents how users of pornography interpret and understand its content. 


\section{Chapter Four: Porn sex versus real sex? Defining the mainstream of pornography}

Pornographic tube sites are now the dominant platforms for engaging with sexually explicit content. The material on these platforms is perhaps what is now considered 'mainstream'. Debates persist about what counts as mainstream content, so this chapter presents participants' perspectives on what constitutes 'mainstream' from their perspectives. This chapter begins with a brief discussion about the pornographication of the mainstream, followed by participants' perspectives on where they typically viewed pornographic content, and what content was present in those spaces. It highlights the way that participants described pornography as idealised and perpetuating rigid expectations about gender and sex. It grapples with some of the complexity around pornography outside of these rigid boundaries, such as feminist pornography, and documents how these alternative forms of pornography are not typically included within the remit of mainstream pornographic consumption.

\section{The pornographication of the mainstream}

The proliferation of sexualised or 'pornographic' imagery in recent decades has permeated popular culture, making it a permanent fixture in many of our day-to-day lives. The increasing influence of pornography has seen it transcend into popular culture representations, contributing to a 'mainstreaming' of pornographic imagery in everyday contexts (Gill, 2012b; Thompson \& Donaghue, 2014), otherwise known as the "pornographication of the mainstream" (Mcnair, 1996, p. 137). However, there is a difference between what is actually 'pornography' and what is merely a representation of pornography in traditionally non-pornographic settings. Boyle (2010) suggests that through the borrowing of pornographic imagery in mainstream culture,

pornography achieves a mainstream currency and visibility, but whilst popular culture may be 'pornified' as a result, it does not become pornography. To properly understand how pornographic quotation of this kind functions depends on understanding the differences as well as similarities between these pop culture examples and the hard-core they reference. Equally, whilst analysing 'pornification' is important and relevant, this does not obviate careful and considered scholarship of pornography itself (p. 2, emphasis in original).

In speaking to careful and considered scholarship of pornography itself, this chapter explores exactly what participants mean when they refer to pornography, especially mainstream pornography. Today, much pornographic material is located on tube sites 
such as Pornhub and Youporn (Smith et al., 2015), and it's difficult to imagine encountering material from those sites in other settings. I am most interested in what is actually mainstream within pornography itself. What material/content has mainstream currency within these streams, and what has become popular? I am interested in these questions as the type of pornography that I am able to view on pornographic websites today appears to be light years away from the pornography that I first encountered as a young person in magazines. Whilst my understanding of Playboy magazine in the 1990s may have depicted a woman posing in sexualised ways in various stages of undress, tube sites today provide an endless menu of hardcore, sexually explicit content.

I am conscious that a discussion of what counts as 'mainstream' within pornography runs the risk of coming across as commonsensical (Smith, 2010), and such a view contributes to its delegitimisation as an area of academic inquiry (Fahs et al., 2017; Irvine, 2015). However, a discussion about what fits within the realm of 'mainstream' within pornography is anything but commonsensical, as "the vast amount of ever-changing sexually explicit material - that may or not be considered under the rubric of 'pornography' - currently available across a range of media makes any attempt to define 'mainstream' pornography challenging" (Long, 2012, p. 112). Indeed, it is the challenging questions in society that are the most pressing, and "despite the mushrooming of porn studies in the last 10-15 years, the emphasis of most porn-sympathetic scholarship has not been on porn's mainstream but on its margins" (Boyle, 2018, p. 85). If most pornography viewed in contemporary times is 'mainstream', then we must ask questions about what is being viewed and how it is understood and interpreted.

\section{Defining the contours of mainstream pornography}

As previously mentioned in Chapter One, defining pornography is a difficult task. Pornography is "hard to define but easy to recognise" (Easton, 2005, p. x) , which leads to pornography being defined by subjective statements like "I know it when I see it" (Justice Potter Stewart, as cited in Gewirtz, 1996, p. 1023). The subjective nature of how pornography is interpreted further contributes to definitional ambiguities, leading to remarkable inconsistencies in academic research. These inconsistencies and contradictions are further compounded when we attempt to define what counts as 'mainstream' pornography. When we speak of the mainstream, what exactly are we 
referring to? This chapter now explores the debates surrounding what constitutes mainstream pornography in contemporary times.

Sostar and Sullivan (2015) argue that anti-pornography scholarship typically analyses mainstream pornographies, whilst pro-pornography scholarship resides in a critical review of "queer, feminist or otherwise countercultural pornographies" (p. 198). DeKeseredy and Corsianos (2016) identify a range of pornographic categories and behaviours as intrinsic to the industry's mainstream. They suggest that mainstream pornography is routinely oriented toward 'gonzo' pornography, incorporating behaviours such as heterosexual anal sex, double penetrations, ${ }^{8}$ double anal, ${ }^{9}$ double vaginal, ${ }^{10}$ and ass-to-mouth (ATM) ${ }^{11}$ scenes. They also point to mainstream pornography as inherently misogynistic, as "the most common images that overwhelmingly cater to a straight male audience are images of women always ready for sex, always willing to please, and always sexually satisfied" (DeKeseredy \& Corsianos, 2016, p. 11). Others have certainly pointed to these shifts in mainstream pornography, particularly regarding aggression and violence (Bridges et al., 2010; Dines, 2006; Fritz \& Paul, 2017; Sun, Bridges, Wosnitzer, Scharrer, \& Liberman, 2008; Sun et al., 2017; Tyler, 2010). That said, Paasonen (2013) suggests that pornography should be defined as a 'plural category' whereby the characteristics within one type of category should not speak of the genre as a whole. I agree, yet I also acknowledge that there is a mainstream and it is identifiable through a number of factors. As Sostar and Sullivan (2015) contend,

...mainstream pornographies are those that operate within hegemonic norms of gender (cis-identified), sexuality (heteronormative), and commerce (capitalist, free enterprise). There is room for great variety and blurring of categories even within this definition of mainstream pornographies, but there is a mainstream, and it is recognizable by its conformity to those norms (p. 199, emphasis in original).

In this vein, mainstream pornography typically refers to the most common genres and representations of sex - for this research, heterosex specifically - that are commonly engaged with by a presumed heterosexual audience. As previously discussed in Chapters One and Two, the perspectives of the audience of pornography have traditionally been

\footnotetext{
8 Double penetration refers to the penetration of multiple bodily orifices simultaneously, for example a woman being penetrated both vaginally and anally at the same time.

${ }^{9}$ Double anal refers to the depiction of two penises or objects in the anus at the same time.

${ }^{10}$ Double vaginal refers to the depiction of two penises or objects in the same vagina at the same time.

11 Ass-to-mouth is the depiction of anal sex in pornography which is immediately followed by oral sex where the penis has not been cleaned before this is performed.
} 
neglected in pornography scholarship. Filling this void, then, this chapter now presents the perspectives of participants in this project about what they understood as 'mainstream' pornographic content. Participants for this project were asked what they considered pornographic, and in so doing, many outlined what they considered to be 'mainstream' content. The following section explores participants' views on the mainstream of pornography and typifies the places, genres and categories that they considered mainstream.

\section{"Mainly Pornhub": Accessing mainstream pornographic content}

As previously discussed in Chapter Two, significant technological advances have shifted contemporary modes of engaging with pornography. Today, pornography is overwhelmingly located on the internet and provides an ever-expanding digital landscape with a seemingly endless menu of pornographic material which caters to user wants, tastes and desires (Smith \& Attwood, 2014; Tibbals, 2014). Many participants in this study reflected on their first encounters with, or exposures to, pornography. For some, they first encountered pornography by discovering someone else's personal collection. This was not always remembered fondly, but a sense of curiosity and uncertainty about what they had encountered came through in a number of these reflections:

I think I was probably like 10 or 11 and I sort of saw that he had some magazines under [father's] bed and I sort of checked them out. - Cameron

It takes me back to when I was like 10 or 11, I like looked at a picture of naked ladies and didn't really know what to do with it. I was just like curious about it. - Kevin

I used to watch porn like when I was really young, like 10 or something. Like I'd go in and like pull it out of Mum's drawer and stuff and be like "oh what's this?" and then like put it on and stuff. - Holly

I remember I was first exposed to pornography when I was maybe like six by a magazine that I found. But then I was quite traumatised by it. And then my brother, when he was about 13, started watching pornography on the internet and I stumbled across quite a lot of it. - Carly

[My] first ever exposure to porn was probably when I was in primary school and it was like non-digital porn. Someone brought like a picture and like whoever probably had it, it was like a poster of a woman and you could see her like vagina. That was probably the first time ever. I didn't really know what was going on back then. - Lilith 
In a study of memory-work, Paasonen, Kyrölä, Nikunen, and Saarenmaa (2015) suggest that participants consider pre-1990 pornography engagements as an 'age of scarcity', whilst today is an 'age of plenty'. Participants overwhelmingly agreed that pornography was easily accessible, and the ubiquity of pornography on the internet meant such content was only ever a few clicks away:

I guess cos with the internet, right, you can like search it up whenever you want. And you know porn exists. - Lilith

I wouldn't know where to get pornographic magazines to be honest. I would have no idea... I think I was watching a comedian the other day saying something along the lines of like back in his day, you had to accidentally stumble across porn in the woods type thing in order to access it. We can just click a few buttons and it's there. - Matt

Especially younger generations where like it's not just all you could've got was a magazine under your parents' bed, you know. That was it. And now it's so much more than that. - Derek

Yeah I guess now it's ubiquitous on the internet... There were a couple of instances where my brother would have a magazine or my friend would have a magazine and I'd get it, get my hands on it. Or I'd be walking home and I'd find one interestingly enough. That happened a couple of times but predominantly, the overall rule was the internet, getting it over the internet. - Ethan

The clicking of a few buttons to find pornography on the internet suggests that locating pornography is simple, and when discussing where pornography was available on the internet, participants overwhelmingly spoke of tube sites. Pornhub is part of a network of sites run by MindGeek, ${ }^{12}$ and the dominance of tube sites within this network were referred to by multiple participants during interviews, denoting the location of mainstream content:

My friend put me onto Redtube which is mainstream, massive streaming site for porn. Then PornHub which is the biggest and now it's just all on PornHub. Trying a little bit to explore a few other things but mainly PornHub, definitely PornHub. - Ethan

Today, it's just I dunno. It's Pornhub if I need it... It's the easiest site. It used to be like Redtube or anything like that, I guess your mainstream. - Derek

And it's so readily available, like you have PornHub, you have YouPorn, you have Redtube, you have all these other sites. - Anna

\footnotetext{
12 MindGeek owns the top eight free porn sites in the online pornography industry. Such content is hosted on 'tube sites' "that offer an enormous amount of free porn that is funded by ads for paid sites, live webcam sites, penis enlargers, and so-called escort services" (Dines, 2016, p. 28).
} 
Tube sites host millions of sexually explicit videos - including both amateur and professional productions - and viewers can navigate and locate pornographic content by category. These categories of content can be vast, with videos often 'tagged' as including a range of acts, behaviours, body types, relationships or actors/actresses to assist with navigation. Tara was surprised at the diverse categories available on tube sites:

I never knew there were so many categories of porn - I thought it was just porn. And then I went onto PornHub and I was like 'okay, alright, I'm gonna watch porn' and then I was like 'oh shit, there's like 50 categories of porn' and I didn't know like about any of them really. - Tara

The categories section of Pornhub is extensive, hosting nearly 90 different categories for viewers to select from under the 'straight' section. As well as generic categorisation, videos themselves are often titled with the type of sexual acts that the video includes. Such tagging intends to give viewers an indication of what the scene or video may be like. For example, a video might be tagged with the terms 'amateur', 'lesbian', 'anal' and so forth. As well as categorising and tagging, the thumbnail of the video often shows snippets of the clip in action, which Matt suggested allows you to "see what kind of pornography it's gonna be by just looking at the thumbnail of the video." In theory, this should act as a bit of a 'taster' for the video, but relying on this taster was not always a guarantee. Cameron commented that "sometimes you'll click on a video and it's labelled completely differently to what it is."

In the same way that comments can be left on YouTube videos, viewers are also often able to leave comments on videos on tube sites, creating a sense of engagement between the viewer and the pornographic content. Brodesco (2016) contends that as comments are not the primary reason that most viewers would be accessing pornography, the number of comments left on videos is surprisingly low. Only one participant talked about the comments sections on tube sites, with Chris commenting that "there isn't really room for discussion" and "nobody puts anything of worth there." Participants typically neglected to reflect on the model that tube sites provided, other than identifying that the categories menu provided an ease of navigation on tube sites. However, Bill noted that the structuring of tube sites leaves you wanting to come back for more. He reflected that "Pornhub... just optimises for clicks, clicks, clicks, clicks, clicks... The business model itself wants to keep you on and clicking and opening a dozen tabs and coming back again and again and again." 
The ease of use on tube sites was appealing for consumers. Luke reflected on their appeal:

These days and probably for let's say the last five, six, seven years, I've been accessing primarily videos. Youporn, Redporn, Redtube rather. Those are like the only two websites I ever typically visit. But obviously yeah videos are where it's at now... Youporn more than Redtube as well. Youporn is and was 90-95\% of what I'd spend my time on if I was looking at pornography... I knew the types of channels that were on Youporn that I enjoyed. And I knew sorta how to find the videos that I'd enjoy. - Luke

As well as being easy to navigate, tube sites were deemed a 'safe' way to view pornography by several participants. Some participants were especially concerned that using pornographic websites could result in contracting viruses on their parents' devices when they were younger, and this concern was realised for Luke as a young person:

I'd like wind up getting myself in trouble cos I'd have these pop-up ads that would populate all over the computer screen. And I'd have to like shut down the computer and then I'd have to turn it back on and try and [laughs] disable it and try and get rid of all these pop ups at like two or three in the morning when I had school the next day [laughs]... sometimes Mum would see them and she'd just be like 'Luke, what's this?' and I'd just go 'oh I don't know, maybe it's a virus!' [laughs] - Luke

The risk of viruses meant that both Derek and Nadia isolated their viewing of pornography to tube sites:

I don't really go searching too hard for other websites cos you can find there's quite a lot of viruses. So sticking to the mainstream in that respect. - Derek

I don't like to just click around on any site cos I'm terrified it's not gonna be a good site. So I will use mainly major search engines because I feel safer and that they will have blocking or they're not gonna give me a virus or whatever. Nadia

Lilith shared a similar sentiment, feeling both concerned about the possibility for viruses, but also that somehow the pornography she viewed would be shared through her personal social media channels. These concerns meant that she stuck to one tube site when viewing pornography:

I also have this irrational distrust of porn sites. Like 'oh no it's going to give me viruses' or like somehow what I'm watching is going to pop up on my Facebook and everyone will know what I watch. - Lilith

Outside of available on mainstream tube sites, four participants spoke about Reddit as a key site for accessing pornographic material. Izzy first encountered pornography when she left home at around age 18 and identified Reddit as the source:

Mainly just on the internet through like Reddit or things like that. Mainly images. I don't really care about videos, I don't know why, it's never really appealed to 
me, I guess, cos there's like more of a chance of getting caught, you can't like tap out of it easily, there's sound. - Izzy

Kevin also used Reddit as a hub for pornography, primarily in GIF ${ }^{13}$ format. He explained the way that Reddit was able to provide both the GIF formats, but also community links to further material involving particular performers that may have featured in the GIF:

I have stopped subscribing to the Reddits that I was using but you still know GIFs and stuff like that which are short image or short video loops. You know what a GIF is? Short video loops. And then check if there's anything like 'oh haven't'seen that before' or 'like the look of that' then you look through the comments and see if anyone's put the link to the actual video. - Kevin

For Pete, GIFs had particular appeal as they offered 'instant gratification':

Mainly now I watch GIFs. You know, like little short image clips, kind of thing. And that's ideal cos it's like just instant gratification. And you're just like 'ah, ah'. It's just the best bits right? Who wants to watch a 20-minute video when you can watch this 3 second GIF?... It's pretty good. And it's cool as well because it's like broken up. Like there's the generic ones, NSFW'14, NSFW GIFs, whatever. But then there's stuff, you've got NSFW petite, big boobs and whatever... you can look in your different subreddits of your different category of what it is that you're after. - Pete

He elaborated on the type of content that was present in the GIFs on Reddit that he viewed:

... there's NSFW videos. So those are usually pretty good. If I am gonna watch videos, those are all like pretty choice. They're alright. But yeah. Just not my main thing cos it's kinda like just a bit of a hassle whereas the GIFs are really easy... [I watch] almost exclusively vaginal penetration... Something that I think's pretty cool. I'm like I like that.

For Chris, he also used Reddit as a central point for engaging in discussions about the pornography industry. Further, he felt that if he was feeling interested in pornography outside of just videos, he could find erotic audio material on Reddit and "could deviate into finding a sub-Reddit where girls pose to erotic audios."

Throughout this section, participants have described the primary places that they engage with mainstream content. Overwhelmingly, mainstream pornography referred to content found on tube sites such as Pornhub, however, alternative platforms such as Reddit also provided a mode of access to mainstream content. The appeal of mainstream pornographic tube sites was related to their endless menus of erotic content, in

\footnotetext{
${ }^{13} \mathrm{~A}$ GIF is a short image/video loop.

14 NSFW stands for not suitable for work, generally indicating content that could be deemed sexually explicit and therefore not suitable to be viewed in the workplace.
} 
conjunction with an ease of navigation and categorisation which made surfing for pornography an easy experience. Further, the relative safety of pornographic tube sites meant that participant concerns about viruses could be ameliorated by sticking to one reputable place. But what do participants think about the type of pornography available on mainstream tube sites? This chapter now presents participants' perspectives on the content of the mainstream.

\section{The content of the mainstream}

As previously discussed in this chapter, substantive debate exists about what constitutes mainstream pornography. I mentioned earlier that I follow Sostar and Sullivan (2015) who suggest that mainstream pornographies operate within hegemonic norms of gender, sexuality and commerce, however there is much room for movement and blurring of these categories within the mainstream. Several participants spoke about the type of pornography that they watched or preferred, or commented on the content of pornography. With this in mind, the definition provided by Sostar and Sullivan (2015) provides a useful framework for categorising the ways that participants understood and interpreted the content of the mainstream. This section now explores participants' understandings of pornography, starting with gendered bodies in pornography.

\section{Pornified bodies}

In speaking about the pornography they viewed, participants overwhelmingly spoke of viewing pornography which represented sexual relations with cis-identifying performers, with only one participant discussing viewing porn involving trans* performers. Further, participants regularly spoke about the bodies in pornography and how these often conformed to Western standards of beauty. In research with young people in Sweden, it was evident that young people were critical of the presentation of stylised, 'porno-style' bodies in pornography (Lofgren-Martenson \& Mansson, 2015; Mattebo et al., 2012), and participants in this research were also conscious of this. For many, pornography was understood as typically promoting idealised, stylised bodies, especially in professionally produced content. Matt neatly summed this up, commenting that:

On the mainstream sites you don't tend to see a lot of I'd say probably sort of I'd say the pornography industry, for us at least, is conforming to a Western standard of beauty. So we've got like slender people, fake breasts and all sorts of 
things like that. Pruning down there, things like that. So I think that's probably the most common thing in pornography. - Matt

A central feminist criticism of pornography is that women are positioned as a 'spectacle' for the male gaze whereby a "male spectator possesses the gaze, a gaze used to appropriate if not conquer the 'woman' in the representation" (Kaite, 1995, p. 67). In describing who is being 'looked' at in pornography, a few male participants noted that they rarely took notice of male bodies, and that his presence - or indeed his attractiveness - was far less important than hers:

I can't remember any time where I've paid active attention to the male. Unless it's something radically different like, I dunno, pink hair or something. Something that sort of sticks out, otherwise I don't generally notice it no. - Matt

I mean as a heterosexual man, no-one's really taking interest in the guy's physique. I dunno that's an interesting question. I've never really paid that much attention to that. - Kevin

But most of the time like really the only focus is them waist down. - Chris

But in I guess what you might call the mainstream, it's like those are gonna be a certain bunch of attractive people. Maybe not all. I think a lot of people would say a lot of guys in pornography, they don't need to be attractive as such [laughs]. - Pete

In pornography, the male body is often presented as athletic, muscular, built and able to perform like a well-oiled machine, capable of endless thrusting and unstoppable erections (Brod, 2007; Cook, 2006). Although men often ignored the man in pornography, several were conscious that depicting men in this way was unrealistic:

Obviously we've got beauty standards that are sort of implied through men as well. They've got big abs and pecs and muscles generally. Yeah. - Matt

The whole idea that porn presents an image of like this masculine guy with a big dick and ripped abs - this is from my perspective - looking at the guy, he's like fit, he can go for hours, sort of setting that expectation, societal expectation I guess, that men should be able to pump it out for at least half an hour and be vigorous and always keen. - Cameron

Jasmine felt that men in pornography were more 'powerful' than women, and that the role of the man in pornography was about him as a bodily instrument rather than a person:

They're more powerful than the girls usually. Even like the camera shots sometimes, it usually doesn't involve the guys, it doesn't associate like the face with the guy. Most of the time it's all about the girl because usually guys don't like to see the guys in porn. Like I've been told that from a couple of guys, like it's 
weird when they see the guy because obviously if they're not attracted to a guy and they're just there watching it for a woman. - Jasmine

Tara felt similarly, arguing that men were less often the focus in pornography and that his role was just as an object for performing sex:

It seemed to always focus on the woman more than the man. The man was like never really, he was just like a dick. Kind of like on the side view and it was always about the woman and the woman was always the one driving it...That was what seemed to feature. But that was like the standard. - Tara

Potts (2002) suggests that "technologies of sex operate to produce particular standards of masculinity, to constitute the 'well-endowed' man as a referent of authentic manhood, of heterosexual prowess" (p. 121). The men in this research were acutely aware that men in pornography had unrealistically large penises. Essentially, men in pornography are "reduced to a phallocentric expectation of sameness" whereby "all penises must measure up" to the pornographic ideal (Potts, 2002, p. 121). Chris noted that this was distinctly related to ethnicity or colour, as "with men they're either White or they're Black. And if they're Black they have gigantic penises." Others mentioned that large penises in pornography conformed to societal ideals about penis size:

I dunno if it's just a curiosity thing, like it's definitely interesting looking at dicks... In pornography definitely... And then it's like oh you do a bit of reading and a bit of thinking about things and it's like oh well okay it turns out that the average dick size is five and a half inches or something like that. It's like 'oh okay' so pretty much pornography is like kinda not like an accurate sample of the population [laughs]. - Pete

Basically pornography - because it's a fantasy - it's always going to be what the media or I guess you could broadly say society says is the ideal... the men are going to be in better shape... the guys are going to have bigger penises. - Tom

In speaking about amateur pornography, two of the men commented on how amateur pornography was less likely to depict stereotypical images of male bodies. Cameron felt that it often contained bodies that were outside what would be an expected pornographic 'norm': "you can see that the guys are not ripped with six pack abs. Generally they're probably actually old men [laughs]... Old men with like pot bellies and stuff [laughs]." Tom agreed, arguing that "maybe the amateurs are slightly more realistic to true life... a lot of amateur stuff, pretty normal looking." That said, the distinction between amateur pornography and professionally produced content is perhaps less simple or easy to decipher when the realities of amateur production are considered more critically. Paasonen (2010) contends that "amateur productions are caught in a web of conceptual 
divisions that mark amateurs apart from the professionals, the non-commercial from the commercial, and the independent from the mainstream" (p. 140). At the same time, however, "the divisions between amateurs and professionals are far from being clear: amateurs aspire to professional standards, professionals do things out of pleasure, and the categories themselves are contingent to start with" (p. 140). Further, the rise of 'ProAm' pornography - produced by professionals but marketed as amateur to capitalise on the amateur market further muddies this distinction between the categories (Paasonen, 2011).

Tom also suggested that "the more unrealistic [bodies in pornography] would probably be the men. A lot of them are jacked." Such a statement implies that women's bodies in pornography were somehow more natural or realistic, which conflicted with women's understandings of women's bodies in pornography. Several of the women commented on the stereotypical depiction of women in pornography, describing their bodies as 'fake':

Like this tiny, little, White, long blonde hair, fake nails, fake everything kind of. Fake tits. - Holly

Pornographic images I think are more the really skinny, big fake boobs, hairless, that stereotype. - Tina

Both Tara and Jasmine felt that the stereotypical female body in pornography persisted because it reflected what men wanted to see in pornography:

I think for the majority of guys who watch the porn they like the big fake boobs and the big ass if that's what they're into. Cos you know there's categories 'big tits' and 'big ass' and stuff. - Tara

Well to guys, the majority of guys, when I say guys I'm not presuming every guy. Most guys would be watching, and most guys I've talked to, watch the typical kind of guy on girl, big boobs, tiny body, make-up, hair, everything you know? Full glam, heels. - Jasmine

Pornography depicts women's genitalia in stylised ways, and they are now typically depicted as hairless (Braun, Tricklebank, \& Clarke, 2013). Moran and Lee (2016) contend that "narrow models of normality based on limited exposure to unrealistic pornographic or artistic images" (p. 230) can be a source of women's genital dissatisfaction, and some women in this study spoke about how women's genitals in pornography were unrealistic:

... they're usually clean shaven. Some actresses have a bit of fluff on the top. Tiny clitorises. Basically no inner labia. Just basically it's all that it's focused on is the hole, like the vagina entrance. That's what it's about. - Anna 
It's like hairless. You can't see the labia, is that right? Like it doesn't hang out... and like symmetrical. - Lilith

[In porn] everyone's hairless. - Holly

Several participants also spoke of how women's bodies were being depicted in different ways in pornography, particularly across professional and amateur productions. Men appeared to be acutely aware of the variety of women's bodies in pornography. Chris felt that "the porn that you find on the front page of sites, they're still geared towards the male audience. In that sense I would say there is definitely a wider variety of women." In detailing this variety, Chris noted that in pornography,

[Some women] are more just completely thin up and down, some are curvier, pretty much every ethnicity under the sun. Like obviously larger women is still a fetish in and of itself... I can't say for certain, but I feel there has been a growing trend for more variety. Still like typically attractive women but still a variety in the things that make up them. - Chris

Kevin agreed that the industry was showing more diverse body types and felt that there was a strong deviation from the Playboy-esque stereotype toward something more 'organic':

The industry I think has trends of what becomes popular and what becomes less popular. Like I know that, from my experience, it feels like it's trying to deviate away from sort of fake, manufactured - I said the word again - you know like the hair extensions, the peroxide blonde, the breast implants, that kind of stuff. Especially lip injections as well. Like I feel like there is maybe a move away from that to something a little bit more organic. Because people are starting to be like 'mm that's not what they want'. They've had that now they want something different. So there's a move toward more amateur organic stuff. - Kevin

Tom spoke similarly, arguing that the "professional porn star stereotype doesn't exist anymore" and that the ubiquity and diversity of genres of pornography meant that "you can look like pretty much anything and you'll find a thing." In reflecting on what pornography used to look like, Tom noted that the porn star stereotype consisted of "lots of White. Very White. Very blonde. Very fake." Such a stereotype meant that he struggled to connect his early pornographic experiences to reality as "no one in real life looked like a porn star." However, he spoke of how pornography had opened doors for normal people to become porn stars:

A lot of porn stars nowadays are looking more and more and more like regular people...porn actresses regardless of how big or small they are tend to be relatively natural. You know they've got curves, they've got butts. You'll see cellulite and stuff like that. Sometimes on their thighs there are certain positions and sometimes if they're bent in a certain way they'll have a bit of a stomach on 
them because they're people. When you're bent in half everyone's going to have a stomach you know? - Tom

The representation of more 'realistic' bodies in pornography is interesting, because it may serve as an indicator to viewers that the sex portrayed in pornography is an accurate reflection of offline sexual interactions, perhaps making it more important in consideration of sexual script theory than ever before.

Nadia agreed that there were more diverse bodies in pornography today, however the stereotype persisted in some professional pornography. She felt that the shift in representation could be credited to feminism, as it had provided an outlet for men to transcend limited notions of expected masculinity and for women to own their bodies and their sexuality:

You will find more superficial bodies or made-up bodies or made up to fit into society's stereotypes and expectations of bodies in professional porn. But that is going away. I do feel that is due to women being educated about their bodies and owning their sexuality and not being afraid of it. Being able to say that yes, I like being in porn. Yes I like doing this. And also I think at the same time, thanks to feminism, men are not afraid to say well maybe I don't like big boobs, maybe I like really small boobs. Or maybe I like this or I like that or I don't really care, you know? - Nadia

In this extract, Nadia speaks to a distinctly third-wave feminist perspective on pornography, whereby women's sexuality and agentic involvement in pornography production and consumption is celebrated. Third-wave feminism is a feminism without exclusion, and Crawford (2007) contends that third-wave feminist writings on pornography are frank and honest, and young feminists approach pornography from a range of perspectives that include celebrating pornography as a form of sexual expression, a type of performance and as a healthy part of an overall agenda focused on sex-positivity. She argues that young feminists implicitly reject the harms-based approach, and

for the most part appear unconcerned with the broad social effects of readilyavailable pornography, and, notwithstanding their overall media savvy, have yet to grapple seriously with the power of the internet to transform the way pornography is produced, distributed and consumed (p. 140).

The third-wave feminist position has been critiqued for the added expectations that it puts on women, particularly with regard to women's bodies (Gill, 2008; 2009; 2017; McRobbie, 2008). Gill (2007a) contends that in a 'postfeminist' world, women are expected to possess sexiness and "are invited to become a particular kind of self, and are 
endowed with agency on condition that it is used to construct oneself as a subject closely resembling the heterosexual male fantasy found in pornography" (p. 152). Few of the women in this research spoke in a similar vein to Nadia or expressed a distinctly thirdwave/postfeminist perspective. As Chapter Six will discuss in more detail, most of the women's perspectives on pornography were cognisant of its misogynistic tendencies and representations, and their engagement with this material, whilst it could be arousing and titillating, could also operate as a site of pain and distress.

\section{Spot the difference: 'porn sex' vs 'real sex'}

As previously discussed, participants routinely identified the types of bodies in pornography as 'fake', and this label of 'fake' extended to the nature of internet pornography generally. But just what is 'fake' or 'fantasy' in pornography, and how do participants tell the difference? Much of this discussion came about when participants were speaking about the differences between amateur and professional content. Cameron felt that the distinction between professional and amateur pornography was "glossy vs real" and that amateur pornography presented a better framework for learning about sex. Ultimately, amateur pornography heralded more intimate moments which were reminiscent of his offline sexual encounters and helped him decipher what was real and what was fantasy:

I guess a lot of amateur porn is done by a consenting couple potentially. Which is I think probably speaks more to like how, for me, like the learning side of things. Like how is sex done. I kind of lately I enjoy that type of genre more because it's more like, it seems more real rather than sort of plastic and glossy and the guy's like, there's less touching and that. For me it was a big thing, touch and kissing, in my own sex life. I find it weird that a lot of professional porn doesn't have any kissing or any caressing or any intimate touch. But a lot of - some - a lot of amateur does have that from my experience. - Cameron

Pete felt that pornography presented types of sex that filmed well, so pornography was largely dictated by the angles and visual techniques that made it look good. Because of this, pornography did not accurately reflect the type of sex that most people regularly engaged in:

As a visual medium, it's kind of like okay, well what looks good? What positions give you a good angle on what you can see kind of thing? So it's not necessarily going to be something that is the way people will regularly have sex. - Pete

Nadia also identified the types of positioning in professionally produced internet pornography, and noted that the focus of internet pornography was on the 'money shot': 
You know, in pro, it's all about the money shot so you notice every position they put the girl in. It's not necessarily a pleasurable position. It'll just be so you can see it like visually what's going on. It's all visual. - Nadia

The focus on the money shot meant that pornography often neglected to show male pleasure outside of ejaculation as the focus was still largely on the women :

The only thing I actually probably would change is some porn doesn't show the guys face when he's coming and they do for the girl. So it is still more focused on the girl but no, I don't like to see the money shot. I don't like to see cum coming from his dick. I want to see his face. Girls enjoy the faces that guys make as much as guys enjoy the faces that girls make. - Nadia

Matt also spoke about the positioning and angles in pornography. He felt that pornography largely depicted a fantastical version of sex between men and women:

A lot of precarious positioning, weird positioning. And things that just surely are not possible. You wouldn't imagine they're possible or comfortable. I think that's the biggest difference is the sort of positioning that seems to be-for me at least - very much based in fantasy.

Lilith, too, felt that internet pornography was a divergence from 'real' sex:

But I think it's just like because there's not much, where else do you go to see people having sex? It'd be cool if there was like realistic sex. Cos it's different from sex. It's different from, it's not realistic. You know that for sex for other people, their sex not porn sex. - Lilith

Derek commented that the lack of reality and superficiality within pornography meant that it had become a "plastic version" of sex which makes it appealing to view for people. However, he lamented that such a depiction "densensitises a lot of males... that's how they think sex should be done. Love should be male. But that's not love at all." Chris agreed that pornography prioritised male pleasure, and he recited the porno-script with ease:

Here is man, here is girl, girl kneels down... Yeah there's definitely like an ordering of how events typically go. Like I feel like there's an obvious question that you may ask soonish about the frequency of girls receiving oral. Because yeah, the prime recipe, there's always the man getting the blowjob. - Chris

But alongside sexual scripting in pornography, the way that women performed in pornography was often referred to, particularly by some female participants, as unrealistic. Tara felt that in "normal heterosexual porn" the girls "were way too loud. I thought it was like way too dramatic. I just got sick of hearing the girls [laughs] screaming and wailing." Rach felt that women in pornography were depicted as 'submissive' and that the type of sex they engaged in was not reflective of a healthy sexual relationship with a loving partner: 
So many of these women are quite submissive in these videos as well, it's a very unrealistic picture of a healthy, intimate relationship with someone you love. Most of them are not loving. I don't do that with people I love. Half of that! - Rach

This idea of women being submissive in pornography was also shared by Kevin, who when distinguishing between what made something 'hardcore' pornography, felt there was an objective intention of men 'doing' the sex 'to' her as a woman. This inevitably presented women as passive receivers of sex, making them objects rather than sexual subjects:

[its] depicting sex for the sake of depicting sex, if that makes any sense? So you've got, it's not just a girl and a guy. It's a girl and two guys and they're like doing the sex to her for the objective intention of doing the sex to her. It's very much like that's the, like it's an act that's being done. In like a really direct way. - Kevin

Anna agreed that women passively received sex in pornography, speaking to the coital imperative in pornography whereby a man's erection dictates how sex will be performed to women. The coital imperative is the "widely shared presumption that heterosexual sex is penis-vagina intercourse; and that anything else is either a preliminary to - or an optional extra beyond - real sex" (Gavey, 2017, p. 94). Discussions about the coital imperative privilege heterosexual intercourse as the "most natural form of heterosexual activity" (Potts, 2002, p. 34), making it the quintessential display of 'real' or authentic sex (McPhillips, Braun, \& Gavey, 2001):

Like porn is usually not in female control. The guy has an erection therefore he goes and the woman receives what she's given... Because women in porn they're not worth much. They're exchangeable. They can be used as the man pleases." Miranda

In terms of women receiving sex, Tara felt that pornography also gave an unrealistic perspective of the way women respond sexually:

I think in general it gives a really unrealistic perspective of what women can be like. Cos yeah there might be women who act like the women in porn, and that's totally cool, but I doubt that's the majority. I mean I don't know for sure but for me that's certainly not the way it is. Like things are more complicated than just like rushing into anal randomly you know? Like that's just not how it works. Tara

By considering sex in pornography as 'porn sex', it could be argued that such a delineation situates pornography as 'fantasy', as it presents a model of sex that is not an accurate reflection of most people's offline sexual engagements. This line of thinking, however, presumes that viewers of pornographic material have some awareness of offline sexual relations being outside of these fantastical depictions. Indeed, for one participant in this 
project, he had not had a sexual encounter at the time of interview and was concerned that offline sex would not 'stack up' to his expectations developed from pornographic representations. For people who have not had a sexual experience - or indeed for people whose sexual experiences mirror pornography, - in the absence of critical media literacy skills and user knowledge that pornography is not an accurate reflection of sex, this has the potential to set a dangerous precedent in our sexual scripts and sexual knowledge. How would people know that "rushing into anal" is not how it works, or how do we know that women are not "exchangeable" as Miranda suggests? If we are "depicting sex for the sake of depicting sex" then what does this tell us about sex generally? Nadia's description of money shots in pornography identified who pornography is made for - men - and highlights how the cinematic form prioritises male pleasure. As Derek noted, pornography tells us that "love should be male." Although many of the participants in this research were critical of pornography, in the absence of some viewers having the skills to critically receive this material and know the difference between porn sex and real sex, this could run the risk of solidifying pornographic representations of sex as accurate portrayals of offline heterosexual interactions, thereby scripting sex solely from the perspective of the imagined heterosexual male viewer.

\section{Intimacy vs dominance? Gendered roles in pornography}

Both men and women spoke about the type of sex that was displayed within mainstream pornography, and although not included as a research question in this project, much of this discussion centred on the inherent aggression within much internet pornography. Mainstream pornography was described as presenting an aggressive sexuality towards women:

I know this is a problem with porn generally, especially with heterosexual porn, but it is based around sort of the wants of the male. Dominance-based. There are very niche groups of porn where it is more sort of intimacy-based and its pornography that's designed to look as real as possible. I know that's available. But that's not the pornography that you would find on the mainstream sites. You have to sort of actively seek that type of pornography. It does appear to be dominance-based. - Matt

Carly agreed that much heterosexual pornography was dominance-based, and that there was an inherent aggressive component in heterosexual pornography:

The stuff that I've been exposed to, or the stuff that I've seen, even in my adult years, it's very much been just about, quite like demeaning to women... I guess 
it's the aggression, the aggression part, in different aspects of it. And it's very male-focussed. - Carly

The idea that men are dominant in pornography and women behave 'sluttily' came through strongly in Jasmine's interview, where she identified their forceful and aggressive nature and how this could serve as a powerful educator for setting sexual scripts:

I'd say a lot of the guys in porn are quite like - in let's just say the popular kind of porn videos - I'd say the guys are quite aggressive in a way, like they're very forceful. Which obviously isn't necessarily a bad thing but it assumes that that's how you can treat anyone. Like if you were a young boy like say 11 and you're watching porn and you're seeing this girl do anything the guy says, you're going to assume that maybe that's what it's like and if the girl didn't do that they'd be like oh. Or if they weren't behaving in a certain way during sex aka being loud or slutty, you know? - Jasmine

As previously discussed in Chapter Two, the aggression that Jasmine refers to has been identified as pervasive in mainstream pornography Should pornography play a role as a sexual educator for young people, concerns are rightfully raised about the dangers of pornography in occupying that position if mainstream pornography routinely depicts an unrealistic, sexist ideology. In using Dworkin's framework of pornography as sexual pedagogy, Mason-Grant (2008) contends that

if the use of mainstream heterosexual pornography is a practice routinely engaged in as one comes to sexual maturity, its users will experience sexual desire, arousal, and satiation in its terms. That is, their desire and pleasure will plausibly become calibrated to the values of gendered, racialized, and classed dominance, subordination, and objectification that mainstream pornography makes available as sex. The transgressive quality of using pornography for sex intensifies this experience, making the social logic that is the vehicle of sexual arousal seem not just normal but natural; in a world where sexual desire and pleasure are typically regarded as unanalysable brute facts, whatever feels sexy must naturally be sexy. Sexual pleasure becomes an indicator of some underlying human nature: if domination and subordination feel good [to the user], they must be a natural part of human nature... surely the cultural prevalence of these norms bolsters rather than mitigates the force of mainstream pornography that, in turn, consolidates their normalizing force ( $p$. 413).

Men and women responded quite differently to aggression and domination in pornography. Participants' discussion of this theme evolved, unexpectedly, into a wider discussion of aggression in their sexual experienced. The significance of aggression and domination forms an important theme in Chapters Six and Seven. 


\section{Lesbian pornography}

As previously discussed, heterosexual sex is by no means the only type of sex portrayed in pornography produced for heterosexual audiences. Earlier in this chapter, I referred to nearly 100 categories of pornography available on Pornhub and one of the most popular categories is lesbian pornography (Pornhub, 2018a). Whilst lesbian pornography is immensely popular, it's important to note that 'lesbian' pornography has been routinely created by men for a heterosexual male audience, and lesbian pornography made for lesbian women is a far smaller category (Lindner, 2012; Rubin, 1993). Several participants opted to speak about viewing lesbian pornography or to discuss the way that women were represented in this genre. Overwhelmingly, it was women who chose to discuss lesbian pornography in critical ways, and their discussions demonstrated their awareness that lesbian pornography was not created for a female gaze. As discussed earlier, Holly felt strongly that lesbian pornography "by males for males" lacked authenticity, and Carly agreed, noting that the acts presented in lesbian pornography signalled its design to be viewed from a male perspective. Carly questioned whether particular acts or behaviours would be present in lesbian pornography if it were actually made for women, as "some of the stuff that I see them doing... I would be like if this wasn't for a guy, I don't understand why they would be doing that." In speaking to the types of behaviours or acts that she had witnessed, Carly commented that

I'm gonna get explicit, that's alright eh? I guess it's like - I dunno - not that it's the stuff that I watch specifically, but things that have been present in the things that I have been watching or things that I've like looked for something and then oh that's not for me. Things like - I dunno - like extreme things. Like extreme dildos, or like extreme penetration in a way that I'm like that wouldn't personally, I don't think that that would be very comfortable... And things like - the other thing that I always find really weird - fake semen. I just... personally I don't really see the big deal about fucking semen [laughs]. - Carly

Despite this, Carly felt that lesbian pornography was 'safer' to view than heterosexual pornography. Whilst it was possible to encounter lesbian pornography that was problematic or had elements of aggression, it was a considerably more pleasant viewing experience than heterosexual pornography:

With lesbian porn I will watch new ones, like you know, but with heterosexual porn I'll only ever watch the same ones that I've ever watched before... Probably cos I know that they're not ones, I know they're not ones that guys talk heaps in, not ones that they're overly violent... I've come across stuff that's really fucked up, like I don't wanna look at that kind of stuff. I personally don't enjoy that. And I guess just don't wanna risk [laughs]. If you've got a few good ones that I wanna 
stick with I would rather. Even though I can stumble across lesbian ones that I don't enjoy but it's not got that same, yeah. I've not got that same repulsion to it. - Carly

Pornography's positioning of men as dominant and women as submissive was alluded to by Lilith, who noted that lesbian pornography had distinct appeal "cos there's no man in it." Tara felt that she "wouldn't be interested" in lesbian pornography, but the reduced level of dramatization made it a more appealing prospect. The idea that pornography would have appeal precisely because it lacks the presence of men rather than celebrates the sex between women speaks strongly to the dominance of men in much heterosexual pornography and the way that some women interpret and understand such representations. Of course, in a world where men are overwhelmingly responsible for the perpetration of violence against women and women overrepresented as victims of such aggression, it's perhaps not surprising that women may wish to avoid encountering such material in their erotic endeavours.

Only a handful of men spoke about viewing lesbian pornography for this research. In speaking about the appeal of particular genres of pornography, Luke commented that lesbian pornography was appealing for men, and he felt "that's like what every heterosexual male would ever say [laughs]." Cameron also spoke about the appeal of lesbian pornography, commenting about how everyone at school was "into it, they liked watching two girls have sex." He reflected that he never really understood the appeal of watching two women having sex, but "could appreciate it for the beauty of it, but it wasn't a huge turn on for me." Ethan had a slightly different perspective on lesbian pornography, and for him, it acted as a mechanism for confirming his masculinity during adolescence. By viewing lesbian pornography, Ethan felt that it assured him he was 'straight':

Because I was so hung up about not being gay I would watch solely lesbian porn at first. Solely. And then I don't know when I made the shift, I don't know when or how or why, maybe it was just like a ménage trois scene and there was a dick involved and I was like 'woah' you know? Or maybe it was a conversation with a friend and they were like oh yeah I watched this couple and I was like oh yeah that's normal. Or maybe it was a general no I'm confident in my masculinity, I'm confident in my sexuality now, I don't need to hide behind this veneer of homophobia or anything stupid like that... like because of that deep, deep seated insecurity I needed that confirmation. I needed to know that I was attracted to women. And actively pursue that confirmation. - Ethan

Tom was the only male participant to talk in-depth about the content of lesbian pornography, even though it was not a genre that he chose to watch. He recognised that 
lesbian pornography had historically been more likely to present foreplay including cunnilingus, however he felt that heterosexual pornography now showed this in more detail:

I don't watch any lesbian stuff. I don't. I find times have changed where a lot of heterosexual porn involves a good amount of foreplay now including pussy licking and stuff like that. So you know if you want to see pussy licking I can still see that in hetero porn. - Tom

Tom believed that women viewed more lesbian pornography, and this was true for a number of women interviewed for this research. However, Tom made an interesting comment about aggression within lesbian pornography. He noted that "even if you watch porn that women tend to watch more, like lesbian porn, they still hair-pull and they still choke. They still slap" and "general light domination" is "what people are into." Tom's articulation stands in direct opposition to some of the perspectives offered by the women earlier in this chapter whereby women identified lesbian pornography as being appealing due to the lesser representations of aggression. As the previous discussions with women suggested, they were acutely aware that lesbian pornography was not created for their gaze, and that a heterosexual male audience was the primary focus. Further, concerns are often raised about the role of pornography in the development and acquisition of sexual scripts, and Tom's statement here could well be a demonstration of how pornography can influence viewers' understandings of what constitutes regular sexual conduct and mores. If pornography - including lesbian pornography - routinely depicts "light domination" and aggression, could this consistent repetition of behaviour present a model for replication and an understanding that this is what women want and men should give them?

\section{Female-friendly pornography: What do women really want?}

As this chapter has thus far argued, the majority of pornography is produced by men, for men. In response to this dominance, there is also an ever-increasing genre of 'femalefriendly' pornography which proposes to display the type of sex that women want to see. Today, 'female-friendly' or 'for-women' categories are present on mainstream tube sites, and indeed Pornhub hosts its own 'popular with women' category. Female-friendly pornography "need not be directed or produced by women in order for it to be considered woman-centred" (Kosick, 2015, p. 422), thereby situating it as something quite different to female-directed, or feminist pornography, which is explicitly political in its ethos. As 
Mikkola (2019) suggests, films depicting confident female characters might fit within the rubric of female-friendly pornography, but such a representation does not permit it to qualify as egalitarian in nature. Women's porn has been criticised by some as a mere imitation of male porn, as it "reflect[s] and maintain[s] patriarchy no less than does male porn. The 'relations' portrayed are no less about power and domination; the realities at once reflected and furthered are no different; and the underlying trope of domination is irredeemably sexist" (Brecher, 2015, p. 159).

A small number of women discussed 'female-friendly' pornography, with two identifying it as a genre that they preferred to view or had engaged with. Both Holly and Tina reflected on female-friendly or for women categories of pornography and identified them as being softer, gentler expressions of sex, as well as including more diverse representations:

I like female-friendly stuff and like proper lesbian stuff or proper solo girl stuff... For me it's stuff that seems to be made by women for women. It's more a whole lot of different chicks and they could be all different sizes and ethnicities and tattoos or non-tattoos and more kind of, I don't know, alternative hairstyles and stuff like that. So not the whole long, 16 inch extensions and stuff like that. It's not like this, usually, like harsh horrible lighting, porn lighting, and like really scripted and terrible. And there's no, well, I mean I think there is female-friendly porn with dudes, but meh. It's just not like gross to me. - Holly

And the for women sort of categories. When they've got a little bit of a story line and that kind of thing... So much of its just like bang bang bang. Like where's the warmth? [laughs] - Tina

Both Holly and Tina felt that female-friendly pornography countered some of the dominance present in mainstream heterosexual representations, giving them an outlet for engaging with pornography which they can feel is 'not gross' and displays aspects of intimacy and warmth. Conversely, Lilith was critical of this type of pornography. Whilst she acknowledged that porn was typically catered to the male gaze, she also felt that 'for women' pornography limited the types of sex that she would be able to view:

Porn itself is quite like misogynistic and patriarchal. It's like catered for the male gaze a lot of the time. But then when you like look at porn for women it's like real cliché and real cheesy and kind of like too much. And like less raw than like male porn but also it sort of buys into this idea of 'what do women want from sex? They're into romance, they're into really nice lighting and really nice camera' you know? I looked up female porn as well as it's that kind of stuff... the porn thatyou can consume seems kind of limited. - Lilith 
Lilith clearly felt that female-friendly pornography attempted to confine her pornography viewing into gendered notions of what women presumably want sexually. Kosick (2015) suggests that whilst female-friendly pornography may generate a wider appeal for women, it is often a reframing of couples' pornography under a new label 'femalefriendly' which "reinforce[s] normative notions of gender by "softening" women's pornographic tastes" (p. 422).

The idea that female-friendly pornography may be a softer, gentler version of sex may also be a contributing factor in men's limited discussions of it. Tom was the only male to comment on female-friendly pornography specifically, and he commented that it was a genre he engaged with occasionally even though it was run by women. The 'for women' label did not act as a barrier for Tom viewing this material, and he noted that representations of cunnilingus - an act typically associated with female pleasure - were more common in this genre:

But then you get something like Nubile and they tend to be the more equal with it. I think there's another one called Sensations which is run by women. So they tend to spend - they call it female-friendly, I don't give a shit. I watch it, its fine. Cos sometimes I'm like yes, I like seeing women getting off. I mean it's a lot easier with oral sex. So it really depends on the company I think. - Tom

Tom's commentary in this extract that sometimes he "like[s] seeing women getting off" suggests that mainstream pornography outside the borders of female-friendly may be less likely to display women's authentic sexual enjoyment. However, he also mentioned earlier that much mainstream heterosexual pornography displayed women receiving oral sex and foreplay. Taking these two comments together, it perhaps suggests that in these scenes where men are present, women's authentic experiences of pleasure and "getting off" are side-lined in pursuit of male pleasure as a priority. Such a suggestion fits when we consider the realities of much mainstream heterosexual pornography production which produces sexually explicit material for a predominantly male gaze. But what about pornography that is more political in its approach and is explicitly feminist in its approach?

Participants primarily found pornography on mainstream tube sites where most content is free for viewers. Mainstream tube sites do have premium content options, but to access a wealth of pornographic material does not typically require a paid subscription. Feminist pornography, however, typically requires payment and/or subscription. As discussed in 
Chapter Two, feminist pornography is inspired by a desire to represent the sexually explicit in ways outside the traditional confines of mainstream heterosexual representation (Taormino et al., 2013). Whilst feminist pornography is not specifically for women per se, there is celebration afforded to feminist pornography's goals, including dedicated Feminist Porn Awards. Multiple women in this research identified as feminists, so I expected they may have been knowledgeable about its goals and existence. However, only one participant in this study reported having ever purchased feminist pornography, and only three were aware of its existence:

That was one of the main things that I thought 'oh this is interesting to talk about' and to also say and put out there because later on I also started watching feminist porn which I only got like a DVD from Sweden of course. Where else? Anna

Both Lilith and Tara were familiar with feminist pornography and had searched for it online. Lilith commented that she had tried searching for feminist pornography but was unable to access it, and she questioned what it would look like:

I've tried looking up feminist porn as well to see if I like can watch it. But then I couldn't access it. Maybe I didn't search very hard but it seems like you have to pay to watch it. But then I'm also like hmmm what would feminist porn be like? Would it be also bad? I think it'd be more diverse in terms of the relationships it has. Maybe like less catering towards the male gaze, male pleasure. I'm worried that because it's like done by the people themselves then it'd be like shit quality, kinda like maybe like bad acting. In terms of quality I mean in terms of the footage but how they film that. It'd be very much like home video and I don't know if I'd want a home video. Big drawback [laughs] - Lilith

Ultimately, however, Lilith commented that it was usually easier to stick with mainstream sites like Pornhub as she did not "really care that much for porn I watch. Or like from where." Tara had heard about feminist pornography in an article and felt that it was hard to find. Further, in the same way that Lilith spoke about how femalefriendly pornography had boxed her in to stereotypical notions of what women should want sexually, Tara encountered a lot of erotica in her search for feminist pornography:

I read an article once and it was about feminist porn and it was about how a man plays a much more stronger role in the thing. And there's none of this derogatory woman stuff. I googled it but I came across a lot of erotica which wasn't what I wanted. I wanted like straight up porn. I didn't want like a whole like lovey dovey thing. Which is totally cool, it just wasn't right for the mood. - Tara

Chris was the only male participant to talk about feminist pornography, and he reflected on the changes he felt were present in the mainstream industry itself. Chris felt those 
changes mirrored the ethos that feminist pornography sought, in that it showed a shift in the representation of female pleasure in pornography. Chris felt being critical of pornography was important, because people need to be able to envision pornography that is produced in more ethical ways, with respect for performers, and that celebrates women as much as men:

I do think it's important to in general be critical of porn... I don't think it's a good idea to just dismiss porn entirely out of hand as all of it's harmful, all of it's terrible, because that removes any chance for growth. If you dismiss it all out of hand as all terrible, then only the people interested in the terrible things would watch it so more of porn would become terrible. If there aren't people that believe that porn can be done healthily, porn can be done respectfully, porn can be done in a way that celebrates in the joy of women just as much as the man, if there aren't those sorts of people then that sort of porn won't be made... It doesn't even have to be explicitly labelled as feminist pornography. As I said a lot throughout this interview, there has been a lot of things that I feel has been trending up throughout time. You know more women being eaten out, more women seeming like they're enjoying it, a wider variety of women, a growing sector of womenfocused porn. So like I definitely feel even without taking the time to say we are setting out to make some feminist pornography, I feel like it's already a changing thing. Could probably change faster but it's already a changing thing. - Chris

In this extract, Chris speaks again to the diversity of pornography and changing trends which celebrate women's sexual needs. However, the idea that female-friendly pornography meets the needs and desires of women was contested in some of the data presented in this chapter, and the idea that the label 'feminist' pornography would not be necessary is an interesting position. Feminist pornography is a pursuit for change, yet in Chris's eyes, such a change is already happening. Interestingly, Chris suggests that these changes are showing "more women being eaten out, more women seeming like they're enjoying it, a wider variety of women", but questions could be asked about who these changes are really for, and whether these changes in mainstream pornography are catering for both the male and female gaze. Further, questions could be asked about whether these changes are merely for a more authentic representation and in line with consumer preferences and desires. These questions are important to consider in the context of the following chapters in this thesis about what men and women see in pornography, and how it is subjectively interpreted and understood.

\section{Summary}

This chapter has presented an overview of participants' typical engagement with pornography. Overwhelmingly, participants described engaging with pornography on 
pornographic tube sites such as Pornhub which host millions of pornographic videos that can be accessed at the touch of a button. In speaking about the content of videos, participants suggested that mainstream pornography was still made for a male gaze and often presented idealised versions and expectations of bodies. Male bodies were described as 'jacked' and conforming to a stereotype that prioritises athleticism and optimal physique, whilst women's bodies were continually up for discussion as they were the primary focus of the gaze. Women often felt that female bodies in pornography were unrealistic, unattainable and this was largely because it was what men wanted to see. Conversely, men often felt that women's bodies in pornography were increasingly diverse and rejected the applicability of a porn star stereotype today.

Participants, particularly women, routinely identified heterosexual pornography as presenting men as dominant and women as passive receivers of sexual activity. They also identified a sense of pornography presenting a particular type of 'sex' that was divorced from reality, situating it in the realm of fantasy. Whilst participants seemed acutely aware that pornography was not a realistic reflection of offline sexual encounters, it points to the power of pornography to operate as a tool to influence the development and acquisition of sexual scripts. In the event that viewers of pornography do not have the skills to critically receive this information and recognise it as fantasy, it has the potential to set a dangerous precedent for scripting our notions of sex and sexuality, especially given the focus of dominance identified by participants.

Lastly, this chapter complicates understandings of lesbian pornography, female-friendly pornography and feminist pornography. Several women spoke of enjoying lesbian pornography precisely because it did not feature men, pointing to their understandings and interpretation of dominance in heterosexual pornography. Further, this chapter suggests that female-friendly and feminist pornography has appeal for some women, but it also has the potential to box others into notions of acceptable use of pornography telling women what they want. Whilst some women do want to see romantic, warm, intimate representations in the pornography that they view, women's desires for pornography are diverse and questions can, and should, be asked about what viewers want to see in pornography. 
The next chapter presents participants' perspectives on the difficulties they experience talking about pornography, and how this is a substantially gendered conversation. 


\section{Chapter Five: The "hidden part of our culture": Stigma, pornography and New Zealanders}

In Chapter Three, I spoke of the ethical challenges faced in completing this research, and how concerns about my safety were a primary concern raised by my university ethics committee. This concern speaks volumes about the stigma associated with pornography as a genre and extends to the audience of pornography through the endorsement of stereotypes about 'who' a pornography viewer is. But what is so troubling about talking about pornography? When media representations in Western society are saturated with sex, and sex is routinely employed - particularly women's bodies - as a marketing tool for completely unrelated products, not being able to speak openly and freely about pornography seems an almost impossible disjuncture. However, conversations about pornography are critically important, not least because of its omnipresence in contemporary society, but because pornography is about us, and it is fundamentally about gender. This chapter presents participants' perspectives on the hidden nature of pornography in their everyday lives. It documents the ways that men and women felt that conversations about pornography were stifled by the stigma associated with pornography as a genre. Further, it identifies the way that some conversations about pornography were possible, especially when it came to talking about pornography addiction. Interestingly, however, the concept of pornography addiction and the appropriateness of speaking about it was a gendered experience, whereby women in relationships with men struggled to speak out about their partner's use of pornography.

\section{Talking dirty with me: interview environments and pornographic conversations}

Whether pornography should or shouldn't exist is pretty much beside the point. It does exist, and it's not going to go away. Why it exists, what it has to say, and who pornography thinks it's talking to, are more interesting questions... Just what is pornography's grip on the cultural imagination? (Kipnis, 1996, pp. Xxxi).

As discussed in Chapter Two, modalities for engaging with pornography have shifted significantly over recent decades, with internet pornography now pervasively available and consumed at previously unprecedented levels. Never has there been a cultural climate so accepting of pornography, so amidst this online saturation of pornography, I questioned whether it was something that men - the primary audience of pornography spoke about in their day-to-day conversations. Prior research has established that pornography provides men with a form of social currency, where they "jockey for 
position in the eyes of other men" (Barron \& Kimmel, 2000, p. 66). In pornography, the positionality of men and women presents as a form of gendered speech, whereby the representations operate as a system of communication between men about masculinity and what it means to be male (Barron \& Kimmel, 2000). If this is the case, do men speak with other men about what they view in pornography, and do particular preferences in pornography trump others as they jockey for position? As I spoke with men, it became clear that pornography was not a topic of everyday discussion, and only certain types of conversations about pornography were had. The following section presents men's perspectives on talking about pornography, beginning with their interviews with me.

As discussed in Chapter Three, my university ethics committee were concerned about my safety in the interview environment, encouraging the presence of a third person in the interview. I was surprised at the level of concern raised about this, and in fact, it seemed paradoxical to my primary concern at the outset of my research which was whether men would even feel comfortable speaking with me about their pornography habits. At the same time, however, I was conscious that the interview experience had the potential to be overly-sexualised, or that men may attempt to perform masculinity (Antevska \& Gavey, 2015; Flood, 2013b). I wondered whether the one-on-one interview environment might facilitate more accurate reflections about men's true feelings about pornography. Ultimately, though, I had no idea what men would say about pornography or how it would be expressed in the interview environment.

As I waded into the unknown, the men I spoke with provided open - and often explicit accounts of the pornography that they viewed and engaged with. Their discussions invoked strong visual depictions of their pornography preferences, and the following excerpts illustrate men's comfort speaking with me about how they read the sexually explicit:

I've fairly recently, in the last couple of years, been interested in [laughs] some sexual activity that I have seen on porn... it's almost like a blowjob, which is funny cos I'm not a fan of them. Where the male straddles the female, fuck it lets just get this out... the female licks the gooch ${ }^{15}$ or the taint and is naked and pleasuring themselves. That is [smacks hands together] fucking fantastic. That is hugely, hugely sexually enjoyable to me. But I've seen it in pornography and meh, it's not enjoyable to watch. Probably cos it's got a guy's asshole in it. And no vagina or breasts or anything. - Luke

\footnotetext{
15 The gooch (also known as the taint) refers to the area between a man's scrotum and anus.
} 
So anything involving the penis, sure, cool, I can easily imagine that happening. But not necessarily just that because there is some great work involving women just by themselves. Because that in itself is a pleasant viewing experience. But when the man gets involved and is just pleasuring the women through either finger or mouth or whatever, it feels like it more detracts from the experience as the man is more of a distraction rather than a person I could substitute myself into. - Chris

I've recently got into more girl-on-girl. Again, a lot more real, a lot more sensual. But then again you've just gotta sift through the bullshit. There is a lot of bullshit too. And then personal ones would be right into anal sex, that as well. Maybe if I'm feeling like going a bit further, squirting ${ }^{16}$ or fisting. ${ }^{17}$ - Derek

Bill I'm not sure if you're familiar with Goatsy. It's a very famous shock image. It's kind of funny, actually. It has a soft spot in my heart these days... Goatsy is a man stretching his anus to about [gestures with hands].

Sam Wow, that's quite a few inches.

Bill Yeah it was honestly massive.

Alongside conversations about pornography, men also spoke about their offline sexual relations with women. Some of these discussions extended into an overview of their own perceived sexual prowess:

Even though porn - yes it is a fantasy - it gives you a pretty good idea. You can go okay, I sort of see what they're doing there and I get it. So it certainly helped with that and it's become apparently something that lots of guys don't do but because a lot of porn I watched early on showed me that's what you do do, so before you have sex that's what you do. I even had a girlfriend that called me Eats-A-Lot-Of-Puss. - Tom

I love going down on women. Well there ya go. I don't enjoy blowjobs but I love going down on women. For me it's about the woman enjoying herself. - Luke

Such narratives could be observed as men 'doing masculinity' by deliberating about their supposed sexual skill in pleasuring women, as men's discussions about women's bodies and their sexual conquests of women operate as a key site for homosocial bonding and men's claiming of heterosexuality (Flood, 2007). This emphasis on men's skills at sexually pleasing women could perhaps be amplified in the presence of a male interviewer, whereby successfully performing masculinity may be considered more important. Yet I was struck by the linguistic familiarity with the pornographic that many of the men displayed. Pornographic categories and industry-specific lingo were a consistent inclusion in most interviews, and their ease and comfort, for the most part, contributed

\footnotetext{
${ }^{16}$ Squirting refers to a phenomenon where women report ejecting fluid from their urethra during sex.

17 Fisting refers to the insertion of an entire first into either the anus or vagina.
} 
to a jovial and relaxed interview environment. I was also struck by the way that most, if not all, of the men spoke so freely in the interview environment, yet also alluded to these conversations being the first they had ever had. I was surprised that men rarely spoke about pornography because pornography is routinely constructed and discussed in media narratives as a 'guy thing' (Paul, 2005), and traditionally accepted as "male territory" (Rubin, 1993, p. 36). Further, pornography's unbridled presence and force in the contemporary technological landscape makes its absence in everyday conversation difficult to comprehend.

In querying men's limited discussion about pornography in their everyday lives, it became clear that much of this was related to the stigma associated with viewing pornography. Goffman's work on stigma is perhaps the most famous, and influential, examination of the concept, which has cemented its continued application across disciplinary boundaries. Stigma refers to the imputing of negative attributes or inferior status to people who have some form of discrediting trait - often visible - such as a physical disability, or a perceived defect in morality which contradicts the norms and mores in a particular time, space and context (Goffman, 1963). Stigma is a powerful attribute which works to reduce individuals tarred with a stigmatised identity from "a whole and usual person to a tainted and discarded one" (Goffman, 1963, p. 3).

Whilst stigma can be attributed to particular individuals, stigma is sticky and can attach itself to entire groups or categories of people, such as drug users (Lee \& Boeri, 2017), sex workers (Armstrong, 2018; Weitzer, 2017), persons living with mental illness (Corrigan \& Watson, 2002), or particularly for this research, people who view or consume pornography (Rubin, 1993), including those who view pornography in perceived 'problematic' ways (Leonhardt, Willoughby, \& Young-Petersen, 2018). As noted in Chapter Three, there is also a unique stigma associated with researching pornography, whereby researchers become tainted as engaging in 'dirty' work, which can lead to a range of negative outcomes, experiences and devaluing of the academic legitimacy of such work (Fahs et al., 2017; Irvine, 2015).

Stigma is a damaging attribute that affects individuals, groups and communities in multifaceted ways. In devaluing and blemishing the character of individuals, stigma induces negative societal reactions to those tarred with a stigmatised identity (Link \& Phelan, 2001; Voss, 2015). Labels about stigmatised groups become commonplace, and 
the label then links "a person to a set of undesirable characteristics that form the stereotype" (Link \& Phelan, 2001, p. 369). As a result of the power of labels and stereotypes about stigmatised groups, the othering of, and dissociation from, stigmatised people, groups and communities becomes a common response, thereby separating "us" from "them" (Link \& Phelan, 2001). Thus, stigma "enables a separation between the stigmatized and non-stigmatized, resulting in discrimination" (Voss, 2015, p. 9). The damage caused by stigma is not always outwardly facing, and stigma can also be internalised by those who become tainted by it, thereby making it 'felt'. The internalisation of stigma (or self-stigma) is a threat to the self-identity of an individual, who comes to view themselves through a stigmatised lens (Goffman, 1963).

With respect to viewing pornography in particular, internalised feelings of shame and feeling 'dirty' are commonly reported experiences, particularly by women (Ciclitira, 2004; Neville, 2018), and are undoubtedly influenced by the stigma associated with pornography. Rubin (1993) contends that the stigma associated with pornography "predates feminist attention to the subject" and "most people in this society are already uncomfortable with pornography and a little afraid of being contaminated with its aura of disrepute" (p. 36). Voss (2015) notes that pornography has been framed "as corruptive, corrosive, seedy, and immoral" (p. 7), and these assumptions about what pornography is then work to shape the stereotypes and assumptions made about the people who engage with such content. Bearing this in mind, then, perhaps the lack of discussion about pornography in the everyday conversations of men and women interviewed for this research should present itself as remarkably more common and expected rather than surprising.

Numerous men interviewed for this research commented that they had not voiced their opinions or thoughts about pornography. However, it was clear that several of them had thought about pornography in often complex ways. They identified their previous discussions about pornography as usually more generalised or philosophical in nature, perhaps making it less likely that their personal consumption would be up for assessment or consideration:

It's not like I'd talk to [friends] about porn, I'd talk to them about what porn represents rather. It would be more of a philosophical discussion you know over coffee, rather than 'oh yeah did you watch that good porn clip last night?' 'Oh 
yeah, that was awesome.' 'I liked it at 4 minutes and 33 seconds when that guy did that thing.' Nah it's not about that... it doesn't happen often. - Nathan

Derek felt that talking about pornography was "not that common", and even questioned why anyone would need to talk about pornography in the first place. Viewing pornography had "always been such a personal, private thing" for Chris, so in-depth conversations were few and far between. The personal being spoken about in public settings - in this case during an interview in a café - contributed to an aura of discomfort when the conversation was overheard by others. Derek recognised this occurring during our interview, commenting that:

[porn] is a very hidden part of our culture... But I don't think there should be such a stigma. We've had at least five different people shift from that table talking about what we're talking about. What the fuck? We're just talking about it. It's not like we're here banging on the fucking table. - Derek

The struggle associated with talking about pornography was also mentioned by Chris, who said that "you can't just sort of strike up a conversation with someone and say hey! I watched some cool porn last night." Tom felt similarly, suggesting it was "certainly not something that I would talk about in front of a group of people that I didn't know." That said, Kevin felt that even in familiar or friendly spaces, "no-one's going to be forthcoming about how much they watch porn" and in his experience, "guys don't necessarily talk about it." On the rare occasion that pornography did arise in conversation, Derek felt that getting the real or honest truth about people's opinions on pornography was complicated:

You would be very lucky to get the 'truth' truth from a lot of people I would say. A lot of people like to keep themselves to themselves. I'd say that there are a few things that people search for that they probably wouldn't share with the bros. Derek

In this extract, Derek alludes to there being a specific non-sharing of certain information with the 'bros', indicating that men perhaps fear judgment for being exposed as the type of person who watches particular genres - or styles - of pornography. In the previous chapter, men overwhelmingly suggested that their primary engagement was with content within the confines of mainstream, so perhaps Derek is suggesting here that it is less acceptable to admit to viewing pornography on the fringes of the acceptable or mainstream. In the contemporary context, this could perhaps be related to concerns about kink-shaming, where someone is judged for their interest or preferences of sexual behaviours outside of the perceived or acceptable social 'norm'. Alternatively, Kimmel (2005) speaks to men's concerns and silences about their pornography preferences as 
correlated to the worries men have of exposing their inadequacies in achieving or performing masculinity:

For many men, there is silence about the question of pornography because there is no question: Pornography is a vital part of many men's sexuality, and the feminist debate may threaten that privilege. Silence is a refusal to acknowledge the debate... I think that men have been the silent spectators in the debate about pornography because, quite simply, we don't know what to say... it is a silence born of confusion about the role of pornography in our own lives, and a more general confusion about how we experience our sexualities, a confusion that remains fixed in place because of our inability to talk frankly and openly with other men about our sexualities, and that is compounded by a paralyzing fear that whatever we say about something as volatile as pornography will reveal us to be less than "real men" (p. 66).

George's comments echo Kimmel's, as he suggests that:

I would think - and I would include my secular friends in this as well - that most people don't watch pornography because they find it's a good recreational pastime. If they did then the conversation would be a lot more open and people wouldn't feel so much shame around it. But I think everyone, most people intuitively know there's something a bit off or wrong about pornography and that's what keeps that silence and shame around it. - George

The anxiety about being revealed as less than real men was also alluded to by Kevin:

You feel like your porn tastes can be a personal thing and you feel like maybe you give away too much of yourself when you talk about that kinda stuff and people can start making assessments and judgments about you based on other things you do as well. - Kevin

Kevin suggests that men's personal sexual practices - in this instance, their pornography preferences - are up for assessment and judgment outside the parameters of the simply pornographic. This concern about being judged for one's own sexuality seems not dissimilar to the judgment and evaluation women experience in the sexual marketplace, whereby men are heralded for their sexual conquests and women are shunned for their sexual engagements (Crawford \& Popp, 2003; Farvid, Braun, \& Rowney, 2017; Flood, 2013a). The dilemmas women face in dealing with being a $21^{\text {st }}$ century, empowered, sexually agentic woman will be discussed in more depth in the following chapter, however it is interesting that men, too, were concerned about being judged for their sexual endeavours. As I consider the concerns that men voiced, I question what types of preferences are up for judgment, and what types of cultural conditions might contribute to these assessments being made. As I spoke with men, it became clear that men were keen to talk about pornography addiction in some depth, so frequency of use was an arena 
where judgments could be made. As the following extracts will show, however, some spaces seemed to be more accepting of these difficult conversations.

\section{Asking for help: men talking about pornography addiction}

As discussed in Chapter Two, increasing scholarly attention is being given to men's experiences with pornography 'addiction'. Although pornography 'addiction' is not yet regarded as a definitive diagnostic label in clinical terms (Ley et al., 2014), a number of men in this research spoke about the troubles they had with stopping viewing pornography. They used language familiar with addiction narratives to describe their use of pornography at particular times throughout the lifespan, with some working from a place of 'addiction' through to a place of 'recovery'. This process of addiction to recovery was not always linear, with some suggesting they had a 'controlled' use of pornography, whilst others were not bothered by their use unless it began to affect other aspects of their lives. However, a number of men spoke about seeking support for their experiences, with particular spaces - particularly online communities - being identified as places that men could speak openly, anonymously and freely about the perils of pornography in their lives.

Klein (2006, p. 245) suggests that the "main cultural narrative" when speaking about pornography centres on "pathetic male consumers" without including their perspectives. Through this framing, men's use of pornography as somewhat out of control seems to warrant the label of 'pathetic', as to be masculine is to be in control. Garlick (2010) contends that control is fundamental to manliness, and through this we can understand the relationship between hegemonic masculinity and pornography. He suggests that "hegemonic masculinity within the pornographic imagination defines a pattern of gender relationships in which men are both in control of women and of themselves" (p. 608). In a sense, then, losing control of one's ability to masturbate to pornography at seemingly acceptable levels may contribute to a difficulty in disclosing the realities of one's use. Kevin felt that men were not able to speak with other men in person about pornography addiction because "the conversation never gets that far":

no guy in my experience - I say no guy but that's pretty general - I couldn't imagine anyone of my friends coming to be and being like 'I think I've got a problem, I watch too much porn'. I couldn't ever imagine how that conversation would go. Or feeling comfortable enough to ever approach and 'hey so and so, I've got something to get off my chest. I watch too much porn'. - Kevin 
Although "guys don't really talk" to each other about pornography, Kevin felt that online spaces were safer forums for such discussions:

You'd see way more discussion in online forums where people are anonymous and can talk about their interests free from being judged by having an honest discussion face-to-face by someone who can see them and make judgments about them. - Kevin

Online self-help forums came up in a number of interviews with men who had experienced issues with their use of pornography. Men primarily spoke of the forum No Fap as the key online community they were familiar with. No Fap is a comprehensive sexual health and pornography addiction recovery movement which - pun completely intended - helps men to "get a new grip on life" (No Fap, 2018).

\section{This image has been redacted. Please see print version for the full image.}

Figure 2: Screen capture from https://www.nofap.com/ the official site of No Fap.

No Fap also has a strong online presence on Reddit, with over 385,000 people in the r/NoFap community (r/NoFap, 2018). The Reddit community details state that the site hosts:

rebooting challenges in which participants ("Fapstronauts") abstain from pornography and masturbation for a period of time. Whether your goal is casual participation in a monthly challenge as a test of self-control, or whether excessive masturbation or pornography has become a problem in your life and 
you want to quit for a longer period of time, you will find a supportive community and plenty of resources here.

Jack commented that No Fap was a place where "people often post their stories, people often post questions and things, or like motivational things." He felt that No Fap gained legitimacy through its focus on science, which he recalled was supported by psychologist Philip Zimbardo:

He has a book called Man Disconnected where he argues that technology is fucking with men. Artificial reality is fucking with men. He does it in many ways. He talks about how gaming can often replace the drive to go out and achieve something because it's a lot more easier. And it's deluding the mind, he believes it deludes the mind into believing you've actually gone and accomplished something. He also feels the same about pornography. He feels that many men are going towards pornography and their mind is designed for the wild. [He recommends] No Fap and YourBrainOnPorn.com and things like that. - Jack

Ethan was also familiar with No Fap, and came across the movement when he was investigating online what may have been contributing to his erectile dysfunction issues:

There are some forums that do say you know it's a growing problem with young men and if it's unidentified then it can be a real problem... there's a growing movement online... I don't prescribe to any movement or anything like that but I found it very useful and actively, actively tried to wind down my porn use and get it to a manageable level. - Ethan

Pete had also engaged with No Fap previously, noting that it offered graded options:

There are different grades. So it's like. They say the main thing that you wanna stop is viewing pornography, masturbating and ejaculating. So some people say you can still have sex. But then they say hard mode is no sort of sexual stimulation at all. - Pete

Jack also spoke about the modes on No Fap, stating there was "easy mode which is you can't edge, you can't masturbate, but you can have sex with a partner. And then there's hard mode which is just nothing whatsoever. Nothing. Can't even do it with a partner." Both Pete and Jack had previously tried using the No Fap abstinence approaches to control their pornography use. Pete had tried numerous times and been unsuccessful, whilst Jack was successfully abstaining at the time of interview. Outside of No Fap, George also spoke about an online app called Fortify which he had used to help him secure a path to abstinence. He described Fortify as:

A program that kind of breaks down the pornography addiction, kind of the cultural backdrop of pornography, where it's come from and it gives you kind of a toolkit or a series of strategies to help actually you know overcome the addiction to pornography. But it's all done in a way that's not shame based, it's 
really affirming and there's quite a high level of accountability involved but it's all self-directed. So it puts the onus of recovery on the person who's going through that cycle of addiction. - George

Whilst No Fap and Fortify may be places where men could openly and freely speak about issues with pornography, Chris felt that the harms-based paradigm that such forums adhered to affected the types of conversations that could be had about pornography for men, so talking about pornography in ways outside of this paradigm were stifled:

The only room to talk about pornography is those sorts of people coming out and saying I have a problem. And even then that can't be easy for them because there will still be people judging them. But if they come out all repentant, all really sorry that they've ruined their lives, most people's reactions would be sympathy. So in that sense like so it's still difficult to talk about it as a problem, but that's still easier than talking about it as a neutral or positive thing. - Chris

The harms-based paradigm is undoubtedly a significant perspective in pornography scholarship, and a number of men's perspectives on the harms of pornography contribute to this literature base (DeKeseredy \& Corsianos, 2016; Jensen, 1996). In writing about men's use of pornography, Kimmel (2000) suggests that "pornography occupies a special place in the development of men's sexuality" (p. 225) and that there are stark differences between men's and women's conceptualisations of sex. He argues that

the claims of antipornography feminists - that pornography causes rape, or that it numbs us to the real effect of real violence in women's lives - have been difficult to demonstrate empirically... yet whether or not there is any empirical evidence that the pornography alone causes rape or violence, there remains the shocking difference between us: on any given day in the United States, there are men masturbating to images of women enduring sexual torture, genital mutilation, rape and violence... one can hardly imagine many women masturbating to [it]... Violence is rarely sexualized for women; that such images can be such a routine and casual turn on for many men should at least give us pause (Kimmel, 2000, p. 226).

Men writing from an anti-pornography position typically support the radical feminist critique of pornography as it "provides the best framework for understanding the production and consumption of graphic sexually explicit material" (Jensen, 2016, p. 1). Further, there is a strong call to abstinence from pornography by pro-feminist men who are "committed to the feminist critique of pornography and the sex industry as patriarchal, brutalizing and misogynistic, [who] call on men to quit pornography and forge ethical sexual and gender relations" (Flood, 2010, p. 177). Kimmel (2005) writes similarly, arguing that men need to examine the position of pornography in their lives:

Men need to raise the issue, to examine the role of pornography in our lives. A 
lot is at stake: although most pornography images are of women, pornography is, at its heart, about men. It is about men's relationships with sexuality, with women, and with each other. It is about women as men want them to be, and about our own sexual selves as we would like them to be (p. 67).

The power of a call by critical masculinities scholars to renounce pornography is striking, yet few men in this thesis supported such a position outright. Only one man - George strongly adopted and adhered to a harms-based position:

I think the wider implications that pornography plays in our culture... you can't talk about mental health or mental wellbeing without talking about trauma because they're so closely linked to one another. And you can't talk about trauma without talking about the culture of consent and rape culture and abuse - you know like domestic violence or partner violence. And you can't talk about that without acknowledging the really - I think - close correlation involved that pornography kind of plays in informing that culture. - George

In this reflection, George draws strong links between pornography and its role in the perpetuation of gender inequality. Such a stance on pornography was a surprising inclusion in this research, as I did not expect to encounter men who had renounced pornography in such a way. George also did not think his views would be mirrored by others in this research:

I watched a Ted talk a few months ago about this porn researcher in the US and he had tried to conduct this study at UCLA I think it was. To find out about the differences between the young men who consumed pornography and the young men who didn't to see what the effect was. But when he tried to do the research, he couldn't get enough young men in the control group of people who hadn't consumed pornography because everyone was consuming it. So this is why I think my story is valuable because I'm actually on the other side of it now. So it would surprise me if there are many people you've interviewed who aren't still consuming pornography. Until you stop consuming it you don't actually know what the impact of not consuming it is. - George

Whilst the majority of men did not support an anti-pornography position, they were cognisant of the harms of pornography, particularly with regard to the harm it might cause to other people. Men spoke of its potential dangers, but they distanced themselves from the type of person that would be affected by these dangers, typically by way of a presumably healthy or mature approach to pornography use:

I understand that pornography can be bad, it's just never been that bad in my experience and usually if it's tempered with 'hey, take it with a pinch of salt', you know, I think it's fine. - Tom

But I think porn, like many things it can be very good and it can be very bad as well. You just need to find the balance and have a healthy view of it I guess. Ethan 
I know there is the dominant narrative about how it can ruin your view of women and sex itself. And there's definitely room for that... I can see how a lot of porn can be harmful to women and how it easily has the capacity to. - Chris

I suppose an overexposure with anything can create a desensitisation and that might have a lot to do with where it particularly, my male generation, maybe the generation below, they might be womanising. - Derek

In the context of a discussion about agency and pornography, Pete spoke about the societal impact of pornography in some depth:

There is perhaps a societal impact. There's perhaps a bigger picture impact and THAT might be the problem. It's not the individual cases, it's that when you have this thing, pornography, that it has an impact on the way people might perceive it. And I dunno. I dunno if that is the case. Like maybe if you didn't have pornography maybe people might still act and feel in the way that they do, I dunno... I think probably in the ideal world we wouldn't have something like pornography. - Pete

Following this, in response to a question about whether he identified as a feminist, he struggled with this concept and presented a view that supported feminist goals as 'achieved' in the Western world. Pete's perspective about women's achievement of feminism speaks to a distinctly postfeminist standpoint, whereby women are presumably now 'done' with feminist goals; acting as "autonomous agents no longer constrained by any inequalities or power imbalances whatsoever" (Gill, 2007a, p. 153). In essence, then, postfeminist thinking suggests that the feminist goals of the second-wave are achieved, making women free to engage in practices that 'empower' them as sexual subjects:

I think that the feminist movement has become confused. In the past it was very clear, suffrage, we wanna vote, it's like yes! Women should, obviously, cool, okay. Next one, should be able to do all the same jobs! Okay, cool, now you can, I presume, women can do pretty much all the same jobs.... There's lots of messed up things in terms of women's rights in other places around the world. But in the Western world, certainly White women have got it pretty good. And so maybe it's just cos I hear the really vocal social justice warriors online or whatever. But I'm like sit down you, you're complaining about shit you definitely shouldn't be complaining about. So maybe they're not representative of what feminism actually is today. Maybe they're just loud and stupid. I definitely find myself not buying into everything that is feminist. - Pete

Pete also spoke of the 'feminist challenge' of equality and the blurred vision for a feminist world:

I have not fully heard a feminist mandate or whatever that I'm like yep, that's totally happy with your assessment. Cos the challenge I see is like okay, yep cool. Be equal. But what I actually want feminists to say, or somebody to come up with, is they need an idea of what the future will look like and it's not enough to just 
say everyone can do whatever they want and people have their bodily rights protected and whatever and don't get catcalled and wolf whistled. It's like okay yeah of course, lots of bad things happen. We recognise that. Everybody recognised that. Lots of pig chauvinist men do stuff that they shouldn't do. What is the destination? What is it that feminism is trying to get to? Because I don't know what that is. I have not been given an impression of what that looks like. That to me is the problem cos you're like if you don't know where you're heading, then how can you know that the actions that you're taking now are the right ones? There's my rant on feminism. - Pete

As I sat through this rant on feminism, I was struck by the contradiction within Pete's account. On the one hand, I could tell that Pete had thought in some depth about feminism, pornography and agency, and his envisioning of a world without pornography was surprising, as it stood in such stark opposition to the rest of his interview where he identified pornography as a routine leisure activity for himself. But this vision for a world without pornography was not an isolated position. Kevin also envisioned a world where conversations about the pitfalls of pornography were possible:

I didn't really ever think that it was impacting my intimacy or anything like that until my current partner raised the issue and since then I've sorta been like yeah actually, 100 percent she's got a point. I wish maybe that I hadn't sort of watched so much of it when I was a kid growing up. I wish there was an easier way to talk about it and wish there was like a more healthy way. I wish there was a more healthy way that you could enjoy that kinda stuff... I wonder like what it would look like in the future if porn was not a taboo subject. - Kevin

Bill also felt that young people needed support navigating pornography in the digital age:

I think it would be really good if there were better ways of just directing adolescents throughout their first steps into engaging with porn. Like back in the day, back in the day kids went down to the railroad tracks and they found like a box of porn magazines someone had left there. And then you get older and you become the person leaving it there. But you know that was porn that like someone had handpicked from someone's connections. Like magazines, like not like too extreme. And somehow that feels almost healthier you know? - Bill

Ethan was conscious of the contradictions in his own use of pornography alongside his concerns about the structural realities of pornographic production, presenting a rather anxious reading of pornographic material:

The man could - men generally have more, generally speaking - can violently coerce women into doing things against their will. I really don't want to be a part of that. I don't wanna watch it. I want to know about it because I feel like that's important to know about these things, know about these evils that are being committed, and actively stop them. But consuming stuff is not actively trying to prevent it, it's actively trying to almost promote it in a very sad, sad way. - Ethan 
Throughout these discussions, it is clear that these men's engagement with pornography is decidedly complex. Men spoke of the difficulties they experienced talking about pornography due to its inherently stigmatised status, but it's clear that not all men were simply uncritical consumers of pornography, and they do want to talk about pornography in detail. As I reflect on our interviews, I recognise that some of the men I spoke with shared their innermost thoughts, anxieties and ambivalences about pornography. For a number of them, they had not had the space to talk about pornography in such depth before, so these perspectives provide a unique insight into the way that men felt that they could, or could not, speak about pornography. The perspectives shared by men here identify the importance of involving men in conversations about pornography and keeping the audience of pornography at the forefront of our discussions about the subject. Further, as women are increasingly forming a significant audience of pornography, it's important that women's perspectives on pornography are also included in research. This chapter now turns to women's experiences of talking about pornography in their everyday lives.

\section{X-rated chat with the ladies: facing judgment}

As frequently mentioned throughout this thesis, heterosexual men make up the majority of pornography's audience, yet women are increasingly viewing pornography (Smith et al., 2015). As the earlier section of this chapter demonstrated, men were aware of the stigma associated with discussing their pornography viewing preferences, and in many ways, this stigma was amplified for women because of their gender, situating pornography as a distinctly gendered activity (Neville, 2018).

Women's sexuality has been the subject of much social control, with women's experiences of sex historically relegated to the private domain. In more recent years, the tides have changed and the requirement for women to be 'sexy subjects' is the new epitome of the $21^{\text {st }}$ century, sexually agentic woman in neoliberal times. In speaking to the presentation of women in advertising, Gill (2008) documents a significant shift since the late 1990s in the figure of the 'new' woman, who is "a young, attractive, heterosexual woman who knowingly and deliberately plays with her sexual power and is always 'up for it' (that is, sex)" (p. 41). This 'up for it' femininity promotes a "sexually savvy and active woman who can participate appropriately in consumer practices in the production of her choice biography" (Evans, Riley, \& Shankar, 2010, p. 115). At the same time, 
however, this 'up for it' sexuality presents a set of extra pressures on women, as the sexually agentic woman continues to occupy a position in a patriarchal culture where women's sexual engagements remain up for debate and critique, and women continue to run the risk of being labelled sluts for operating 'too far' outside the limits of an acceptable, agentic sexuality (Lamb, 2010).

Actively engaging with pornography is a primary indicator of the $21^{\text {st }}$ century, sexually empowered and agentic woman. Rosalind Gill (2007) argues that for women living in 'postfeminist' cultures, "the display of a certain kind of sexual knowledge, sexual practice and sexual agency has become normative - indeed, a 'technology of sexiness' has replaced 'innocence' or 'virtue'" (p. 72). Today, to be a 'cool' girl is to borrow from pornographic imagery, be familiar with pornographic vernacular and to be 'up for it' - that is, up for the type of sex that pornography presents. As Gill (2012) suggests, “'sexual empowerment' or at least its proxies: 'adventurousness' or 'confidence' - has itself become a compulsory part of a normative, heterosexy, young female subjectivity" (p. 743). However, this is a double-edged sword, as women's engagement with pornographic material suggests a particular type of sexuality, and the assumptions made about women's sexuality run the risk of being premised on the type of pornography that women view, which may not reflect type of sex that women are interested in.

Women participants were forthright about their experiences with pornography, including their enjoyment or disdain for it as a visual medium. In the same way that men were open about the appeal of pornography for them, many of the women identified the types of pornography that they viewed, but their conversations about what was appealing in pornography were almost always buffered by an acknowledgement that certain aspects detracted from its appeal:

When I first started watching porn it was just like girl/guy porn. Then I started watching more like lesbian porn and then... just I've kinda tried watching a lot of things, but at the moment like the gangbang kind of thing is what I'm into and I have no idea why I find it attractive. - Jasmine

Sometimes I go completely off porn and I just can't watch it at all cos it's just not sensual enough and it just completely turns me off and I'm like yuck you know? I can't orgasm or anything... When it's not just like hardcore, kind of no romance at all. But then sometimes I watch that. It's just depending on my mood. - Carly

Whilst these women clearly felt confident speaking with me about pornography, they made it clear that speaking about pornography outside of the interview context was more 
difficult. Jasmine occupied an 'on the fence' position about pornography, and felt that it was difficult to speak openly about pornography because of this position:

I don't really know what my official opinion is if that's what you're trying to get out of it. Like I'm in the middle... Because the people that just enjoy porn don't really, only the people with really strong opinions talk about it. Whereas if you're like me, you're in the middle, I'm not super pro-porn, it might contribute to that but also I enjoy porn. It's been part of my life for quite a few years you know. Jasmine

A number of other women held ambivalent views about pornography. Women's ambivalences about pornography could be related to myriad issues, but this ambivalence seemed to be especially related to the discomfort they felt about viewing pornography yet also identifying as feminist women. Carly noted that she felt

quite conflicted about pornography. Especially - I shouldn't say it too loud especially being a female who identifies as a feminist. Yeah. Like my exposure to it and I feel on the one hand, like I feel hypocritical if I ever watch it. - Carly

She explained further about the internal conflicts she felt about viewing pornography as a feminist woman:

I feel like it's the whole argument of completely objectifying women and that's probably the one that I struggle with the most. It's like I go on about how I don't want to, I'm really anti-objectification and subjectification, and yet these people who are in pornography, yeah. It's objectifying themselves. And that's where Ifeel really conflicted because then I carry on watching it so therefore I'm engaging in it and keep fuelling the business of it. - Carly

Carly's concerns about resisting objectification in her everyday life and activism, yet also enjoying pornography, signal a straddling of rather opposing realities. This was also recognised by Miranda who questioned her own use of pornography, asking "why do I watch something as a woman where women are mistreated in my opinion?" This was quite a different situation than was shared by men. Whilst some of the men acknowledged that pornography had the potential to show women being mistreated, this did not seem to cause such significant internal conflicts or make them feel 'hypocritical' every time they watched it.

Nadia felt differently regarding the debates about pornography, in that she felt the antipornography position completely shunned women's engagement with pornography as a pleasurable activity:

I would say the closing note for me would be what annoys me is when people think - and I actually feel it's not as common anymore, but still - people have thought in the past that completely rough sex or violent or anal, what they 
consider to be violent or whatever is damaging to women's rights. Or that it's about violence against women. That makes me think well you suck in bed [laughs]. I know it's kind of judgmental but I'm like well women like this stuff too. That's my thing. - Nadia

Nadia opposes the idea that women could not, or do not, like particular kinds of pornography. Recalling Neville's (2018) work with women who consume gay male pornography, she demonstrated how participants saw women watching hardcore pornography as slutty, but viewing soft-core or pornography for women was seen as erotic and acceptable. This speaks further to the notion that 'for women' pornography conforms to gendered notions of acceptability, as discussed in Chapter Four.

Ultimately, women's conversations about pornography were complicated. In the previous section, men spoke about the stigma associated with speaking about pornography especially about pornography use - and these conversations firmly rooted pornography in the arena of 'private' conversations. If was almost as if instead of the saying being 'what happens in Vegas, stays in Vegas', it was 'what happens on Pornhub stays on Pornhub'. Was this the same for women? This section now turns to women's discussions about pornography as a stigmatised conversation.

In speaking to the stigma associated with speaking about pornography, a few women felt that this was particularly amplified because of their gender. Lilith reflected that:

When I was younger I think I felt like I was doing something naughty... the sort of like stigma surrounding porn. I remember when you're like a woman, and especially when you are young, because you are like... I guess like its weird eh, cos it's quite new to you for the first time so it's quite shocking... So yeah like to be doing that. - Lilith

Carly felt that men's viewing of pornography was acceptable, suggesting that women's viewing is less so, which counters the positions suggested by men earlier in this chapter:

Whereas not often, I feel, like you would find females that'll be like 'I watched porn the other day and I found this really weird blardy blah'. I just don't think that would occur. It hasn't in my experience occurred as much... I feel like it can be talked about in a way that's just accepted in society, like guys watch porn. So it's like 'yeah I watched this porn the other day and blardy blah'. And like it's not often talked about in a serious way, it'll be talked about like something they've seen and maybe it'll be like in a joke or whatever. But the reference is there to the fact that they watch porn. - Carly

Given that men's discussions about speaking about pornography in front of women were minimal in their interviews, could it be that men's conversations in front of women may 
be more explicit, or more likely to include information about what type of pornography they were viewing? Would conversations about pornographic genres in detail serve as an indicator of a man's sexual preference, or indeed his prowess, to women? Carly suggested that in group environments, men were more likely to speak about pornography, but women would be less likely to join in in their presence:

I would say in general it's not something that's easy to talk about... I think with females it's a lot less - say if I was in a group of males and females and males were talking about pornography - I think it would be less common for females to be like 'yeah I watch pornography too'. I think if you were in a group of females it would be an easier space for females to talk about it. Whereas I think men would talk about it. I feel like they would be more comfortable talking about it in both settings. - Carly

The idea that women may not want to join in a conversation with men is likely related to the gendered nature of pornography viewing. As mentioned at the beginning of this section, women viewing pornography run the risk of being assumed to be interested in a particular type of sex, or being judged for their pornography preferences, therefore bringing a set of consequences that transcend pornography and impact their offline sexual lives (Farvid et al., 2017; Lamb, 2010). The reality of being 'slut-shamed' for engaging with pornography remains a real issue for women, which could also contribute to the silence around women's pornography consumption. Slut-shaming disproportionately affects women and girls, acting as a form of social control which discredits people by associating them with perceived sexual indecencies or deviancies based on the social norms in a particular context or space (Sweeney, 2017).

The idea that women's consumption of pornography comes with a set of double standards was a real issue for Jasmine. Jasmine frequently engaged with a range of pornographic categories, and at the time of interview, she had a keen interest in rougher pornography such as gangbangs. Jasmine's interest in pornography, particularly gangbangs, came with a set of concerns if this interest were to be 'outed' to men: "they would assume things about you I feel. Like if you're a girl that watches porn... It makes you a little bit hesitant to talk about it especially around boys your age and girls your age." Interestingly, Jasmine also suggested that she would be hesitant to talk about the pornography that she viewed in front of girls her age as well, suggesting that speaking about pornography with other women runs the risk of experiencing judgment from this 
quarter as well. At the same time, Jasmine desired to speak with other women about pornography and how it affected their sex lives:

I can't really talk about porn with girls so I have no idea what other girls think about porn, like whether it affects their sex lives. I have no idea. I'm just going off what I know... I'd love to be able to have that conversation with girls because I don't think it's something people should be shy about. - Jasmine

Carly, too, felt that conversations with women would be an opportunity to lift the stigma associated with pornography and confirm that viewing pornography is not a 'deviant' activity:

I know that lots of my friends probably would feel uncomfortable about talking about it but I don't know if they even want to. But then I dunno, I feel like maybe, like surely, you would wanna feel like you're doing something that isn't deviant. - Carly

Tara acknowledged that speaking with women about pornography can be "very stigmatised" as there are a lot of girls who "don't really like porn." Tara recounted that she had "come across some girlfriends aren't comfortable watching porn and it's like 'fuck I like porn!' and they're like 'urgh.'” Feeling judged for viewing pornography was also reported by Jasmine. Upon arriving at her university accommodation, Jasmine quickly realise that access to pornography was blocked on the communal internet. She recalled feeling as if other women seemed not to care for, or about, pornography, which in turn made it difficult to talk about. Jasmine took part in this study because she questioned why conversations about pornography were okay for men to partake in but not for women:

I saw [the recruitment flyer] on the back of the toilet door and I was like that's really interesting... no one really likes to talk about it and I noticed that when we were talking about the fact that it's blocked in the halls. All of the girls were like urgh, like it matters, like to them. And I was thinking well girls watch porn too you know what I mean? And so I just wondered why it's so like taboo to talk about but boys openly talk about masturbation, porn, their interests... when the boys said oh porn's blocked in the halls they were all like [gasps]. I was hesitant to say anything... they were like 'oh it doesn't really matter to us'.

The idea that pornography did not really matter to women could signal women's lack of interest in pornography, but it could also signal their lack of desire to openly disclose their use of pornography in an environment where men are present. Upon reflecting on Jasmine's earlier concerns about assumptions being made about her sexuality as a result of her pornography preferences, it's no wonder women might be apprehensive about outing themselves as pornography viewers. The judgment that women face for viewing 
pornography seems to speak to their sexuality as a whole and is merely a replication of persistent sexual double standards in wider society.

Throughout this chapter, I have documented the ways that women experienced judgment related to their own use of pornography. However, I want to posit that women also experience a different type of judgment when it comes to pornography. Earlier, I presented men's perspectives on asking for help in online communities to combat their experiences of pornography addiction. However, two women spoke about their experiences in relationships with men who were self-identified pornography addicts, and they, too, described feeling judged for pornography use that was not their own, but their partners. Their experiences will be elaborated on below and in Chapter Eight. However, their concerns about being judged for their partner's use of pornography suggest that women's sexuality is again on the agenda for assessment and critique.

\section{A different kind of judgment: women experiencing blame for their partner's abuse of pornography}

Two of the women in this research opted to take part because they wanted to speak about how their partner's use of pornography had affected them and their relationship. Izzy and her partner were engaged when she discovered her partner's use of pornography and telephone commercial sex services. Izzy's partner was using pornography "pretty much every single day and paying for services". His use resulted in financial concerns as he spent more than $\$ 1500$ on such services over a three-month period. Izzy struggled with "secretive nature" and the "deceit" involved with her partner's use of pornography, and described the whole experience as "really horrible, long, drawn out, [and] disgusting." Izzy felt there was little space to speak about what she was experiencing in her relationship, describing pornography addiction as a "sensitive topic" which meant she "didn't really feel comfortable talking to my friends about it." She also indicated that pornography addiction was somewhat salacious, as 'it seems like something you'd hear about someone else's boyfriend or whatever? Like 'oh did you hear that so and so is addicted to porn?' It's still quite like taboo so it's quite scandalous."

Rach felt completely helpless when it came to her partner's use of pornography. In discovering her partner's pornography addiction, Rach commented that she would "come home from work, find things like soiled items of clothing and handtowels" and there "was a pattern to how he treated me before and after" viewing pornography. Rach became 
worried that her daughter would discover her partner's use of pornography, and his use of pornography had contributed to their relationship ending multiple times. She described her partner's use of pornography as a cycle of relapse, where sometimes her partner was able to abstain, and she felt that "'oh I really can trust him' or 'this will get better'. And then the relapse is worse, gets worse every time, the feeling of it. It's like it just cuts open what you're trying to heal." She had "lived a whole year without telling anyone" despite feeling like it ruled her life. Rach chose not to tell people in the first instance as she was unsure if people would understand her situation and what she was going through. As previously discussed in Chapter Two, levels of pornography consumption are at an all-time high, with record levels of pornography usage on tube sites such as Pornhub. Further, research suggests that some women believe that it is their role to please their partner sexually, which includes accepting his use of pornography, or engaging with it as a couple (Benjamin \& Tlusten, 2010; Parvez, 2006). Rach was acutely aware that "many of my friends watch [pornography] with their partners", so presenting a negative perspective on pornography was challenging. When Rach confided in her friends with what she was dealing with at home, it was met with an "oh it's just this, just accept it" response, which meant her relationships suffered as she was not seen to be 'sorting' out her partner's problem:

I had one friend say look you've either got to sort out this problem before we can continue to be friends... I didn't know how to sort it out because I wasn't getting, no one was even trying to understand, trying to listen to how I felt. And because her and her partner don't have a problem with it, I realised that she was never really gonna fully understand. - Rach

Ultimately, Rach felt blamed for her partner's pornography addiction, and this blame meant that she was somehow responsible for helping her partner overcome it. However, this blame was not experienced from just friends. Rach noted that her family were also unsupportive when they found out what she was going through:

I mean you can't go to your Mum and say 'hey look I'm having trouble with him because he's doing this.' My sister doesn't see a problem with it, and these are all really important people to me. So then I was questioning how important am I to them? - Rach

Rach felt surprised that her Mum was unsupportive when she found out third-hand about what she was experiencing. Her Mum suggested that she should make more effort in the relationship in order to make it work: 
[Mum said] maybe it is you, maybe you need to lose weight, maybe you need to do yourself up a bit and be more attractive, maybe you shouldn't talk that way. You know? And it's like I'm going through enough emotions here that I don't need you to blame me for someone else's problem. And I didn't want her knowing in the first place, knowing that that would be her reaction... her and my Nan don't want me to leave him. That I should just put up with it. - Rach

Rach felt like she could not win against her partner's pornography addiction, and her Mum continually reminding her about it amplified her distress:

She makes comments like 'oh I made your bed today and I found [a dirtied garment he had ejaculated on] stuffed down the side of the drawers.' I didn't know it was there but can you just wash it and not tell me? I've got enough on my plate... I can't win... I'm probably one of the loneliest people I know because no one really wants to help me. - Rach

Izzy also recognised that women were judged for men's experiences of pornography addiction. She referred to the media coverage of New Zealand Olympian Nick Willis's public disclosure of pornography addiction, ${ }^{18}$ and how the online commentary centred on his wife and the part she played in helping him overcome his addiction to pornography:

Izzy that's why I really wanted to participate as well cos I just thought like people need to talk about it more cos no one's ever gonna know... There's so much judgment around it as well. I can't remember who it was but like some - was it like a sportsman or something in NZ - who had a porn addiction?... It was really weird like it got involved with his wife and stuff and I feel like there was quite a few judgments made around it. I think people don't really take it seriously as well. They're like oh, you can't stop looking at porn. You know people view it as like really weak.

Sam I think it's kind of joked about as well.

Izzy Yeah, yeah, yeah. Oh like his wife found him looking at porn, like for fuck's sakes, who doesn't look at porn haha?

In speaking to the extent that men's pornography addiction can go to, both Rach and Izzy commented that their partner's use had profound impacts on their intimate relationships, which will be discussed in more depth in Chapter Eight. However, the impacts that both women experienced in their relationships encouraged both to seek support from professionals. Rach and her partner had tried counselling, but she felt it failed to help her partner understand the impacts she was experiencing:

18 In 2016, New Zealand Olympian Nick Willis publicly disclosed his battle with pornography addiction which was extensively covered by New Zealand media outlets. Further information about his story can be found at https://www.nzherald.co.nz/sport/news/article.cfm?c id=4\&objectid=11600782 
We've tried counselling... We went to an addiction counsellor but he specialised in gambling. So he couldn't like understand my feelings towards it... I even said to him when I kicked him out one time, read The Love Languages ${ }^{19}$ book and find out more about me and then you might understand why this is affecting me so much. - Rach

Rach also acknowledged that accessing help was limited by financial constraints, and that there was a lack of specific support for her as a partner, despite feeling like she was the one experiencing the majority of issues:

I'm the only one trying to get help through counselling and stuff and that's why it's getting expensive because the funding is only really for someone with the problem, not the person dealing with the person with the problem. - Rach

Izzy's experience with counselling seemed more positive, and she highlights in this excerpt how she expected that her experience would be unique which speaks to the silence associated with speaking about pornography addiction for partners:

It was good to have someone to talk about it with that I knew couldn't pass information along. And also someone like a bit older I guess as well, to have like a different sort of perspective about it... I thought they would be really shocked but obviously I didn't think about everything that they hear every day. So they were just like oh yeah. Like I even had this phone counselling session with this like really sort of elderly sounding lady and she was just like oh yeah, that's pretty common. I was like oh okay! [laughs]. I know that's really bad when you judge someone on their age but you kind of think they're going to be more shocked about it [laughs]. How bad is that?

Alongside attending counselling, Izzy pointed to the assistance that the online community No Fap provided in gaining information about pornography addiction, however she noted that there were not many resources on there for women as partners:

It's just lucky that there are places like No Fap now because like imagine it, you'd feel so alone if you didn't know what was happening or whatever... There were women on the discussion boards and stuff but there wasn't many resources for women on there I suppose. - Izzy

No Fap proved an invaluable resource for Izzy, and she noted that the resources and support available in that environment surpassed what the counsellor could provide outside of a sympathetic ear:

even like the counsellor didn't have as many resources as No Fap did. Especially like if someone, like if a counsellor or something says oh well just don't look at it, if you don't have that confirmation from people who have actually been through

19 The Five Love Languages: The Secret to Love That Lasts by Gary Chapman is a book about how to stay in love. It is a Number One New York Times Bestseller, has multiple editions and is celebrating its $25^{\text {th }}$ anniversary. Data taken from https://www.amazon.com/Love-Languages-Secret-thatLasts/dp/080241270X 
it themselves it's really difficult to imagine how that's going to help, what that's going to do, how you're going to get through that. - Izzy

In this extract, Izzy identifies the lack of support available to women who are in relationships with men experiencing pornography addiction. Given the profound impacts that women can experience as a result of their partner's pornography addiction, it is questionable why resources and support services are not more accessible in this space. Throughout this chapter, however, I have explored the way that the stigma of pornography has stifled the possibility for conversation about pornography for both men and women. In this sense, then, it's unsurprising that support services are not available for a 'problem' which is barely acknowledged or discussed in wider society, despite its pervasive presence in the online realm.

\section{Summary}

This chapter has discussed the difficulty involved in talking about pornography in the digital age. Despite its pervasive presence online and the saturation of society with sex more generally, both men and women included in this research spoke of the difficulties associated with having open and honest conversations about pornography because they remained shrouded in stigma. The stigma afforded to pornography was decidedly gendered in these perspectives, whereby women suggested that it was somewhat appropriate or expected that men talk about pornography, but much less acceptable for women to be open or frank about their pornography viewing. Surprisingly, however, several men suggested that they, too, struggled to speak about pornography because of the stigma associated with the subject, and their conversations were perhaps less about their preferences and more about pornography as a normal thing.

Several men also spoke about their experiences of pornography addiction, and it seemed that men felt it was possible to speak openly and freely about pornography addiction in online communities such as No Fap. However, women's perspectives on being in a relationship with a male partner who was addicted to pornography suggest that pornography addiction is a gendered experience, whereby women feel a lack of support in this space, which exacerbates the difficulty in speaking about what is occurring in their intimate relationships. Ultimately, then, the stigma of pornography continues to limit the possibilities for open and honest conversations about pornography for heterosexual emerging adults in New Zealand. 
Given the difficulties involved in talking about pornography, the following chapters are a refreshing insight into the realities of pornography in 2019. In Chapters Six through Eight, I present men's and women's individual perspectives on pornography and demonstrate the complex, nuanced ways that pornography is experienced across gendered lines. 


\section{Chapter Six: Women and pornography: navigating roughness and aggression in sexually explicit material}

As previously discussed in Chapter Two, the feminist critique of pornography rests on the premise that pornography as a genre is inherently degrading, dehumanising, and misogynistic. Fundamentally, the "critical feminist analysis demonstrates that pornography is not just "sex on film," but sex routinely presented within a domination/subordination dynamic" (Jensen, 2016, p. 2). Further, feminist concerns are inextricably bound to representations of aggression in sexually explicit material. As previously mentioned in both Chapters Two and Four, aggression in pornography has been identified as a cornerstone of contemporary, mainstream material. Aggression came through as a key them with participants, but discussions about aggression in pornography were gendered and complicated. Women expressed an interest in rough sex, but their understandings of rough sex and its suitability were fundamentally rooted in consent. Further, their engagement with pornography was described as a constantly navigated nexus of pleasure and pain, whereby women straddled opposing realities - as women, and as pornography viewers. This chapter critically evaluates women's interpretations and understandings of pornography and is followed by a chapter dedicated to men's experiences.

\section{What women see: encountering aggression in mainstream pornography}

In Chapter Four, a number of women described much mainstream pornography as for the male gaze. Of course, the primary audience of pornography remains male, but women are increasingly engaging with internet pornography (Smith et al., 2015), but their perspectives remain neglected in academic literature (Ashton et al., 2017; Attwood, 2005; Boynton, 1999; Ciclitira, 2004; Gurevich et al., 2017; Parvez, 2006). This chapter builds on this sparse literature platform and provides an in-depth insight into the ways that a group of heterosexual New Zealand women understood and experienced pornographic material.

Women in this research recognised the degradation, roughness and aggression in mainstream pornography. They spoke about aggression in pornography rather matterof-factly, signalling its normative fixture in mainstream content. Tara felt that "regular porn" tended to be "borderline violent," "forceful," and "derogatory." Holly, too, recognised 
the objectification and degradation of women in pornography, pointing to this being regular rather than exceptional:

But I just hate the really zoomed in fucking gross porn. Like Penthouse and shit and it's just like a pussy, like a two-page spread of a pussy, I'm like fucking Jesus that's confronting! Oh my god! [laughs]... And that's coming from someone that likes girls and likes pussy but it's like woah... I like boudoir photo shoots and really like to me that's just - now I've got the image of it in my head! To me it's just degrading chicks literally just to their vagina, so I'm like woah... I see that stuff as degrading. Yeah I would never be like 'oh yeah 'and open up a page of like a fucking like a dick, two page dick [laughs] and be like 'yeah that's what I want!' what the fuck! - Holly

In this excerpt, Holly identifies men as the intended audience of pornography and the instrumentalisation and objectification of women's bodies invokes a clear image of men's pleasure as a priority. Miranda agreed, stating that "most of the porn out there is pretty misogynistic... it's not about consent, it's not about equal pleasure. It's about look I have an erection, you have a pussy, we have to do it [laughs]." The suggestion that men having erections and women having vaginas means that penetrative intercourse is a 'must do' speaks to the replication of the 'coital imperative' in pornography, as previously discussed in Chapter Four. The reinforcement of the coital imperative in pornography meant Miranda only recently realised that "just because a man has an erection doesn't mean he's aroused." Further, the lack of equal pleasure referred to in the previous extract suggests that men are in complete control of the sexual activity in mainstream material. By saying "it's not about consent" and "I have an erection, you have a pussy," men are positioned as the ones directing the sexual activity, therefore the sexual subjects, and the woman is the passive receiver of heterosex because of his erection. This reflection sits neatly within the radical feminist critique of pornography which argues that "while both men and women are portrayed as hypersexual, men typically are the sexual subjects who control the action and dictate the terms of the sex. Women are the sexual objects that fulfil male desire" (Jensen, 2016, p. 2).

As previously discussed in Chapter Two, Dines (2006) contends that mainstream pornographic videos routinely label women as "cum buckets", "sluts" and "cunts" (p. 286), cementing derogatory and verbally aggressive language toward women as a foundation of mainstream pornography (Tyler, 2010). Carly suggested that "with heterosexual pornography, I feel like there's dirty talking and a lot of like derogatory speak to women" which "you'd hope it's just portrayal in it." The hope that such depictions were 
merely portrayal suggests that there is a concern that such abusive vernacular could have real effects, intent and meaning behind them. Of course, these depictions in pornography could be theorised as a portrayal, but they are also the documented evidence of such activity happening involving human actors, and the difficulty involved in deciphering fantasy from reality was a real issue for Holly. Holly had a strong aversion to aggressive or demeaning pornography, stating that she "fucking hate[s] really aggressive, really aggressive porn. Real demeaning, aggressive porn towards women." Part of her aversion related to an uncertainty about whether such behaviours were actualised, as she said that "yeah it could be fake but it could be real."

Both Carly and Holly's concerns about deciphering the difference between real-life depictions of abuse toward women were a common thread in conversations with other women in this research, however, it became a more complicated discussion when it came to 'rough' material. In the following section, I present women's perspectives on delineating the differences between roughness and violence in pornography, and how these interpretations posit an alternative way of thinking about what counts as 'aggression' in sexually explicit material.

\section{The 'right' kind of rough? Understanding 'rough' sex in pornography}

As previously discussed, much research about pornography is concerned with representations of aggression, particularly targeted acts of violence towards women. Women rarely used the word 'aggression' to describe acts or behaviours in mainstream pornography. On the contrary, a number of women spoke of 'rough' sex, and how this had some sexual appeal or interest. However, their understandings of what counted as 'rough' sex were complicated and subjective. 'Rough' sex was conceptualised as something that could, in some circumstances, be sexy, but also had the potential to cross the line into 'violent' territory, thereby losing its sexy label. At the same time, women's understandings of rough sex in pornography were tied to consensual representations, and their offline sexual experiences inevitably influenced how they understood what they were viewing. This chapter now turns to an analysis of women's interpretations of 'rough' sex in erotic material.

As clearly discussed in both this chapter and in Chapter Four, women frequently lamented the degrading and demeaning nature of much mainstream pornography. This presented as a challenge for women engaging with pornography, which could be 
simultaneously arousing but also disturbing or concerning. Alongside these discussions, however, several women spoke about 'rough' sex being a type of sexual activity that they were interested in, engaged in, or had considered experimenting with. This was not always a necessity, nor was it always a preference, but the notion of 'rough' sex having sexual appeal was an intriguing aspect of my conversations with a number of the women.

Recent Pornhub Insights data suggests that female viewers are increasingly engaging with 'rough' sex categories in pornography, especially women under the age of 30. Figure 4 depicts Pornhub's assertion that young women are $63 \%$ more likely to view rough sex categories than men:

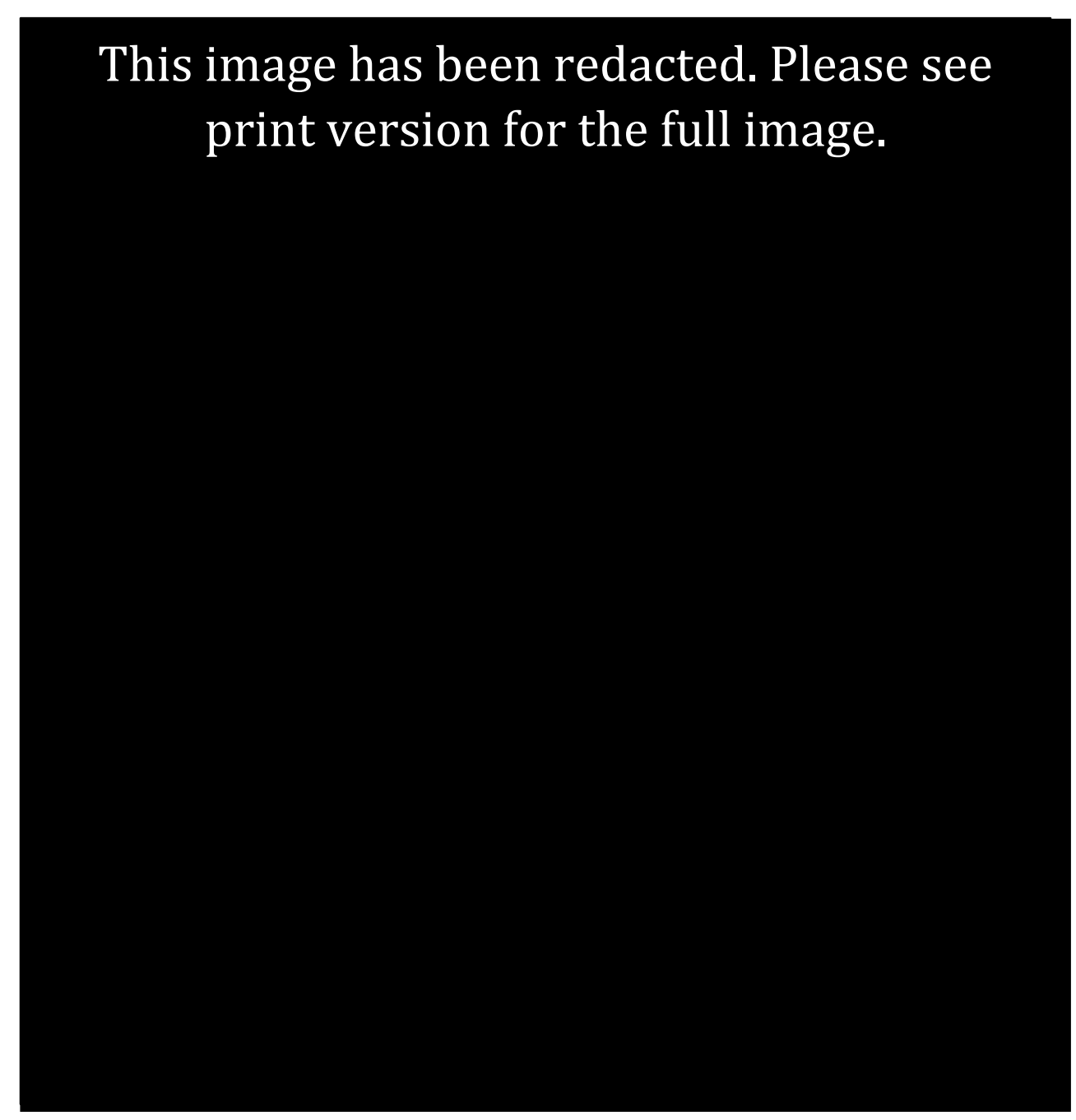

Figure 3: Image taken from 2018 Pornhub Insights data, accessible from https://www.pornhub.com/insights/extremecategories

It is important to clarify that a comprehensive breakdown of how Pornhub gathers its data is not easily obtained. During the course of this research, I asked Pornhub for more information on how this data was gathered and/or analysed, but this request did not gain 
any traction. This makes it difficult to provide a meaningful analysis of these figures - and in fact, it's difficult to even break down exactly what Pornhub means when they claim women are watching 'rough' sex in pornography. It could be argued that Pornhub has presented this data as evidence as to why some (or perhaps much) pornography on its website routinely presents aggressive behaviour. By the same token, however, questions can and should be raised about what women mean when they talk about the appeal of 'rough sex', the origins of this interest, and whether 'rough' sex understandings mirror the depiction of rough sex in pornography.

\section{Conceptualising rough sex}

Whilst discussions about aggression and/or violence in pornography surfaced in many of the interviews with women for this research, and women importantly denounced these representations and often had a strong aversion to such content, a total of five women discussed instances where they might engage in rough sex in their offline sexual encounters, or where it had the potential to be arousing or enjoyable. These discussions were individualised and complicated, and a simple reading of 'women enjoy rough sex' is an inaccurate statement or representation of a) what the women interviewed enjoyed in their sexual encounters and b) what they considered within the realm of 'rough' sex. As the following accounts and narratives demonstrate, many of these discussions were fundamentally rooted in notions of consensual sex with respectful partners, with few of these discussions reading as a mirror image of the rough or aggressive sex presented in much mainstream pornography.

Lilith spoke of rough sex being something that she "would like", but it was important that rough sex was "never like too much". In speaking about rough sex, she commented that she "wouldn't mind" being slapped on the face during sex, and she knew of a friend whose boyfriend did similarly. Lilith felt that being slapped on the face "would work", but was uncertain whether her partner would feel comfortable doing this during sex. If he did, Lilith felt that it would feel "very much acted rather than say you just like do in the moment", indicating that rough sex feeling 'natural', and desired by both parties, was a key component of its appeal. Jasmine also expressed that she had a preference for "more rough and like interesting sex." In what counted as less interesting sexual interactions, Jasmine reflected on a recent encounter with a new sexual partner: 
I had sex with this guy who's like super nice like two weeks ago. And I was in a relationship for like nearly a year before I came [to university] but I broke up with him before I came. The sex with the most recent guy was so different to the sex I was having with my ex-boyfriend and it makes you think about what people's different ideas of sex are. Cos like I really enjoyed the sex I had with my ex-boyfriend but then the sex I had with this guy I was like is this what other sex is gonna be like? His sex was like really like gentle and like kind of boring if I'm honest...it was just like missionary, he lasted like 4 minutes or something. Whereas the sex that I was having with my ex was like an hour you know? I was like oh no, I kind of liked him then I was like, I feel like sex does play a big part in relationships because you have to be sexually attracted to a person to be with them. It's like nice guy - bad sex. Probably deal breaker for me, probably wouldn't go there. My ex, not-so-nice guy, still a good friend but like enjoyable sex and you're sexually attracted to them. - Jasmine

Jasmine's identification of her recent sexual partner's sex as "gentle" and "boring" was directly related to her knowledge and understanding of the type of sex that was displayed in pornography and how it had influenced her expectations of sex:

I would say it's affected my taste in sex... pretty bluntly I like to change up positions, I like the guy to be like - I say forceful, but like forceful because I like it and I ask them and if I said 'oh no I don't like that' he'd stop kind of thing. And like sex is fun but you wanna be having sex with someone that also understands that, like my ex understood that. - Jasmine

Importantly, however, Jasmine clarifies that her enjoyment of more rough or intense sex with her sexual partners is fundamentally underpinned by her having a degree of agency or control over the interaction. The ability to say 'no' and have this heard and respected by her sexual partner was pivotal in her enjoyment of 'rough' sexual play. In considering this type of sex as 'rough', it seems that such encounters may perhaps be dissimilar to what is portrayed in 'rough' or aggressive pornography. In Jasmine's description, it presents as quite a different reading of the word 'rough' - rough relates to interesting, changeable, consensual sexual encounters that she feels she has some control over. In comparison, rough sex in pornography is often presented with men in control of the encounter and women's no's are rarely verbalised (Bridges et al., 2010).

Nadia also described a particular interest in 'rough' sex in her offline sexual relationships, as well as in the pornography that she viewed. Nadia said that she was really into "choking, I really like name calling, dirty talking, being spat on, like really hard, rough pounding, slapping." As previously discussed, these behaviours are routinely included in definitions of aggression in pornography, but Nadia noted that these behaviours were better understood as "very rough" or "very hardcore" material. At the same time, Nadia 
acknowledged that defining what counted as 'rough' pornography was not simple or clear cut:

When I try to articulate what is rough porn, it's difficult because I literally will just type in search words and then click on a box that I like. And if I don't like it, I exit out and I find another one until I like something. And I know that's how most people look at porn. - Nadia

Despite the difficulties involved in characterising rough pornography, Nadia felt some behaviours, like "choking" and "role-play or like sleeping porn,"20 were types of pornography she considered under the rubric of "very rough" pornography. Further, she felt rough pornography was characterised as:

Very fast, definitely very hard. You hear slamming noises. She's being very loud. Make up is running, stuff like that. So it would set up a scene like, I don't know, James Deen and Stoya. ${ }^{21}$ They're starting all smooch cheesy scene or whatever, then they go to like kiss or whatever and then like rip off her clothes and everything. A lot of energy. A lot more higher energy. - Nadia

In this description, Nadia refers to rough sex in pornography being related to intense, high energy sexual encounters between the parties. Importantly, however, she does not describe rough sex as being degrading or full of aggressive behaviours, as are routinely identified in analyses of mainstream pornographic content (Bridges et al., 2010; Sun et al., 2008).

For a number of women in this research, roughness in pornography was seen as acceptable when it was underpinned by a feeling of desire and consent. Lilith neatly summed this up, saying that the "right kind of rough sex" was enjoyable:

I think I have a preference, like I'm like 'oh yeah, rough sex' and I've looked up BDSM I think as well. And then I'd watch it and I'd be like 'ohhh, I don't think I'm into this'... like rough sex, it has to be like the right kind of rough sex. Cos sometimes it would be like quite like rapey, you know?... I guess like if it's the way the woman might be acting. Like it might not seem like, the desire isn't there. Or the man is like too aggressive. - Lilith

Tina felt 'rough' sex required an element of romance or care to make it enjoyable:

\footnotetext{
${ }^{20}$ Sleeping pornography is a genre of pornography where one party is usually asleep before the sex starts, and sometimes remains asleep for the duration of the interaction.

21 James Deen and Stoya were both high-profile pornography performers. In 2015, Stoya tweeted that James Deen had raped her. Stoya's disclosure was followed by multiple other accusations by other actresses. Further information can be found at https://www.theguardian.com/culture/2015/dec/04/how-stoya-took-on-james-deen-and-broke-the-
} porn-industrys-silence 
Like sometimes you know you like to have a bit of rough sex and have fun. But I'd only do that with someone I actually loved and trusted and I'd give them a cuddle afterwards you know, go to sleep. So it's still got that nice side to it. - Tina

Holly spoke similarly, suggesting that rough sex was bound with lust, pleasure and desire. It was "hard fucking, like doggy style and stuff like that. Like the "oh my god I need you now" kinda fucking." Nadia proposed a tripartite view of roughness, whereby there could be "rough passionate sex", "rough fucking" and "violent fucking". Rough passionate sex was intense, with a deeper emotional connection:

I would say rough sex is where it is more intense and deep and there's more of a connection with the person with your minds ... but at the same time it's more rough, therefore creating more intensity and more intense orgasms. Feels really dirty, it's great. But at the same time it feels right because it's with that person right? So there's like romance tied into it... Like rough, passionate sex, we made a lot of eye contact, I remember it. - Nadia

Rough fucking, however, was:

Coming back at 1 in the morning from a concert and you just had a really great time with this guy and whatnot. He makes you laugh the entire night, you're feeling a bit horny. So what I did is like we got back from a concert, went to his bedroom and I straight around fucking slapped him. And he knew that means like 'fuck me!'... rough fucking, it was pretty much just doggy-style. So there's a loss of a connection but at the same time it's still really, really great. - Nadia

Through these excerpts, it is clear that women conceptualise and understand rough sex differently and subjectively. However, what came through in a number of these accounts was that rough sex had the potential to be enjoyable and pleasurable when it occurred within the confines of a respectful, consensual, sexual relationship. Fundamentally, lust, desire and pleasure were an embedded part of how rough sex was substantiated as 'acceptable'. From an outsider's perspective, it appears that these women's narratives suggest that 'rough' sex or 'rough' pornography is more about intensity, desire and pleasure than about specific behaviours, and the relationship between the parties is a crucial platform for considering its acceptability. As a number of these women have suggested, care, consent and being listened to were key operatives in their understandings of what constituted rough sex and whether it would be a pleasurable experience.

As well as this focus on intensity and care, consent was critical for women when they deciphered what depicted rough sex in pornography, and what depicted violence against women. Jasmine had a preference for viewing gangbang style pornography and felt that 
the men in this type of pornography were "forceful" and "literally just like take turns using her body." However, if women were enjoying - and consenting - to what was being engaged in, this meant that the depiction was acceptable:

If the girl is enjoying it and that's what she likes, I feel like that that's rough. Whereas violent is more like they're not consenting to what's happening or you know they're making her do things that she doesn't want to do you know? Jasmine

Tina, too, felt that violent sex was where women did not look like they were enjoying what was happening in the scene and it was a "one-sided act":

I think in my head I'll say rough I guess is when it's consensually rough but you know that if it was too rough or anything you could be like hey chill out, that hurt or something and it would be respected. There's that trust element in there. But when it's violent it's almost like is it consensual or how is she enjoying that at all? It doesn't look like she's enjoying any part of this and it's a very one-sided act... But it's hard to define. - Tina

Pornography often presents women responding positively or ambivalently to receiving targeted acts of aggression, and women's refusals or displeasure to aggression are uncommon (Bridges et al., 2010, p. 1077). Further, Jensen (2016) argues that pornography depicts women as sexually insatiable and that they "like all the sexual acts that men perform or demand" (p. 2). In discussions with women, they rarely spoke of women in pornography saying 'no' or negotiating consent, but Jasmine felt that some pornography instructed women to 'act' like they were not enjoying what was occurring in pornography:

I'm sure there's like actual porn videos that are not acting. Oh well like some girls obviously get told to act and say, pretend that they don't like it as well. That's another thing which is where the line's kind of like blurred because some of its acting. Sure a lot of porn isn't acting, like you were saying child porn and stuff, I can't even believe that's a thing. Urgh. It's just like porn is supposed to be acting, supposed to just let people kind of enjoy their fantasies or whatever. - Jasmine

At the same time, Jasmine felt that you could 'tell' whether a woman was enjoying what was happening in pornography, especially when they might be presenting as if they were dissociating. Dissociation refers to a psychological process - often related to experiences of trauma, although not exclusively - whereby people 'dissociate' from their experiences through a reduced or altered level of consciousness (Bird, Seehuus, Clifton, \& Relline, 2014). This can manifest in a multitude of ways, such as dissociating from the experience entirely, or through dissociation occurring in-the-moment (Stappenbeck et al., 2016). Jasmine suggested that: 
You'd be able to tell by her body language, the things she's saying, like obviously if someone didn't like it they wouldn't want to be there so they'd probably be like trying to just put their brain somewhere else you know?

Other women also felt that identifying what might count as violent sex was an easier task than defining what would count as rough, suggesting that rough sex is perhaps a bit of a grey area and relates to subjective interpretations and nuances in their understandings of how sex should be. In describing what types of behaviours might be present in violent sexual representations, both Holly and Nadia provided clear accounts. Their acknowledgement of such material indicates that searching for pornography can be a risky venture for women, which has been reported elsewhere (Chadwick et al., 2018; Chowkhani, 2016). Holly considered violent pornography equated to torture on screen:

I do like rough sex and rough porn but not like you know like torturey over here violent kind of what the fuck kind of stuff... when it's like 10 guys and she's strapped down and like gagging and tears and fucking like mascara flowing and yeah. That shit just, I hate it. - Holly

Further, she noted that rough oral sex in pornography was not something that was pleasurable, as it is "not my idea of hot seeing like a chick crying and gagging and vomiting and [laughs]... just really rough kinda. It's just urgh." Rough oral sex also featured in Nadia's description of pornography which crossed the line between rough and violent. She identified elements of male domination and women's suffering as moving into violent territory:

Too rough. Okay. I don't like face-fucking or like - this is so once again, just my opinion - I guess things that I feel like the woman doesn't actually enjoy. But then again saying that, it's something that I know I don't enjoy. Like I don't like Asa Akira's scenes cos of all the times she'll do like rough anal where it'll be like two dicks in her ass, two dicks in her butt... I'm like I don't think it'd feel good, two dicks in the butt. Like that's surely just the visual. Or show her like covered in like cum or whatever, they'll be pulling her hair and they'll like slap her like really, really hard and like throat fuck her and stuff like that. And I'm like 'it's starting to be too much, there's too much going on' and whatnot. So like there's no way she's actually enjoying it, it's just that this is her job. Then again, there are some girls that may actually enjoy that. So too rough I would say is yeah, what I would not be into... violent is just like yeah, a guy just turning round face-fucking you. Nadia

Nadia is careful to point out that whilst viewing women being throat fucked and covered in semen was not a pleasure point for her, there may well be women who enjoy such representations. Such an acknowledgement speaks to the sex-positive mantra referred to in Chapter Three, whereby Wodda and Panfil (2018) envision a not 'yucking' of anyone's 
'yum' when it comes to consensual sexual interactions. Such a vision is undoubtedly situated within a notion of 'choice', whereby women's engagement with pornography which could be interpreted as demeaning or degrading - or by Nadia's definition 'too rough' - is not problematised because its mere existence presents it as an option for women to choose to engage with. As will be discussed in the next chapter, this perspective is closely associated with the way men understood the appropriateness of engaging with aggression in pornography for other men. Simultaneously, Nadia also suggested that consent between performers in pornography was implicit, particularly in professional pornography:

I guess in porn it just looks physically violent, but at the same time you know that it's consensual. I do think it kinda helps that said person is an actress. Or that said two people do scenes together and they're really good together. - Nadia

The idea that women consent to all behaviours experienced in pornography comes through in this excerpt. Szabo (2010) posits that

except perhaps in some of the most explicitly violent pornography, women portray women who consent to and enjoy their role in satisfying male sexual desires. The appearance of consent seems to let this pornography off the hook... pornography eroticises this patriarchal context, but gives it the air of legitimacy by showing it in a context of consent (p. 90).

Theoretically, then, consent is implicit in mainstream heterosexual pornography by the presence of a camera and its placement on places such as Pornhub. Purcell (2012) contends that the ethos of pornography is the way consent is implied in professional productions, making the possibility of sexual coercion or violence in pornography unfathomable due to contractual consent and payment. Whilst viewers might be uncertain about the conditions within which a production has been made, or have concerns about it being 'too rough,'

we have to let go and have faith that she agreed to it, even if we suspect that most women wouldn't. Mainstream pornography allows us to let go because we assume that legal maturity, contractual consent, and payment were all in play when the scene was shot. And we know that, for us, it's just a fantasy anyway (p. 2, emphasis in original)

Nadia pointed to James Deen and Stoya as two performers who did high intensity scenes together well, but as previously mentioned, James Deen has been accused of being sexually violent in pornography. These documented experiences of sexual abuse on set of which there could be many more - are undoubtedly still available online and still widely consumed. What does this mean for our understandings of consent in 
pornographic production? Does their mere existence - and because payment was presumably received - make these productions something we can just 'let go of'? Further, what sort of precedent does this set when we consider the influential role that pornography can play in the development of sexual scripts? If women in pornography are simply 'putting up with it', what does this tell viewers who are engaging with such material?

These questions are important to consider when we speak with people viewing mainstream pornography. If rough sex is desirable and routinely depicted in mainstream content, then interrogating the 'implicit' consent of performers is crucial. If pornography has the power to alter the development of sexual scripts, then the routine presentation of women consenting to any and all sexual acts in pornography - particularly rough sex runs the risk of suggesting that this is the type of sex and sexuality that should be engaged in.

I do not pretend to have the answers as to where some women's interest in rough sex comes from, and I certainly do not pretend to even 'know' what counts as rough sex from these accounts. Of course, it is completely possible that some women are interested in rough styles of sex purely because it is pleasurable and enjoyable to experience. For some of the women interviewed for this research, that was certainly the case. But it is also important to restate that women, on the whole, were averse to women being degraded in pornography, and experiencing violence at the hands of men, suggesting that consent is a fundamental consideration in negotiating and navigating the acceptability of 'rough' sexual play. That said, I suspect that some women's interest in rough types of sex could have origins in the new sexual expectations placed on women in the $21^{\text {st }}$ century, in conjunction with pornography operating as a powerful tool in shaping sexual expectations and understandings.

Harvey and Gill (2014) argue that in new, modernized versions of sex, women are "women are exhorted to become 'sexual entrepreneurs' able to present themselves as 'appropriately' desirable and desiring and willing to perform a number of practices previously associated with the sex industry... to keep their men happy and turned on" (p. 488). They argue that self-help genres provide a powerful educative tool for shaping women's understandings of how to have successful heterosexual relationships. Further to this, I would argue that pornography could play a key role in this shaping. If women 
learn from, and borrow, the practices previously associated with the sex industry, we need to explore women's direct - as well as indirect - engagement with mainstream pornography. As well as considering where the interest in rough sex might come from, interrogating exactly what 'rough' sex encapsulates is critically important for our understandings of what particular types of sex in pornography can mean, and be experienced by, the audience.

As this section has explored, all of the women who discussed rough sex as having some sexual appeal understood it as acceptable when it took place in the context of sexual relationships which respected women's communicative consent during sexual interactions. As much pornography does not display communicative consent in an easily decipherable way, it sets the scene for the development of a sexual script that eroticises rough sex without parameters for ongoing negotiation and communication. In essence, it runs the risk of scripting 'consent' as implicit, so the need for critical media literacy and reception skills which acknowledge the implicit consent in pornography is paramount.

\section{A fine line between pleasure and pain? Women's conflicted feelings about pornography}

Throughout this chapter, I have discussed the ways that women encountered and understood aggression in pornography, including 'rough' sex. I now wish to examine the complicated feelings many of the women held about pornography more generally, especially as consumers. Most of the women in this project viewed pornography and it functioned as a site of sexual arousal, sexual education, as well as a form of social entertainment. However, women's engagement with pornography was not without its pains, and this chapter now presents women's complicated engagements with pornography.

Parvez (2006) suggests that women's ability to experience pleasure from pornography "seem[s] to be regulated by whether women can relate to the porn actress... empathising with the porn actress and imagining oneself in her scenario is the mechanism by which the films evoke certain emotions, desires, or memories" (p. 617). If images of women are routinely presented as degraded or dehumanised, what does this mean for the types of emotions or desires it invokes? Gurevich et al. (2017) argue that women's enjoyment of pornography is a constantly revolving set of concerns set amidst potentially arousing depictions. They suggest that 
women's enjoyment of porn presents a set of (often) irreconcilable contradictions; while some images are pleasurably arousing, they can be simultaneously distressing or lead to engaging with other women's possible distress. Concerns about the treatment of female porn actors, the objectifying and/or unrealistic images of women, and questions about men's ability to discern reality and fantasy sex are central dilemmas (p. 568).

A number of women spoke about the concerns they had for women in pornography, as well as the concerns they had for themselves as the audience of pornography. This section now explores women's feelings about their pornography use and highlights the way that "porn's probable hazards are emphasized alongside its possible pleasures" (Gurevich et al., 2017, p. 568).

Recent recognition of women's engagement with pornography has highlighted their increasing size in pornography's audience, however it remains a distinctly gendered activity (Tarrant, 2016). Miranda acknowledged that her use of pornography had primarily been for masturbation, but she noted that the strong arousal invoked by pornography dictated that masturbation was necessary. She commented that pornography's only use was to induce arousal, because "if I turn porn on, then you definitely want to masturbate, why else would you watch it?" Miranda added that her decision to begin viewing pornography in adolescence was driven by cultural narratives that situated pornography as the vehicle for masturbation. She felt that watching pornography was something that "you were supposed to do [laughs]. That's the issue really, I was just following the script right? [laughs].

Carly held a similar view in that she was able to identify much of the degrading nature of pornography, but it still functioned as an outlet for sexual arousal and orgasm. She commented that "not that masturbation and pornography go hand-in-hand, but if I am and I watch pornography it will be more like a means to an end, as opposed to like an experience." Lilith felt that pornography created a different type of arousal to sex with a partner:

I think that's also why I watch porn. It's not much effort... It's so different from like sex. Like I don't associate it with sex at all. Like the different, sex with another person, is another thing. And the kind of arousal that you get seems different as well... I guess cos there's something to watch. And I find that when I'm masturbating, I don't really fantasise about stuff, it's very much about the sensation. But when you're like watching, you're also aroused in some way cos you're watching images of people having sex and it's just easier to come. - Lilith 
Nadia felt similarly, in that the arousal that pornography incited meant that pornography "just does the trick, I guess. It's not like I look to it for like inspiration or ideas." The idea that pornography achieves maximum results with minimum effort with regard to sexual stimulation has been reported in previous qualitative research with pornography users (McCormack \& Wignall, 2016; Smith et al., 2015). McCormack and Wignall (2016) contend that for participants in their sample, pornography was used "as a means of sexual gratification, corresponding with it being immediately and intrinsically rewarding, as well as relatively short-lived" (p. 982, emphasis in original). However, whilst pornography might have the potential to do the trick in achieving orgasm, this unfortunately came with a number of consequences for some of the women in this research which I now explore.

\section{The perils of porn}

Women's engagement with pornography is increasingly contested and has impacts on their enjoyment of pornography (Gurevich et al., 2017; Parvez, 2006). Some women's concerns about engaging with material that could be seen as degrading invokes worries about their complicities in other women's pain (Ciclitira, 2004). Research with other women suggests that encountering pornography with unwanted content can make searching for pornography a risky endeavour (Chadwick et al., 2018; Chowkhani, 2016). Carly reflected on her use of pornography and noted that if she was regularly engaging with sexually explicit material, it contributed to her feeling bad about her usage. Viewing pornography less frequently seemed to reconcile her feelings, however viewing pornography left her feeling a bit 'dirty':

If I am doing it like once a month, I don't feel shit around it. But I'll like close my computer and put everything back as it was and pretend like I've never done it to myself. So I don't want to be reminded. Like afterwards, it's that whole thing, that cliché of feeling a bit dirty. It's like I feel a little bit like it. Definitely. But it's not like I let that linger. - Carly

Miranda reported negative feelings about her use of pornography throughout her life. Whilst acknowledging that much of the treatment of women in pornography was problematic, Miranda continued to masturbate to such material which left her feeling depressed, particularly as she had difficulty stopping and had felt that her use of pornography had become a form of 'automatism':

It was more depressed in the sense that I didn't like how they were treating the woman. I was enjoying - like sexually enjoying - the porn in some way cos I was also masturbating at the same time. So it's kind of like programming myself in a 
way. And that just left me like why do I watch something as a woman where women are mistreated in my opinion? And that was the issue that I had with it. But then at the same time because I did that, because it was an automatism, it also was hard for me to stop as well. - Miranda

As will be discussed in the following chapter, Miranda's reflection on feeling addicted to pornography shares some of the similar themes that men shared around their experiences with pornography addiction and the difficulties they had in stopping viewing pornography.

Tara felt confused about the way pornography made her feel because of the way women were treated in its production. She enjoyed watching pornography, but she remained concerned about women in pornography and their experiences:

Like I said, the thing I quite like about sex - it's just how I feel - but I quite like the excitement of just sex as it is. And sometimes porn will just depict that. It's not about the context of a relationship, it's just like sex. And sometimes I like seeing that but not so much anymore since we've talked about like how I feel about women and how they're portrayed and stuff. In the context of those conversations, without like putting that aside, I do quite enjoy watching it. But when that whole woman being treated shit is put into it, it's kinda yeah. - Tara

Feeling guilty about watching pornography was a feminist conflict for Lilith, who relayed that viewing pornography invoked feelings of guilt because "it's like an institution - do you call it an institution - an area that I like disagree with the ideas it perpetuates about women." Carly's feminist roots contributed to her feeling confused and guilty about viewing pornography, leaving her feeling "hypocritical". These feelings of confusion or guilt about watching pornography being complicit in the exploitation of women have been previously reported. Ciclitira (2004) noted that women in her study encountered a dilemma reconciling their feminist values and ideals yet simultaneously enjoying pornography. In recent work with women, pornography was situated as instrumentally useful but simultaneously "not right" because of its degrading representations (Gurevich et al., 2017, p. 569), thereby sitting in conflict with some feminist ideas about pornographic representation.

Alongside these feelings of guilt and confusion, a number of the women spoke about the impact of being a woman who viewed pornography, particularly rough or violent pornographic material. This ranged from women reporting having 'flashbacks' to particularly disturbing material, right through to concerns about men's expectations of women's sexual behaviours if they were pornography viewers. Miranda spoke about the 
way that she felt that some images in pornography were the type that "stay with you." One of the clearest images she spoke of was the representation of deep throating or rough oral sex. As mentioned earlier in Chapter Two, depictions of women "gagging" on men's penises have become a mainstay of mainstream heterosexual representations (Bridges et al., 2010). A number of the women in this chapter vocalised their distaste for such representations in erotic material, and it was those very depictions that made Miranda question what she expected of herself as a sexual person. She commented that:

There's other images like where a woman is giving head and he pushes his penis so far back in that she has to vomit, things like that that just stay with you. And then so while you're giving head yourself, right, it's really hard because then for me it was what do I expect of it myself? What feels good for me? Do I actually like that or is it because I have seen it in porn? That's like a big thing.

The conversation with Miranda about images staying with you came about as she reflected on the way she experienced 'flashbacks' to pornographic images. These flashbacks created a sort of 'head cinema' for Miranda which were particularly distressing and intrusively permeated her offline sexual interactions:

Miranda I don't watch porn anymore to try and not get more images. Because I think it does something to my head. I think an aspect of it is mental health.

Sam And you mentioned that you had to stop one particular position because it felt like you were being raped or sexually abused?

Miranda Because I associated it with it.

Sam So is that from porn that you were so scared of that?

Miranda It was doggy style right? And I felt that in that position I had less control. And he didn't look at my face, I couldn't look at his face, and it used to be one of my favourite ones by the way, but because it wasn't face to face there was no communication. Somehow I had this head cinema in my head... images kept on going... that's something that I think is really scary about porn, that years after you've really watched it, it can still come back.

Miranda's experiences of 'head cinema' contributed to her gratefulness at never having seen extreme pornography such as snuff, as such violent depictions would be particularly traumatic to experience as flashbacks:

I never watched any snuff porn which I'm very, very, very, very, very grateful for. Because I think it would've done things to my mind. I think already what I've watched has done things. That's one thing, these images that you watch, they stay with me. The images, like even today when I'm not watching porn, I have specific porn scenes that are somehow linked to sexual arousal. So even if I would be masturbating, I sometimes have these flashbacks to porn. - Miranda 
Miranda's concerns about flashbacks to traumatic material demonstrate the power of pornography as a visual medium and the visceral viewing experience that pornography provides. The power of pornography to invoke flashbacks to distressing content may well also be a contributing factor to women's descriptions of viewing pornography as a 'risky' endeavour (Chadwick et al., 2018). But pornography did not just have the power to 'stay with you' like it did for Miranda, it also had the power to switch off Jasmine's moral compass and affect her judgment over what was happening in a pornographic scene. Jasmine felt that because she was aroused when she viewed pornography, it made whatever she was viewing in pornography seem normal and enjoyable:

The only time I watch porn is to masturbate. I don't know, what I've noticed is that when you're turned on and you're watching porn it's normal, it's like enjoyable, but then when you're not and you watch it, it seems kind of like disgusting. Or like there's a lot of porn out there and you think about how many girls and guys are in that industry. It's kind of like your morals when you're not turned on are there but when you are it's like a natural instinct to like switch it off or something. I don't know, I just noticed that and I was thinking that maybe that ties into like when guys sexually assault someone, maybe it just like switches off in their head or something? - Jasmine

She further alluded to pornography turning off her morals when it came to viewing gangbang pornography:

The type of porn that I watch isn't like accurate to what I want in real life. So I don't know why I'm attracted to it, and it's the total opposite of what I believe in, but I'm sexually aroused by it when I know it's like acting. So I like to watch like gangbang kind of porn where there's several guys and one girl. But, I would hate for that to happen in my real sex life or happen to anyone else like in the sense of like rape because I know that rape doesn't always happen with like one guy, one girl. Obviously sometimes it's like several guys, one girl. So I have no idea why I like watching that kind of porn but I feel like in porn I don't really associate the girl as being like a girl. You know? Like she's just like a actress which is what I'm saying is like potentially the issue with porn, because it does desensitise you to the fact. And you don't associate them with having like a life outside of it, it's just kind of like that video, them there, it's done, turn it off. Out of your life.

She felt that such pornography was attractive when she was aroused, but if she were to watch it in a non-aroused state it was repulsive:

Jasmine They literally just like take turns using her body. Which is like really gross to think about but for some reason I just switch that off in my head but if I were to sit down and just like watch it I'd be like urgh you know?

Sam So if you weren't turned on?

Jasmine I would never watch it. I think that's really odd like it makes you think about what porn is and how it affects your brain because it's almost like 
kind of like there must be some kind of chemical reaction in your brain that's kind of like a drug. You know how like you're in love, it's kind of like those chemicals go off, you can be a bit stupid, not be rational. Kind of the same thing with porn I feel because you can just desensitise yourself a little bit. Forget about what's potentially like really going on.

This idea of forgetting about what was really going on in the production of pornography was furthered when she spoke about the type of women involved in pornography, and that the realness of pornography only really hit home if she was in a non-aroused state:
I think it's more about the type of people that are in porn, not assuming that someone's who's educated and stuff wouldn't do porn, but I feel like the girls in porn are like dumbed down, made to be incredibly slutty and kind of objectified. Like in some senses in porn the guy can do what they want to them because the girls are getting paid and they're getting directed by someone to tell them that this is part of the deal, like you're in this, you've gotta do this. So yeah, like if you're not aroused I feel like the reality of porn is much more prominent whereas if you are turned on it's just enjoyable, you know? - Jasmine

Jasmine's concern that pornography had the power to turn off your morals shows the ways that pornography can simultaneously be hot but not. Further, it also highlights the ways that pornography could operate to sanitise viewer's understandings of what is presented.

This is an interesting point as a number of women were concerned about the influence of pornography on men's treatment of women, or the expectation of behaviours that women would accept in offline sexual relations, potentially signalling the way that the sexual scripts in pornography could work to turn off men's morals and judgements about appropriate sexual behaviours. Gurevich et al. (2017) note that women's fears about men's interpretations of pornography are an inevitable pain associated with the pleasures of pornography, and Tara spoke about this in the context of rough oral sex, where she was concerned that such behaviours could inevitably influence people's understandings of 'normal' sexual behaviour:

I found out that [rough oral] was like a whole category. I dunno like I read a couple of articles about it and I was like, this is fucking gross. Like lots of people, lots of guys are watching this you know? And then I tried to avoid it, so I didn't see that but then the way they were treating women was just consistent throughout all of it. And even though it's like the woman is scripted to enjoy it in a lot of it, it's just it worries me that that might translate to be normal for some people. - Tara

Jasmine also felt that the forceful nature of men in pornography could encourage men who were consuming such material, especially young boys, to think that all women 
should behave a certain way in pornography and would be happy with men acting forcefully or aggressively toward them:

I'd say a lot of the guys in porn are quite like - in let's just say the popular kind of porn videos - I'd say the guys are quite aggressive in a way, like they're very forceful. Which obviously isn't necessarily a bad thing but it assumes that that's how you can treat anyone. Like if you were a young boy like say 11 and you're watching porn and you're seeing this girl do anything the guy says, you're going to assume that maybe that's what it's like and if the girl didn't do that they'd be like oh. Or if they weren't behaving in a certain way during sex aka being loud or slutty, you know? - Jasmine

This concern about the treatment of women was realised for Jasmine and she talked about it in the interview in detail. Jasmine reflected on what it meant to be a woman who had an interest in rough sex, and how this transformed the way that some men - including ex-sexual partners, treated her. Jasmine felt that pornography had a desensitising effect on her early sexual initiation:

Like if it comes up I'll be like yeah I watch porn, yeah I do this. I feel like porn kind of desensitised me to this idea of like sex is a big thing. Like the girls that I know that haven't watched porn were all about their first time being like really special you know, with the one or whatever. Whereas I wanted my first time to just kind of be over and done with and I said to my friend that I'd been through school with but not like close friends, we just were both virgins and we were just talking about it and I was like we should just have sex because it didn't mean a lot to me. - Jasmine

Jasmine had sex with that friend from school at 15, and she recognised that there were real life consequences that came from her early involvement in sex and being an openly accepting woman when it came to pornography:

I mean a 15-year old guy that had sex is obviously going to be pretty stoked about it, he's gonna want his mates to know about it. And then that came with assumptions about me as well. And heaps of guys would like text me randomly and just be like oh hey and then I'd just be talking like normal and then it would come up. Even the other day in town, so I was 15 at the time, I'm 18 now, it's like three years ago I had sex with that guy. He's in Wellington as well and we're still friends. I bumped into one of his mates and I didn't recognise him but he's like oh you're Jasmine aye? I was like yeah. He goes 'oh you're that girl that fucked [name]'... I got really offended by that because I thought I trusted him... As much as sex is like great, porn's great, it does like come with real-life consequences like we were saying about the porn actresses. They might just enjoy sex, I mean sex is enjoyable, but being filmed, even being paid to have sex, I mean that sounds great to me! But like it comes with consequences.

For Jasmine, the consequences of being an openly sexual woman who views porn and enjoys rough sex also meant that she felt it gave her ex-partner licence to try coercing her 
into group sex:

He texted my friend who was staying with me and my family for New Years at a bach. He text her off my phone when I was in the bathroom asking her to come into our bed because he was always asking me for like threesomes and foursomes with people. And then he deleted it off my phone. Obviously my friend said to me the next day like 'oh Jasmine did you text me last night?' and I said 'no' and she goes 'oh well I got a text from you asking to come into your guy's bed'. I was thinking like sex with my ex ex-boyfriend was forceful but like intimate as well but then secretly behind my back he was always tryna kinda like convince me into doing stuff with other people and kind of using me in a way. That's when you think maybe I shouldn't be so open about like what you like or whatever because then he automatically assumed that since I was into more rough sex I would be into having sex with other people. I think he was just really into it, he wanted to have sex with two girls at once. But you don't use your girlfriend for that you know? Unless she brings it up and wants to. But you don't secretly text them behind their back. And then yet again like telling your friends about the kind of stuff we did in our sex life isn't okay because I had sex with you and trusted you, you can't go and tell people what I'm into you know, because then they assume things about me yet again. - Jasmine

Jasmine felt that her ex-partner probably watched threesome-style pornography and that this contributed to his feeling that he could treat her however he wanted and coerce her into group sexual interactions:

He probably watched kind of threesome porn and really wanted it but if I didn't want that, you can't assume that if my friend came into my bed and I'm drunk that it's gonna happen. Cos every time he tried to do that it was when we were drinking. And it's just like just because it happens in porn doesn't mean it's gonna happen in real life. Especially like I wasn't with him for sex, I was with him because I liked him... In some aspects I feel like porn - I dunno - convinces guys that it's okay to like treat a girl in a certain way. - Jasmine

Although Jasmine's voice here about the repercussions of being an open, sexually aware woman with an interest in rough sex is an individual one, similar experiences have been reported with adult women in rural Ohio about their violent experiences. DeKeseredy and Hall-Sanchez (2016) identified "introducing sexual partners" as a key theme and this was perceived by women to be related to their partner's pornography consumption. The authors noted that "some interviewees were forced to have group sex or sex with 'other people,' which is endemic to gonzo" (p. 839) and that one participant had reported her ex-partner using pornographic videos to "prime" her for sexual acts, such as threesomes, which were constantly depicted in mainstream heterosexual pornography. This use of pornographic videos as a primer for later sexual activity resonates in Jasmine's description here of her partner attempting to coerce her into threesome-style sex. In 
many ways, Jasmine sees her partner's use of pornography as setting a precedent for acceptable behaviour in an intimate relationship, and his imitation of what he viewed in pornography became something he felt reasonably able to expect of Jasmine in their relationship. This was inevitably influenced by the expectations that she felt he would have had about her:

Like if you're a girl that watches porn or you know even just talks about masturbation or something, I feel like they assume that maybe you're a bit of like a slut or you're keen for sex but I don't think that's necessarily true at all. Jasmine

She felt that this was not a dissimilar sentiment to the way that even her male friends would perceive her given the discussions she had had with them about pornography:

I have talked about it before with some of my friends, like guy mates, and they seem really shocked but in like a good way kind shocked. Like it suggests something about me. Like oh like you watch porn, what are you into kind of thing. And I think that that is asking like what kind of sex am I into, whether I would be appealing to their kind of sex interests and stuff. - Jasmine

She later spoke to wider sexual double standards that see women shunned for their sexual behaviours but men esteemed for their heterosexual conquests (Farvid \& Braun, 2016; Farvid et al., 2017; Kreager \& Staff, 2009). She likened this most clearly to her knowledge of Shannon Rose, a YouTuber who previously had a career in the pornography industry. She talked about Shannon's experiences of slut-shaming and abusive treatment from men because of her role in pornography:

Yup because they [men] get credit for it. Girls get kinda shunned for it. Like there's this girl on Youtube called Shannon Rose and she's an ex porn star and she had body image difficulties, depression, stuff like that. I feel like not all but many of the girls that are in porn maybe don't value themselves which comes back to the thing when you're not turned on, you look at it and you think you know is this really right? She talks really openly about porn but she's had like a history of quite abusive partners as well, because I think that since she's done porn or since she's a slut, they can treat her like a slut. You know? And she has talked like really openly about that and said that it's hard for her to have normal relationships and be open about the past that she's had in porn and stuff because that's what people see her for, like a porn actress. - Jasmine

In many ways, the comments that Jasmine makes here about the way pornographic actresses experience slut shaming is not dissimilar to what she experienced as a sexually active woman who merely views pornography. In this way, the pleasure of pornography as an outlet for sexual expression is simultaneously a reminder of the pain that is associated with the sexual double standards in wider society that see women chastised 
for their sexual choices, actions and behaviours, despite the new sexual climate which supposedly celebrates women's sexual agency and 'empowerment'.

Another individual voice which I wish to showcase here is from Tina who reported a particularly troubling relationship with some types of pornography. Tina enjoyed watching pornography much of the time and it simultaneously operated as a source of masturbatory arousal as well as social entertainment with friends. However, Tina also reported that she had difficulty reconciling her interest in pornography which she felt was degrading to women, but it became a type of pornography that she was able to orgasm to despite its derogatory nature. The derogatory nature of this material was related to her experience of childhood sexual abuse and left her feeling triggered and uncertain about what this meant:

So this is not completely off topic but still on the same area. I don't know why but in the last few years I've been triggered about sexual violence that I experienced when I was really young. So I was only about 3 and it was quite ongoing. So my Mum, we were living with her friends and they had a son who was like 7 years older than me. So it was an ongoing sort of abuse that was going on to me, and he used to urinate on me. And so in the last few years I've been triggered about all of this. And then when I was at primary school, which was probably about the same time that I first watched porn which I never actually thought about, one of my best friend's Dad tried to sexually abuse me. I managed to tell him stop doing it and he did. Since all of this, I have no idea why it's come up after it's been suppressed for so long, but somehow it's come back out. I've been watching a lot of pissing porn. Which I don't know if that's from what happened when I was young but that's come up. Which is a little bit worrying. Sometimes I can't get off watching porn without [it], but orgasm when I watch that kind of porn which is really not a nice category of porn. It's a very dehumanising kind of derogatory to women and everything. Which kind of makes me feel like do I not have selfconfidence in myself and that side of it. So when I heard about you doing that study I was like oh I wonder how that sort of stuff would link in? - Tina

Tina's experience clearly illustrates how the pains of pornography can be situated alongside their pleasures. Tina's use of pissing porn was a painful reminder of her early experiences of trauma and sexual abuse, but it also became something which was pleasurable despite the way that it made her feel afterwards. This complicated relationship between trauma and sexual violence clearly demonstrates the difficulties that women can experience with pornography and the complex ways that pleasure and pain are situated in their lives. Gurevich et al. (2017) talk about the pleasure/pain distinction for women and situate pornography as a 'contested arousal tool', and this was very much the case for Tina, who was triggered by what she was viewing in pornography 
but came to be aroused by those very triggers. In essence, then, it's difficult to imagine women's consumption of pornography without some consideration of the inevitable pains.

\section{Summary}

Women's perspectives on pornography have received little critical research attention until recent years. In New Zealand, women make up a significant proportion of pornography viewership, so critically exploring women's engagement with pornography remains fertile research ground. This chapter has presented the perspectives from 11 New Zealand women on pornography and identified the complicated, conflicting understandings they attribute to the pornography that they view. Women understood aggression in pornography as a mainstay, but they also acknowledged that consensual, positive version of more intense sex had the potential to be exciting in their offline sexual interactions. In conceptualising rough sex, some of the women described it as having some sexual appeal. Their deciphering of rough sex differed on an individual level, but it fundamentally rested on the idea that rough sex was acceptable when it occurred in the context of consensual sexual relationships. Such a position directly acknowledges that women's experiences of heterosex are not always consensual, and future research should problematise the notion of rough sex in more detail. Lastly, this chapter has demonstrated how women's engagement with pornography routinely rested alongside its pains. Whilst pornography has the potential to be arousing and titillating, women appear to be navigating a constant nexus of pleasure and pain, whereby their engagement remains a complex and complicated experience.

The following chapter presents another complicated picture about pornography and engagement and draws on men's perspectives on pornography and how they understand, interpret and navigate aggression in pornography. 


\section{Chapter Seven: Men on pornography}

As discussed in the previous chapter, women's perspectives on engaging with pornography were remarkably complex and inherently gendered. So, too, are men's perspectives on pornography, and the lack of research attention to the primary audience of pornography is a surprising omission given the claims frequently made about the effects on men's lives (Hardy, 1998). If these concerns are to be substantiated then it is necessary that we speak with men directly about how they experience, understand and interpret the sexually explicit material that they consume. This chapter presents men's perspectives on pornography and how they understood and interpreted what was presented in sexually explicit material. It begins by presenting men's positions on the appeal of pornography, particularly regarding how they deciphered women's authentic sexual pleasure. It then moves to describe the complex ways that men understood what counted as aggression in pornography, and how they responded to these encounters. Lastly, it presents men's perspectives on the power of pornography to impact their everyday lives, including their sexual experiences.

\section{The appeal and allure of sexually explicit material}

As a genre, pornographic material invokes strong bodily, emotional and personal responses to its content. As discussed in the previous chapter, many women spoke of the power of pornography as a visual medium to facilitate their feelings of sexual arousal, but it was simultaneously framed as a contested arousal tool, illustrated by the ways that the pleasures of pornography were juxtaposed alongside their pains. The narratives presented from the men in this next section highlight the pleasures and appeals of pornography, but they also illustrate the difficulties and complexities involved in interpreting and navigating pornography.

For several men, the ubiquity and visibility of pornography online contributed to its normalisation as a practice in their lives. Pornography was thought of as 'ordinary', and Kevin went as far as saying that our interview "must be the most boring conversation just talking about heterosexual porn." At the same time, however, talking about pornography was also acknowledged as a private issue. As Chapter Five demonstrated, men were aware of the acceptability of talking about pornography in certain spaces, but at the same time they acknowledged that the space for critical discussions about pornography was somewhat limited. The limited space for these discussions was demonstrated by refrains 
such as "I haven't really talked about [pornography] before in this depth" from Nathan, and "I wish there was an easier way to talk about [pornography]... I wish there was a more healthy way that you could enjoy that stuff" from Kevin.

With men feeling constrained in their conversations about pornography, it seems unsurprising, then, that they find it unusual to be questioned about its appeal. That said, men were remarkably open and honest about what was appealing about pornography for them in this research. Men spoke about what they found attractive in pornography genres, categories, bodies, and behaviours - as well as the types of acts or behaviours that detracted from its appeal. Antevska and Gavey (2015) reported that men "related pornography's appeal to an intrinsic pleasure of looking at women's bodies" (p. 615), and the same can be said for several men included in this research. The female form was the dominant focus of the male gaze when they viewed pornographic videos:

Quite into the female form. So I do spend a lot of time - it's like sorta whether their boobs are real nice or like you know... it's like the contours of their bodies and that sort of thing. - Pete

Nubile films being a channel that I watch is a pretty apt description generally. Slender. B-C cups. So fairly modest breast size. Typically white. Not interested in African-American women, but I'm quite happy to watch say Indian races, that side of things appeals sexually to me. Not African-American and I don't know why. Or African. It's just meh. - Luke

I've explored porn of all different shapes and sizes. I've explored older people, yeah I've explored everything. Explored different races, different ethnicities, different cultures, different lifestyles. Like yeah. Watching porn with larger women, with skinnier women, different body types. Just want to yeah, try and soak it up. - Ethan

In these excerpts, Pete, Luke and Ethan point to the diversity of women's bodies in pornography and how they observe and understand what is pleasurable about women's bodies for them. However, the men also acknowledged that pleasure was also gainfully obtained when women's bodies were presented as experiencing pleasure. They described how women's 'authenticity' in their pornographic performances was a key factor in what made pornography appealing for them. Luke commented that a "huge, huge part of what I get out of pornography is watching females enjoy themselves" and this sentiment was shared by both Ethan and Pete:

Something I find really appealing is if the woman actually looks like she's enjoying herself. That's a really big thing for me. - Ethan 
Some women you watch and it's like she genuinely looks like she's enjoying what she's doing. And THAT seems kinda cool. - Pete

In both narratives, men point to women's 'genuine' or 'authentic' pleasure as having demonstrable appeal. At the same time, the commentary that only some women in pornography look as if they are genuinely enjoying themselves suggests that a number of women in pornography do not appear to be enjoying what they are engaging in. Chris commented that some women in pornography are "putting on an act, putting on loud, overly fake moans, things like that", whereas other pornographic videos "seem a lot more like the people in them are enjoying themselves." Similar findings have been reported in research with men about the appeal of degrading practices, such as ejaculation on a woman's face, in pornography (Sun et al., 2017). They noted that most participants

highlighted the female performers' (depiction of) pleasure as important in enhancing their own arousal and argued that they could tell if the women were really enjoying the act or not. In other words, although the men understood that the pornography was staged, in their accounts they argued that it was the (perceived) authentic pleasure of the women - rather than, or in addition to, the women's pain or degradation - that gave the men pleasure as consumers (p. 1720).

A number of the men recognised that pornography was scripted, and Pete acknowledged that "pornography is often directed. So somebody is telling these people what to do as opposed to it being an authentic act." However, the female performer's perceived authentic pleasure nevertheless gave them pleasure as consumers. So how do men decipher what's authentic in pornography? This next section discusses the ways that men navigated, understood and interpreted authenticity in pornography.

\section{Deciphering women's authentic sexual pleasure in pornography}

Authenticity in sexual activity is often highly regarded, and research with clients of sex workers suggests that authenticity within the client interaction is a sought after commodity (Bernstein, 2007). In speaking to the delivery of the girlfriend experience ${ }^{22}$ in sex work interactions specifically, Milrod and Weitzer (2012) suggest that clients expect a facsimile of affection whereby intimacy becomes a valuable, and purchasable, commodity in men's sexual interactions with women. Authenticity is also a key market value in pornography (Berg, 2017) and the increasing popularity of amateur-style

${ }^{22}$ The Girlfriend Experience relates to sex work services which incorporate aspects of intimacy which mirror loving relationships between partners. Bernstein (2007) suggests that this has become one of the most sought after services by clients. 
pornography is a direct result of an overt drive for more authentic sexual representations. Speaking to amateur pornography specifically, Paasonen (2011) suggests that amateur pornographic images are "coded as truthful, authentic, and somehow less manufactured than professionally produced images" (p. 80). Yet Young (2014) contends that "in an industry built on filming the glamorous performance of sex, the concept of authenticity is an anomaly" (p. 186). She argues that

in the depths of the San Fernando Valley, young women with crisp fake tans, long platinum blonde hair extensions, silicon breasts, and acrylic nails are fucking cocks that are artificially erect. They vocalize a performative sense of pleasure with moans and squeals as their male counterparts lead them through a formulaic equation of sexual positions that 'opens' the penetrative action up to the camera for the viewer's pleasure - not their own. This assemblage of 'fast food' pornographic sex continues until the female performer is instructed to 'fake' an orgasm and receive a load of hot cum on her face (p. 186).

Ashley (2016) agrees, noting that mainstream pornography is still designed to serve the imagined consumer, traditionally men, whose commercial wishes are presumed to include uncomfortable elaborate positions, big boobs/big dicks, guaranteed explosive female orgasms for minimal effort" (p. 187). However, Ashley (2016) also acknowledges that the climate that pornography is produced in means that

established producers only feel able to fund what they can guarantee will sell. Storytelling, especially aspirational storytelling, sells. The desire to watch something that removes the viewer from the functionality of everyday life, and therefore everyday sex, is and always has been a valued part of entertainment (p. 189).

Through the narratives of a number of the men in this research, the desire for more 'authentic' portrayals of sex came through strongly. Their expectation that women's performances in pornography were 'authentic' was a key factor in their determining of the pleasure they received as viewers. In demarcating what 'authentic' female pleasure looked like, Luke suggested that rather than "screaming in pleasure", women in pornography gave "more subtle signs of genuine pleasure." Chris agreed, noting that scenes where women were "putting on loud, overly fake moans" detracted from their genuineness. Other tell-tale signs included:

Cheap looking sets. Just not my cup of tea at all. It's not real. I don't think the actresses are enjoying it... Personally I'm not a fan of blowjobs... because I have a problem with the female not getting anything out of it. Maybe this is because I'm an only child, maybe it's because I was raised more by my mother, but for me the female enjoying herself is what gives me sexual gratification. - Luke 
Further, a female performer's attitude and sincerity in her performance was vital to Luke's enjoyment. He commented that women's "attitude towards the act they they're performing in for me" was key, and that images of her "smiling", being "friendly" and "laughing. Almost as if they weren't being filmed sort of thing" all contributed to the authentic nature of a pornographic scene. Essentially, his enjoyment hinged on whether he interpreted a female performer's performance as "a sincere thing." Through this extract, there are similarities between men expecting women's pornographic performances to be sincere and the sincerity expected in client/sex worker interactions. Milrod and Weitzer (2012) suggest that clients of sex workers vary in their expectations of the client/sex work relationship, but that a desire for authentic, mutual intimacy is expressed by some, whereby women are then expected or presumed to reciprocate the feelings that the client feels toward them. Yet in pornography, is this ever possible? Indeed, it seems like it's an expectation. The desire for women's performances to feel sincere was also shared by Derek. He felt that contemporary pornography tended to feel "superficial" which detracted from its authenticity:

Today it seems so superficial... it seems like it's all just for a price tag. Like it's for a quick payment slip. Which seems a lot more hollow to me... When looking at your like videos, physical, it's a lot more acting for me. It's not so true. Like say your orgasms are just faked, they're not real. That, to me, is going through the effort of bothering to watch something like that, it matters a lot. - Derek

Pete thought some types of pornography were more authentic and countered a sense of superficiality. He commented that XArt was "really cool cos these people are just quite into each other and it's very organic." This desire for a more organic sexual representation suggests that there may be a boredom or tiring with the tropes in mainstream content. The 'plastic' or 'superficial' type of sexuality discussed here seems to suggest that a desire for more authentic, more real representation is well and truly here. But should 'real' sexual authenticity on the part of the performers - in the pursuit of pleasure for the audience - always be a necessary inclusion when creating pornography? Ashley (2016, p. 190) suggests not, as "porn is not a monolith, it is a medium used to document, and express ideas, and to tell stories... Does the pleasure on screen always have to be 'authentically' felt? Sometimes, yes. More often, maybe. Always, no." As I considered this desire for authenticity that several of the men suggested, I also queried what this might mean in relation to representations of aggressive or rough portrayals. Would women's authentic responses to aggression or rough sex in pornography detract from its appeal if 
it was clear that she was not enjoying what she was engaging in? This chapter now explores men's encounters with aggression or violence in pornographic material.

\section{Distant engagements: men navigating aggression in pornography}

In the previous chapter, women suggested that misogyny and degradation was everpresent in pornography, but when it came to aggression - or rough sex - this was often trickier terrain for some of the women to navigate. The men I spoke with for this research also spoke of encountering aggression in pornography, and I invited them to speak about what this looked like from their position. In contrast to the perspectives presented by women, men were less interested in delineating between rough or violent sexual behaviours, but they were clearly able to provide a visceral outline of what violent portrayals looked like. Further, they were clear to distance themselves from the type of men that enjoyed violent material, but the power of pornography to invoke a strong bodily arousal meant that this was not always possible.

In terms of who is on the receiving end of violence in pornography, men overwhelmingly suggested that women were the likely targets. Cameron was the only participant who acknowledged that men could be the recipients of aggression, which he conceptualised as "anything that simulates rape for me. Anything where you can clearly see the guy or girl saying no or crying or anything. Those are probably the main ones. Which is hard to avoid sometimes." Luke felt that aggression in pornography was visible "in the female's faces. Red in the face. Veins popping. Down turned mouths. Generally looking pretty unhappy with the act that they're performing." He went on to say that these representations in pornography were equal to "paid rape" and they were "pretty fucking horrible to watch." Derek, too, commented that women's experiences of pain were unappealing, saying that "I don't wanna watch someone that's in pain or something, just trying to put up with, you know? That's not what I'm about."

In speaking to the types of behaviours that men understood as aggressive in pornography, slapping and choking were regularly discussed. Matt commented that these representations, in conjunction with situational factors, contributed to a scene feeling aggressive:

It's a culmination of a bunch of things. Like violent dirty talk, things like that, which is very much based around his - I don't wanna use the word dominance too much - but his sort of position, his sort of like fake relationship... You come 
across sort of actions as well, like slapping, spanking, things like that. Which are just seen, again - I mean I know there are people that are into it - but in an industry that is specifically catered towards men, you've gotta wonder at some point how much of this is based in reality as to what sex should look like. - Matt

Cameron also spoke about slapping and hitting and recognised that these used to be considered hardcore, but he now understood them as merely "a part of preference":

Like I definitely thought really what I would consider hardcore pornography, when I was young, like hitting, slapping, biting, anything like that. I thought that was kind of like wrong... as a young person watching porn and stuff, anytime there'd be a like a hard slap or like gagging someone or anything that seemed non-consensual just turned me off. - Cameron

The idea that aggression in pornography had appeal for others was referenced by a number of men that I spoke with. Men seemed to recognise aggression in pornography as a common portrayal but opted to distance themselves from being 'that guy' that engaged with it. By the same token, men were careful not to suggest that it would not have appeal for other people, presumably other men:

I'm not into watching that. It doesn't really get me off that hard aye when you've got a guy choke a chick out. I find it a little bit - not disturbing - it's just not me. I mean there's whole categories based on blowjob and creampie and facials. Facials [laughs] the word for it. That's not my scene. Nah it's not what I watch at all. That's more of the male getting pleasure there rather than the female. That's not my sexual preference, you know. - Derek

The language used here suggests that women's experiences of pain do not have erotic appeal for Derek specifically, but they could be in line with other people's sexual preferences. Ethan and Nathan presented similar narratives:

Whatever floats my boat may not float another person's boat. Very liberal, very liberal interpretation of what people want and what people need and what society as a whole should give people. You know what's good for me might not be good for someone else. So if someone wants to watch hardcore pornography, who am I to say, who the hell am I to say nah? All the power to you. All the power to the people who want to watch what they want to watch. - Ethan

Porn is in the eye of the beholder if you will. Just because watching one type of porn might turn me on, it might not turn other people on you know? - Nathan

In some ways, these narratives support the mantra of 'not yucking anyone's yum' which was referred to in Chapter Three. If we hold that there is implicit consent in pornography (Purcell, 2012), then who are men to suggest that their trash is not another man's treasure? Or that the normalised and eroticised aggression and sexism in much mainstream pornography is problematic at all? This type of thinking, however, becomes 
more complicated when we consider the realities of pornographic production and understand that not all pornography is produced in a consensual climate, nor is all pornography licit to consume. For example, would men feel similarly about other men viewing child pornography? Whilst men seemed to engage with this notion of user preference, I feel that these perspectives are mostly related to material that fits within the confines of 'mainstream', perhaps the material that is located on places like Pornhub. However, research with men about how they navigate degrading practices in pornography suggests that there may be an element of identity work involved, as it:

presents a way for the men to maintain a sense of themselves as good people... men may not want to think of themselves as the type of man who receives sexual pleasure from physical violence, rape, or the active subjugation of women (Sun et al., 2017, p. 1718).

As well as this, research has suggested that men are unlikely to question or critique male dominance in pornography. Instead, such representations are

minimized through humor or distancing, or rationalized through claims around individual choice on one hand and biological realities on the other... although male dominance was enacted in pornography, it was not what they personally were attracted to-that is, it was beside the point of their own pleasure (Antevska \& Gavey, 2015, p. 616).

Throughout the men's narratives, they identified that male dominance or aggression was present in pornography, but that it was not what they were attracted to personally. At the same time, they acknowledged the appeal of this type of pornography for others. Such a position almost suggests that men are able to maintain a sense of themselves as good people, in that they are simultaneously 'good' by not engaging with such material, but also 'good' because they are not preventing others from having their fun too. Such a position speaks almost to the free speech arguments around pornography more generally, whereby suppressing particular categories of pornographic material impinges on the rights of others. As Strossen (2000) argues, "to allow a noisy minority that chooses not to partake of sexual expression themselves to censor it for everyone else" (p. xxvi) is counterintuitive to the fundamental rights of Americans. In a sense, a number of men in this research seem to support a similar perspective, whereby trashing another man's treasure would somehow impinge on the rights of others to view what they want to view and is counterintuitive to a position that accepts pornography as men's right to view. 
At the same time, men also identified the power of pornography to affect viewers' perceptions about sex, so being able to distinguish between fantasy and reality was seen as important. Their perceived ability to successfully distinguish between reality and fantasy helped them separate themselves from the type of men they perceived to be influenced by pornography. Matt spoke about deciphering fantasy from reality, and how this could be difficult for some men to interpret:

I remember there's been a lot of times where I've been like this is just actually too much. But for the most part - I think - at least that I can identify, I can distinguish between sort of fantasy and real-life and so for me it hasn't been an issue. But I can see a lot of men not seeing through that at all. Especially if that's the only exposure that they have to sex, is through pornography. - Matt

Derek also acknowledged that other men - particularly young men - could have difficulty separating pornography from real-life sex:

I suppose an overexposure with anything can create a desensitisation and that might have a lot to do with where it particularly, my male generation, maybe the generation below, they might be womanising. It's hard to say. I can't really bar off that. From my own perspective, it doesn't fit. - Derek

Chris spoke about the potential for pornography to be "corrupting," and presented the following narrative in response to his own perceived reliance on pornography:

I know there is the dominant narrative about how it can ruin your view of women and sex itself. And there's definitely room for that. I feel like it's definitely a danger but I feel I am well entrenched in that narrative that just pure reliance on porn as an instructional material can corrupt your thinking towards sex. I feel that was emphasised - not specifically towards me - but in the general area that I was in that I can watch it and go like 'okay, yeah I'm being aroused by this, but I also know real sex is not this'. - Chris

Mulholland (2013) speaks similarly in her work with young people negotiating pornification. The young people in Mulholland's research suggested that their 'matured' approach to pornography helped them make "a well-grounded claim to sexual selfhood and their capacity to reason in relation to the sexual" (p. 157). These men appear to be legitimating their knowledge around fantasy versus reality in these narratives, which speaks to this idea that one's matured engagement, in this instance through engaging with pornographic material over the lifespan, contributes to a sense of being able to decipher what's real and what's not in pornography. Chris went on to say that that pornography had the potential to be dangerous to consumers, but that education had the potential to mediate those harms: 
I think if people are just solely taking porn in and of itself without that idea in their mind that this is not accurate, then yeah it can be dangerous. But if they have that education of like this is not accurate, sure this is arousing and that's fine but this is not accurate, then cool. It's fine... just making sure people are aware, don't expect people to do this. They can if they want but don't expect a girl to immediately start sucking you off like she loves it! - Chris

Despite their knowledge about the dangers of pornography, men's narratives suggested that having a matured approach to pornography made them immune from its dangers. Such a stance further maintains a sense of being a 'good' consumer of pornographic material, because should they consume material which had aggressive or sexist tendencies, the knowledge that it can be dangerous separates them from being prone to said influences. Overall, a number of the men in this research acknowledged that aggression in pornography was present and had the potential to be harmful, but they distanced themselves from the type of men that engaged with that material and were careful not to suggest that men should not be able to engage with it. Further, they suggested that they were somehow immune to the dangers of pornographic material because they could distinguish between fantasy and reality, thereby maintaining their status as 'good people'.

\section{Tuning in or tuning out? Responding to aggression in pornography}

Continuing with thinking about this concept of 'good people', I'd now like to consider what men did in response to encountering aggression in pornography. Men spoke about encountering aggressive material, but for the majority, their strategy in responding to such material was to discontinue viewing it, perhaps indicating a degree of empathy with the women in the scenes. Throughout these conversations, men spoke about the difficulties involved in navigating consent in pornography, and their anxieties about the type of pornography that they viewed. Previous research suggests that when men encounter degrading practices in pornography, they

used strategies to avoid empathizing with [women]; for example, when encountering scenes that were too violent or disgusting to bear, respondents reported fast-forwarding or lowering the volume to mute the verbal abuse. In doing so, these men managed their own discomfort but avoided empathizing with the female performers whose experience of degradation was made invisible (Sun et al., 2017, p. 1721).

Several men commented that they chose to disengage with pornography which showed women's experiences of suffering or pain. Derek commented that he was "not into anything like snuff or anything like that. If I can see where there's a dis-enjoyment then I'll 
cancel out. Don't really wanna support that by viewing it. It's not what it's about for me." Others also spoke about exiting away from material which displayed violence or aggression towards women. Cameron mentioned that it was possible to encounter pornography online that was "labelled completely differently to what it is" and when this happened, his response was to "click away" and "move on". Chris recalled a situation where he had downloaded pornography which appeared to be real-life depictions of rape. In response to this material, he deleted it and pretended it did not exist:

Because I can't verify where this came from, I am fairly concerned that this is actual rape. I was like wow, I cannot watch this at all, I am deleting this, I am going to pretend I never downloaded it. - Chris

He also mentioned that he avoided material about which he had heard rumours that it was produced non-consensually:

Like I've heard rumours that this one porn production company 'Girls Do Porn' fly's people to a particular location - like probably in California - and it's basically like we're not flying you back til you do this porn. I haven't seen any concrete evidence but I've seen enough people alleging that that's the case and I can sort of corroborate that with the sense that the girls in it feel rather awkward. Which would also be true if they were just amateurs but because the girls feel awkward in it, it doesn't feel that they're that eager, and because I've heard those rumours I'm like okay, I'll avoid them. - Chris

At the same time, however, Chris mentioned that it could be difficult to fully understand whether pornographic representations were consensually produced, and there was always a risk that consuming professionally-produced pornography could include women who were not there willingly:

I know when I watch professional productions, there is a risk that they're not enjoying it but they're just putting on a really convincing show. So it's more just like a gut feeling, like their moans are overly forced, they're more being a recipient of the sex rather than a participant of the sex. - Chris

Tom was also aware that non-consensual pornography existed, but felt that pornography by well-established companies was a way to keep himself safe when viewing pornography online and ensuring consent:

A good way to kind of keep myself mentally cogent or consistent I guess would be a better word, is I go to well-known sites like PornHub for example. Maybe Xnxx. I know you stick to companies that are relatively well established. We've already talked about a few of them but things like BangBros and Tiny $4 k$, all that kind of stuff.

However, he also noted that there were ways that you could tell if amateur content was produced consensually: 
Even when it comes to amateurs, you can see the difference. If they're looking at the camera or they've both acknowledged the camera at some point, you're pretty safe in assuming they know they're being filmed. That's the easiest way to do it, you just go. - Tom

Ethan also referred to the distinction between amateur and professional content in pornography, and felt more anxious consuming amateur pornography:

You can see with the production whether it's professional or amateur pornography. And generally, I have a general rule: professional. Not like I always watch professional but I see professional as there's more consent involved... amateur pornography, I'm much more - I can be much more - anxious about consent. Because you really do not know what is happening behind the scenes. It's not about commodity, it's about it could be revenge porn, it could be anything. - Ethan

These anxieties about the circumstances around pornography production meant that when he encountered material that he felt had the potential to be non-consensual, he tried to avoid it; "if it's like I get the slightest hint that the woman is not you know fully 100\% consenting - or any partner isn't - then I try and just click away." But Ethan also acknowledged that navigating consent in pornography was difficult, especially in heavier genres of pornography, so he tended to steer away from such material:

Consent does substantively matter. But then where do you draw the line between consent and non-consent?... when I'm watching a scene, I can't tell if these two people-unless it's specifically said please beat me, even then you can't really tell because there could be financial coercion, there could be emotional coercion, there could be physical coercion. Well physical coercion seems to be the point but yeah you never know. And that does kind of, that's why I'm not really too into that heavier more violent genre of porn. Just because it can be a bit of a grey area and you can't know, you can't know every factor involved in those two people, or three people, or four people, or five people. - Ethan

The complexities involved in navigating consent in pornography were clearly an issue that a number of participants in this project were aware of. Cameron recognised that the 'feel' of the scene was sometimes the only way you could gauge the circumstances involved with the production of a particular scene:

I think it just depends on the feel of the scene, if you wanna say it like that. Cos sometimes you know say it's just someone's really - to put it lightly - really keen. Sometimes it happens and then they're showing signs that they are into it, versus you know signs that that's happening but then you can sorta tell that they're not really enjoying it at all and that they're not really wanting to be there. -Cameron

He went on to identify 'casting couch' as a key genre that could make understanding consent in pornography difficult. As referenced in Chapter Two, casting couch is a popular 
pornographic category that plays on young women seeking favours and men in positions to grant them:

Often, in terms of what I've seen, is that it seems consensual and they're probably actors but then there's the occasional one who's you can really tell doesn't wanna be there but has felt pressured that they need to perform sexual acts under those circumstances. Whether it be because they think they're going to get a job or property, I dunno. So I think another point is that sometimes the storyline plays a part in my perception of what's happening, of the scene... so there's obviously a bias like for - maybe not a bias, maybe the wrong word - so they think they're going to get a flash modelling job or whatever, or whatever the job may be, and they feel like they have to give head to get ahead kind of idea. Sometimes that's obvious that - for me - it's sometimes I perceive it as oh yeah, they're just an actor. Like you can kind of tell when they're an actor but then other times it's more like oh this is actually a potentially problematic situation where someone is, you know, they pick them up on the side of the road or something like that and they're clearly just a regular person? But then when I say that, it's hard, like how do I know? Is that just an inference I'm making? I don't know. Or is it just a choice that I made at that particular time to perceive them as an actor or a non-actor? - Cameron

In speaking about genres in pornography that could be more ambiguous around consent, Luke spoke about 'drunk girl' pornography as a genre that he had previously engaged with:

That does bring up something else that I was briefly enjoying which was just this amateur sort of footage that you might see of drunk girls having sex with guys. And they'd normally be the one's initiating it. And so it was never a rape culture thing to me. But it was still sort of - I wouldn't even say that it was a blurred line, to quote whatever his face was. - Luke

In this excerpt, Luke stipulates that women's initiation of sex in 'drunk girl' pornography separated it from being instances of coercive sex and somehow okay to consume. In essence, his understanding of consent rests on women's active engagement in sexual activity and ignores the situational inclusion of alcohol. In elaborating further in the interview about what drunk girl porn entailed, he spoke about how his attitude toward sex generally influenced how he perceived consent in drunk girl pornography:

if you've been drinking with a girl and you're both at a bar together and you've been doing a bit of grinding or whatever and then you wind up having sex, then I have no problem with that. And sometimes I have watched porn that is essentially to that effect. And sometimes it's like sex parties or something like that and its places where people will go to willingly get drunk and have sex with people... I mean this is just purely in porn... I feel like my tastes are generally pretty tame... A bit of pashing, a bit of groping and it would lead to a bit of sex in a private place where they both seem to be enjoying it... maybe it's just an act. Maybe they're not drunk. I dunno... And sometimes that is what makes me mildly 
uncomfortable about watching it and enjoying that type of porn. That was a brief spell in my pornographic viewing history. It was maybe 4 or 5 months or so. And I was quite enjoying it. But it was certainly something that like I assumed, or at the very least hoped, was consensual to be filmed or whatever. - Luke

For Luke, the ambiguity around whether such material was consensually filmed or produced was a key driver for stopping watching that type of material:

It's probably the primary driver for stopping watching drunk girl porn. Because of the doubt of whether or not it was consensual... It's made me feel guilty about perhaps I'm [com]plicit in, if that's the right word to use, in perpetuating that culture. - Luke

Thus far, a number of these excerpts have showcased some of the complexities and ambiguities involved in navigating consent in pornography. As discussed earlier in this chapter, men were acutely aware of the dangers of pornography in terms of its ability to influence viewers' understandings of sex, but alongside the complexities involved in navigating consent, men also spoke of pornography's power as a visual medium which meant getting 'carried away' to dangerous pornography could be a real issue. In writing about aggression in pornography specifically, Purcell (2012) discusses degradation, humiliation and violence in pornography as something which can be interpreted in various ways by consumers

depending on their level of exposure to mainstream material and depending on the sexual values they bring with them when they watch porn... the semiotic versatility of sexual practices makes it difficult to determine the dominant readings of many popular pornographies... This ambiguity makes it difficult to separate pornographies that pair aggression with hostility from those that pair aggression with pleasure (p. 121).

In turn, Purcell argues that "pornographers themselves may not be conscious of the multiple meanings that [sexual acts] invoke, and viewers experience arousal for reasons that can be opaque even to them" (p. 121). After critically reflecting on the difficulties navigating consent in pornography, Ethan noted that he had been 'carried away' masturbating to aggressive pornography in the past:

That's not saying that I haven't been carried away with you know pleasuring myself before. But that's what I try and do. Try and be guided by consent as the main anxiety I have about porn, I suppose. - Ethan

Ethan's honest acknowledgement here about the power of pornography indicates the way that pornography can, due to the powerful bodily responses that it invokes, to an extent disable someone's moral compass in pursuit of their own pleasure, arguably at the expense of someone else's. The ability of pornography to switch off one's moral compass 
was referred to in the previous chapter with Jasmine speaking about how it did similarly for her when engaging with gangbang style pornography. In this commentary, Ethan describes feeling similarly, resulting in a somewhat anxious reading of pornography.

For other men in this research, the consumption of pornography that portrays degrading practices can be something which is actively sought. In theorising men's consumption of such pornographic material, Sun et al. (2017) argue that men "push out" the awareness that women on-screen may be suffering, and engage in wilful denial to enjoy degrading practices in pornography. However, one participant in this project signalled a rather different engagement with aggressive pornography. Pete spoke about encountering material where women did not appear to be enjoying the scene that they were performing in, and this suffering could even have a 'morbid intrigue':

I just have to go by my intuition. It's something you watch and you're like, uh, that's not cool... When I say that, sometimes there's kind of like a morbid intrigue to it. - Pete

In this extract, the female performer's pain or suffering is acutely acknowledged, and the 'not coolness' of the scene is side-lined by a 'morbid' intrigue and interest. Such an engagement with pornography is quite a different reading than wilfully denying or pushing out a woman's suffering, as in this form of reading pornography, her suffering is the appeal, it is the intrigue, it is the drawing point, again attesting to the power of pornography as a visual medium.

\section{Going down the 'rabbit hole' of pornographic content}

Another way that the men spoke of the power of pornography was related to the 'rabbit hole' of content on the internet. A common narrative around people who view pornography - usually men - is that it produces an increasing desire for more and more violent or degrading content (Shor \& Seida, 2018). Such a stereotype invokes the idea of the internet presenting a web of content that gets deeper and deeper, presenting a vortex of erotic material with a strong pulling force for viewers. Two participants in this research spoke about the power of internet pornography, and it appeared that getting carried away in a 'rabbit hole' of content was part and parcel of their viewing experience. Bill spoke about how pornography on the internet could lead a viewer down a click too far, and the state of arousal that pornography invokes affects moral judgments in that process: 
It's so easy to like click, click, click and go one click too far and be like this is pretty weird but I'm here so I might as well. It's this pattern of like if you go down a Wikipedia rabbit hole, you can do the exactly the same with porn. And cos you're like turned on for the duration of like clicking so you don't really have any judgment and then you get to the end you're like Jesus Christ! Like fine, but really? - Bill

Nathan provided a slightly different narrative. Nathan spoke about searching for unreality in the pornography that he viewed, and how he had dedicated his life to pleasuring himself to the "demons of reality". Whilst Nathan did not disclose in full detail the type of pornography that he viewed, he discussed how he pleasured himself to the demons of reality through fantasy-type pornography. In speaking about the rabbit hole, he mentioned that viewing pornography online could be conceptualised as:

You're going down the rabbit hole, how far down the rabbit hole can you get basically is a thing. The more further down I go, the deeper it becomes you know? Because at first look you're like I can see the bottom, but then you jump in and you're like falling, and falling and falling. And you're like oh I can still see the bottom, just a little bit further, and keep going. That's like the art of desensitisation I guess is that you keep on going and pushing it and pushing it and pushing it. - Nathan

In reflecting on his perceived reliance on pornography, or addiction to masturbation, I asked Nathan about what issues he saw with his reliance on pornography, if any. In reflecting on this, he was consciously aware that the pornography he viewed - which he did not speak about in much detail - was a sign of a bigger problem within himself.

The way that I keep myself safe, I feel, is by having that separate reality. So I don't act in real life to some of these issues, because then it will become a problem. But it's much like you know with kids, with people playing video games you know. Video games can be a similar thing because there's a lot of violence, similar issues I think, similar problems as you might put it arise in the same category. If kids are like have you seen Bad Boy Bubby? So if a kid like that, and his only understanding of the world is playing Grand Theft Auto $V$, then as soon as he gets let out he's going to start killing people you know? That's just what the movie pretty much says you know. So yeah, from that point of a view it's a problem. As long as you've got the right education, maybe it shouldn't be a problem. Or maybe the type of porn that you listen, that you watch is because of something that's in your brain that needs to get out you know? A type of expression or something. Whether you watch taboo or rape or anything like that, that needs to be analysed for actually a deeper condition or issue that you have going on, you know. Like when you dream, you know... By looking at porn and looking at the type of porn that I watch, I know that they will all lead back to something. Past discrepancies that I've faced perhaps. And if I can overcome that it will make me a better person. And if I don't overcome it, then that may lead into something a lot darker, you know. One of my inner demons might express itself in a negative way on 
society. So yes. For the moment, porn's fine. But if I don't deal with it soon then it might not be that great for me. - Nathan

In these accounts, men openly acknowledged the perils and dangers of pornography in the internet era, and the potential for pornographic content to lure them to content which is further and further down a 'rabbit hole.' Such narratives sit neatly in line with the concerns that are often raised about internet pornography, in that it is often theorised that viewers of pornography, particularly men, will be constantly lured to more and more depraved content, as the rabbit hole of content in that space leaves viewers wanting and desiring more and more extreme material. That said, the knowledge that such a rabbit hole exists, and the power of pornography to facilitate arousal to content which would not typically be arousing, did little to detract from pornography's overall appeal for men in this project. So what other impacts or influences did men identify in these conversations? The next section of this chapter explores the way that men identified pornography's influence on their understandings of sex and sexual behaviour, as well as its potential to be addictive.

\section{The influence of pornography: men open up about the role of pornography in their lives}

Throughout this chapter, I have shown the way that men have complex engagements and encounters with pornography. Further, I have suggested that a number of men are consciously aware of the dangers or pitfalls of pornography both in this chapter and in Chapter Five. In the perspectives presented in this chapter, men spoke of distancing themselves from the type of man that viewed violent or sexist pornography, which helped them maintain a sense of being 'good people' when it came to viewing pornography. At the same time, they were conscious not to impinge on the rights of other men to view pornographic material that appealed to them. Further, some of the men tried to be ethical in their use of pornography by avoiding material that they felt may have been nonconsensually produced. However, men also spoke about the influence that they felt pornography had on their lives, especially with regard to their sexual selves. This chapter now presents men's experiences in this space, beginning with pornography's perceived influence on their experiences of sex and sexual behaviour.

As previously discussed in Chapter Two, research is often concerned with pornography's role in influencing the development and acquisition of sexual scripts (Bridges et al., 2016; Sun et al., 2017). If the 'porno-script' (van Doorn, 2010) presents and reproduces a 
particular model of sex and sexuality, it is important that we ask questions about what this means for viewers and how they perceive it to have influenced their lives, if at all. For a number of men in this research, they felt that pornography had had a direct effect on their understandings and perceptions about sex and their engagement in sexual behaviours. Pete spoke in depth about the way he felt his early exposure to pornography and consistent use throughout his life had affected his approach to sex and his view of women in general:

Pete Basically I would consider myself a promiscuous person. I don't feel that I strongly connect sex and love. That a loving relationship might not necessarily have sex at all in it. It's not a requirement in my mind. I also feel I'm distanced from - sometimes you catch feelings or whatever - but yeah. Just having flings or whatever. It's like that's cool, I enjoy that.

Sam And you'd say that that came from porn you think?

Pete May have done. I feel that it is perhaps a contributing factor.

Pete felt that pornography had contributed to his preference for emotionally detached sex:

There could be lots of other things as well right, cos maybe it's just my nature. But I get bored of things. So I think this whole you know like, this kind of possibly the thing, the impact that pornography has had, because it's like 'oh such much variety'. You're like oh I'll watch that one, now I'm gonna watch something else kinda thing. So sex to me, if it's just a regular methodical thing or whatever it's like, I'm not very excited by that. But the prospect of something new or different, it's like that's cool, I like that, that sounds great. - Pete

In this narrative from Pete, I see striking similarities to the perspectives shared by Jasmine in the previous chapter. In Chapter Six, Jasmine spoke of how pornography had influenced her interest and taste in "adventurous" types of sex, and how gentle, missionary sex with romantic partners was a boring comparison to the type of sex presented in pornography. In speaking about women's perspectives once more, in Chapter Six, women also expressed concern and worry about men's interpretations and understandings of what they viewed in pornography, particularly how women can, and should, be treated. In speaking about pornography influencing perspectives, Pete felt that it had influenced his objectification of women's bodies:

Pete I do also have that ponder about how being exposed to pornography quite young, and in quite a large volume, consistently really. And I think that probably has had a really significant impact on my approach to sexuality. And the way I view women.

Sam So could you tell me a bit more about that? 
Pete Well what you might call checking people out, it's like definitely do that like all the time... Looking at women it's like, women in like you know tight yoga pant type things. You're like yeaaaah that's great. You're driving along and it's like yeah, just soak that up... maybe if I had not looked at lots of pornography maybe I'd still feel that way. I dunno. That's the theory I have that it's possibly had an impact.

Later in the interview, Pete went on to discuss how he processed pornography as a consumer. In doing so, he alluded to his objectification of women's bodies, and how it meant was less concerned about who she was as a performer or what her personality was like:

When I look at pornography, like I say, it'd be nice if they looked like they enjoyed it and that sort of thing. But it's not like I'm like oh, I wonder what kind of person she is. Or I wonder what her personality is like or what her hobbies are. These are not thoughts that cross my mind. I think she is attractive. All I'm thinking about is the physical aspect. Is that objectification? I don't know. - Pete

As I reflect on these perspectives, I am cognisant of the critical insight Pete shows into his own pornography habits. Pete spoke honestly about how he viewed pornography and drew connections between how this viewing may have affected his life. This critical reflection on the role of pornography in men's lives was also shared by Kevin:

Kevin I guess like one of the things, and I'm sure will be super common now I think about it, but I realised how much like my behaviour in sex was influenced by porn. If that makes sense? Like you're acting out what you see. What you see you think is like a normal sexual relationship so therefore you do the same kind of things and that in a relationship that you do there... Like I know that there was a, maybe not a huge focus but like, and I dunno if it always was, but like anal sex definitely got like blasted when you were a kid. So when you become a teenager that becomes the -I dunno if it's different for people who are older, a generation older than me - but I remember that being something to almost not strive for, but you know. Like a sexual opportunity, like just that kind of stuff. Deep throating as well, that's like a huge thing. You see that so much so you're like 'well that must be how you do that'. As a guy

Sam That must be how women do it?

Kevin That must be how women do it, exactly.

Research with young people in the United Kingdom suggests that young women especially attribute their male partner's pressure to engage in particular sexual acts, especially anal sex, as directly influenced by men's use of pornography (Marston \& Lewis, 2014). Sexual scripting theory also suggests that pornography as a medium provides a cultural media script which creates a readily accessible model of sexuality to draw on in sexual interactions (Sun et al., 2016). In this extract, Kevin recognises the presence of behaviours 
in pornography, such as anal sex and deep throating, as becoming something to strive for in sexual interactions. He went on to say that he became more aware of pornography's influence on sexual scripts later in life, and how this had an impact on intimacy through a detached model of sex:

Kevin And you learn it's not true but you can see how there are some particular times where you realise oh yeah I know definitely felt influenced by that because I've seen that before... that whole need to like act out sex in a way... I think 100 percent watching porn definitely influenced that. It's weird like if I could describe it, like being influenced by porn from a young age, then you replicate it but you replicate like porn sex and so you're not doing it for yourself but you're doing it for some invisible audience almost and then that's where the intimacy breaks apart. You realise you're almost there fulfilling a role in a way. And I've felt like that a lot more than I realised with a lot of different people.

Sam So it seems what you're almost describing is a bit like a performance? Is that right?

Kevin To a degree obviously like you're still with another person so it's not like that. But there are shades of that sometimes.

Kevin's acknowledgement that his sexual relationships were a measure of 'performance' for an invisible audience speaks to wider concerns and anxieties that men have about their sexual performance and sexual abilities, which are not a new condition. Kimmel (2005, p. 144) points to the type of language men use to describe sex and how this is often related to work, such as 'getting the job done' or 'performing well'. Such linguistic comparisons illustrate the way that men's sexual performances are constantly up for evaluation, and Kimmel argues that such language symbolises a detachment of men from their bodies and their emotional selves, making the body "a sexual machine, a performer instead of an authentic actor". Once the body is viewed as a sexual machine, "the penis is transformed from an organ of sexual pleasure into a "tool", an instrument by which the performance is carried out, a thing, separate from the self" (p. 144). This bodily and emotive detachment means that men's tools, their penises, become a source for anxiety and shame should they fail in their performance.

Brod (2007) argues that the focusing of sexual attention in pornography on the penis increases male performance anxieties and perpetuates the "myth of male perpetual readiness" (p. 398) which in turn means that when men fail to perform to pornographic standards, it fuels male insecurities. The idea, then, that men should be able to perform penetrative intercourse for extended periods of time contributes to a sense of insecurity 
and failure in the event that such success is not able to be attained. Cameron noted that he felt that pornography presented an image of

This masculine guy with a big dick and ripped abs - this is from my perspective - looking at the guy, he's like fit, he can go for hours, sort of setting that expectation, societal expectation I guess, that men should be able to pump it out for at least half an hour and be vigorous and always keen. I think that's probably affected me. Yeah. Or at least made me think that my partner thinks I should be like. Which it probably isn't/it may not, but in my head it does. - Cameron

Cameron spoke about the way that his anxieties about performance and conforming to a stereotype of the men in pornography was amplified when his sexual partner at the time identified that this was the type of sex she was interested in engaging in:

So not my current girlfriend but my previous girlfriend, she was the person that sort of introduced me to feminism. So we would talk a lot about these types of issues. And we talked about these kind of things a lot and expectations but for me it made things worse. Like so we'd say oh okay blah blah blah I don't expect you to do this and I don't expect you to do that and you don't have to do that, but this is what I like. And it was exactly what porn portrays, you know what I mean? So just say for me, I'm more of like a gentle make love type person rather than a smash and bash type. At least for that partner, she sort of was like yeah I accept that blah blah blah thatyou're not really this, but this is still what I like. So I still felt that pressure to conform to the idealised version, or the representation that men should be. If that makes sense. - Cameron

In the previous chapter, I alluded to women's navigation of pornography as a 'risky' endeavour due to the inherent sexism in much internet pornography. Previous research has established that some women's engagement with pornography is 'risky', resulting in a strategizing use of pornography to avoid the pitfalls and perils of pornography. Women's strategizing of their use of pornography was evident in Chapter Four, where some women spoke of engaging with lesbian pornography as a safer option, or sticking to particular videos that were safe. In conversations with two of the men for this research, a similar concept of strategizing use of pornography came through, but in a remarkably different way. Two of the men in this research identified their use of pornography as a means of enhancing their sexual performances when they engaged in sex with their partners to increase her pleasure. This idea that extended staying power was for a partner's pleasure has been identified in research with men about their use of Viagra. In a sample of New Zealand men who used Viagra, researchers noted the emergence of a "distinct discourse that suggests his efforts are motivated towards his partner - 'for her"' (Grace, Potts, Gavey, \& Vares, 2006, p. 303), whereby his pleasure, or focus, is related to 
her pleasure. Cameron recalled using pornography as a 'stamina trainer' due to his concerns about sexual performance and length of time prior to ejaculation during an adolescent sexual relationship:

I was sort of like worried about performance. So I was like scared that I'd just like cum real quick and she'd laugh at me or something. So I used porn as an endurance aid, if you wanna call it that. Stamina trainer. - Cameron

Ethan also spoke about using pornography to enhance his sexual performance and sexual staying power in the pursuit of being a generous and caring sexual partner. Ethan described his use of porn as 'tactical' and largely in pursuit of ensuring his partner's pleasure through extended erections and coital interactions:

I was quite tactical with my porn. I would use porn because I was always like, I've always been caring about other people. So I would try and use that, or try to expand that care into my sexuality. I try generally to please my partners over myself. So I try to do things like lasting longer and a lot of foreplay, a lot of stimulation for them as opposed to me. So I would use porn - I would masturbate - for the sole purpose of emptying the tank if you will so I could last longer in bed. I wasn't like full and would just be a two-pump chump. - Ethan

Ironically, Cameron felt that using pornography had the opposite effect in that it increased his existing anxieties about sexual performance:

Looking back on it now, I'd like to say it would work but I think it made me more anxious. And I think I still have some of those fears now, even though I'm 24 and have been in multiple long-term relationships with women who I know love me.Cameron

Despite this critical reflection, Cameron continued to use pornography regularly in the pursuit of a prolonged sexual performance later in the evening:

And I think I still use it now, probably at least 5 times a week. Especially if I know we're going to have sex later in the evening. I'll use it to like get the excitement out... A pre-party pump [laughs]. - Cameron

In these conversations, men simultaneously identify pornography as a source of sexual education, but also as a source of anxiety and insecurity about their own sexual performances. Whilst men's anxieties about sexual performance are not new, the idea of using pornography prior to sex as a means of enhancing their partner's sexual pleasure may well exacerbate performance anxiety because of the way men's bodies are presented in pornography. As Brod (2007) contends,

the necessary corollary to pornography's myth of female perpetual availability is its myth of male perpetual readiness. Just as the former fuels male misogyny 
when real-life women fail to perform to pornographic standards, so do men's

failures to similarly perform fuel male insecurities (p. 398).

Concerns about pornography more generally were also described in relation to feeling addicted to pornography, which a larger group of men reflected on during interviews for this research. This chapter finally turns to an analysis of men's perspectives on feeling addicted to pornography, and what this meant for them.

\section{Encountering addiction: men's experiences of addiction to pornography}

Pornography addiction has been the subject of much media attention in recent years, and as a label is typically used to describe someone - usually a man - who views sexually explicit imagery, most commonly internet pornography, at high frequency (Ley et al., 2014). Extensive public discussion about the pathology of addiction to sexually explicit imagery exists, and some scholars suggest that these public media discussions are often shrouded in a sense of certainty about the realness of addiction to sexually explicit imagery, with parallels often drawn between substance abuse and pornography addiction by way of a gateway thesis, whereby pornography use is tied to habituation (Montgomery-Graham et al., 2015).

There is no recognition across disciplines of a recognised, definable diagnostic category of what constitutes addiction to pornography (Ley et al., 2014; Montgomery-Graham et al., 2015; Voros, 2009; Williams, 2016), yet it continues to be regularly applied, primarily to men who have perceived excessive or uncontrollable usage of pornographic material. Voros (2009) argues that pornography addiction occupies not only a place where it is a central focus of academic research, but also "a central position in understanding the dynamics of addiction to sex and new technologies" which makes "addiction to pornography... less an object of medical knowledge with clearly defined contours than a malleable concept developing out of a melting pot of different emerging fields of knowledge" (p. 244). Voros (2009) identifies that the utility of an addiction framework for understanding pornography consumption is less about encouraging healthy and safe sexual relationships and is more an attempt to regulate sexuality into restricted normative ideals of successful, safe sexual practice, typically within the confines of confined, accepted heterosexuality.

The premise of this project was not to develop a definition of pornography addiction, or to specifically recruit participants who were addicted to pornography. Instead, I was 
interested in the way participants felt influenced by pornography, in either positive or negative ways. Conversations about pornography addiction were gendered discussions. Only one woman in this research spoke about feeling addicted to pornography (as discussed in Chapter Six), however six men spoke about this in detail. No men spoke about being in a relationship with an addicted partner, but this was discussed by two women.

What was interesting about the men's perspectives was that despite recognising that they were reliant on pornography, some did not consider their use of pornography as an issue. Others identified that they had overcome the issues and were in a controlled state of use:

I had a year - at least a year - where I was addicted, I'd say started to show signs of a porn addiction. Reliance and just everyday staying in bed watching porn. It is a very powerful drug at some points. It's hard. Once you're in that trap it can be very hard to get out of it. Porn can be very addicting I find. And yeah because we're made to reproduce, the high we get from that orgasm is amazing so yeah. - Ethan

I think because I knew right from the start that it was something I shouldn't be doing, from the time I started until I started my recovery, maybe twice a week. Thereabouts. I mean it was obviously lesser sometimes and worse at other times but if I average it out over the 12 years of addiction then it's probably around about twice a week on average maybe. - George

Ethan talked about how he had come to recognise that he was addicted to pornography and how it affected his experiences of sex, but that he now had a 'controlled addiction':

I can't remember when I realised it was an addiction, it would've been a couple of years into our relationship. Would've been last year I imagine. Yeah I started researching porn addiction and things like that and realised I need to actively, consciously try and stop consuming so much porn. Because it was having like effects. I wasn't getting as much out of my sex life with my partner at all. Obviously I was still maintaining my side of trying to please her but I wasn't getting as much pleasure out of it as I wanted. I was researching the effects of porn addiction and I actively tried to stop but because it was an addiction it was very hard. And to this day I haven't completely broken the addiction. But now I'd say I very much have almost a controlled addiction. No way near as much as I used to and I don't use it as affirmation of any insecurities or alignments I suppose. Yeah I use it when I feel like it, I don't use it as a way to cope with sadness or anything. I do it when I'm bored basically. That's a good way to put it, I do it when I'm bored. And when I'm horny and my partner's not around. - Ethan

He recalled a poignant situation where he celebrated using pornography instead of socialising, which was a sign of his addiction to pornography: 
There was this very poignant moment where a group of friends from college organised - we were all at University at this point, a couple of years in so we hadn't seen each other in a long time. We were all organising to get together and watch a movie for a friend's birthday. And I decided instead of going I would just lie in bed and watch porn and just get off and feel good. So looking back at it, it was a very poignant moment, but I was almost celebrating it you know? Much rather do this than go out and see friends. So unhealthy. Just not good at all. But yeah I was pretty addicted. - Ethan

This acknowledgement of the social effects of his use of pornography shows a depth of insight into how pornography was affecting his life. Alongside this, Ethan also acknowledged that his reliance on pornography had a detrimental impact on his understandings about consent in pornography:

When it was less manageable I was much less concerned about consent. Unfortunately yeah it was a drug for me so it was much more self-orientated. Probably more on the objectification side. The apathy side of things. So yeah. That's unfortunate but yeah that's the reality, I was addicted. I was reliant on porn. - Ethan

For Ethan, he was consciously aware that a change in circumstances, such as becoming single, could have a significant impact on his ability to control his use of pornography:

It's definitely not a problem anymore but that's because I'm consciously aware of it. I try and not see porn as a drug and I try to not use it every day five times a day... A very heavy user at some points... That's going to be interesting when I'm single again, how I deal when I cross that bridge. I think I've begun using other drugs to try and stop using porn as a drug and try and keep porn in that box of sexual exploration and sexual expansion and sexual self-exploration. - Ethan

Two participants in this thesis drew clear lines between an addiction to pornography and an addiction to masturbation. At the time of interview, Nathan felt that he was in the grips of an addiction to masturbating, given the frequency that he masturbated:
Nathan
I think I'm addicted... Not to porn but to masturbating, for sure.
Sam What makes you think that?
Nathan Because I've masturbated for like twice a day ever since, ever since I was 13.
Sam And have you always masturbated to pornography?
Nathan Nah. My mind has been pornography, so if that counts.

Chris, too, felt that at the time of interview he was addicted to masturbating, but he also recognised that there were few instances where he would be able to masturbate without pornography:

Chris Still early in my teenage years - I'd definitely considered myself to start being more of a regular porn viewer. Initially porn in the limited sense of 
flesh people doing bone stuff but over time that did broaden to animated pornography, written pornography, audio recordings. And I feel like porn was probably the cause, but I would consider myself currently addicted to masturbation... You could phrase that as addicted to porn if we're using the wider definition of porn. Not necessarily though as there are things that can be considered masturbation material without being pornography.

Sam So you mentioned that you would say that you felt addicted to masturbating, so do you always masturbate to pornography?

Chris Yeah that's why I try to make the distinction between addicted to pornography and masturbation because no, that's not the case. I would say the vast majority of the time yes. But I would say - making up figures - 90\% of the time to pornography, 9\% of the time to non-pornographic alluring materials and like a small, small portion of the time - probably so small maybe even just a dozen times of my life - when I just go purely off mental images.

Throughout the interviews with both Chris and Nathan, neither of them considered their addiction to masturbating and/or pornography as a problem, despite them both being able to identify impacts that they were experiencing as a result of their use of pornography. Nathan identified that his use of pornography, alongside his addiction to pornography was "an issue, I wouldn't say it's a problem. But yeah I guess if it doesn't get dealt with it can become a problem." Chris commented that

I mean like if it wasn't for the difficulty in stopping if I so desired, I would consider it as an analogous time waster to playing video games. Except with that added danger of warped perceptions if you weren't careful. - Chris

In reflecting on the stigma associated with pornography which was discussed in Chapter Five, and the suggestion that being addicted to pornography is a direct corollary of men's loss of control, it could be that both Chris and Nathan chose to reject the label 'addicted' to pornography for this reason. Regardless of opting to be labelled or not, both Chris and Nathan identified that they were experiencing impacts in their everyday lives from their reliance on masturbating and/or pornography. For Chris, he talked about the loss of time he experienced as a significant impact, alongside a difficulty stopping:

If we're basing it off the frequency of masturbation then easily two times a day, sometimes depending on the day, going up to 4. And most of those instances would involve pornography. Usually for a fairly decent period of time at a single go. So like if I'm really bored and there's nothing else to do, maybe an hour. The reason why I consider it an addiction is because of that length of time that is taken up, because of the frequency, and because it has become such a habit that - firstly because it's so easy to do - if I'm ever like oh I should try stopping masturbating, then that night or that morning I'm like well I could just masturbate. So because of that difficulty stopping. - Chris 
He elaborated in the interview on the time loss, and how his use of pornography and/or masturbation could also affect his sleep and studying abilities:

In that sense of time loss. And in the sense that I am scheduling my day, so I have set times when I can masturbate and probably if I didn't have those times I could extend studying. But like if I had to give up something to keep masturbating, it would probably be sleep. So keep studying at the same amount but sleep less. Which in turn has flow on effects for the next day I feel more tired, harder to focus, stuff like that. - Chris

Further, Chris noted that he had tried to stop using pornography in the past, but the lack of suffering he experienced from his addiction meant that his efforts had been halfhearted:

A few times. I don't put in a decent effort because like I wouldn't consider myself overly suffering. The main thing I'm losing out on is just that time during the day. Sure, I'd be able to get a lot more things done if I wasn't spending all that time masturbating, but I'm still doing fairly well at life. - Chris

Nathan felt that he separated the porn world from the real world, but he acknowledged that each world can affect the other, and this was an impact he was experiencing in terms of his feelings of happiness:

\begin{abstract}
Nathan I think I identify porn in more of a reality to the dream world. I can compare it to the dream world more than I can compare it to the real world. In the sense that by analysing both worlds, I have the potential to see how I can better my life and better my brain and get out of these nasty habits that I have. Also the real world has a lot more to effect on the people around me whereas the dream world and the porn world are very distant, based on myself. It can affect just myself. In a good way or a bad way. So it's the real world that I've gotta focus on ensuring that I'm healthy and positive. And so it's almost like the porn world is like the opposite of that. So it's more negative in the porn world than it is in the real world. But the problem is that this one can affect this one. They can affect each other.
\end{abstract}

Sam Is it affecting it now?

Nathan Iguess so. Because I didn't watch any porn this morning. The less I do it, to a point, I feel a little bit happier you know. And a little bit more able to converse with people. Especially with people from the opposite sex. Whereas if I masturbate heaps, I don't, I find I get really reclusive. And don't talk much. But then after like four days or something, if I don't watch porn or masturbate then I'm clouded again. Then I get reclusive. So like once every two or three days is a kind of a goal I'm going for.

Nathan's story shows that addiction to pornography/masturbating is undoubtedly a powerful thing to experience. As he suggests in this excerpt, the effects of pornography can have real-life impacts on their everyday lives. Further, as George suggests, stopping 
an addictive relationship with pornography is difficult because "there isn't just a tap you can switch off" as,

Our addiction is rooted and it's tied into our sexual identity and you can't just switch that off. So it's not about cutting it off or repressing it completely, it's about how do you redirect your sexuality into something more healthy. - George

Throughout this section, I have presented men's perspectives on how feeling addicted to pornography and/or masturbation had affected their lives. A number of men reported that it had impacted their experiences of sex, ranging from erectile dysfunction through to reduced pleasure in sexual interactions. Some men also reported that it had social and relational impacts, in that it affected their ability to be social or attend university. As we consider these perspectives in line with the discussions about the stigma of pornography presented in Chapter 5, there are obviously spaces - particularly online communities for men to talk about the difficulties they are experiencing with pornography. But this conversation needs to be wider and it needs to be more accessible. As I spoke with men, they detailed how difficult it was to speak about pornography generally, but if they were to speak to about pornography addiction in online communities, it would require a renouncing of pornography and a commitment to abstinence. But where does this leave men like Chris and Nathan? As they reject the label 'addict', yet still experience issues related to their pornographic consumption, what spaces do these men have to seek help and support to counter the negative experiences they report?

\section{Summary}

In the same ways that Chapter Six concluded that women's experiences with pornography were remarkably complex, this chapter suggests that men's experiences with pornography are complex, but in different ways. In this chapter, I have presented how the men interviewed for this research shared their perspectives on the appeals of pornography and spoke of how they engaged with pornographic material. In so doing, some of the men suggested a complex reading of pornography and complicated the idea of men as simply uncritical consumers of pornography. In some of their narratives, they speak to the difficulties involved in navigating consent in pornography, as well as the difficulties involved in reading and understanding aggression in sexually explicit media. Further, some of the men speak of the power of pornography in their lives, and the ways that pornography affected their social and sexual realities. Lastly, I presented some men's experiences of pornography addiction and identified a number of ways that this directly 
affected their lived experiences. Ultimately, this chapter presents a gendered reading of pornography which opposes the idea that men are simply uncritical viewers who celebrate women's degradation and abuse. Men's perspectives on pornography were inevitably subjective, complex and at times contradictory. However, the audience of pornography remains absent in critical perspectives on pornography as a genre, so this chapter presents an important voice in the wider pornography debates.

The following chapter combines the perspectives of men and women and discusses the role and influence of pornography in intimate relationships, which to date, has received little qualitative research attention (Montgomery-Graham et al., 2015). 


\section{Chapter Eight: Pornography and partners}

Pornography and its influence on romantic relationships has been the subject of much academic attention in recent years. Researchers remain divided on its effects, with research reporting either the harms of pornography (Bergner \& Bridges, 2002; DeKeseredy \& Hall-Sanchez, 2016; Lambert et al., 2012; Manning, 2006; Schneider, 2000), or the lack of harm and potential positive influence that pornography can have for couples (Campbell \& Kohut, 2017; Grov et al., 2011; Kohut, Balzarini, Fisher, \& Campbell, 2018; Kohut et al., 2017; Montgomery-Graham et al., 2015). These conflicts mean that ongoing study in this area is warranted, especially given the complex and subjective ways that pornography is experienced by consumers, partners and couples. To date, there is little to no research in New Zealand which is specific to pornography and intimate relationships. A thorough scope of the literature in New Zealand in this area shows only one study which has specifically explored some of these questions. Martin's (2016) survey of 136 women suggested that men's use of pornography in intimate relationships negatively affected women's levels of intimacy as usage of pornography increased. Martin concluded that further conversations in this area were needed to explore the impact of pornography on intimate relationships in New Zealand. This study fills a significant literature gap in New Zealand and provides perspectives from emerging adults about their experiences with pornography in their intimate relationships.

\section{Partners and pornography: couples viewing erotic material together}

Couples viewing pornography together is not a new phenomenon, and research suggests that a significant number of couples view sexually explicit material together (Daneback et al., 2009), especially young, unmarried couples (Maddox et al., 2011). The partnered use of pornography in intimate relationships is often considered from a harms-based perspective, with a number of studies exploring women's experiences of their partner's use of pornography using this framework (Bergner \& Bridges, 2002; Schneider, 2000; Stewart \& Szymanski, 2012). Paul (2005) suggests that the fantasies induced by pornography create a mediated form of intimacy whereby relationships become characterised by 'you, me and pornography':

There's a distinction between free-flow fantasy and porn-induced fantasy. While both often involve "other" women, fantasy is an individual's prerogative; pornography is an industry prescriptive. Fantasy is all in the mind; pornography is in print, on video, and online. Fantasy inspires a man to seek 
out and understand his desires; pornography lets others decide for him. Fantasy is open-ended; pornography designates a beginning, middle, and end. Fantasy is private; pornography is mediated. Fantasy is nature; pornography is artificial and commercialized. Pornography also comes across differently to women than it does to men... For a man to say, 'don't worry, you're different from the girls in porn; you're my wife,' is hardly reassuring" (Paul, 2007, p. 141).

Indeed, numerous studies which support Paul's notion of the detrimental impacts of pornography on relationships, especially for female partners. Qualitative research with women affected by their partner's use of pornography has clearly demonstrated the negative personal, social and relational effects that men's use of pornography can have on women (Bergen \& Bogle, 2000; DeKeseredy \& Schwartz, 2013; Manning, 2006; Shaw, 1999; Shope, 2004). More recently, research with rural women in Ohio suggests that women's experiences of their partner's use of pornographic material can be part of a gendered experience of domestic and sexual violence in intimate relationships, where women are coerced into viewing pornography by their male partners (DeKeseredy \& Hall-Sanchez, 2016). Research with men about the harms of pornography use on the couple relationship is limited, however research on the psychological, relational and sexual impacts of pornography use on young heterosexual men suggests that men's use of pornography is "associated with their gender role conflict and avoidant and anxious attachment styles and negatively associated with their relationship quality and sexual satisfaction" (Szymanski \& Stewart-Richardson, 2014, p. 76).

The exploration of the impacts of pornography from a solely harms-based framework has been criticised, and Campbell and Kohut (2017) argue that the utilisation of a harmsbased framework

places critical limits on what can be learned about the typical impact of pornography on the couple... harm-focused rationales that underlie such investigations are also at odds with observations reported by persons who live in relationships in which pornography is used, which typically suggest that pornography users and their partners perceive more relationship benefits than harms associated with pornography use (p. 7).

In line with this, some research suggests that the partnered use of pornography in relationships affords couples an erotic climate which opens up possibilities for enhanced sexual satisfaction, perhaps due to ongoing, engaged communication with partners about sex and sexuality (Daneback et al., 2009; Green et al., 2013). Further, viewing sexually 
explicit material only in the presence of a partner - that is, no solo viewing - has been associated with increased dedication in dyadic relationships (Maddox et al., 2011) More recently, research with emerging adults in the United States suggests that a significant number of men and women believe there are appropriate circumstances, either alone or as part of a dyad, for using pornography in a relationship (Olmstead et al., 2013).

Viewing pornography in the presence of a partner came through in a number of interviews with both men and women. Overall, men seemed more likely to view the use of pornography with a partner as a positive inclusion in their romantic relationships and beneficial to their sexual experiences with a partner. In speaking about his use of pornography alongside a female partner, Luke spoke overwhelmingly positively about this activity. He also acknowledged that filming sexual activity with a partner was an enjoyable shared engagement:

I've been with partners that have enjoyed watching porn while we've had sex. I've never had any negative impact from my enjoyment of porn with partners. And there's been instances where you know, you might enjoy filming having a bit of sex or whatever. Or blowjobs or whatever. It's obviously never a shared thing. Well maybe not obviously [laughs]. But it's something that does sort of, I'm not opposed to a) watching porn while having sex b) using a big mirror and watching each other having sex and c) filming ourselves having sex. And then enjoying that as a form of pornography later on. - Luke

Kevin also reflected on using pornography with his partner in previous relationships, saying that "I'd watched it together with whoever I was with. Ha. It was alright. It was good."

In speaking to pornography in relationships, two men spoke about how they had used pornography to sexually educate their partners. Of course, what one partner may see as education, the other may experience as coercion. In the following excerpts, Derek and Tom speak about the role pornography can play in educating their sexual partners, and it's important to consider that this use of pornography as an educator may well have been perceived differently by their partners. Derek spoke about how he had used pornography to demonstrate to his partner how other people behaved sexually, making pornography a “tool." Derek spoke about pornography as merely "another toy for the bedroom" and went on to say that he hadn't "necessarily watched porn with a partner and then like tried to reenact what was seen." However, throughout the interview, he contradicted this by discussing how he had to 'open' his partner up to anal sex. He commented that the benefits of pornography in his relationship were "mostly maybe for my partner rather than myself. 
To show her that other people do similar things too." He alluded earlier in the interview that pornography may have contributed to his sexual adventurousness, and his partner was more sexually conservative than he was. In speaking about being comfortable talking about pornography with his partner, he suggested that it was:

Me more than her, definitely. She's quite picky what she will bother to watch. And like if it will get her off at all. I think that's something that we'll probably get more into as we go on. Yeah. She's definitely much more of a prude compared to the sexual background that I've come from. - Derek

He acknowledged that she "would sorta lean more to the girl on girl side. That's more up her alley. Not that she, we haven't necessarily found a girl for us sort of thing." Derek had identified his personal preference in pornography as being "right into anal sex", and his partner's sexual 'prudishness' meant that "she isn't very big on anal play which I've had to like, also introduce her to. She's finding the pleasure in some things like that." Undoubtedly, heterosexual anal sex can be a positive and pleasurable experience for many women. However, it is also acknowledged that women's experiences of anal sex are not always pleasurable and/or enjoyable (Fahs \& Gonzalez, 2014), and some young women largely attribute their experiences of coercive anal sex in heterosexual relationships to men's pornography consumption (Marston \& Lewis, 2014)

Derek acknowledged that he and his partner purchased pornography together, however it was her who was 'dared' to buy it:

$\begin{array}{ll}\text { Sam } & \begin{array}{l}\text { And you've mentioned that you and your partner might buy } \\ \text { magazines together? }\end{array} \\ \text { Derek } & \text { She does [laughs] } \\ \text { Sam } & \text { She does? } \\ \text { Derek } & \text { Idare her to and she would. }\end{array}$

In light of this, he recognised that their viewing of pornography magazines together was probably experienced differently:

My partner and I will buy magazines that come with a little DVD or something. Something like that. I quite prefer the magazines for that whole purpose of vintage appeal... we will sort of sit down and both go through it together looking at it, just sort of like pointing out what we like and don't like about it. It's not necessarily for a sexual thing or just keeping up to date with what's going on with what people wanna do with themselves really... she would have a much different perspective of it than I do, so I don't know if she watches the DVDs that come with it like I. - Derek 
Derek's own acknowledgement that his partner likely views their pornographic viewing differently suggests that there may well be an element of unequal power in the decisionmaking around the use of pornography in the relationship.

Speaking about pornography as a 'tool' once more, Tom spoke about how pornography had the potential to illuminate his partner's sexual interests and preferences, as well as navigating soft and hard boundaries in their sexual experiences:

I use it as an educational tool. So I will find particularly good videos, things like Kink.com and stuff, and we'll watch it together and I'll be like listen, this is what I like. And then we'll watch it and I'll be like okay, are there things in there that you absolutely won't do, are there things that you might do, are there things that you thought were really interesting? So it can be really useful in that respect... Usually it goes really well. Cos usually they see things and they go well I've never done that, I've heard about that and now I've seen what it actually looks like, yes I think we could try that. - Tom

Tom went on to say that he felt that some women were "naturally averse" to admitting that they view pornography, and that broaching the topic of watching pornography could therefore take some time:

Some girls are naturally averse to saying that they watch porn for some reason. It's like listen, we've already had sex, I know you have sex. You watch porn, it's okay. So sometimes it takes a little bit of time to just let them know I watch porn, you watch porn, we've already had sex, it's fine... I've seen you naked, I know what gets you off, we're fine. And it's like I want to watch this because I want to know what else gets you off. - Tom

In this excerpt, Tom specifically frames showing his partners pornography as a mechanism for identifying their needs and sexual satisfaction. In the same way that some men spoke earlier in Chapter Seven about women's authenticity in pornography as key to their own pleasure, Tom suggests similarly in these extracts, pointing to her pleasure as the foundation of showing pornography to a partner. At the same time, the suggestion that he knows she watches pornography could also be perceived as coercive, in that it could be difficult to counter it with a negative response, particularly when viewing pornography and being sexually 'up for it' seems to be a mainstay of cultural expectations for women. Further, however, he comments that women were naturally averse to admitting their use of pornography, and this resonates with comments made by women in Chapters Five and Six who suggested that men knowing about their personal pornography preferences could lead men to make assumptions about their sexuality. The stigma associated with women's use of pornography which was discussed 
in Chapter Five also means that some women opening up about their use of pornography is perhaps an unlikely reality.

As I spoke with women about viewing pornography with a partner, a number of them spoke about the realities of choosing the type of pornography that would be viewed in these sessions. In the previous section, both Tom and Derek spoke about being the ones in charge of the type of pornography that was viewed. Tom provided his partners with a selection of "good videos", whereas Derek encouraged his partner to purchase pornography for them to view, but that she was unlikely to engage with it in the same way as he did. In conversations with some of the women interviewed, they also seemed to be the ones who were responsible for selecting videos to watch with their partners. However, the decision-making process suggested that women were working hard to find pornography that they were comfortable viewing. This is perhaps unsurprising given the perspectives women shared on how they felt about pornography in Chapters Four and Six, where women's recognition of the misogyny and degradation inherent in pornography was a cornerstone of the viewing experience. Tara acknowledged she and her partner sometimes viewed pornography together, but she alluded to her partner suggesting it in the first instance:

Sometimes we co-watch porn together. When we have sex and stuff or before sex but then it's like always an issue of finding porn that I don't find repulsive. Or that's super scripted and fake... He was always like 'yeah let's do this, find something you like'. So for him I don't really think it was an issue with finding something he liked cos I was the picky one. Cos I really, really don't like the super scripted fake stuff or stuff that treats women like shit. It's more of an issue of finding something that I'm comfortable watching. - Tara

Lilith was concerned about being judged for the pornography she selected when viewing pornography with her partner, who she commented had chosen to abstain from viewing pornography from a moral perspective:

Cos it's a thing that supposedly couples do together so I'm like 'oh right, let's try it'... We did it but it was like really like weird. It was weird in the sense that to allow what porn we should watch he was like 'you choose,' cos he doesn't watch porn. Because he decided when he was like in first year that it wasn't okay to women and wouldn't do it anymore. So then we like spent ages choosing and I felt self-conscious about searching up whatever I would want to search up. So we just like browsed through and then we decided, chose this random one. Kind of like you know, okay and like normal, like vanilla. And then we like watched it, but when you're watching it with another person you kind of realise how ridiculous porn is and you sort of realised, you notice all the weird stuff about it and so it was hard to like watch it seriously... we're not gonna do it again [laughs]. - Lilith 
Carly also alluded to a fear of being judged for the pornography she chose to view in the company of her partner, yet also acknowledged it was something she did not like engaging in:

I've watched porn with him a couple of times together - but I don't really like watching porn with someone else and it's like I would always choose, it'll always be porn, he's like 'you put something on' and I'll choose it. But then I feel hesitant about what I'll put on or I'll feel judged about what I put on. Not that he is at all judging me but it's like I just get paranoid about it and then I don't actually end up watching it. - Carly

In contrast to these perspectives, Nadia presented a more enthusiastic and engaged involvement in choosing pornography to view with her partner. However, she also acknowledged that they had different tastes, and finding pornography that she enjoyed was most important:

My last partner of three years, we definitely would have sex to porn and everything... It wasn't something that was really given a second thought... sometimes we would just throw it in, let's watch porn together. I would be the one holding it because he'd be behind me, you know?... It was funny cos we had different tastes. So sometimes I'd get to choose, sometimes he'd get to choose. Sometimes we would like choose together. But it was funny cos I like to get my way, I'm a princess. Even when it was his turn to choose, I ended up getting my way, I'd say 'oh I don't like that one' and we wouldn't watch that one. - Nadia

Whilst selecting the type of pornography that is enjoyable opens up a private aspect of the self, for women it perhaps has the potential to open up the gendered notions of what's appropriate and not appropriate for women to view. Lilith commented that talking about pornography "is almost like more personal than like talking about sex. I think because of its kind of like - I still think of porn as quite like a taboo thing... it's more intimate than like talking about sex." Lilith also commented that finding pornography that she found enjoyable was often a click and determine type exercise, and some pornography - such as rough pornography - was only attractive when it was the "right kind of rough." Bearing in mind gendered expectations around speaking about pornography as discussed in Chapter Five - and indeed concerns about the gendered double standards surrounding women's use of pornography outside the confines of these gendered expectations - this perhaps suggests that women's divulging of their pornography interests in the presence of their male partners could have real-life consequences. As Jasmine discussed in Chapter Six, she preferred gangbang style pornography but had no interest in engaging with it outside of pornography. Opting to open up about pornography which is erotic - but not an offline sexual preference - means that women may run the risk of men seeing this as 
an invitation to engage in that particular type of sex. As discussed in Chapter Six, women also expressed concern about men's readings of pornography and their subsequent treatment of women, and this is perhaps amplified when pornography is suggested by women as it could a precedent for presumably 'what women want.'

\section{Pornography and coercive sexual practice: women on male partners using pornography to shape sexual interactions}

In the previous section, some of the women were clearly involved to some extent in the decision-making process around viewing pornography. However, the same difficulties women expressed in Chapter Six around navigating the pains of pornography were present in these narratives, whereby some women seemed to struggle to find pornography that they would enjoy with their partners. Yet women's involvement in choosing the pornography was not universal, and a number of women spoke of their male partners being in charge of the pornography use in their relationships, and using pornography as a coercive mechanism for sex. DeKeseredy and Schwartz (2013) contend that

men's consumption of pornography hurts their intimate female partners on numerous levels. Many women report feeling betrayed, having lowered selfesteem, or anger from being pressured to imitate what their male partners see online, and they also suffer a range of other negative effects that aren't the result of physical force (p. 123).

As will be demonstrated in the following section, four women presented their experiences of their male partner's using pornography coercively in their intimate relationships, and how this contributed to a range of negative effects for the women I spoke with. As Miranda reflected on a previous relationship, she commented that her and her partner had viewed pornography together "occasionally", however, the decision to view pornography together was almost exclusively directed by him. In her words, she said "it was very much driven by him rather than by me." Miranda felt that viewing pornography together in that relationship "became this thing that we don't watch vanilla porn... vanilla is usually things that are not kinky enough, that are too standard, that are not deviant enough for him." In identifying what would count as not 'kinky' enough, Miranda outlined that much of this pornography was within the realm of BDSM:

I would say it has to do with dominance, either on the female or the male side. It usually was heterosexual porn. Not always. Also I think a few lesbian porns, yeah I do actually remember [laughs] a porn that we watched, it was spitting also. And he was the one who was into golden showers, he was really fascinated by that. It 
wasn't for me thankfully. But yeah. Like scat was not for him. Those were the kinds of BDSM porn he was into. Like clear about power play rather than specific practices. - Miranda

Miranda's ex-partner's preferences for pornography shaped what she thought were her own preferences for pornographic material and what she thought was 'normal'. This was troubling for her, and much of her pornography engagement at this time was described as satisfying her partner's needs rather than her own:

I was just really confused about what my own preferences were and very open in the sense that I watched things that I probably wouldn't necessarily watch. And not because I think they're bad but because they don't suit me. I would definitely watch more kink, and I thought it was normal as well. I thought this was just one expression of how men love women. And that it bothered me came so much later you know. And because I said that he was also switching like in terms of sadism and masochism and so on, I never felt like I wanted to be sadistic myself. So the masochist side I didn't know what to do with that. But I also, to please him, I pushed myself into doing these kinds of things as well... I just thought [the porn] was weird and strange... So if that doesn't do it for you in porn, and it doesn't do it for you in real life, then that's probably not for me right? But because I was trying to explore that sort hard for his sake, I kept on watching different things like that as well. - Miranda

In speaking further about the relationship, Miranda mentioned that her partner's sexual interests also included visiting sex clubs and swinging, which she felt pressured to engage with, again to service her partner's needs:

Yes. Yes I did feel pressured. And I pushed it down a lot because I felt pressured, I felt really ambivalent about it. It was yes, no, yes, no, yes, no. And now I've learnt that this kind of ambivalence means a no from me. Until it's a hell yes I just don't need to try it. - Miranda

The idea that men used pornography to influence their partners in terms of what they wanted sexually was also shared by Tina. Tina spoke of a previous sexual relationship she had with a work colleague when she was newly single and "was in a bit of like a not very confident with myself, wasn't loving myself at all" type of mind-set. The relationship sounded quite coercive in nature and took advantage of her emotional vulnerability at the time:

He text me, got my number off my supervisor and said I'm going to fuck you at work tomorrow. And I was like okay? [laughs]. Just with like the headspace I was in, I didn't really care. Didn't think of my body as mine. Did the whole like sweet as, the typical I'll open my legs to make myself think that someone wants me but it just really degrades yourself. - Tina

From the outset, this sexual partner made it clear that he held the power in their sexual relationship, and he expected her to watch "a lot of that kind of like quite dom/sub porn 
which kind of instead of being nice it was more of just women being used as an object." He used to "send me videos and GIFS and all of that other stuff" which made her feel "pretty down about myself" because it "made sex not a special thing at all, it was just I was there for him. Like it wasn't anything to do with me. Which wasn't a nice feeling at all." Tina noted that this relationship went on for a couple of months although she "definitely didn't get anything out of it", until she realised that "nah this isn't for me." Naomi also spoke of her partner using pornography to coerce her into sex which he desired. In reflecting on her first ever adolescent relationship, Naomi spoke of the pattern of emotional and physical violence she experienced:

I guess because you know it was my first sort of everything... First love, first virginity, everything. Sort of things that I felt were normal in relationships which absolutely aren't. You know heaps of it, things that I sort of felt were normal in relationships and then realised that completely aren't normal at all. I guess that's how the relationship worked. Because it was my first time for everything it was sort of like oh yeah that's normal, but it's not... he only like physically assaulted me once. But he sort of threw me against a wall and sort of held me there and he punched the wall next to me. So there was bleeding hands and things like that... he would also emotionally manipulate me all the time because I wouldn't move in with him because I guess I still had like a little bit of doubt deep down because my family were so disappointed in me and I was sort of worrying about that... all my friends were trying to stop it but he was really trying to like remove me from my friends and family and make me feel bad about them. You know that kind of thing? Like he'd get into my head about people that I was friends with and stop me from hanging out with them... he'd come to my place of work every day and just sort of like sit in the store. Because a lot of my other friends from uni or school would come visit too but he'd sort of try and get rid of them - Naomi

Throughout this excerpt, it's clear that Naomi's partner attempted to isolate her from her friends and family, as well as using physical and emotional violence to manipulate her and maintain control over her in the relationship. This violent pattern of behaviour also extended into the sexual realm, where Naomi's partner used pornography to 'push' her along and coerce her into sex:

I guess like with sex, it started off really early. Like I did feel like - for lack of a better word and this is probably a bad word to describe it - I did feel like I was getting groomed. You know for him to do that he would, you know if I'd sort of say things like I'd like to wait until this point in time, because I had no idea of what I wanted to do, and he'd get quite mad and he'd like pick up his laptop, try and find something porn related to watch and he'd go into the toilet and come back and sort of like sulk for a while. I guess that was sort of like my first experience. I guess in order to like push me along a bit, then he'd start watching it in bed [next to her]... he'd try and make me feel shit for not doing it so he had to find other ways - Naomi 
At the time of this behaviour, Naomi and her partner had not yet had sex, and his use of pornography was "always" related to her refusing his sexual advances. Her partner's coercive use of pornography continued once they began having sex, where "he'd watch it to like show me different things that he'd like to try." These experiences with pornography were Naomi's first, and she noted that she "didn't have any idea of what porn really consisted of and I'd never gone to sort of look at it myself because my parents are religious so it didn't really interest me." These initial encounters with pornography, however, had lasting impacts:

I think because I was being emotionally manipulated I felt like I had a lot to live up to and that this was the epitome of like the perfect woman... I think that it made me feel like I was lacking as like a partner. And it sort of made me to want to sort of live up to his expectations of what sexual activity should look like... as garish as it sounds, during videos and things like that, when you see these women wearing like lingerie but not just your usual bra and undies, like above and beyond, he expected a lot of that. And like costumes and things like that too." Naomi

Throughout these narratives, the women interviewed have identified the ways that their partners used pornography coercively to shape their sexual interactions. These experiences suggest that pornography can be used as part of a pattern of sexually coercive behaviour in a relationship by presenting a set of expectations for sexual behaviour for women to engage in to please their partners. These narratives raise the question of how men thought their use of pornography may have affected their partners, and this chapter now presents these perspectives.

\section{Men's thoughts about how their pornography use affects their partners}

Research suggests that men and women's perceived expectations of the appropriateness of viewing pornography in a relationship are complex and varied (Olmstead et al., 2013), and the experiences reported in this thesis confirm this observation. In the context of speaking about pornography in their intimate relationships, a number of men and women spoke about how their partners perceived their use of pornography. In total, four of the men interviewed spoke about this specifically, and this chapter now explores their perspectives in turn. Qualitative research with emerging adults suggests that men are more likely to discuss obtaining approval from their partners before they felt it was appropriate to view pornography either alone or together (Olmstead et al., 2013). Cameron mentioned that both he and his partner had spoken openly about pornography use in the context of their relationship, and that whilst his partner typically left the 
decision up to him about whether or not he could use pornography, she did not like thinking of him having sex with another person:

If I was to say can I watch porn yes or no? She's not the type of person that would say yes or no, it would just be like it's up to you. She doesn't mind porn but she doesn't like thinking about me having sex with someone else. She knows that I use porn. I sort of just told her, well asked her, are you okay with me using it? She's like yeah I don't care. I don't like to think of you having sex with another girl but yeah... I think her perception is when you're watching porn you're imagining yourself being the guy fucking or having sex with the girl that's there. But for me, it's not necessarily what's going on. It's kind of complex. - Cameron

Throughout this extract, there are connections here between Cameron's partner's perspective and the common perception that pornography use in a relationship can be perceived as tantamount to cheating or infidelity, particularly by women (Bridges et al., 2003; Olmstead et al., 2013). Ethan, too, commented that his fiancé perceived pornography as akin to cheating and was "very conservative." Ethan, who had struggled with an addiction to pornography, said that his partner's views on pornography meant he had to use pornography behind her back:

Back then, I'd say in our first few years. I'd still use it on the sly behind her back because I didn't consider it cheating... But back then I suppose it was an addiction, it was not something I could easily - back then I didn't narrativise it as an addiction, I just liked it. Like a drug. I can't remember when I realised it was an addiction, it would've been a couple of years into our relationship. - Ethan

This 'on the sly' use meant that Ethan felt "guilt" and questioned "am I actually cheating?" and "what am I doing to this person that I love?" However, Ethan noted that his partner's difference in opinion about pornography meant that their relationship was likely to end as "our differences have become too great and I'll have to break up with her." Pete also commented that his use of pornography had created a pressure point in his relationships and they had not survived. In his current relationship, both he and his partner were open about pornography, but his partner struggled with his use:

We do communicate quite well about it. And she is not entirely happy about it. She doesn't mind me looking at pornography but she does get upset that I do not direct so much energy into her. - Pete

Later, he elaborated on the strain his pornography use had caused:

So that'll be a smaller piece in the bigger feeling that she'll get. And this is a recurring thing that I've had in relationships in that I am perhaps not very expressive in terms of affection and towards my partners. And also the whole kind of adventurous side of things that I am, it's like I'm not entirely focused on this one person. I'm kind of outward looking. So this has been a recurring - in 
three major relationships that I've had, that has - definitely in two, probably in the other one... [and] including this one. - Pete

Nearly 18 months after our interview, Pete contacted me to provide some additional information about his life following the interview. He mentioned that he had "fallen in love" with someone and was attempting to complete 90 days of No Fap - the no pornography or masturbation version. Unfortunately, Pete did not elaborate further about his decision to try No Fap again in his new relationship, however it was presumably in an effort to ensure the relationship lasts given his use of pornography had been a significant problem in his previous relationships.

Kevin also reflected on his relationships during the interview and noted that using pornography in previous relationships "was never an issue" and was more likely endorsed, as "it was more like an 'it's okay to watch that. It's alright." However, later in the interview, Kevin reflected that he was less sure about whether his partner had actually been okay with his use of pornography in the relationship:

In reflection there were other things she said like sometimes she'd be like 'oh I know I don't look like the people that you look at online'. So that kind of stuff I think, upon reflection, like maybe she wasn't as comfortable cos she's like 'oh you look at porn, that's fine. It'd be crazy if I didn't let you'... I think whether or not that was the person at the time felt like she needed to say that because that sort of such an established norm, guys watch porn, that in order to sort of seem cool or seem understanding you have to say 'I'm okay with it'. Or whether or not she genuinely was, I was actually like definitely thought about it more recently whether that was the case or not. - Kevin

In this extract, Kevin queries whether his partner truly agreed with his use of pornography. He suggests that maybe she felt obliged to agree or comply with his use of pornography, especially because men's use of pornography is such an established norm. In a sense, Kevin is speaking to the notion of women being expected to comply with an 'up for it' (Gill, 2008) sexuality, where men's use of pornography is accepted and women's active engagement with such material is also part of the reality of being a sexually open, agentic and empowered women. In previous chapters, women frequently identified pornography as a genre which was primarily for men, and that their use of pornography was commonplace - as Jasmine so aptly puts it, "it's a need for them in a way." But what about how the women thought their partners perceived their use of pornography? 


\section{Women's understandings of how men view their use of pornography}

During conversations with men, none spoke negatively about their female partner's use of pornography. Interestingly, however, three women spoke about how their male partners perceived their use of pornography. Miranda reported feeling that at times in her life she had felt dependent on, or reliant on, pornography. In hindsight, she was 'annoyed' at how she had been reliant on pornography and not able to see how damaging it was:

I definitely have had days where I have abused porn, like where I came 8 times, all the times with porn, or even 11 even. And the difference is that self-care is not harming yourself and I was raw by the end of that. Really, really honest [laughs]. So I do think - it wasn't very often and it wasn't habitual, but just that that has happened shows to me that it's very, very powerful, porn itself. And on top of that, that wasn't like with porn I handpicked and chose and you know curated for my own needs, it was whatever was there. So yeah I would say I definitely have a dependency... I didn't really see that many things wrong with it because I grew up with it, it's normal, you can watch it, it's easily accessible but now it actually annoys me. - Miranda

Miranda's husband encouraged her to stop using pornography, and he had strong views about pornography himself which he communicated to her:

I used to watch porn early on in my relationship. Early on being until about two years. But he has an issue with it, and rightfully so, because he said it's a detachment of my sexual life that's not circled around him and he sees it as cheating. And I don't want to cheat on my husband... I have a sexual history myself without porn. Or not necessarily, I mean it's always been influenced by porn. Apart probably from the current marriage which is probably why it works so well right?... He's one of the first men that I've met, that I'm in a relationship with, who say I actually don't like porn and I don't like you to watch it, right? In terms of navigating that, because it can sound controlling right? Before that was also my own realisation that I don't like it. Or not that I don't like it but that it's not good for me. I mean I masturbated myself raw, I felt crappy afterwards. Even now there are some things that I know have turned me on but it's more like a shock. - Miranda

Miranda noted that she had tried to talk to her partner about pornography, but pornography was less important than her marriage, so it was not often a discussion point:

To me it doesn't really matter, it's not worth discussing. I have also raised it but it's just not worth fighting over because it's just not important enough to me. I don't need to have porn, I would like to keep my marriage instead. Because I think that's what it could go down to. Not that he ever gave me an ultimatum or anything but made it very clear how important it was to him. - Miranda

Lilith's partner had made an active decision to stop using pornography in his first year of university, and she commented that his feelings about pornography were closely tied into 
notions of morality. She reflected that he viewed it as:

It's like bad. Like it's not the same as like what sex is actually like. It's very much performed. But also because the exploitation of women in the porn industry and also because of the way in which women are portrayed. The porn industry is like problematic in terms of the exploitation of women. I think just like, I think he's like a moral person and porn is kind of immoral. - Lilith

In asking Lilith how he felt about her using pornography, she commented that "we've had conversations about like why he didn't watch it, and then I've also, I guess we've talked about it, but I guess I don't feel bad enough to not watch it." Lilith's comment about not feeling 'bad enough' to not watch it suggests that her partner perhaps expresses his views about pornography to her, but they are not so strongly worded to stop her from viewing erotic material. Carly mentioned that her and her partner had spoken about pornography, and that he had not indicated to her that he felt negatively about her using pornography. However, she alluded to a potential anxiety that he may have had about her use of pornography being higher than his, which led her to question whether he would prefer she not watch pornography at all:

I mean he's never said anything - not that I recall - about like negatively about it. But in saying that maybe he's implied something because I have some sort of apprehension there about talking with him about it. Maybe it's just the fact that has been like 'you watch more porn than me'... Well not in that way, but it's come up in our conversations about it. So yeah, I dunno. I don't know if he would be, he would probably prefer it if I didn't, but then I don't know. I am completely speculating and speaking for him and maybe if he was here he'd be like I really don't care. - Carly

Alongside the three perspectives shared here by women about how their partners perceived their use of pornography, I also wish to present some of the women's perspectives on men's use of pornography in relationships. This was a key theme which came through in a number of interviews with women, and this chapter now turns to these perspectives.

\section{Women's perspectives on men's use of pornography in intimate relationships}

As previously mentioned, much research on pornography and intimate relationships has been concerned with women's perspectives on their partner's use of pornographic material. Many women's experiences of their partner's use of pornography are often reported to have detrimental impacts on their own self-esteem and self-worth, as well as trust and faith in the relationship a whole (Bergner \& Bridges, 2002; Bridges et al., 2003; Manning, 2006; Schneider, 2000). In none of the interviews with men did they speak in- 
depth about their female partner's use of pornography, however several women spoke about their feelings surrounding their partner's use of pornography in their relationship. The idea that men were unlikely to speak about their female partner's use of pornography perhaps suggests both that pornography use remains a 'guy thing', but it also supports research in this area that suggests that most men are unlikely to feel threatened or concerned about their female partner's use of pornography. As Bridges and Morokoff (2011) identify, the gender differences associated with how men and women perceive sexual media use in an intimate relationship is likely related to the different attributions men and women make about this activity. They argue that "men tend to interpret women's use of sexual media as an attempt to enhance the couple's lovemaking, while women tend to report greater negative affectivity to hypothetical scenarios of a partner's use of sexual media" (Bridges \& Morokoff, 2011, p. 565).

In the perspectives with women which follow here, their positions showcase how their feelings about their partner's use of pornography can be influenced by their partner's treatment of them sexually, but also how pornography can have significant detrimental impacts in couple relationships, especially when pornography use is perceived as an 'addiction' or at problematic levels. Zitzman and Butler (2009) argue that "understanding the mechanisms and pathways by which pornography use negatively impacts attachment, intimacy, and generativity is essential to evaluate the significance of pornography viewing in the context of the pair-bond couple relationship" (p. 214). In so doing, they argue that pornography "scripts expectations and behaviour that place it on a collision course with the requisite dynamics for secure attachment and authentic intimacy" (p. 214). In considering pornography use and its impacts in line with sexual script theory (Gagnon \& Simon, 1974; Kimmel, 2007; Simon \& Gagnon, 1986), it could be argued that as individuals view pornographic depictions which are typically outside the realm of ordinary depictions of sex and sexuality, the expectations for their partners or sexual activity may begin to alter. In line with sexual script theory, then, "pornography would be linked to eventual negative couple outcomes by altering individual sexual scripts and perhaps fostering unrealistic expectations of sexual partners (Willoughby, Carroll, Busby, \& Brown, 2016, p. 146).

Ultimately, a number of women spoke about how their partner's pornography use had negative impacts on their relationship, especially regarding how it affected their offline 
experiences of sex in their relationships. As previously discussed, Naomi felt that her partner's use of pornography had affected his expectations for how she should behave sexually, but also her own expectations for herself and how she should 'perform' for him. Izzy commented that her partner was "trying to introduce things from the porn into our sex lives but I didn't know what was happening so I was just like this is really weird. I don't know what's going on sort of thing." She elaborated it that it was "dominatrixy" kind of stuff which was the opposite of what my personality is" and her partner would "get me to say really mean stuff to him during sex... I'd just feel really awful about everything that I'd said and I'd be like apologising." This was a first for her in her sexual relationship history, and it "felt really bad for me. I didn't like it." Once she stopped being involved in this type of sex for her partner, he started "ringing sex lines and they were telling him he was shit. They were being horrible to him over the phone", which although this was what he wanted, it was the ultimate betrayal for her in their relationship. Holly commented that she felt that her current partner had been influenced by pornography, especially regarding rough oral sex:

Certain things with how he fucks, I see, it reminds me of porn. And it just makes me wonder. Cos he used to watch heaps of porn and shit... just wondering if that's affected or shaped the way that he likes fucking. And I think it has, it must've. Maybe some other shit as well [laughs]. - Holly

I asked Holly whether there were any things she had noticed about the way her partner had sex with her that she thought were shaped or influenced by porn. She commented that there was:
Heaps of dirty talk! And I'm not used to dirty talk outside of work. It's just heaps of dirty talk all the time. Which at first I was like 'oh my god!' but then I just fucking got used to it at this point [laughs]. And like with blowjobs and stuff, I'm a tease and shit cos that's just what I am. And I like to do things slow and enjoy things but he likes really like skullfucking, I'm like 'fuck!'. And deep throat and all the stuff that I associate with PSE's ${ }^{23}$ at work. Cos they're all into the deep throat and you have to you know deep throat them and lots of eye contact and lots of dribbles all everywhere, urgh. It's not usually hot to me. I mean sometimes, depends what mood I'm in, but yeah. Cos I don't like giving blowjobs like that. I don't particularly like gagging on dick. - Holly

Holly commented that she felt she had to be "a bit porn starry" to keep her partner sexually satisfied and she attributed this to the influence of pornography on his life. She

\footnotetext{
${ }^{23}$ PSE stands for 'Porn Star Experiences' which relates to a particular type of service offered by some sex workers. In the New Zealand context, this could include the playing out of fantasies within the confines of consensual interactions. As this narrative shows, in Holly's experience she included behaviours such as deep throating during oral sex as within the bounds of PSE's.
} 
felt that her partner was also influenced by spanking in pornography, however she presented this as somehow more manageable than the rough oral sex which she equated to 'skullfucking'. She noted that he had been influenced by the "spanking, which is fine" but was keen to point out that

He's not like this terrible fucking monster or anything [laughs]... he can be really really sweet. Like he's never ever been sweet like in the past. He's always fucked, like that's how he's fucked. Him dominating, him being in control and stuff like that. Now he can be really sweet and stuff when I want and I don't have to ask. So he's come a long way. - Holly

Tara also felt that her partner may have been influenced by what he was viewing in pornography. In an earlier, long-distance relationship, Tara also noted that during oral sex, her partner would push her head down and she queried whether this was influenced by his use of pornography:

He used to just push my head a lot and I'd be like 'bro that hurts, don't do that, you need to stop doing that' but he just kept doing that. Not at that time but throughout the relationship it just seemed to be something that he liked to do despite me being like I really don't fucking like that. And I didn't know about that genre or that act of porn being a thing until, I dunno I started reading random articles about porn that I found and it made me think maybe there's a thing there, I dunno. Like maybe that's something that he watched. Cos we did a long-distance relationship, he was in the army, so I don't doubt he watched porn. I don't doubt that. - Tara

Ultimately, Tara felt concerned about feeling second best to pornography. Tara noted that she had become more okay with her current partner watching pornography, however she was concerned that in her previous relationship, pornography would have left her feeling second best to the women in pornography:

I think I've become more okay with my partner watching it now, like back then I kind of would've been like urgh because I wasn't seeing him a lot and I was concerned that that would be better. I was concerned that like if he watched lots of porn, when we met up to have sex it might not have been that great. But now I just don't give a flying fuck really - sorry excuse my language - if my boyfriend watches porn. So I think that would be one thing that's changed in the context of relationships and porn. I don't care if someone watches it because sex is sex and it's great, you know? - Tara

In this excerpt, Tara identifies how her partner's use of pornography was associated with her own anxieties about sexual inadequacy, but also living up to the expectations of how women are presented in pornography. These findings are common in literature with women who are in relationships with men who use pornography (Bergner \& Bridges, 2002; Bridges et al., 2003; Schneider, 2000). Holly presented a similar concern about 
feeling 'second best'. In her relationship with her partner, Holly mentioned that at the time of interview, she "felt shit about how I look" which meant she felt "all paranoid thinking [women in pornography] look better." She elaborated on this, commenting about how she felt concerned "that he's thinking about them and not me and he's gonna fucking cheat on me again." Holly mentioned that she now avoided putting herself in situations where she could feel this way because she was unsure with how she would react. She reflected that:

Sometimes I'm like 'oh it's so hot thinking of him fucking other people' and like it makes me cum when I think of it and then other times I don't even want him to put on porn cos I'm like 'ahh you might look at some' - I don't even know. I'm like a contradiction [laughs]. - Holly

Rach also reported feeling second best to pornography. At the time of interview, Rach was recently separated - but still cohabiting - with the father of her child who was a selfdescribed pornography addict. Rach spoke about her initial discovery of her partner's use of pornography and she recognised that there was a pattern to how he treated her when he used pornography:

I'd come home from work, find things like soiled items of clothing and handtowels or things like that... I just became a lot more curious about what he was doing with his time on a Saturday and realised that there was actually a pattern. So the days that he did it, which was every day, there was a pattern to how he treated me before and after. So it sort of like when he was watching it, he compartmentalised it where when he was finished, it never happened. And he would never admit to it even though I either saw evidence or dealt with evidence...

Rach stated that that dealing with the evidence was "degrading", and she became "obsessed" with his use of pornography. Ultimately, this led to Rach experiencing negative impacts on her self-esteem and "feeling replaced". This was most accurately depicted when Rach shared a story of how her partner's use of pornography had affected the intimacy in their relationship and left her feeling replaced and second best:

There's been a couple of times that he's watched it before coming to bed and that's hurt my feelings because I'm second best, and I don't want to be second best, I want to be number one... [It's affected my] confidence in intimacy because I would find times that I would go to bed early, he'd watch it and then come to bed and use me as the finishing to him watching it which doesn't make you feel good about yourself. You kinda just feel like a fill-in [crying]. Do you get a lot of people that cry? I didn't wear make-up thinking I might. - Rach

Rach commented that she became so concerned about her partner's use of pornography that she "didn't want to go to work and I didn't want to leave the house because I didn't 
want to be replaced by something that was happening when I wasn't there." In research with emerging adults, it has been suggested that some women accept 'controlled use' of pornography as acceptable within a couple relationship, whereby the use of a certain amount of pornography is considered as appropriate, or may be context-specific (Olmstead et al., 2013). Rach's concerns about feeling replaced encouraged her to suggest that they watch pornography together, despite her feelings about pornography. Viewing it together, she thought, would make her feel less left out or second best and perhaps suggests that a level of controlled viewing of pornography in the relationship was somehow 'safer':

You know, when I first kind of had an inkling he was watching it a little bit more than what I found acceptable for a relationship, I said well what is it? What's your fascination with it? Why do you need it? Why can't it be shared? Like I was willing, even though I wasn't as open to it as other women are in their relationships, I was willing to do that for my relationship. So say let's just pick a date once a month, say like the $13^{\text {th }}$ of every month, where we watch it together in a safe environment with each other and then I don't feel left out, I don't feel second best. - Rach

The impacts of Rach's partner's use of pornography were significant for their relationship, and she still struggled to understand the "lies and the dishonesty", which had meant she had "sat through twice our relationship absolutely ending over it." The impacts for Rach overall of her partner's use of pornography in the relationship led her to wonder whether she could be in another relationship in the future, therefore having significant negative relationship outcomes for her:

I don't even know if I could be in another relationship for a very long time knowing that it's so normal for guys to watch porn these days. I have got to be okay before I jump into another relationship and go through all that again on someone else who probably doesn't deserve it because there's no problem with him, you know? And then to put these feelings on my daughter too. I could screw her up with the way that I'm thinking about it. - Rach

Rach was not the only woman interviewed who shared her experience of being in a relationship with a partner addicted to pornography. Izzy acknowledged how her views on pornography had changed since discovering her partner's pornography addiction and the deleterious impacts it had for their relationship:

[Izzy's partner] actually had quite a problem with porn and so that's one of the reasons why I was interested in partaking in the study. I've never really come across that before and yeah, that was something that really affected us... he was quite a heavy user which I didn't really - like I knew that he looked at porn, I never really had a problem with him looking at porn, and I've always been quite 
open about it. I've said 'you know you can look at that, it doesn't really bother me, it doesn't affect my self-esteem or anything like that.' But it became quite a bad porn habit which was really affecting his life... I used to think of porn as being pretty harmless and I didn't really see what the big taboo was and I was like 'oh well, whatever, you wanna look at that then you look at that.' But then again it's the same as anything, you can have a drink and be fine or you can have a drink and become an alcoholic... [porn] is quite harmful. - Izzy

Izzy also noted that her partner's use of pornography had "pretty much destroyed all the trust that we had and then we had to go back to square one." Her partner's use or pornography was difficult to understand because "he was hiding it from me and that feeling that he'd lied to me... The secretive nature of it was what was really upsetting me." Research with emerging adults' shows that whilst both men and women are aware that pornography has the potential to cause harm to a relationship, alarms were raised more frequently by women regarding "personal inadequacy associated with their partner's use of pornography" (Olmstead et al., 2013, p. 631). Further, research with women in relationships with men who use pornography suggests an overwhelming sense of inadequacy is experienced by female partners (Bergner \& Bridges, 2002; Schneider, 2000). Izzy identified the harms of pornography use in her relationship as extensive, affecting her own sense of self, and she became critical of her position as his partner and whether she was somehow inadequate:

I didn't really want to ask him what he was looking at. I was kind of scared as well, I didn't really want to know what he was looking at. I thought for instance if he was looking at a bunch of really, really thin women then that would be really bad for my self-esteem so I didn't really try and like delve too much into that, I tried to address the problem as a general one without specifics... I guess I just sort of wondered why cos like we have quite an active sex life so I didn't really see where I was not fulfilling a need of his or you know there was something that I wasn't doing right. Kind of like I was quite critical about myself. Then - I dunno - it led to me thinking am I really his type or if there's something more that I can do? - Izzy

Women internalising their partner's use of pornography has been previously reported, and the sense of inadequacy that Izzy refers to suggests that men's pornography use is somehow women's responsibility. As discussed in Chapter Five, women in relationships with men who were addicted to pornography were routinely blamed for their partner's use of pornography, which draws on the narrative that men use pornography as a 'fill in' for a lack of sex in their everyday lives. Again, such a narrative suggests that women exist to fulfil men's sexual desires, and in the absence of women doing so in their intimate relationships, the ever sexually insatiable women in pornography are a way to fill that 
void. Again, it seems that women are bearing the brunt of the realities of pornography in both men's and women's lives.

Throughout these accounts, these women shared open - and at times, distressing accounts of how their partner's use of pornography had detrimental impacts on their lives. Reading these stories, in conjunction with the perspectives in Chapter Five, makes for difficult reading. These women identified that they experienced blame and shame for their partners' pornography addiction. Yet dedicated research on women's experiences with pornography addiction is a neglected area of academic literature, especially in New Zealand. Whilst early qualitative research explored women's experiences in this area, in an era of proliferated sexual material online and ever-increasing levels of use of pornography, these discussions require more in-depth analysis and consideration.

\section{Summary}

There is a lack of literature which explores the influence of pornography on couple relationships. In this chapter, I have presented men's and women's experiences of the influence of pornography in intimate relationships. These perspectives suggest a distinctly gendered experience when it comes to pornography. Whilst many men spoke positively about viewing pornography as part of a couple, a number of women's experiences suggested that viewing pornography in the presence of a partner can be part and parcel of sexually coercive experiences. Further, the way the appropriateness of pornography in relationships was received was also gendered, in that men were less likely to view to consider their partner's use of pornography as problematic, but several women spoke of the way their male partner's use of pornography had detrimental impacts on their sexual experiences and their everyday lives. Pornography in this chapter is primarily being positioned as a harm to couple relationships, in that the depth of harm expressed by participants substantiates the need for future research in this area. As pornography continues to become more commonplace in both men's and women's everyday lives, the effects of pornography on intimate relationships require more thorough investigation.

The following chapter is a critical discussion and reflection on the key themes which emerged from the data and formed the basis of Chapters Four through Nine. 


\section{Chapter Nine: Why we need to talk more about pornography}

Pornography is ubiquitously available in the digital age. The ever-increasing levels of engagement with pornography as discussed in Chapter Two are a testament to the normalised nature of pornography in the lives of some men and women. Despite this overwhelming engagement with digital sexually explicit material, however, pornography remains a remarkably private practice. This chapter brings together the key themes explored in Chapters Four through Eight of this thesis. It commences with a discussion about what is considered mainstream in pornography today, and how despite this familiarity with pornographic vernacular and tropes, the stigma of pornography meant that participants struggled to speak openly and freely about pornography. I then critically interrogate women's understandings of aggression and 'rough' sex in pornography and suggest that this an area that requires further research attention. I then move to consider men's engagements with aggression in pornography, and how their perspectives position them as accepting of other men's engagement yet distancing themselves from the type of man that views violent content. Following this, I discuss the gendered nature of addiction to pornography, drawing on the views expressed by participants. Lastly, this chapter considers the gendered nature of pornography in intimate relationships and argues that gendered conversations about pornography are long overdue.

\section{Bringing the audience into conversations about pornography}

Technology has facilitated our access to an ever-expanding stream of sexually explicit content in ways that early researchers on pornography - such as those investigating the content of pornographic magazines - could probably never have imagined. Today's engagement with pornography is easier than ordering pizza and having it delivered to your door. The pervasiveness of pornography available on the internet means that in seconds we are able to navigate to platforms such as Pornhub, select a category in line with our desires, and engage with that material for as long - or as little - as we like, in the privacy of our own homes.

Today's pornography is a world removed from the pornography that once graced the glossy pages of Playboy or Penthouse. Pornographic magazines used to present glossy depictions of scantily-clad women who gradually removed their attire over a series of pages. There were stories written alongside these models - for example, the Playboy Playmate of the Month section told us everything viewers presumably wanted to know 
about the model in the image. We knew things such as her name, her age, her weight, her bust size and her aspirations. We had the opportunity to know more about her than simply what she looked like naked and the contours of her body.

If we fast forward to 2019, today's pornography also tells us things about the people involved in the pornography that some people view. Previously, viewers might have known a porn actress's age and aspirations, and the labelling of pornographic categories on platforms such as Pornhub can tell us what people are 'down' for and what some people get up to in their sexual lives. It categorises sex and bodies into bite-sized pieces, with every aspect of pornographic representation up for assessment and consideration. Any type of body performing a multitude of sexual acts can be searched for. Whether it be blonde women and creampies, ${ }^{24}$ big dicks and rough sex, or naïve amateurs having their 'first' anal experiences, this material is available and accessible online. Should this be the pornographic material one desires, finding this material online is quite the treat. Without that desire, however, encountering such material online has the potential to be troubling and distressing - a sly trick rather than an erotic treat.

Alongside these behaviours and attributes, pornographic videos often include vernacular that would not have graced the pages of Playboy at the height of its popularity. Indeed, it's hard to imagine that Playboy's Pet of the Month would have the word "slut" written alongside her images. Although her involvement in pornography might have encouraged viewers to make assumptions about who she was, this is quite different from pornographic imagery consistently labelling women in pornography with terms intended to degrade her. A quick search of the $7,425,373$ videos available on Pornhub on 23rd February, 2019 brings up some 60,833 videos most relevant to the search term 'slut', 22,433 videos titled 'bitch', 18,191 videos titled 'whore' and 8,283 videos titled 'cunt'. Whilst titles including such vernacular seem miniscule in respect of the number of videos available on Pornhub in its entirety, they are often viewed millions of times. Further, the small numbers in the search terms does not mean that such words are not used in the videos themselves, or that all other pornography videos present lovely, gentle sexual

\footnotetext{
${ }^{24}$ Creampies are a common depiction in pornography, where a male ejaculates into the vagina or anus without a condom. The image then focuses on the male's semen dripping from the vagina or anus.
} 
relations between the parties involved. ${ }^{25}$ As Carly suggested in Chapter Six, "a lot of the time with heterosexual pornography, I feel like there's dirty talking and a lot of like derogatory speak to women."

Whilst I agree that pornography is a world removed from the pages of yesteryear's Playboy, pornography needs to be considered as a 'plural category', whereby one genre does not speak for the majority (Paasonen, 2013). But it is the very differences in pornography which require interrogation and critique. The shift in pornography across formats, as well as the shift and diversity in pornography on platforms such as Pornhub, warrants our scholarly attention.

Within pornography studies generally, a significant stream of scholarship has been to conduct research within a cause and effects paradigm, which has allowed for the inclusion of a wealth of experimental research in the pornographic literature landscape (Hald \& Malamuth, 2015; Hald et al., 2010; Hald et al., 2013; Malamuth et al., 2000; Szymanski \& Stewart-Richardson, 2014). These experimental studies, as referenced in Chapter Two, are mostly quantitative and document the supposed real 'impacts' of pornography on consumers. Of course, experimental research can provide a unique lens through which we understand types of pornography or relationships in a scientific environment, but few quantitative works offer an in-depth, critical assessment of the way the audience understands and interprets pornography. The absence of the audience of pornography in pornographic scholarship is a significant omission and a missed opportunity to include the voices of those most important to, and most affected by, the realities of pornography. Conversations about pornography are overdue and need to be with those most affected by it - men and women who are living in an environment where pornography is ubiquitously available, universally accessed, and constantly evolving and changing.

In Chapters Four through Eight of this thesis, I presented the perspectives of 24 Kiwi, heterosexual, emerging adults on pornography. I have positioned their perspectives at the forefront of the research and have constantly reflected on my own positionality and

\footnotetext{
${ }^{25}$ For example, the first video which appears under the search term 'bitch' is titled "mentaly retarded bich" (sic). It is listed as a "professional" production and has a total of 1,318,388 views as at $26^{\text {th }}$ February, 2019. The video is tagged with the terms "ass fuck," "stupid bitch," "mental patient," "rough," "dirty talk," "dark haired," "crazy girl," "insane," "yelling," "slap," "choke," and "hair pull." Video accessed on $26^{\text {th }}$ February 2019 from https://www.pornhub.com/view video.php?viewkey=ph55f37036b1e9e
} 
tried to divorce my own personal feelings about pornography - as confused as they are! - from the perspectives shared by my participants. I was struck by similarities between my own feelings about pornography and those shared by a number of my participants. What I found was that many people are confused, ambivalent, contradictory, and conflicted about pornography, and it seems this may well be more the norm than an anomaly. It is these confusions, ambivalences, conflicts and contradictions which are at the heart of this thesis, and these feelings came across as inherently gendered.

In Chapter Four, I explored what participants meant when they spoke about pornography, and how they understood what was considered 'mainstream' pornographic material. In Chapter Five, I analysed the way that the stigmatised nature of pornography as a genre impeded the possibility for open and free conversations about pornography in people's everyday lives. In Chapters Six through Eight, I presented the results of open and honest conversations about pornography in the lives of my participants. These chapters demonstrate that we need to talk more about pornography, and that this conversation is overdue. In the following sections, I wish to unpack the gendered discussions from Chapters Four through Eight in more detail, focusing on three key areas: the conceptualisation of mainstream content; the gendered interpretations of pornography; and the gendered impacts of pornography on the lives of participants in this research. I now turn to an overview of the parameters of mainstream pornographic material.

\section{Mainstream pornography: misogynistic and mostly male}

Conversations about what counts as mainstream pornography often point to the misogyny, degradation and violence inherent within it. As so many scholars suggest (Boyle, 2010; DeKeseredy \& Corsianos, 2016; Dines, 2006; Dines et al., 1998; Jensen, 2007; 2016; Tyler, 2010; Whisnant, 2004), mainstream pornography eroticises violence and male entitlement. It does so by fusing sex with aggression and presenting women as sexually insatiable alongside men who are perpetually sexually forceful. Such a representation contributes to what can only be considered a hostile climate of heterosexual interaction. While such an understanding is not reflective of all pornography, there certainly are dominant themes of male dominance, entitlement and hostility present in much mainstream pornography. I say this because men and women in this research pointed to routinely encountering these depictions. 
In Chapter Four, many participants referred to initially encountering pornography as young people in pornographic magazines, but now referred to mainstream pornography being found on popular internet websites such as Pornhub and Reddit. As Lilith suggested, "you know porn exists... you can like search it up whenever you want" and Ethan reflected that "now it's just all on Pornhub." Derek concluded that "Pornhub... it's the easiest site... I guess your mainstream." Participants alluded to the expansive nature of pornography available on Pornhub, and Bill suggested that the "business model itself wants to keep you on and clicking and opening a dozen tabs and coming back again and again and again."

In speaking to the content of pornography, most participants acknowledged that mainstream pornography tended to present stylised, idealistic bodies which conformed to Western standards of beauty. Women were the focus of the gaze in mainstream pornography, and men said that they paid little attention to the men in pornography, describing their role as more of a 'tool' in the pursuit of an authentic, sexual performance delivered by the female performer or performers. Women were cognisant that pornography primarily catered to the male gaze, and Tara, too, acknowledged that men in pornography were "just like a dick... it was always about the woman." At the same time, men also acknowledged that pornography was primarily aimed at them as the audience, as Chris noted that "the porn that you find on the front page of sites, they're still geared towards the male audience."

Whilst some participants acknowledged that men's representations in pornography were unrealistic and stylised, suggesting that men were "jacked" or a "masculine guy with a big dick and ripped abs", it was women's bodies that were consistently up for assessment, critique and consideration, and men's behaviours towards women which were on the agenda. In considering women's bodies in pornography, women suggested that they conformed to expectations of what men wanted in pornography. As Tara reflected, "for the majority of guys who watch the porn they like the big fake boobs and the big ass", but this seemed to be in opposition to what men suggested they actually viewed in pornography. Men spoke of a desire for more authentic, diverse, "organic" women's bodies, and discussed how women's bodies in pornography were less likely to conform to a Playboy-esque stereotype, as the "professional porn star stereotype doesn't exist anymore." Regardless of whether the porn star stereotype persists or is merely keeping 
new company with a range of friends, it is still women's bodies that are the site of appraisal and critique.

As previously discussed in Chapter Two, a key concern for feminist scholars is pornography's representation of women in degrading and dehumanising ways, as well as pornography's eroticisation of male dominance and entitlement (Brownmiller, 1975; Dines et al., 1998; Dworkin, 1981; Jensen, 2007; 2016; Whisnant, 2016b). These concerns were reiterated by participants in this research. Both men and women described pornography as "dominance-based", "demeaning to women" and "aggressive". Early theorising of internet pornography suggested pornography was having a profound effect on sexuality because it was easily accessible, affordable and able to be accessed anonymously (Cooper, 1998). The triad of access, affordability and anonymity was an important theoretical contribution to the realities of pornography on the internet but given the technological advancements and shifts in the content of mainstream pornographic material, these A's require some clarification and modification.

In updating the triple ' $A$ ' engine, it is perhaps better conceptualised as a quad: accessible, anonymous, aggressive, and with the potential to be addictive. I specify the inclusion of aggression and addiction in this conceptualisation as both themes came through strongly in this research. The frequency that participants spoke of encountering aggressive content are a testament to its ubiquity in mainstream pornographic material, and aggression became a key theme explored in both Chapters Six and Seven. Regarding addiction, nearly half of the men included in this research, and one of the women, spoke of experiencing 'addiction' to pornography, making it another key theme which emerged from the data.

The extent to which participants spoke of aggression in pornography cemented its normalised presence, and the desire to speak about aggression in pornography was a remarkably gendered conversation. Men and women spoke quite differently about what it meant to them to encounter aggressive, or 'rough' pornographic material, and I now wish to unpack these gendered encounters in more depth, beginning with women and their understandings of 'rough' sex. 


\section{Consensually rough: women on aggression and 'roughness' in pornography}

As mentioned in Chapter Two, claims about 'empowerment' are increasingly central to discussions about women's sexuality and agency. In outlining the complicated nature of what it means to be a sexual woman in the $21^{\text {st }}$ century, Rosalind Gill (2012a) frames the debates about the sexualisation of culture and women's empowerment into two camps with distinctly opposing arguments:

On one side of the argument are those who mobilize women's 'choice', 'agency' and 'empowerment' to champion aspects of 'sexualised' culture such as pornography, burlesque or the popularity of pole dancing as a recreational activity - these activities can be defended (or even celebrated) because they are 'empowering'... On the other, empowerment is regarded merely as a cynical rhetoric, wrapping sexual objectification in a shiny, feisty, postfeminist packaging that obscures the continued underlying sexism... a further position is interested in the extent to which sexual 'empowerment' has itself become a normatively demanded feature of young women's sexual subjectivity, such that they are called on routinely to perform confident, knowing heterosexiness" (pp. 736-737).

The final position to which Gill refers here is perhaps the most important in considerations around women's understandings and interpretations of rough sex, and it is this issue I wish to tease out here in more depth. I was particularly struck by the way that women spoke about aggression in pornography. They described being "repulsed" by it and how it had a tendency to be "borderline violent and like forceful". Holly referred to some pornography as "degrading chicks literally to just their vagina", Carly hoped that the derogatory speak toward women in pornography was "only a portrayal", and Miranda suggested pornography was fundamentally "misogynistic" and "not about consent."

Nearly all of the women in this thesis denounced the degrading and demeaning nature of much mainstream pornography, and this caused a substantial amount of conflict for some of these women as pornography consumers. A number of women cited a difficulty reconciling their feminist values and ethos with their viewing of pornography, and this is a common theme in research with women about their use of pornography (Ciclitira, 2004; Gurevich et al., 2017; Parvez, 2006). Miranda reported that her viewing of pornography made her feel "depressed", leaving her questioning why she watched material "where women are mistreated," Carly felt "hypocritical" if she ever watched pornography, and it contributed to an "inner battle" within her head about what this meant for her as a feminist woman. Further, Lilith reported that she felt "guilty watching porn" because of the "ideas it perpetuates about women." 
As well as having trouble reconciling their use of pornography, a number of women spoke of the tenuous relationship that they had with pornography, whereby using pornography had the potential to be both pleasurable and painful. Miranda reported experiencing traumatic flashbacks - what she described as "head cinema" - which infiltrated her sexual interactions. For Tina, pornography - whilst arousing - was a painful reminder of her experience of childhood sexual abuse. Carly felt that viewing pornography left her "feeling a bit dirty" and she did not "want to be reminded" of what she had viewed. Jasmine was concerned that men knowing about her pornographic preferences would put her at risk of being treated like the women she viewed in gangbang pornography, or that they would presume she was "slutty." These conflicts differed significantly from perspectives shared by men. Men did not report experiencing "head cinema" or feeling "guilty" for watching pornography because of the ideas it perpetuates about women. The feelings that women reported meant that their experiences with pornography were a constantly navigated nexus of pleasure and pain.

Speaking about pain and pornography in a somewhat different sense, several women suggested that they were interested in what they described as 'rough' sex. Given women's strong opposition to the inherent aggression and misogyny in pornography, I was surprised that they experienced an interest in sex that could incorporate the elements they so vehemently denounced. At the same time, however, this is perhaps less surprising when Pornhub suggests that women between the ages of 18 and 25 are the most likely viewers of rough sex (Pornhub, 2018b). The rough sex category on Pornhub boasts some 20,000 videos, and the website suggests that 'rough' sex is a category frequently combined with the category 'popular with women'. The thumbnail of the 'rough sex' category depicts a woman with a large penis down her throat, running make-up, and her eyes are being held open by the man's hands to really demonstrate the difficulty she is experiencing.

Weaving through the women's accounts of what constitutes rough sex for them in this research, it seems a different picture than what is presented in this thumbnail. There seems an uneasy juxtaposition between the realities of rough sex in pornography and women's conceptualisations of rough sex in their offline sexual relations. In Chapter Six, a number of women spoke of rough oral sex as an unappealing sexual act. Some women spoke of being "throat fucked" as an act associated with violent sexual portrayals. Others 
spoke of how their male partners forced their heads down during oral sex or expected they could "skull fuck" them. Holly said she enjoyed rough sex and rough pornography, but not the "torturey" pornography where the female performer is "gagging and tears and fucking like mascara flowing." Holly's graphic description of what was a turn off when it came to rough sex is almost a mirrored image of the rough sex thumbnail on Pornhub. So what exactly is 'rough' sex, and what makes 'rough' sex, sexy?

Without knowing the origins of Pornhub Insights data, it is difficult to know exactly what some women's interest in the rough sex category means. Are they simply viewing the rough sex category and then exiting out when 'repulsed' by what they encounter? Is Pornhub as a platform presenting 'rough sex' in conjunction with the 'for women' category to suggest that this is what women really want? Are some women just genuinely interested in rough sex? Are some women viewing rough sex in pornography because their male partners suggest that they might want to try it, or that they expect it? Do some women feel pressured to engage in rough sex to be a 'cool' woman (Whisnant, 2004) who presents an 'up for it' sexuality? (Harvey \& Gill, 2014). I do not pretend to have the answers to these difficult questions, but they provide an interesting basis for future research on what 'rough sex' actually means, given how complex and conflicting women's positions were on the issue.

The women interviewed for this research suggested that there was a fine line between representations of rough sex and violence. Their conceptualisations of rough sex were intrinsically bound to consensual sexual interactions, whereby their refusals or communicative consent would be heard and respected. Their specific articulation that their communicative consent be heard and respected in rough sex interactions directly acknowledges that women's sexual refusals being disregarded are an ever-present risk in heterosexual interactions. In Just Sex: The Cultural Scaffolding of Rape, Gavey (2005) writes of hearing women's experiences of sex where "a man was rough and brutish, and the woman described letting sex happen because she felt unable to stop it" (p. 136). Through women's narratives of their sexual experiences, she notes that it is "clearly unremarkable" for women's "no"s to be disregarded in sexual interactions (p. 145), and contends that it is important to consider the context or situation in which assertive communication is required when women decline unwanted sex. 
In considering rough sex as the situation or context for declining unwanted sex, it is perhaps particularly difficult for women's "no"s or communicative consent to be heard or listened to. If rough sex represents versions of rough or brutish style fellatio, where women's heads are forced downward by men in the pursuit of "throat" or "skull" fucking, how easy is it to even verbalise "no" during this act? When a woman is being choked during a sexual act - a key component of rough sex for some women in this research how easy is it to verbalise "no" when you are struggling to breathe? Further, when pornography presents choking and gagging as glamourized aspects of normal, everyday heterosexual interactions, how easy is it to challenge this pornoscript as it plays out in one's offline heterosexual interactions? Ultimately, women's experiences of heterosex are not always foundationally built from consensual beginnings, and the women in this research were aware that this was an ever-present reality.

As I consider some of the women's interest in, and the appeal of, rough sex, I am sure that rough, consensual sex that they have some control over can be an arousing and pleasurable sexual experience. Thinking more broadly, however, I cannot help but consider whether some women's interest could be related to how discourses of 'empowerment', 'agency' and 'choice' function to encourage women to be involved, sexual agents in what some have argued is a 'postfeminist' world. Over the last thirty years, research has become increasingly interested with exploring female sexual agency and sexual empowerment (Evans et al., 2010; Gavey, 2012; Gill, 2008; Lamb, 2010; McRobbie, 2008). Within this climate, debates about women's 'empowerment' orient

around the issue of agency, so that valuing women's choices and reported pleasures in participating in sexualized culture, while also locating analysis of women's participation within a culture that has re-sexualized women in ways that apparently re-produce objectification and the male gaze (Evans et al., 2010, p. 125).

These debates have contributed to a tense literature terrain for feminist scholars considering the complexities of women's engagement in the new sexual culture, situated within a discourse of subjectivity and empowerment. Gill (2007b) argues that for young women living in 'postfeminist' cultures and climates, "the display of a certain kind of sexual knowledge, sexual practice and sexual agency has become normative - indeed, a 'technology of sexiness' has replaced 'innocence' or 'virtue'” (p. 72). By the same token, however, young girls and women are still "caught in a bind, it would seem, required to balance tight tensions between conformity to traditional feminine sexual mores and 
appearance on the one hand and more "liberated" sexual norms on the other" (Gavey, 2012, p. 722). Women, therefore, are expected to present themselves as sexually desirable in pursuit of being empowered, but such empowerment is only ascertained when it is acquired through appropriate representation.

Harvey and Gill (2014) suggest that modern "women are exhorted to become 'sexual entrepreneurs' able to present themselves as 'appropriately' desirable and desiring and willing to perform a number of practices previously associated with the sex industry... to keep their men happy and turned on" (p. 488). This gendered performance, they argue, is "presented simultaneously as moments of freedom, choice, empowerment, and pleasure, yet also as hard work that is normatively demanded and essential to the success of heterosexual relationships" (p. 488). Perhaps some women's interest in rough sex comes from a place of wanting to conform or adhere to the expectation that women in the 'postfeminist' turn are 'up for it', down for anything, and open to being sexually 'adventurous' (Gill, 2008; 2009; Harvey \& Gill, 2014).

As I mentioned at the beginning of this chapter, porn actresses on sites such as Pornhub tell us what they are 'down for', or what's popular, or expected, in heterosexual interactions. If, as Pornhub data suggests, that some women are increasingly viewing rough sex in pornography, perhaps we need to interrogate further women's understandings of rough sex, and whether some women's interest in rough sex could be related to the expected pursuit of sexual adventurousness. To be the 'sexy' subject who is willing to continually up her skills and interest in the pursuit of her own, and her partner's, presumed sexual pleasure, are women then expected to consider rough sex as the avenue for this achievement?

Interrogating gendered understandings, interest and engagement in rough sex is important because, as Chapter Six demonstrated, women's understandings of what was considered 'rough' differed substantially, but were fundamentally tied into consensual sexual interactions. However, this becomes more difficult when we consider the way that men understood consent in pornography, and consent in aggression more generally. Whilst Pornhub Insights data tells us that men are not watching 'rough' sex categories to the same extent as women, men such as Tom "know" that women like to be choked in their offline sexual lives. When men 'know' that women watch pornography, and they know that the categories of pornography that women watch, such as lesbian and rough 
sex, routinely depict behaviours such as choking and slapping, what does this mean for women who do not like these behaviours, or indeed do not watch pornography? How easy is it for women to say 'no' to these acts, when that is what many men may conceive as normal? Further, in an increasingly technology-mediated environment where platforms such as Tinder serve as a starting point for negotiating sexual interactions, what happens when someone says that they like 'rough sex'? How is this understood, negotiated, and what exactly does each party think this entails?

My concern is that pornography as a genre has the potential to script sex in a way that presents a certain form of 'knowledge'. Pornography tells men what women presumably want in their sexual lives, but it also has the power to tell women what they should want. This is further amplified by men's knowledge about what women like, making it difficult for women to suggest that they may perhaps feel differently. In a sense, then, in the 'postfeminist' world in which we live, it can be hard to be a woman who does not watch pornography, or at least understand it as an acceptable or a normative aspect of both men's and women's lives.

\section{It's just not for me: men navigating aggression in pornography}

Moving on from women's discussions of 'rough sex' and aggression in pornography, I now wish to critically explore men's engagement with pornography. Throughout Chapter Seven, I presented men's perspectives on the appeal and discontents of pornography, and how the way they described aggression in pornography was different to the women's discussions, in that 'rough sex' did not seem to feature, but 'violent' sex did. Some men described pornography as appealing when it showed women's 'authentic' pleasure, with Ethan suggesting "if the women actually looks like she's enjoying herself", then her pleasure is the appeal. Violent sex was equated with women not consenting to sex. As Cameron suggested, "anything that simulates rape... where you can clearly see the guy or girl saying no or crying or anything" was considered a violent portrayal. Luke felt that such portrayals were "pretty fucking horrible to watch" and Derek suggested that getting off on women's pain was "not what I'm about." What I am most interested in, however, was the way that some of the men separated themselves from the type of man that revelled in women's pain and suffering, the type of guy that likes watching girls saying no, crying, and gets off to portrayals of "paid rape", as Luke described it. 
The men I interviewed accepted that aggression or violence was omnipresent in pornography but many of them distanced themselves from the type of man who viewed such material. This is not to say that they had not been "carried away" by this type of pornography in the past, but it was a suggestion that they tried to stay away from it. When they encountered pornography which may have been non-consensual, some distanced themselves from that material by "clicking away", or as Chris mentioned, when he downloaded pornography which he felt was real women being raped, he deleted it and had to "pretend I never downloaded it." At the same time, however, men were careful not to denounce this type of pornography altogether, opting to frame it within a discourse of 'user preference', whereby they left the door open for other men to engage with such material, thereby not trashing other men's treasures. This is a similar finding to research with New Zealand men about how they understood male dominance in internet pornography. As Antevska and Gavey (2015) suggest, men's understandings of male dominance in pornography were "rationalized through claims around individual choice on one hand and biological realities on the other" (p. 616). The men's perspectives in this research also speak to notions of 'choice' within the individualistic rhetoric of neoliberalism.

I was surprised that some of the men took this position since they appeared so opposed to engaging with violent material themselves. The men I spoke to were cognisant of the pitfalls and dangers of pornography, its ability to "warp" men's perspectives and understandings of sex, and how easy it was to fall in to the "rabbit hole" of pornography content. By the same token, however, these anxieties were not enough to suggest that such pornography should not exist, or that others should not be able to engage with it. Men's support for others' freedom to engage with violent pornography remains difficult to comprehend and fully understand. As a young woman who has encountered more than enough violent, coercive pornography during this research journey, it is difficult to imagine how anyone could ever suggest that people viewing such material was 'okay'. Whilst I appreciate the mantra that we should not 'yuck' other people's 'yum' (Wodda \& Panfil, 2018), it is difficult to imagine how violent, coercive sexual portrayals would fit within the remit of a 'yum' representation. As I consider these men's perspectives, I wonder where they draw the line in trashing other men's treasures. If the door remains ajar for violent pornography, then what about pornography of other genres, such as child pornography? If hardcore pornography showing women being "choked out" is okay, then 
does the same standard exist for pornography involving children? Further, what for pornography that is (hopefully) consensually produced, but designed specifically to suggest that sex was unwanted but ultimately enjoyed?

I do not profess to be an expert on men's psyches or positions on pornography, nor do I come from a place of shared experience to the men in this research, outside of having grown up in a similar generation. Casting aside my own inner conflict about what men think about pornography, however, I suggest that some of the men's heralding of other men's right to view what they like is rooted in two separate but linked foundations: the implicit consent script in pornography, and the reality that pornography remains a maledominated arena. Pornography is a genre which is created for the male gaze, positions men as in charge of sex, and it remains a reflection of the structural realities of men's position in society more generally. Such a representation substantiates pornography as a 'guy thing', and something that men are entitled to view.

A critical discussion about consent in pornography is intricate and complex, and a critical investigation of the structural realities of choice, agency, labour and production in pornography are outside the scope of this research. However, men in this research did speak about consent in pornography, and the difficulties they experienced navigating what was consensual and what was not when it came to sex on screen. This uncertainty and anxiety about consent in pornography led to men tending to stick to professionally produced pornography to help stay safe or "mentally cogent." Ultimately, however, the script in pornography implies that consent is ever-present (Purcell, 2012). Some pornographic scenes and videos include “bookends or 'exit interviews'... where performers are interviewed before a scene to clearly and often legalistically establish their desires and limits, and afterwards to assert on film that these limits were respected (Lodder, 2016, p. 376). At the same time, however, these 'consent contracts' could well be viewed as more a reflection of risk-averse pornographic studios being conscious of the potential for litigation, rather than acting in the interests of performers.

In the hub of mainstream content, pornographic scenes are increasingly fragmented (van Doorn, 2010). Pornographic scenes are substantially shorter than pornographic videos used to be, with the trend for gonzo giving us only the 'best bits', removing perhaps the preliminary conversations about consent in pursuit of getting to the nitty gritty - the hardcore sexual intercourse. Perhaps this speaks to the appeal of pornographic GIFs 
described in Chapter Four - it is hard to imagine the consensual negotiation of sex, the "is this okay?" or the "does this feel good for you?" being a warrantable inclusion in the "best bits' sought out in the "instant gratification" of the pornographic GIF. Nevertheless, however, the mere existence of certain types of pornography indicates that it was produced consensually, and it is the implicit consent of pornography which helps men to not trash other men's treasures.

The second reason that I theorise that some of the men may have been less likely to trash other men's interests in pornography relates to the reality that pornography remains a distinctly male arena catering to the needs and desires of its primary audience. As previously cited in Chapter Seven, Ashley (2016) suggests that mainstream pornography "is still created primarily to serve the only imagined guaranteed, paying porn consumer: 'the casual cis guy' (p. 187). In Chapters Four and Six, many women were acutely aware that pornography was not designed for them, even in categories they felt should be, such as lesbian. Robert Jensen (2007) suggests that "mirrors can be dangerous, and pornography is a mirror. Pornography as a mirror shows us how men see women" (p. 14). In pornography, men see women as sexually eager, willing and able to partake in any sexual act which caters to the male parties' needs (Brod, 2007; Jensen, 2016). By presenting women's bodies as always 'up for it', pornography eroticises male entitlement and dominance by never showing resistance, unless women's resistance to men's advances is the actual selling point. In the same way that pornography eroticises male entitlement, the narratives from men in this thesis posit that men are entitled to view whatever they wish in pornography, precisely because it is men's right to view it.

\section{Pornography as an addictive, but gendered experience}

Outside of discussions about aggression in pornography, addiction to pornography also emerged as a key theme from the data. The figure of the pornography 'addict' is one of the leading figures in the stereotype of who exactly a pornography consumer is (Ley et al., 2014; Tarrant, 2016). In the absence of the audience of pornography in debates about pornography itself, this narrative gains traction. Whilst debate persists about the utility of a clinical label of pornography 'addiction' (Ley et al., 2014; Voros, 2009; Williams, 2016), it was clear that for participants in this thesis, pornography addiction was a real experience with a host of deleterious impacts for the people it affected, and these impacts were experienced across gendered lines. 
In Chapters Five and Seven, I presented several men's experiences with pornography addiction. They often used the term 'addiction' to describe their relationship with pornography at various points of their lives. Ethan and Jack both spoke about pornography's direct impact on their sexual satisfaction in their intimate relationships. Ethan framed his pornography addiction as negatively affecting his sex life, as he "wasn't getting as much pleasure out of it as I wanted." Both Pete and Ethan acknowledged that their use of pornography had a negative effect on their intimate relationships, with Pete suggesting that it was the reason for a number of relationship breakdowns, and Ethan acknowledged it was the likely reason that he and his fiancé might end their relationship. In contrast, two men in this research did not feel that they were addicted to pornography, but that they were addicted to masturbating. This seemed odd given the frequency by which these men reported using pornography to masturbate, but perhaps it is an indication of a will to reject the stereotypical label of 'pornography addict' because of the stereotypes surrounding the figure of the 'pornography addict'. At the same time, both men were aware that their use of pornography had negative effects on their lives. Chris spoke of pornography and masturbation as taking up time which he set aside for other activities in life, and he had a difficulty stopping himself from masturbating for up to four hours a day. Further, Nathan felt that if he let his online "dream world" affect the "real world" then "it can become a problem". He acknowledged that "if I don't deal with it soon then it might not be that great for me."

Some men's acknowledgement that pornography had negative effects on their lives encouraged a number of them to explore mechanisms for helping them abstain from using pornography or controlling their use. They spoke of how some online spaces - such as No Fap - were critical platforms for discussing the difficulties involved for men experiencing pornography addiction. In Chapter Five, I discussed the way that pornography remained an inherently stigmatised topic, and whilst popular narratives lead us to believe that men talk about pornography all the time, the reality was that they felt they were only able to speak about pornography in certain ways. The inherent stigmatisation of pornography meant that adult conversations about pornography were oriented around issues of what pornography might represent, rather than one's own personal preferences for pornographic content. As Nathan suggested, such conversations were more "philosophical" in nature. As Chris also pointed out, "you can't just sort of strike 
up a conversation with someone and say hey! I watched some cool porn last night." Further, some men alluded to the only space for conversations about the negative effects of pornography were when men admitted they had a problem with pornography. Considering this, spaces such as No Fap foster a sense of community engagement and equip men with the tools they might need to counter their pornography addictions. Whilst I agree that such spaces and forums are undoubtedly necessary, and men speaking about pornography and its effects are well overdue, I remain surprised that the women interviewed for this research felt that there was a lack of support available for them as partners of men who experienced pornography addiction, and it is the difficulties that these women experienced to which I now turn.

Women in relationships with men who they identified as addicted to pornography felt that there was little space to open up about these experiences for fear of being blamed. For both Rach and Izzy, their experiences in relationships with partners who were 'addicted' to pornography was described as nothing short of devastating for them. Rach commented that dealing with her partner's use of pornography was "degrading", made her feel "second best" and a "fill-in" for her partner in his pursuit of sexual gratification. These feelings negatively affected her self-esteem, leading her to feel "replaced", and it had resulted in the relationship ending multiple times throughout its history. For Izzy, she described the discovery of her partner's use of pornography as destroying the trust in her relationship, causing them to have to "go back to square one" and rebuild their relationship from the beginning. Ultimately, her partner's use of pornography negatively affected her self-esteem, and led her to question whether she was somehow responsible. She commented that "I didn't really see where I was not fulfilling a need of his... I was quite critical about myself", implying that her partner's use of pornography was somehow an indication that she was not performing her role as a sexual partner for him.

In the interviews with both Rach and Izzy, I was struck by just how much their partner's use of pornography had affected them. Rach cried during the interview, and it was clear that this was perhaps one of the first times she had spoken about her partner's use of pornography and received a sympathetic, non-judgmental response. Both Rach and Izzy referenced a concern about being blamed for their partner's use of pornography. Rach commented that people were "never really gonna fully understand" what she was experiencing because they were accepting of pornography in their own relationships. 
This led her to feeling blamed by both her friends and her family for her partner's use of pornography. As she reflected, her Mum had said "maybe you need to do yourself up a bit and be more attractive" as if this would somehow prevent her partner from needing to use pornography in the first place. Izzy also felt that others would be unlikely to be sympathetic to women's experiences, because "for fuck's sakes, who doesn't look at porn?"

Throughout these narratives, I am struck by the way they describe experiencing yet another layer of judgement when it comes to pornography. As discussed in Chapter Five, women felt that talking about pornography as a woman was inherently stigmatised, and women's open acknowledgement of their use of pornography runs the risk of being subjected to the already existing sexual double standards. A long history of patriarchal thinking has ensured that women's sexual engagements are consistently up for critique. As Gavey (2005) suggests, at the dawn of the sexual revolution, "everyone knew that sex was different for men and women" (p. 1), and this relates to not just women's and men's sexual pleasure during heterosexual interactions, but also the wider way that men's and women's sexual engagements are viewed and understood. The sexual double standard heralds men for their heterosexual contacts, whilst deriding women for their engagement in the same interactions (Farvid et al., 2017; Flood, 2013a; Kreager \& Staff, 2009; Tolman, 2002), meaning "girls who show some sexual agency risk being described as sluts" (Lamb, 2010, p. 298). There is a significant body of literature which explores the sexual double standard among teen girls (Crawford \& Popp, 2003; Tolman, 2002), however the sexual double standard applies far more widely to adult women's sexuality.

Bogle (2008) suggests that on American college campuses, "the sexual double standard leads to an environment where women need relationships in order to protect their reputations" (p. 103). However, in conversations with some women in this research, the very nature of a relationship was the source of strain and risk to their reputations. Women are consistently blamed for being 'too' sexually agentic, despite agency and choice being the cornerstone of women's sexual 'empowerment'. They continue to run the risk of being labelled a 'slut' for those sexual interactions which fall outside the scope of still 'accepted' norms of femininity in a patriarchal world. Further, women are routinely blamed for their experiences of sexual violence, absolving men of responsibility for perpetration and putting the onus on women to prevent their own victimisation. As 'responsibilised' sexual agents, women are tasked with overseeing their sexual selves in 
a multitude of ways. During all of this, we must also consider the fact that women run the risk of being blamed for their partner's use of pornographic material.

Women spoke of pornography as a normative part of male sexuality, and they all seemed to 'know' that men viewed pornography. As Jasmine suggested, "it's a need for them in a way." This notion of men's pornography use as normative suggests that women should view any and all use of pornography by men in their intimate relationships as acceptable. When men's use of pornography moves from somewhat 'acceptable' to 'problematic' use, however, it seems that any critical assessment of this behaviour rests on women's inability to sexually satisfy their partners. In essence, it seems that women's 'inadequacy' to sexually satisfy their partners 'forces' men to use pornography as an outlet for their uncontrollable sexuality, perpetuating the male-sex-drive discourse (Gavey, 2005; Hollway, 1984; Vares, Potts, Gavey, \& M. Grace, 2007) which "constructs male sexuality as active, driven and uncontrollable" (Milnes, 2010, p. 255). Phillips (2000) suggests that women "are charged with situating themselves and their experiences in a set of discourses that... hold women responsible for pleasing men and acting as gatekeepers for male (mis)behaviour" (p. 109). The same is being reported here, with women internalising the notion that they are somehow responsible for their male partner's pleasure, for why else would he look at pornography?

\section{The gendered nature of pornography in intimate relationships}

The last theme which I wish to draw out in more detail in this chapter is the way that men and women spoke of the gendered nature of pornography in their intimate relationships. One of the most pressing concerns presented in Chapter Eight was the way that women spoke of pornography's influence on their male partner's sexual behaviours, and of men using pornography as part of a coercive pattern of behaviour in their intimate relationships, either directly or indirectly. There is some research which now explores the role of sexting coercion as a component of women's experiences of intimate partner violence (Stanley et al., 2018), and some research substantiates that men can, and do, use adult pornography to coerce their partners into sexual activity (DeKeseredy, 2015; DeKeseredy \& Hall-Sanchez, 2016).

Discussions about pornography and intimate relationships were remarkably gendered in this research. In none of the conversations I had with men did they speak about their partners' use of pornography negatively. This is perhaps unsurprising, when other 
research positions women's pornography consumption in intimate relationships as something to be celebrated or perceived as a 'good thing'. Perhaps women's use of pornography in relationships suggests a level of sexual openness, and is a testament to women being 'up for it' (Gill, 2008) type of sexuality. At the same time, however, a number of women alluded to their partner's being less supportive of their use of pornography in relationships. Lilith reflected that her partner had chosen to abstain from pornography because "it wasn't okay to women" so she was conscious that he may not have approved of her use. Miranda also acknowledged that her partner disapproved of her use of pornography, and she chose not to view pornography any longer because "I don't need to have porn, I would like to keep my marriage instead." Women speaking about their partners' feelings about their use of pornography was a surprising discussion, given the lack of men in the research who considered women's pornography use as a bad thing. That said, some of the women described their partners as actively abstaining from pornography, so perhaps it is more likely that men who feel strongly against pornography would express these positions.

In several women's narratives, they described how they felt their partner's sexual behaviour - including sexually coercive behaviour - had been shaped by pornography. In Chapter Eight, women referenced situations such as "rough oral", and Tara noted that her protestations at her partner forcing her head down during oral sex were not heard. Further, Holly felt that the "dirty talk" and "skullfucking" that her partner expected were at direct odds with how she liked performing oral sex, leaving her feeling that she had to be "a bit porn starry" in order to keep her partner sexually satisfied. Naomi reported that her partner expected her to go above and beyond and perform like the women do in pornography, "wearing like lingerie but not just your usual bra and undies... like costumes and things like that too." In Chapter Six, Jasmine spoke of her partner's viewing of pornography as related to him 'inviting' a third person into their sexual relationship when she was intoxicated. The expectation that women participate in group sex as a result of their partner's pornography use has been reported elsewhere, whereby women reported they were "forced to have group sex or sex with "other people," which is endemic to gonzo" (DeKeseredy \& Hall-Sanchez, 2016, p. 10).

At no stage in conversations with any of the men did they describe similar experiences, where they felt coerced by their female partners. In fact, in Chapter Seven, several men 
spoke of pornography as an 'educative' tool in their intimate relationships, and when these perspectives are considered alongside women's discussions about the use of pornography as part of a coercive pattern of behaviour in intimate relationships, it can be hard to ignore some men's use of pornography as a coercive mechanism.

As previously discussed throughout this thesis, sexual script theory is a key theoretical construct in research on pornography's influence on sexual behaviours. Research has substantiated that pornography does have the power to influence behaviours and understandings of sexual scripts (Braithwaite, Aaron, Dowdle, Spjut, \& Fincham, 2015a; Braithwaite et al., 2015b; Braithwaite, Givens, Brown, \& Fincham, 2015c; Foubert \& Bridges, 2016; Marshall, Miller, \& Bouffard, 2018; Sun et al., 2016), and research suggests that women consider men's expectations of anal sex in heterosexual interactions as directly influenced by their consumption of pornography (Fahs, Swank, \& Clevenger, 2014; Marston \& Lewis, 2014). Whilst this research did not set out to 'test' the relationship between pornography use and sexual behaviours, numerous women certainly felt that pornography had the potential to influence men's behaviours in their offline sexual interactions. Further, women's discussions of men using pornography coercively in sexual relationships is a field which requires further interrogation and consideration. Could this be a motivation behind women's increased engagement with 'rough sex' categories on places like Pornhub? Could it be that men 'suggest' rough sex in their offline interactions, which encourages women to view such material online? Or is it something entirely different?

\section{Summary}

Despite the proliferation of pornography online, research that examines the meanings that people attribute to pornography, and how it impacts their experiences, remains remarkably rare. In New Zealand, only a handful of studies provide qualitative insights into consumer experiences with pornography, and there is little known about what and how pornography is experienced in contemporary times. Through my conversations with heterosexual emerging adults in New Zealand, pornography is evidently experienced in decidedly complex, conflicting, nuanced and gendered ways. Whilst pornography studies continue to struggle for academic legitimacy, conversations about pornography remain silenced due to the stigma associated with the subject, and the difficulties we face speaking about sex generally. But open, honest and frank conversations with people 
about pornography are long overdue. The history of pornography inquiry has created a siloed, divided research landscape with battle lines drawn between the anti-pornography and the pro-sex positions. Within this divided landscape, the realities of pornography for the people most affected by it - the audience and their partners - are left behind, whereby assumptions are made about what pornography means, does and represents by so-called 'experts' in the field. But who really are the experts on pornography? It is time that the voices of those most affected by pornography are brought to the forefront of pornography scholarship.

Throughout this chapter, I have posited that the aggressive nature of much mainstream pornographic material remains a key concern for scholars of pornography, and future research should consider how conceptualisations of aggression are formed and understood between both men and women, and what the implications are for these understandings. Further, I have considered the way that some men understand and navigate aggression in pornography as fundamentally related to men's right to view pornographic material, and the implicit consent script which is inherent in pornography's mere existence. As well as this, I have considered that conversations about addiction to pornographic content are also required, with questions being asked of both men and women about how this phenomenon is experienced, what the impacts are, and how these impacts remain gendered. Lastly, I have documented the gendered nature of pornography in intimate relationships and suggested that we need to consider pornography's role in influencing and shaping sexual scripts, as well as being utilised as a potential tool for men's coercive behaviours toward women. Fundamentally, then, this chapter suggests that we are long overdue a more comprehensive and inclusive conversation about pornography that positions gender at the foundation of our understandings. 


\section{Chapter Ten: Future Directions}

Pornography has been the source of feminist contention and debate for over four decades. These debates have oriented around whether pornography depicts women in derogatory or dehumanising ways, and how these depictions influence the real-life perpetration of violence against women and children in their everyday lives. These debates persist and are perhaps more relevant, and necessary, than ever before given the pervasiveness of internet pornography in the $21^{\text {st }}$ century. Internet pornography is a world removed from the glossy, scantily clad depictions which graced the pages of Playboy's past. Today's pornography presents an aggressive, hostile sexuality which eroticises male dominance and entitlement. It fuses sex and aggression in a way which depicts men as the enforcers and women as passive - yet enthusiastic - receivers (Bridges et al., 2010; Jensen, 2016; Sun et al., 2008). Today's pornography has the power to play a primary role in influencing the development and acquisition of sexual scripts (Braithwaite et al., 2015b; Bridges et al., 2016; Flood, 2009; 2010; Kimmel, 2007; Sun et al., 2017), especially for young people exposed to it as it "helps to sustain [their] adherence to sexist and unhealthy notions of sex and relationships" (Flood, 2009, p. 384).

We remain largely in the dark in New Zealand about the way pornography is experienced, understood and interpreted by the audience of pornography themselves. Whilst a small number of qualitative studies have examined the way pornography is engaged with (Antevska, 2012; Antevska \& Gavey, 2015; Kingi \& Poppelwell, 2005; Kingi et al., 2004; Martin, 2016; Office of Film and Literature Classification, 2018), there remains a void of qualitative inquiry which documents the realities of pornography engagement. The effects of pornography on consumers remain contested, yet there is an ever-growing body of research which speaks to the harms of pornography for adult men, women and young people (Bergner \& Bridges, 2002; Bridges et al., 2003; DeKeseredy \& Hall-Sanchez, 2016; Flood, 2009; 2010; Manning, 2006; Office of Film and Literature Classification, 2018; Shope, 2004; Sun et al., 2017). As this thesis has demonstrated, pornography was experienced in a range of both positive and negative ways, but the harms of pornography for this group were hard to ignore. We are right to be concerned about the content of pornography and its impacts on consumers' attitudes and experiences of sex, intimate relationships, consent and violence against women. 
This thesis has examined the way that a sample of 24 heterosexual emerging adults experienced and understood pornography in the digital age. It contributes to the gap in knowledge and understanding about how pornography is subjectively experienced by providing a uniquely gendered analysis. As outlined in the introductory chapter, this thesis aimed to:

- Examine what emerging adults in New Zealand consider to be pornography and in what ways it is engaged with

- Consider the ways that emerging adults perceived pornography to have influenced their lives, if at all, in positive and/or negative ways

- Consider the gendered implications of pornography consumption for emerging adults

- Provide a foundation for future research in a contemporary, rapidly changing area of study

Whilst exploratory in nature, this thesis has demonstrated that experiences with pornography are anything but simple or straightforward. As much as research tells us about what pornography means and represents, the voices of those most affected by pornography - the audience and their partners - have been left behind. Bringing in the audience to conversations about pornography is critically important and this thesis has started with these voices. This research provides a platform for future research in this area, and this concluding chapter now explores some of the future directions for research in this area.

\section{Thinking ahead: A focus on gender in contemporary pornography research}

As a genre, pornography is inherently gendered. It is gendered in its production, in its viewership, and in the way that it is experienced. That said, comparative gendered research on pornography remains limited. The legacy of the sex wars continues to silo academic research on pornography, with much of the scholarship remaining split on moral or political grounds. Whilst qualitative scholarship which attends to men's and women's differential experiences with pornography is building, there remains a critical need for a gendered analysis of men's and women's experiences with mainstream pornography. Gender has been at the crux of the analysis throughout this research, and the gendered experiences reported by participants demonstrate the importance of continuing to keep gender at the forefront of contemporary pornography research. 
Future research would benefit from critically examining a number of areas in further depth, which could help contribute to a gendered, subjective body of scholarship that moves beyond the traditionally stagnant anti/pro positions. In building on the findings of this research, further gendered analysis of the ways that aggression in pornography is defined and understood by the audience would further illuminate the complexities in this area. I contend that there are multiple avenues for future research on pornography, and now turn to how the findings from this research serve as a platform for future considerations.

\section{Gendered interest in pornography}

Heterosexual men have long been the primary audience of pornography (Boyle, 2010; Flood, 2010), however research suggests that women's interest in pornography is increasing, and young women are increasingly viewing pornography online. Research has traditionally neglected women's engagement with pornography, so ongoing discussions with women about the appeal of pornography - including specific genres - would help further illuminate the push and pull factors for their engagement with online pornography. Further, continued investigation of some men's interest in particular types of pornography, and indeed research with men who have decided to abstain from pornography, would help build a more complete picture of what is both appealing and unappealing about pornography in the digital era.

\section{Gendered understandings of aggression in sex and pornography}

The methodological disagreements associated with defining aggression for content analyses have contributed to a murky literature terrain, and research findings about the content of pornography, specifically aggressive and/or violent pornography, are inconsistent. By speaking with men and women about how aggression in pornography is defined, conceptualised and understood by them as consumers, this could help provide more nuanced and relevant operationalisations of aggression in pornography for researchers.

Participants in this research overwhelmingly suggested that mainstream pornography displayed aggressive acts and behaviours, which were primarily aimed at women. At the same time, however, several women spoke of an interest in rough sex, and Pornhub analytics data suggests that some women are increasingly viewing rough pornography. Future research which interrogates the phenomenon of rough sex is clearly warranted. 
Questions should be asked about what type of behaviours are considered in the realm of rough sex, the origins of this interest, and the circumstances or contexts in which rough sex is engaged in. As the perspectives from some of the women in this research showed, their interest and engagement in rough sex was fundamentally related to consensual sexual relations with men, so assessing the circumstances or contexts which give rise to engaging in rough sex is important.

Whilst rough sex did not appear as frequently in conversations with men as it did with women, future research with men about what they consider to be rough sex would help clarify any differences in understanding between men and women. This seems particularly important in the digital era, as relationships and sexual negotiations are increasingly occurring on online platforms. If men's and women's understandings of rough sex are markedly different, then this has the potential to result in sexual experiences which may be perceived as 'rough' by one party, but as 'violent' by another. In considering how these situations may be handled by police if complaints are made, more nuanced understandings of how rough sex is understood or negotiated could have important implications for those tasked with responding to such complaints.

Alongside these areas, future research would benefit from interrogating specific aggressive behaviours in pornography - such as choking - and to examine whether these behaviours are becoming part of a standard or normalised heterosexual sexual script. In New Zealand, recent legislative change has meant that strangulation is now included as a separate offence within family violence statutes (Bennett, 2018). It is well understood that strangulation is a key risk factor for women's experiences of lethal violence in intimate relationships (Dobash, Dobash, Cavanagh, \& Medina-Ariza, 2007; Glass et al., 2008), yet choking appears to be a common behaviour depicted in pornography (Bridges et al., 2010), and was also a sexual interest for some of the participants in this research. Exploring the eroticisation of behaviours that are indicators for women's experiences of serious offline violence are important, and research which explores this in more depth would be a welcome contribution to the literature.

\section{Gendered impacts of pornography}

The impacts of pornography reported by participants in this research were markedly gendered. Pornography addiction was a key theme which emerged that had decidedly gendered effects. Whilst several men spoke of experiencing pornography addiction, they 
spoke of being able to access and secure support on online forums such as No Fap. Ensuring that men continue to have access to specific support services - both online and offline - for issues such as pornography addiction would serve to further open up the conversation about the harms of pornography more generally, which as this research has shown, can have very real impacts on the lives of individuals.

Whilst pornography addiction was primarily reported by men (with the exclusion of one female participant), there were several women who felt that there was a lack of support available for them as they battled their partner's use of pornography. Whilst both women accessed counselling services, this was not always experienced positively, and finding support in the counselling sphere which specifically focused on this issue was a difficult task. The creation and provision of support services to partners of people with pornography problems would ensure that those experiencing trauma and distress in their intimate relationships have an outlet for managing what can only be described as a heart-breaking situation.

A further gendered impact which was reported in this research was pornography's influence in intimate relationships. Men rarely spoke of their partner's use of pornography in troubling ways, whilst a number of women felt that their partner's use of pornography had influenced or affected their experiences of sex, including coercive sexual behaviours. As previously discussed in this thesis, there is little qualitative research on the role of pornography in intimate relationships, so this research contributes to this scarce literature field. That said, future research which incorporates gendered understandings of the effects of pornography on intimate relationships is warranted. Research on pornography in intimate relationships fits within the scope of intimate partner violence and sexual violence research more generally, and whilst some critical criminological attention has been paid to this (DeKeseredy \& Hall-Sanchez, 2016), much more insight is needed to critically understand the dynamics and complexities around pornography use in intimate relationships.

\section{Pornography as a critical inclusion in education}

In New Zealand, sexuality education is one of the seven key areas of learning in the health and physical education area of the New Zealand education curriculum. Sexuality education is the only learning area that requires schools to consult with the school community on the way it is delivered, meaning that each school varies in the way they 
deliver such content. This variation invariably means that some schools teach sexuality education well and comprehensively, whilst others teach it poorly. The failures in delivery of sexual education in New Zealand schools have been recently highlighted in a report commissioned by the Education Review Office (2018), whereby less than half of all schools included in the research taught sexuality education comprehensively. Further, sexual violence and pornography were the two topics least likely to be included in the delivery of sexual education across the board.

The lack of critical discussion about pornography and sexual violence in sexual education for young people is a glaring omission, especially when recent New Zealand research suggests that young people are increasingly influenced by pornography and "use it as a way of learning about sex" (Office of Film and Literature Classification, 2018, p. 10). The recent NZ Youth and Porn report also contends that more comprehensive sexuality education, inclusive of critical conversations about pornography, is necessary, and indeed desired for, by young people themselves (Office of Film and Literature Classification, 2018). In the absence of a utopian world without pornography, it is critical that young people are equipped with critical media literacy skills to navigate the increasingly aggressive, hostile online climate of pornography.

Internationally, debates have surfaced about the need to incorporate 'porn literacy' within school curriculums to help young people develop a critical appraisal of pornography (Albury, 2014). The desire to equip young people with critical media literacy skills is not without critique, and Gill (2012a) argues that requiring young people to be critical of media, including pornography, has become a "panacea for various social ills" (p. 737). Through requiring young people to be critical consumers of media, Gill (2012a) contends that it

leave(s) media themselves untouched, shifting all the responsibility onto young people to think critically and deconstruct, but it also misunderstands the complexity of young people's (indeed all people's) relations to media, with its implication that being critical will automatically displace other kinds of affective responses including shame, hatred or desire (p. 737).

Whilst it could be viewed that requiring young people to be critical absolves media outlets - including pornography producers - of the responsibility to present content which depicts healthy relationships, the reality is that pornography is not going to magically disappear. Further, research with young people in New Zealand suggests that many 
already held quite a critical view of pornography, and were aware that it promoted false expectations and normalised violence and aggression (Office of Film and Literature Classification, 2018). Young people themselves were calling for more comprehensive sexual education which included conversations about pornography, so including pornography on the agenda of sexuality education, and equipping young people with the skills to further develop their existing critical lens, validates young people's needs and desires.

By providing comprehensive education to young people about pornography, it has the potential to provide a counter-narrative to the common themes and tropes pornography depicts. Further, it provides an opportunity to deliver nuanced and contemporary conversations about consent with young people, which is critically important given the lack of discussion about consent in pornography generally. If young people are increasingly using pornography as a primary sexual educator, then young people need to be able to understand what communicative consent in offline sexual relationships looks like.

Outside of educating just young people, education efforts with parents of young people appear to be also critically important. The recent NZ Youth and Porn report suggested that parents were more likely to have conversations with boys about pornography than girls, but girls were more likely to have encountered pornography accidentally, which may result in more distressing engagements online (Office of Film and Literature Classification, 2018). By equipping parents through community education about how to converse with young people about pornography, this would serve to further the critical lens that many young people already hold.

Another area that this research has relevance for is the delivery of rape prevention education. In much mainstream pornography, the gendered depiction of sex presents men as the strong, aggressive deliverers of sexuality and women as passive receivers who enthusiastically receive, and enjoy, all sexual acts. Pornography reinforces the gender hierarchy which positions men as dominant and women as subordinate, presenting a fused version of sex with aggression alongside a hostile approach toward women. Critically interrogating mainstream pornography's depiction of gendered bodies, aggression, sex and consent is a critical inclusion in sexual violence prevention education, as such factors contribute to an environment that can encourage and perpetuate sexual 
disrespect, sexual harm and violence against women and girls. New Zealand's rates of family and sexual violence remain at alarmingly high levels, with one in three girls reporting sexual violence before the age of 16 (Fanslow, Robinson, Crengle, \& Perese, 2007), and one in five women reporting sexual assault in adulthood (Fanslow \& Robinson, 2004). These rates necessitate ongoing preventive efforts, and it is imperative that education about the factors which contribute to such rates, including pornography, are delivered in a comprehensive and age-appropriate way to young people growing up in an increasingly digitally mediated environment.

\section{Concluding statement}

This thesis has provided, to my knowledge, the first in-depth insight into the way that emerging adults in New Zealand experience pornography in the digital age. The findings from this research signal the urgent need for more comprehensive, complex discussions about pornography, which are only possible through breaking the silence around conversations about sex generally. The findings of this research serve as an important platform for future research in New Zealand, but also globally, given the paucity of qualitative research from the perspectives of those most affected by pornography. By bringing the audience into pornography for this project, it demonstrates the complex, nuanced and gendered ways that pornography is experienced.

Pornography as a genre is protean, and the same can be said for the way that it is experienced and understood. We need to continue to acknowledge the misogynistic, aggressive foundations of pornography and explore how these are interpreted by viewers, because pornography is not going anywhere anytime soon. Regulating internet pornography is challenging, so the focus needs to be on understanding more about what pornography means to the people who view it, and how they interpret it. Only then can we consider the best ways forward for educating young people as they navigate this increasingly sexual, technologically mediated world. Pornhub is not just a place, it's a source. It can be a source of inspiration for consenting adults, but it can also be a source of sexist education for many. In this vein, the pleasures of Pornhub are uncomfortably situated alongside its pains, and we need to acknowledge both aspects in order to move in the direction of a more critical, nuanced and gendered understanding of pornography in the digital age. 


\section{Appendices}

\section{Appendix A: Memorandum of Ethical Approval}

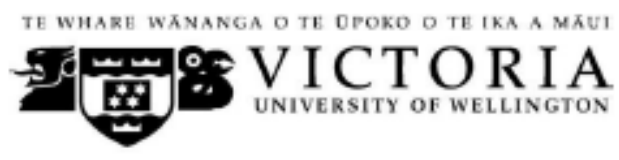

MEMORANDUM

Phome $0-4-4635490$

Email surancorbettovraw.acna

\begin{tabular}{l|l}
\hline TO & Samantha Keene \\
\hline COPY TO & A/Prof Jan Jordan \\
\hline FROM & AProf Susan Corbett, Convener, Human Ethics Committee \\
\hline DATE & 13 July 2016 \\
\hline PAGES & 1 \\
\hline SUBJECT & $\begin{array}{l}\text { Ethics Approval: 23174 } \\
\text { Young people's experiences of pornography, sex, and intimacy in } \\
\text { the digital age: An exploratory study of New Zealand perspectives }\end{array}$ \\
\hline
\end{tabular}

Thank you for your application for ethical approval, which has now been considered by the Standing Committee of the Human Ethics Committee.

Your application has been approved from the above date and this approval continues until 1 October 2018. If your data collection is not completed by this date you should apply to the Human Ethics Committee for an extension to this approval.

Best wishes with the research.

Kind regards

\section{This image has been redacted. Please see print version for the full image.}




\section{Appendix B: Support Services Sheet}

\section{Resources and Contacts}

\section{General Counselling and Support Services}

Lifeline Aotearoa's $24 / 7$ helpline offers free, anonymous counselling for a wide range of issues.

Contact phone: (0800) 543354 or http://wwwwlifeline.org.nz/

\section{Sexual Therapy and Sexual Health Promotion}

Family Planning provides a range of health and sexual reproductive services, as well as education and training and research.

$\begin{array}{ll}6^{\text {th }} \text { Floor, 35-37 Victoria St } & 2^{\text {nd }} \text { Floor, } 29 \text { Waterloo Road } \\ \text { Wellington } & \text { Wellington } \\ \text { (04) } 4991992 & \text { (04) } 5695025\end{array}$

Sexual Therapy Wellington provides a therapeutic environment where people can become more comfortable with their sexuality, whether in a relationship or not.

$\begin{array}{lll}\text { Geraldine Lakeland } & \text { (04) } 4711241 & \text { www.stw.net.nz } \\ \text { Marion Wade } & \text { (04) } 3850094 & \text { www.stw.net.nz }\end{array}$

\section{Wellington Abuse Support Services}

Provides support and information, medical services, counselling for individuals and families/whanau

Wellington Sexual Abuse HELP Foundation

Level 7, Education House

178-182 Willis St

(04) 4997532 - $24 \mathrm{hr}$ service available

Male Survivors of Sexual Abuse

(022) 4193416

enquiries@mssatwgtn.org.nz
Wellington Rape Crisis

Level 2, Southmark House

203-209 Willis St

(04) 8018973

Women's Refuge

$24 \mathrm{hr}$ crisis line (0800) 733843

httos://womensrefuge.org.nz

\section{Community Health Services}

Provides medical, counselling and social work services to under $24 \mathrm{~s}$ in Wellington and the Hutt Valley.

Evolve Wellington Youth Service VIBE Hutt Valley Youth Service

Level 2, James Smith Building 4 Daly St, Lower Hutt

(04) 4660525

Cnr Cuba and Manners St

(04) 4736204

http://evolveyouth,org.nz/

Unit 7, Building 10, 68-70 Ward St,

Upper Hutt

(04) 5286261

\section{University-specific Support Services}

Provides medical and counselling services to students of Victoria University of Wellington and Massey University Wellington.

vUW Student Health and Counselling

(04) 4635308

Massey Student Health and Counselling

(04) 9793030 


\section{Appendix C: Participant Information Sheet}

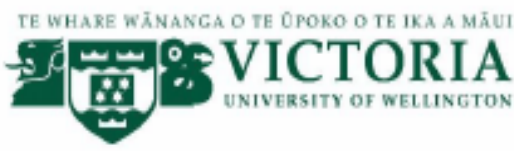

\section{The Porn Study: An exploratory study of young New Zealander's experiences of pornography, sex, and intimacy in the digital age}

\section{INFORMATION SHEET FOR PARTICIPANTS}

Thank you for your interest in this project. Please read this information before deciding whether or not to take part. If you decide to participate, thank you. If you decide not to take part, thank you for considering my request.

Who am I?

My name is Samantha Keene and I am a Doctoral student in Criminology at Victoria University of Wellington. This research project is work towards my PhD thesis.

What is the aim of the project?

This project explores the way that pornography affects young, heterosexual people's lives, especially their sexual behaviours, relationships, intimacy, and their sense of self. This project is focused on people between the ages of 18 and 30 , as they are a group that have grown up with access to hardcore, internet pornography. I will be speaking with young people directly about the impacts of porn in their lives, as well as key stakeholders who work with young people affected by porn, or have expert knowledge in this area. This research has been approved by the Victoria University of Wellington Human Ethics Committee $\# 23174$.

How can you help?

If you agree to take part I will interview you in a public place, such as a café or meeting room at Wellington City Library. I will ask you questions about the impact of pornography on your life. The interview will take about an hour and will be audio recorded for later transcription. You can stop the interview at any time, without giving a reason. You can withdraw from the study at any time prior to $30^{\text {th }}$ June, 2017. If you withdraw, the information you provided will be destroyed or returned to you.

What will happen to the information you give?

This research is confidential and you will not be identifiable in the final thesis. A pseudonym will be applied throughout. Only my supervisors and I will read the notes or transcript of the interview. The interview transcripts, summaries and any recordings will be kept securely and destroyed 5 years after the research ends. Confidentiality will only be broken if behaviour is disclosed that directly contributes to the perpetration of harm to either you or someone else, such as the creation or distribution of objectionable material. 
What will the project produce?

The information from my research will be used in my PhD thesis. I may also use the results of my research for conference presentations, and academic reports. I will take care not to identify you in any presentation or report.

If you accept this invitation, what are your rights as a research participant?

You do not have to accept this invitation if you don't want to. If you do decide to participate, you have the right to:

- choose not to answer any question;

- ask for the recorder to be turned off at any time during the interview;

- withdraw from the study up until $30^{\text {th }}$ June, 2017;

- ask any questions about the study at any time;

- receive a copy of your interview recording (if it is recorded);

- read over and comment on a written summary of your interview;

- agree on another name for me to use rather than your real name;

- be able to read any reports of this research by emailing the researcher to request a copy.

If you have any questions or problems, who can you contact?

If you have any questions, either now or in the future, please feel free to contact either:

Student:

Samantha Keene

Samantha.keene@vuw.ac.nz

(04) 4635233 xtn: 8444

(021) 1608239
Supervisor:

Associate Professor Dr Jan Jordan

Institute of Criminology, School of Social and Cultural Studies

(04) 4635811

\section{$\underline{\text { Jan.jordan@vuw.ac.nz }}$}

Human Ethics Committee information

If you have any concerns about the ethical conduct of the research you may contact the Victoria University HEC Convener: Associate Professor Susan Corbett. Email susan.corbett@vuw.ac.nz or telephone +64-4-463 5480. 


\section{Appendix D: Participant Consent Form}

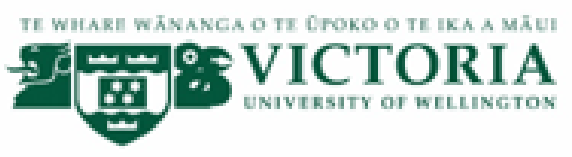

\section{The Porn Study: An exploratory study of young New Zealander's experiences of pornography, sex, and intimacy in the digital age \\ CONSENT TO INTERVIEW}

This consent form will be held for 5 years.

Researcher: Samantha Keene, School of Social and Cultural Studies, Victoria University of Wellington

- I have read the Information Sheet and the project has been explained to me. My questions have been answered to my satisfaction. I understand that I can ask further questions at any time.

- I agree to take part in an audio recorded interview.

I understand that:

- I may withdraw from this study up to $30^{\text {th }}$ June, 2017 and any information that I have provided will be returned to me or destroyed.

- The information I have provided will be destroyed 5 years after the research is finished.

- Any information I provide will be kept confidential to the researcher and the supervisor. | Confidentiality will only be broken if I disclose behaviour that contributes to the offline perpetration of harm to either myself or others. I understand that the results will be used for an PhD report and a summary of the results may be used in academic reports and/or presented at conferences.

- My name will not be used in reports, nor will any information that would identify me.

- I would like a copy of the transcript of my interview: $\quad$ Yes $\square$ No

- I would like a summary of my interview: $\quad$ Yes $\square$ No

- $\quad$ I would like to receive a copy of the final report and have added my email Yes $\square$ No address below.

Signature of participant:

Name of participant:

Date: 
Appendix E: Recruitment Flyer

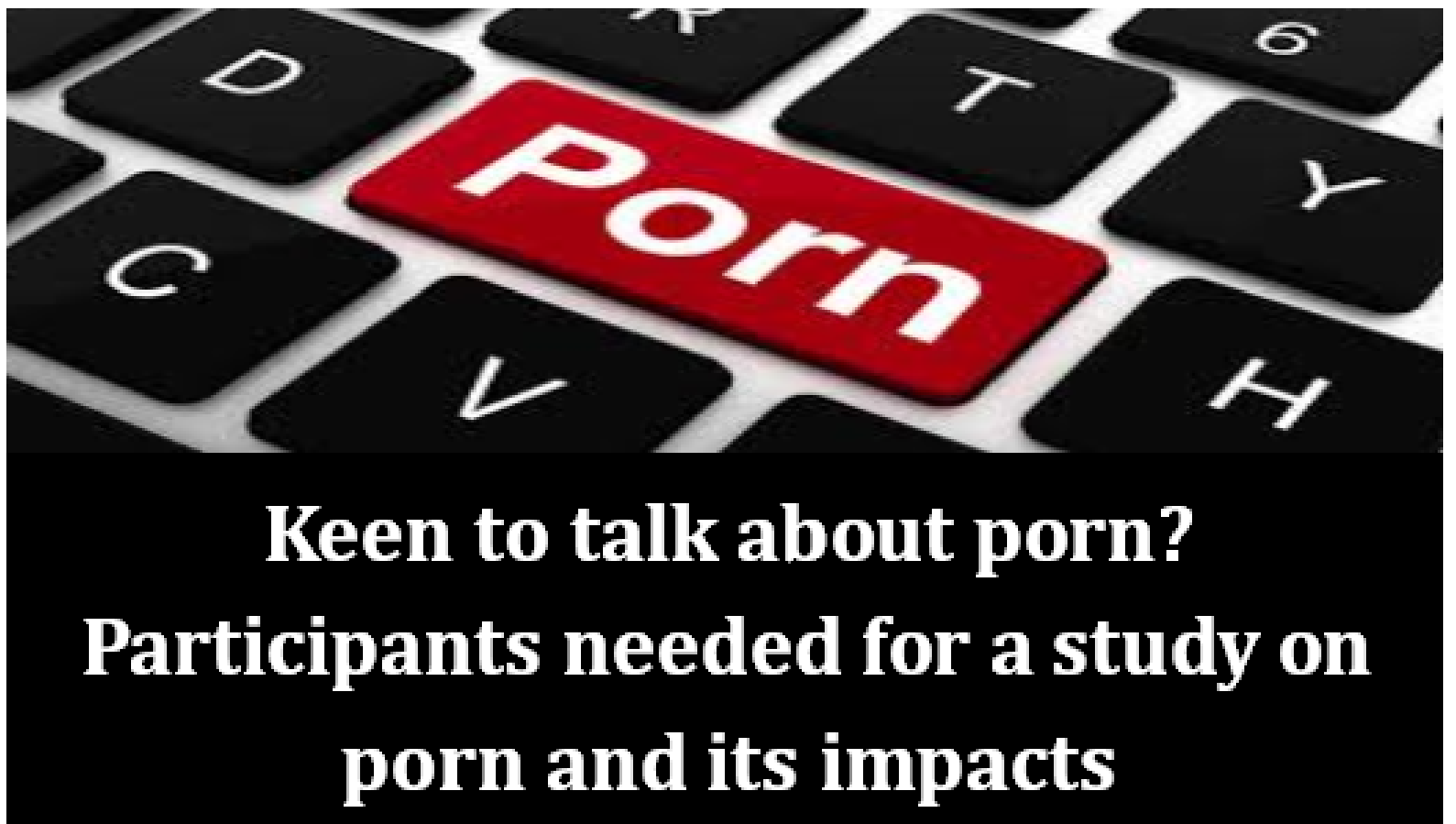

If you:

- Self-identify as male or female

- Are aged between 18 and 30 and live in NZ

- Identify as heterosexual

- Feel that porn has impacted your life, either positively or negatively

\section{I would love to hear from you!}

I am a PhD student in Criminology at VUW and am interested in how porn affects people's lives. If you have any questions or queries about the study, please get in touch with me or my supervisor.

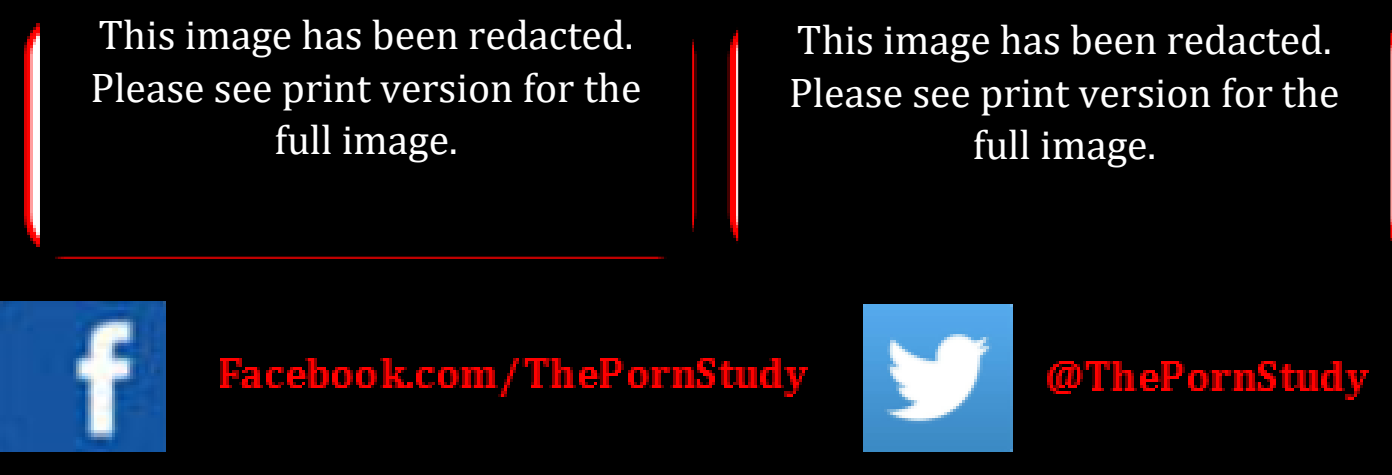

This research has received ethical approval from the vuW Human Ethics Committee \#23174 


\section{Reference List}

Albury, K. (2014). Porn and sex education, porn as sex education. Porn Studies, 1(1-2), 172-181. doi:10.1080/23268743.2013.863654

Allen, L. (2006). "Looking at the real thing": young men, pornogarphy, and sexuality education. Discourse: Studies in the Cultural Politics of Education, 27(1), 69-83.

Antevska, A. (2012). What is appealing about pornography? Men account for production and consumption. (Master's), The University of Auckland, Auckland.

Antevska, A., \& Gavey, N. (2015). "Out of sight and out of mind": detachment and men's consumption of male sexual dominance and female submission in pornography. Men and Masculinities, 1-25.

Armstrong, L. (2018). Stigma, decriminalisation, and violence against street-based sex workers: Changing the narrative. Sexualities, $0(0)$, 1-21. doi: $10.1177 / 1363460718780216$

Arnett, J. (2000). Emerging adulthood: a theory of development from the late teens through the twenties. American Psychologist, 55(5), 469-480.

Arnett, J. (2015). Emerging adulthood: the winding road from the late teens through the twenties (2nd ed.). New York, NY: Oxford University Press.

Ashley, V. (2016). Porn - artifice - performance - and the problem of authenticity. Porn Studies, 3(2), 187-190. doi:10.1080/23268743.2016.1184481

Ashton, S., McDonald, K., \& Kirkman, M. (2017). Women's experiences of pornography: A systematic review of research using qualitative methods. J Sex Res, 1-14. doi:10.1080/00224499.2017.1364337

Attwood, F. (2005). What do people do with porn? Qualitative research into the comsumption, use, and experience of pornography and other sexually explicit media. Sexuality and Culture, 9(2), 65-86. doi:10.1007/s12119-005-1008-7

Attwood, F. (2007). "Other" or "one of us"?: the porn user in public and academic discourse. Participations: Journal of audience and reception studies, 4(1).

Attwood, F., Maina, G., \& Smith, C. (2018a). Conceptualizing, researching and writing about pornography. Porn Studies, 5(1), 1-5.

Attwood, F., Smith, C., \& Barker, M. (2018b). 'I'm just curious and still exploring myself': young people and pornography. New Media \& Society, 20(10), 3738-3759.

Baker, K. E. (2016). Online pornography - Should schools be teaching young people about the risks? An exploration of the views of young people and teaching professionals. Sex Education, 16(2), 213-228. doi:10.1080/14681811.2015.1090968

Baldwin, M. (1984). The sexuality of inequality: the Minneapolis pornography ordinance. Law \& Inequality: A journal of theory and practice, 2(2), 629-653.

Barron, M., \& Kimmel, M. (2000). Sexual violence in three pornographic media: toward a sociological explanation. The Journal of Sex Research, 37(2), 161-168.

Beggan, J. K., \& Allison, S. T. (2003). "What sort of man reads Playboy?" The self-reported influence of Playboy on the construction of masculinity. The Journal of Men's Studies, 11(2), 189-206.

Benjamin, 0., \& Tlusten, D. (2010). Intimacy and/or degradation: Heterosexual images of togetherness and women's embracement of pornography. Sexualities, 13(5), 599623. doi:10.1177/1363460710376492

Bennett, L. (2018). Changes to Family Violence (Amendment) Act in effect from Monday. Retrieved

from https://www.nzherald.co.nz/nz/news/article.cfm?c id=1\&objectid=12168481 
Berg, H. (2017). Porn work, feminist critique, and the market for authenticity. Signs, 42(3), 669-692.

Bergen, R. K., \& Bogle, K. A. (2000). Exploring the connection between pornography and sexual violence. Violence and victims, 15(3), 227-234.

Bergner, R. M., \& Bridges, A. J. (2002). The significance of heavy pornography involvement for romantic partners: research and clinical implications. Journal of Sex \& Marital Therapy, 28(3), 193-206. doi:10.1080/009262302760328235

Bernstein, E. (2007). Temporarily yours: intimacy, authenticity, and the commerce of sex: University of Chicago Press.

Bird, E. R., Seehuus, M., Clifton, J., \& Relline, A. H. (2014). Dissociation during sex and sexual arousal in women with and without a history of childhood sexual abuse. Archives of Sexual Behavior, 43, 953-964.

Blackman, S. J. (2007). 'Hidden ethnography': crossing emotional borders in qualitative accounts of young people's lives. Sociology, 41(4), 699-716. doi:10.1177/0038038507078925

Boeije, H. (2010). Analysis in qualitative research. Thousand Oaks, California: Sage Publications Ltd.

Bogaert, A. F., Turkovich, D. A., \& Hafer, C. L. (1993). A content analysis of "Playboy" centrefolds from 1953 through 1990: changes in explicitness, objectification, and model's age. The Journal of Sex Research, 30(2), 135-139.

Bogle, K. A. (2008). Hooking up: sex, dating and relationships on campus. New York: New York University Press.

Böhm, M., Franz, P., Dekker, A., \& Matthiesen, S. (2015). Desire and dilemma - gender differences in German students' consumption of pornography. Porn Studies, 2(1), 76-92. doi:10.1080/23268743.2014.984923

Boyle, K. (2000). The pornography debates: Beyond cause and effect. Women's Studies International Forum, 23(2), 187-195. doi:http://dx.doi.org/10.1016/S0277$\underline{5395(00) 00077-7}$

Boyle, K. (2010). Introduction: everyday pornography. In K. Boyle (Ed.), Everyday Pornography. Abingdon, Oxon: Routledge.

Boyle, K. (2018). The implications of pornification: pornography, the mainstream and false equivalences. In N. Lombard (Ed.), The Routledge Handbook of Gender and Violence (pp. 85-96). Abingdon, Oxon: Routledge.

Boynton, P. M. (1999). 'Is that supposed to be sexy?' Women discuss women in 'top shelf' magazines. Journal of Community \& Applied Social Psychology, 9(6), 449-461.

Braithwaite, S. R., Aaron, S. C., Dowdle, K. K., Spjut, K., \& Fincham, F. D. (2015a). Does pornography consumption increase participation in friends with benefits relationships? Sexuality \& Culture, 19, 513-532.

Braithwaite, S. R., Coulson, G., Keddington, K., \& Fincham, F. D. (2015b). The influence of pornography on sexual scripts and hooking up among emerging adults in college. Archives of Sexual Behavior, 44, 111-123.

Braithwaite, S. R., Givens, A., Brown, J., \& Fincham, F. (2015c). Is pornography consumption associated with condom use and intoxication during hookups? Culture, health \& sexuality, 17(10), 1155-1173. doi:10.1080/13691058.2015.1042920

Braun, V., \& Clarke, V. (2013). Successful qualitative research: a practical guide for beginners. London, UK: Sage Publications Ltd. 
Braun, V., Tricklebank, G., \& Clarke, V. (2013). “It shouldn't stick out from your bikini at the beach": Meaning, gender, and the hairy/hairless body. Psychology of Women Quarterly, 37(4), 478-493. doi:10.1177/0361684313492950

Brecher, B. (2015). Andrea Dworkin's Pornography: Men Possessing Women - A Reassessment. In H. Marway \& H. Widdows (Eds.), Women and Violence: The Agency of Victims and Perpetrators (pp. 145-161). London: Palgrave Macmillan UK.

Bridges, A., Wosnitzer, R., Scharrer, E., Sun, C., \& Liberman, R. (2010). Aggression and sexual behavior in best-selling pornography videos: a content analysis update. Violence Against Women, 16(10), 1065-1085. doi:10.1177/1077801210382866

Bridges, A. J. (2010). Methodological considerations in mapping pornography content. In K. Boyle (Ed.), Everyday pornography (pp. 35-49). Abingdon, Oxon: Routledge.

Bridges, A. J., Bergner, R. M., \& Hesson-McInnis, M. (2003). Romantic partners' use of pornography: its significance for women. Journal of Sex \& Marital Therapy, 29(1), $1-14$.

Bridges, A. J., \& Morokoff, P. J. (2011). Sexual media use and relational satisfaction in heterosexual couples. Personal Relationships, 18, 562-585.

Bridges, A. J., Sun, C. F., Ezzell, M. B., \& Johnson, J. (2016). Sexual scripts and the sexual behavior of men and women who use pornography. Sexualization, Media, \& Society, 2(4), 2374623816668275. doi:10.1177/2374623816668275

Brinton Lykes, M., \& Crosby, A. (2014). Feminist practice of action and community research. In S. N. Hesse-Biber (Ed.), Feminist research practice: a primer (pp. 145181). Thousand Oaks, CA: SAGE.

British Broadcasting Corporation. (2017). Playboy brings back nudity saying it's removal was a mistake. Retrieved from https://www.bbc.com/news/world-us-canada$\underline{38963007}$

Brod, H. (2007). Pornography and the alienation of male sexuality. In J. Schiffman \& M. Edwards (Eds.), Gender Violence: Interdisciplinary Perspectives (2 ed., pp. 395408). New York: New York University Press.

Brodesco, A. (2016). POV to the people: online discourses about gonzo pornography. Porn Studies, 3(4), 362-372.

Bronstein, C. (2011). Battling pornography: the American Feminist anti-pornography movement, 1976-1986. New York: Cambridge University Press.

Brosius, H.-B., Weaver, J. B., \& Staab, J. F. (1993). Exploring the social and sexual "reality" of contemporary pornography. The Journal of Sex Research, 30(2), 161-170. doi:10.1080/00224499309551697

Brownmiller, S. (1975). Against our will: Men, women and rape. New York: Simon \& Schuster.

Buchwald, E., Fletcher, P. R., \& Roth, M. (1993). Transforming a rape culture. Minneapolis, MN: Milkweed Editions.

Bynum, C. L. (1991). Feminism and pornography: A New Zealand perspective. Tulane Law Review, 65, 1131-1182.

Campbell, L., \& Kohut, T. (2017). The use and effects of pornography in romantic relationships. Current Opinion in Psychology, 13, 6-10. doi:https://doi.org/10.1016/j.copsyc.2016.03.004

Carroll, J. S., Padilla-Walker, L. M., Nelson, L. J., Olson, C. D., McNamara Barry, C., \& Madsen, S. D. (2008). Generation XXX: Pornography acceptance and use among emerging adults. Journal of Adolescent Research, 23(1), 6-30. doi:10.1177/0743558407306348 
Cawston, A. (2018). The feminist case against pornography: a review and re-evaluation. Inquiry, 1-35. doi:10.1080/0020174X.2018.1487882

Chadwick, S. B., Raisanen, J. C., Goldey, K. L., \& van Anders, S. (2018). Strategizing to make pornography worthwhile: a qualitative exploration of women's agentic engagement with sexual media. Archives of Sexual Behavior, 47(6), 1853-1868.

Chowkhani, K. (2016). Pleasure, bodies and risk: women's viewership of pornography in urban India. Porn Studies, 3(4), 443-452.

Ciclitira, K. (2004). Pornography, women and feminism: between pleasure and politics. Sexualities, 7(3), 281-301. doi:10.1177/1363460704040143

Cook, I. (2006). Western heterosexual masculinity, anxiety, and web porn. Journal of Men's Studies, 14(1), 47-63.

Cooper, A. (1998). Sexuality and the internet: surfing into the new millenium. Cyberpsychology \& Behavior, 1(2), 187-193.

Corrigan, P. W., \& Watson, A. C. (2002). Understanding the impact of stigma on people with mental illness. World psychiatry: official journal of the World Psychiatric Association (WPA), 1(1), 16-20.

Corsianos, M. (2007). Mainstream pornography and "women": Questioning sexual agency. Critical Sociology, 33(5-6), 863-885. doi:10.1163/156916307x230359

Cowan, G., \& Campbell, R. R. (1994). Racism and sexism in interracial pornography: A content analysis. Psychology of Women Quarterly, 18(3), 323-338. doi:10.1111/j.1471-6402.1994.tb00459.x

Cowan, G., Lee, C., Levy, D., \& Snyder, D. (1988). Dominance and inequality in X-rated videocassettes. Psychology of Women Quarterly, 12(3), 299-311. doi:10.1111/j.1471-6402.1988.tb00945.x

Coyne, S. M., Padilla-Walker, L. M., \& Howard, E. (2015). Media uses in emerging adulthood. In J. J. Arnett (Ed.), The Oxford Handbook of Emerging Adulthood (pp. 349-363). New York, NY: Oxford University Press.

Crawford, B. J. (2007). Toward a third-wave feminist legal theory: young women, pornography and the praxis of pleasure. Michigan Journal of Gender and Law, 14(1), 99-168.

Crawford, M., \& Popp, D. (2003). Sexual double standards: a review and methodological critique of two decades of research. The Journal of Sex Research, 40(1), 13-26. doi:10.1080/00224490309552163

Crutcher, E. E. (2015). "She's totally faking it!": the politics of authentic female pleasure in pornography. In L. Comella \& S. Tarrant (Eds.), New views on pornography: sexuality, politics, and the law (pp. 319-334). Santa Barbara, California: ABC-CLIO, LLC.

Daneback, K., Træen, B., \& Mansson, S. (2009). Use of Pornography in a Random Sample of Norwegian Heterosexual Couples. Archives of Sexual Behavior, 38, 746-753.

DeKeseredy, W. (2015). Critical criminological understandings of adult pornography and woman abuse: New progressive directions in research and theory. 2015, 4(4), 18. doi:10.5204/ijcjsd.v4i4.184

DeKeseredy, W., \& Corsianos, M. (2016). Violence against women in pornography. New York: Routledge.

DeKeseredy, W. S., \& Hall-Sanchez, A. (2016). Adult pornography and violence against women in the heartland: results from a rural Southeast Ohio study. Violence Against Women. doi:10.1177/1077801216648795 
DeKeseredy, W. S., \& Schwartz, M. D. (2013). Male peer support and violence against women: the history \& verification of a theory. Boston: Northeastern University Press.

Department of Justice. (1989). Pornography: Report of the Ministerial Committee of Inquiry into Pornography. Wellington, New Zealand: Department of Justice

Dickson-Swift, V., James, E. L., Kippen, S., \& Liamputtong, P. (2009). Researching sensitive topics: qualitative research as emotion work. Qualitative Research, 9(1), 61-79. doi:10.1177/1468794108098031

Dines, G. (1998). Dirty business: Playboy magazine and the mainstreaming of pornography. In G. Dines, R. Jensen, \& A. Russo (Eds.), Pornography: the production and consumption of inequality (pp. 37-64). New York: Routledge.

Dines, G. (2006). The White man's burden: Gonzo pornography and the construction of black masculinity. Yale Journal of Law and Feminism, 18(1), 283-298.

Dines, G. (2016). "There is not such thing as IT": toward a critical understanding of the porn industry. In H. Brunskell-Evans (Ed.), The sexualized body and the medical authority of pornography: performing sexual liberation (pp. 21-42). Newcastle upon Tyne: Cambridge Scholars Publishing.

Dines, G., Jensen, R., \& Russo, A. (1998). Pornography: the production and consumption of inequality. New York: Routledge.

Dobash, R. E., Dobash, R. P., Cavanagh, K., \& Medina-Ariza, J. (2007). Lethal and nonlethal violence against an intimate female partner: Comparing male murderers to nonlethal abusers. Violence Against Women, 13(4), 329-353. doi:10.1177/1077801207299204

Donatelli, J. (2015). Playboy is doing what?!? Retrieved from http://www.playboy.com/articles/no-nudity-announcement

Duffy, A., Dawson, D. L., \& das Nair, R. (2016). Pornography addiction in adults: a systematic review of definitions and reported impact. The Journal of Sexual Medicine, 13(5), 760-777. doi:10.1016/j.jsxm.2016.03.002

Duggan, L. (1995). Introduction. In L. Duggan \& N. D. Hunter (Eds.), Sex wars: sexual dissent and political culture (pp. 1-14). New York, NY: Routledge.

Duggan, L., Hunter, N. D., \& Vance, C. S. (1995). False promises: Feminist antipornography legislation. In L. Duggan \& N. D. Hunter (Eds.), Sex wars: Sexual dissent and political culture (pp. 43-67). New York, NY: Routledge.

Dworkin, A. (1981). Pornography: Men possessing women. New York, NY: Penguin Group.

Dworkin, A., \& MacKinnon, C. A. (1988). Pornography and civil rights: a new day for women's equality: Organizing Against Pornography.

Easton, S. (2005). The problem of pornography: regulation and the right to free speech. New York, NY: Routledge.

Eaton, A. W. (2017). Feminist pornography. In M. Mikkola (Ed.), Beyond speech: pornography and analytic feminist philosophy: Oxford Scholarship Online.

Eck, B. A. (2003). Men are much harder: gendered viewing of nude images. Gender \& Society, 17(5), 691-710.

Education Review Office. (2018). Promoting wellbeing through sexuality education. Retrieved from Wellington: https://www.ero.govt.nz/assets/Uploads/Promoting-wellbeing-throughsexuality-education.pdf

Elder, W. B., Morrow, S. L., \& Brooks, G. R. (2015). Sexual self-schemas of gay men: A qualitative investigation. The Counseling Psychologist, 43(7), 942-969. doi:10.1177/0011000015606222 
emerald, e., \& Carpenter, L. (2015). Vulnerability and Emotions in Research. Qualitative Inquiry, 21(8), 741-750. doi:10.1177/1077800414566688

Evans, A., Riley, S., \& Shankar, A. (2010). Technologies of sexiness: theorizing women's engagement in the sexualization of culture. Feminism \& Psychology, 20(1), 114131.

Fahs, B., \& Gonzalez, J. (2014). The front lines of the "back door": Navigating (dis)engagement, coercion, and pleasure in women's anal sex experiences. Feminism \& Psychology, 24(4), 500-520. doi:10.1177/0959353514539648

Fahs, B., Plante, R. F., \& McClelland, S. I. (2017). Working at the crossroads of pleasure and danger: Feminist perspectives on doing critical sexuality studies. Sexualities, $O(0)$, 1-17. doi:10.1177/1363460717713743

Fahs, B., Swank, E., \& Clevenger, L. (2014). Troubling anal sex: gender, power, and sexual compliance in heterosexual experiences of anal intercourse. Gender Issues, 32(1), 19-38. doi:10.1007/s12147-014-9129-7

Fanslow, J. L., \& Robinson, E. M. (2004). Violence against women in New Zealand: Prevalence and health consequences. New Zealand Medical Journal, 117, 1-12.

Fanslow, J. L., Robinson, E. M., Crengle, S., \& Perese, L. (2007). Prevalence of child sexual abuse reported by a cross-sectional sample of New Zealand women. Child Abuse \& Neglect, 31(9), 935-945. doi:https://doi.org/10.1016/i.chiabu.2007.02.009

Farvid, P., \& Braun, V. (2016). Unpacking the "pleasures" and "pains" of heterosexual casual sex: beyond singular understandings. The Journal of Sex Research, 1-18. doi:10.1080/00224499.2016.1143442

Farvid, P., Braun, V., \& Rowney, C. (2017). 'No girl wants to be called a slut!': women, heterosexual casual sex and the sexual double standard. Journal of Gender Studies, 26(5), 544-560. doi:10.1080/09589236.2016.1150818

Ferguson, C. J., \& Hartley, R. D. (2009). The pleasure is momentary...the expense damnable?: The influence of pornography on rape and sexual assault. Aggression and Violent Behavior, 14(5), 323-329. doi:http://dx.doi.org/10.1016/i.avb.2009.04.008

Flood, M. (2007). Exposure to pornography among youth in Australia. Journal of Sociology, 43(1), 45-60. doi:10.1177/1440783307073934

Flood, M. (2009). The harms of pornography exposure among children and young people. Child Abuse Review, 18(6), 384-400. doi:10.1002/car.1092

Flood, M. (2010). Young men using pornography. In K. Boyle (Ed.), Everyday Pornography (pp. 164-178). London: Routledge.

Flood, M. (2013a). Male and female sluts. Australian Feminist Studies, 28(75), 95-107. doi:10.1080/08164649.2012.758024

Flood, M. (2013b). Negotiating gender in men's research among men. In B. Pini \& B. Pease (Eds.), Men, Masculinities and Methodologies (pp. 64-76). United Kingdom: Palgrave.

Foubert, J. D., \& Bridges, A. J. (2016). Predicting bystander efficacy and willingness to intervene in college men and women: the role of exposure to varying levels of violence in pornography. Violence Against Women. doi:10.1177/1077801216648793

Fraterrigo, E. (2016). "Soft-core feminism"?: Playboy, Christie Hefner, and the feminist antipornography movement. In Porno Chic and the Sex Wars (pp. 196-226): University of Massachusetts Press.

Frith, H. (2000). Focusing on sex: using focus groups in sex research. Sexualities, 3(3), 275-297. doi:10.1177/136346000003003001 
Frith, H., \& Kitzinger, C. (2001). Reformulating sexual script theory: developing a discursive psychology of sexual negotiation. Theory \& Psychology, 11(2), 209-232. doi:10.1177/0959354301112004

Fritz, N., \& Paul, B. (2017). From orgasms to spanking: a content analysis of the agentic and objectifying sexual scripts in Feminist, for Women and mainstream pornography. Sex Roles, 77, 639-652.

Gagnon, J. H., \& Simon, W. (1974). Sexual conduct: the social sources of human sexuality. Chicago, IL: Aldine Press.

Garlick, S. (2010). Taking control of sex?: hegemonic masculinity, technology, and internet pornography. Men and Masculinities, 12(5), 597-614. doi: $10.1177 / 1097184 \times 09341360$

Gavey, N. (2005). Just sex?: The cultural scaffolding of rape. East Sussex: Routledge.

Gavey, N. (2012). Beyond "empowerment"? sexuality in a sexist world. Sex Roles, 66(1112), 718-724.

Gavey, N. (2017). Viagra and the coital imperative. In A. Braithwaite \& C. M. Orr (Eds.), Everyday women's and gender studies: introductory concepts (pp. 94-99). New York, NY: Routledge.

Gewirtz, P. (1996). On "I Know It When I See It". The Yale Law Journal, 105(4), 1023-1047. doi:10.2307/797245

Gill, R. (2007a). Postfeminist media culture: Elements of a sensibility. European Journal of Cultural Studies, 10(2), 147-166. doi:10.1177/1367549407075898

Gill, R. (2008). Empowerment/sexism: figuring female sexual agency in contemporary advertising. Feminism \& Psychology, 18(1), 35-60. doi:10.1177/0959353507084950

Gill, R. (2009). Mediated intimacy and postfeminism: a discourse analytic examination of sex and relationships advice in a women's magazine. Discourse \& Communication, 3(4), 345-369. doi:10.1177/1750481309343870

Gill, R. (2012a). Media, empowerment and the 'sexualization of culture' debates. Sex Roles, 66, 736-745.

Gill, R. (2012b). The Sexualisation of Culture? Social and Personality Psychology Compass, 6(7), 483-498. doi:doi:10.1111/j.1751-9004.2012.00433.x

Gill, R. (2017). The affective, cultural and psychic life of postfeminism: A postfeminist sensibility 10 years on. European Journal of Cultural Studies, 20(6), 606-626. doi:10.1177/1367549417733003

Gill, R. C. (2007b). Critical respect: the difficulties and dilemmas of agency and 'choice' for feminism: a reply to Duits and van Zoonen. European Journal of Women's Studies, 14(1), 69-80. doi:10.1177/1350506807072318

Glass, N., Laughon, K., Campbell, J., Block, C. R., Hanson, G., Sharps, P. W., \& Taliaferro, E. (2008). Non-fatal strangulation is an important risk factor for homicide of women. The Journal of emergency medicine, 35(3), 329-335. doi:10.1016/j.jemermed.2007.02.065

Goffman, E. (1963). Stigma: notes on the management of a spoiled identity. New Jersey: Prentice-Hall.

Gorman, S., Monk-Turner, E., \& Fish, J. N. (2010). Free adult internet websites: how prevalent are degrading acts? Gender Issues, 27, 131-145.

Gossett, J. L., \& Byrne, S. (2002). "Click here": a content analysis of internet rape sites. Gender and Society, 16(5), 689-709. doi:10.2307/3081955

Grace, V., Potts, A., Gavey, N., \& Vares, T. (2006). The discursive condition of Viagra. Sexualities, 9(3), 295-314. 
Graham, P. (2017). Men and sex: a sexual script approach. Cambridge: Cambridge University Press.

Green, L., Brady, D., Holloway, D., Staksrud, E., \& Olafsson, K. (2013). What bothers Australian kids online? Children comment on bullies, porn and violence. Kelvin Grove, QLD: ARC Centre of Excellence for Creative Industries and Innovation

Grov, C., Gillespie, B. J., Royce, T., \& Lever, J. (2011). Perceived consequences of casual online sexual activities on heterosexual relationships: a U.S. online survey. Archives of Sexual Behavior, 40, 429-439.

Gunelius, S. (2009). Building brand value the Playboy way. Basingstoke: Palgrave Macmillan.

Gurevich, M., Brown-Bowers, A., Cosma, S., Vasilovsky, A. T., Leedham, U., \& Cormier, N. (2017). Sexually progressive and proficient: Pornographic syntax and postfeminist fantasies. Sexualities, 20(5-6), 558-584. doi:10.1177/1363460716665785

Haggstrom-Nordin, E., Sandberg, J., Hanson, U., \& Tyden, T. (2006). 'It's everywhere!' young Swedish people's thoughts and reflections about pornography. Scand J Caring Sci, 20(4), 386-393. doi:10.1111/j.1471-6712.2006.00417.x

Hald, G. M., \& Malamuth, N. M. (2015). Experimental effects of exposure to pornography: the moderating effect of personality and mediating effect of sexual arousal. Archives of Sexual Behavior, 44(99-109).

Hald, G. M., Malamuth, N. M., \& Yuen, C. (2010). Pornography and attitudes supporting violence against women: revisiting the relationship in nonexperimental studies. Aggress Behav, 36(1), 14-20. doi:10.1002/ab.20328

Hald, G. M., Malamuth, N. N., \& Lange, T. (2013). Pornography and sexist attitudes among heterosexuals. Journal of Communication, 63(4), 638-660. doi:10.1111/jcom.12037

Hammersley, M., \& Traianou, A. (2012). Ethics in qualitative research: controversies and contexts. London: Sage Publications Ltd.

Hardy, S. (1998). The reader, the author, his woman and her lover: soft-core pornography and heterosexual men. London: Cassell.

Hardy, S. (2004). Reading pornography. Sex Education, 4(1), 3-18. doi:10.1080/1468181042000176506

Harvey, L., \& Gill, R. (2014). The sex inspectors: self-help, makeover, and mediated sex. In K. Ross (Ed.), The handbook of gender, sex and media (pp. 487-501). United Kingdom: John Wiley \& Sons, Inc.

Hawkins, G., \& Zimring, F. E. (1988). Pornography in a free society. Cambridge: Cambridge University Press.

Hesse-Biber, S. N. (2014). A re-invitation to feminist research. In S. N. Hesse-Biber (Ed.), Feminist research practice: a primer. Thousand Oaks, CA: SAGE.

Hite, S. (1981). The Hite report on male sexuality. Retrieved from New York:

Hollway, W. (1984). Women's power in heterosexual sex. Women's Studies International Forum, 7(1), 63-68.

Hunt, L. (1996). Introduction: Obscenity and the origins of modernity, 1500-1800. In L. Hunt (Ed.), The invention of pornography: obscenity and the origins of modernity, 1500-1800 (pp. 9-45). New York, NY: Zone Books.

Irvine, J. M. (2015). The other sex work: stigma in sexuality research. Social Currents, 2(2), 116-125. doi:10.1177/2329496515579762

Jensen, R. (1995). Pornographic lives. Violence Against Women, 1(1), 32-54.

Jensen, R. (1996). Knowing pornography. Violence Against Women, 2(1), 82-102. 
Jensen, R. (2007). Getting off: pornography and the end of masculinity. Cambridge, MA: South End Press.

Jensen, R. (2016). Pornographic values: hierarchy and hubris. Sexualization, Media, \& Society, January-March, 1-5.

Kaite, B. (1995). Pornography and difference. Bloomington: Indiana University Press.

Kappeler, S. (1986). The pornography of representation. Cambridge: Polity Press.

Katz, J. (2006). The macho paradox: why some men hurt women and how all men can help. Naperville, Illinois: Sourcebooks, Inc.

Kendrick, W. (1987). The secret museum: pornography in modern culture. New York, NY: Viking.

Kimmel, M. (2000). The gendered society. New York, NY: Oxford University Press.

Kimmel, M. (2005). The gender of desire: essays on male sexuality. Albany: State University of New York Press.

Kimmel, M. (Ed.) (2007). The sexual self: the construction of sexual scripts. Nashville: Vanderbilt University Press.

King, N., \& Horrocks, C. (2010). Interviews in qualitative research. London: SAGE Publications Ltd.

Kingi, V., \& Poppelwell, E. (2005). The viewing habits of users of sexually explicit movies: a Hawke's Bay sample. Retrieved from Wellington, New Zealand:

Kingi, V., Poppelwell, E., \& Paulin, J. (2004). "I know i'm not a dirty old man" The viewing habits of users of sexually explicit movies. Retrieved from Wellington, New Zealand:

Kipnis, L. (1996). Bound and gagged: pornography and the politics of fantasy in America. New York, NY: Grove Press.

Klaassen, M. J. E., \& Peter, J. (2015). Gender (in)equality in internet pornography: a content analysis of popular pornographic internet videos. The Journal of Sex Research, 52(7), 721-735. doi:10.1080/00224499.2014.976781

Klein, M. (2006). Pornography: What men see when they watch. In P. Lehman (Ed.), Pornography: film and culture (pp. 244-258). New Jersey: Rutgers University Press.

Kohut, T., Baer, J. L., \& Watts, B. (2015). Is pornography really about "making hate to women"? Pornography users hold more gender egalitarian attitudes than nonusers in a representative American sample. The Journal of Sex Research, 1-11. doi:10.1080/00224499.2015.1023427

Kohut, T., Balzarini, R. N., Fisher, W. A., \& Campbell, L. (2018). Pornography's associations with open sexual communication and relationship closeness vary as a function of dyadic patterns of pornography use within heterosexual relationships. Journal of Social and Personal Relationships, 35(4), 655-676. doi:10.1177/0265407517743096

Kohut, T., Fisher, W. A., \& Campbell, L. (2017). Perceived effects of pornography on the couple relationship: initial findings of open-ended, participant-informed, "bottomup" research. Archives of Sexual Behavior, 46(2), 585-602. doi:10.1007/s10508016-0783-6

Kosick, W. R. (2015). Pornography. In J. DeLamater \& R. F. Plante (Eds.), Handbook of the sociology of the sexualities (pp. 413-433). Switzerland: Springer International Publishing.

Kreager, D. A., \& Staff, J. (2009). The sexual double standard and adolescent peer acceptance. Social psychology quarterly, 72(2), 143-164. doi:10.1177/019027250907200205 
Lamb, S. (2010). Feminist ideals for a healthy female adolescent sexuality: A critique. Sex Roles: A Journal of Research, 62(5-6), 294-306. doi:10.1007/s11199-009-9698-1

Lambert, N. M., Negash, S., Stillman, T. F., Olmstead, S. B., \& Fincham, F. D. (2012). A love that doesn't last: pornography consumption and weakened commitment to one's romantic partner. Journal of Social and Clinical Psychology, 31(4), 410-438. doi:10.1521/jscp.2012.31.4.410

Leavy, P. (2014). Introduction. In P. Leavy (Ed.), The Oxford Handbook of Qualitative Research (pp. 1-16). New York, NY: Oxford University Press.

Lee, N., \& Boeri, M. (2017). Managing stigma: women drug users and recovery services. Fusio: the Bentley Undergraduate Research Journal, 1(2), 65-94.

Leonhardt, N. D., Willoughby, B. J., \& Young-Petersen, B. (2018). Damaged goods: perception of pornography addiction as a mediator between religiosity and relationship anxiety surrounding pornography use. The Journal of Sex Research, 55(3), 357-368. doi:10.1080/00224499.2017.1295013

Ley, D. (2018). The pseudoscience behind public health crisis legislation. Porn Studies, 5(2), 208-212.

Ley, D., Prause, N., \& Finn, P. (2014). The emperor has no clothes: a review of the 'pornography addiction' model. Current Sexual Health Reports, 6, 94-105.

Liamputtong, P. (2007). Researching the vulnerable: a guide to sensitive research emthods. London: Sage Publications, Inc.

Liberman, R. (2015). 'It's a really great tool': feminist pornography and the promotion of sexual subjectivity. Porn Studies, 2(2-3), 174-191.

Lindner, K. (2012). 'In touch' with the female body: cinema, sport, and lesbian representability. In K. Ross (Ed.), The Handbook of Gender, Sex, and Media (pp. 277293). West Sussex, UK: John Wiley \& Sons, Ltd.

Link, B. G., \& Phelan, J. C. (2001). Conceptualizing stigma. Annual Review of Sociology, 27, 363-385.

Livingstone, S., Haddon, L., Gorzig, A., \& Olafsson, K. (2011). Risks and safety on the internet: the perspective of European children. Full Findings. . LSE, London: EU Kids Online

Lodder, M. (2016). Visual pleasure and gonzo pornography: Mason's challenge to convention in 'the hardest of hardcore'. Porn Studies, 3(4), 373-385. doi:10.1080/23268743.2016.1241160

Lofgren-Martenson, L., \& Mansson, S. (2015). Lust, love, and life: a qualitative study of Swedish adolescents' perceptions and experiences with pornography. In L. Comella \& S. Tarrant (Eds.), New views on pornography: sexuality, politics and the law (pp. 335-359). Santa Barbara, California: ABC-CLIO, LLC.

Loftus, D. (2002). Watching sex: how men really respond to pornography. New York: Thunder's Mouth Press.

Long, J. (2012). Anti-porn: The resurgence of anti-pornography feminism. London: Zed Books Ltd.

Love, T., Laier, C., Brand, M., Hatch, L., \& Hajela, R. (2015). Neuroscience of Internet Pornography Addiction: A Review and Update. Behavioral Sciences, 5(3), 388-433. doi:10.3390/bs5030388

Maas, M. K., \& Dewey, S. (2018). Internet pornography use among collegiate women: gender attitudes, body monitoring, and sexual behavior. SAGE Open, April-June, 19.

MacKinnon, C. (1993). Only Words. Cambridge, MA: Harvard University Press. 
MacKinnon, C. (2005). Women's lives, men's laws. Cambridge, MA: Harvard University Press.

MacKinnon, C. A. (1989). Sexuality, pornography, and method: pleasure under patriarchy. Ethics, 99(2), 314-346.

Maddox, A. M., Rhoades, G. K., \& Markman, H. J. (2011). Viewing sexually-explicit materials alone or together: associations with relationship quality. Arch Sex Behav, 40(2), 441-448. doi:10.1007/s10508-009-9585-4

Malamuth, N. M., Addison, T., \& Koss, M. (2000). Pornography and sexual aggression: are there reliable effects and can we understand them? Annu Rev Sex Res, 11, 26-91.

Malamuth, N. M., Hald, G. M., \& Koss, M. (2012). Pornography, individual differences in risk and men's acceptance of violence against women in a representative sample. Sex Roles, 66(7-8), 427-439.

Malamuth, N. M., \& Spinner, B. (1980). A longitudinal content analysis of sexual violence in the best-selling erotic magazines. The Journal of Sex Research, 16(3), 226-237. doi:10.1080/00224498009551079

Manning, J. C. (2006). The Impact of Internet Pornography on Marriage and the Family: A Review of the Research. Sexual Addiction \& Compulsivity, 13(2-3), 131-165. doi:10.1080/10720160600870711

Marshall, C., \& Rossman, G. B. (2011). Designing qualitative research (5th ed.). Thousand Oaks, CA: Sage Publications, Inc.

Marshall, E. A., Miller, H. A., \& Bouffard, J. A. (2018). Bridging the theoretical gap: using sexual script theory to explain the relationship between pornography use and sexual coercion. Journal of Interpersonal Violence, 0886260518795170. doi:10.1177/0886260518795170

Marston, C., \& Lewis, R. (2014). Anal heterosex among young people and implications for health promotion: a qualitative study in the UK. BMJ Open, 4(8). doi:10.1136/bmjopen-2014-004996

Martin, A. (2016). Men's pornography habits and women's experience of intimacy within heterosexual relationships. (Master's Thesis), University of Otago, Christchurch.

Mason-Grant, J. (2008). Pornography as embodied practice. In A. Soble (Ed.), Power, Nicholas P (pp. 401-418). Lanham, maryland: Rowman \& Littlefield Publishers, Inc.

Mason, G., \& Stubbs, J. (2012). The SAGE Handbook of Criminological Research Methods. In. London: SAGE Publications Ltd. Retrieved from http://methods.sagepub.com/book/sage-hdbk-criminological-researchmethods. doi:10.4135/9781446268285

Matacin, M. L., \& Burger, J. M. (1987). A content analysis of sexual themes in Playboy cartoons. Sex Roles, 17(3), 179-186. doi:10.1007/bf00287624

Mattebo, M., Larsson, M., Tyden, T., Olsson, T., \& Haggstrom-Nordin, E. (2012). Hercules and Barbie? Reflections on the influence of pornography and its spread in the media and society in groups of adolescents in Sweden. Eur J Contracept Reprod Health Care, 17(1), 40-49. doi:10.3109/13625187.2011.617853

Matthews-King, A. (2018). Porn site age verification to be in force by spring next year after delays, minister says. Retrieved from https://www.independent.co.uk/news/uk/home-news/porn-site-ageverification-uk-pornhub-sex-online-adult-video-government-id-a8631886.html

McCormack, M., \& Wignall, L. (2016). Enjoyment, exploration and education: understanding the consumption of pornography among young men with nonexclusive sexual orientations. Sociology. doi:10.1177/0038038516629909 
McKee, A. (2005a). The need to bring the voices of pornography consumers into public debates about the genre and its effects. Australian Journal of Communication, $32(2), 71-94$.

McKee, A. (2005b). The objectification of women in mainstream pornographic videos in Australia. J Sex Res, 42(4), 277-290. doi:10.1080/00224490509552283

McKee, A. (2006a). The aesthetics of pornography: the insights of consumers. Continuum: Journal of Media \& Cultural Studies, 20(4), 523-539.

McKee, A. (2006b). Censorship of sexually explicit materials in Australia: what do consumers of pornography have to say about it? Media International Australia, $120,35-50$.

McKee, A. (2007). The relationship between attitudes towards women, consumption of pornography, and other demographic variables in a survey of 1,023 consumers of pornography. International Journal of Sexual Health, 19(1), 31-45.

McKee, A. (2015). Methodological issues in defining aggression for content analyses of sexually explicit material. Arch Sex Behav, 44(1), 81-87. doi:10.1007/s10508-0130253-3

McKee, A., Albury, K., \& Lumby, C. (2008). The Porn Report. Carlton: Melbourne University Press.

McKeown, J. K. L., Parry, D. C., \& Penny Light, T. (2018). "My iPhone changed my life": how digital technologies can enable women's consumption of online sexually explicit materials. Sexuality \& Culture, 22, 340-354.

Mcnair, B. (1996). Mediated Sex Pornography and Postmodern Culture. London: Arnold.

McPhillips, K., Braun, V., \& Gavey, N. (2001). Defining (hetero)sex: how imperative is the "coital imperative"? Women's Studies International Forum, 24(2), 229-240. doi:https://doi.org/10.1016/S0277-5395(01)00160-1

McRobbie, A. (2004). Post-feminism and popular culture. Feminist Media Studies, 4(3), 255-264. doi:10.1080/1468077042000309937

McRobbie, A. (2008). The Aftermath of Feminism : Gender, Culture and Social Change. London, UK: SAGE Publications.

Mikkola, M. (2019). Pornography: a philosophical introduction. New York, NY: Oxford University Press.

Miller, J., \& Glassner, B. (2016). The 'inside' and the 'outside': finding realities in interviews. In D. Silverman (Ed.), Qualitative Research (4th ed., pp. 51-66). London, UK: Sage Publications Ltd.

Milnes, K. (2010). Challenging the sexual double standard: constructing sexual equality narratives as a strategy of resistance. Feminism \& Psychology, 20(2), 255-259.

Milrod, C., \& Weitzer, R. (2012). The Intimacy Prism: Emotion Management among the Clients of Escorts. Men and Masculinities, 15(5), 447-467. doi:10.1177/1097184X12452148

Mondin, A. (2014). Fair-trade porn + niche markets + feminist audience. Porn Studies, 1(12), 189-192.

Monk-Turner, E., \& Purcell, H. C. (1999). Sexual violence in pornography: How prevalent is it? Gender Issues, 17(2), 58-67. doi:10.1007/s12147-999-0015-7

Montgomery-Graham, S., Kohut, T., Fisher, W., \& Campbell, L. (2015). How the popular media rushes to judgment about pornography and relationships while research lags behind. The Canadian Journal of Human Sexuality, 24(3), 243-256. doi:10.3138/cjhs.243-A4 
Moran, C., \& Lee, C. (2016). 'Everyone wants a vagina that looks less like a vagina': Australian women's views on dissatisfaction with genital appearance. Journal of Health Psychology, 23(2), 229-239. doi:10.1177/1359105316637588

Mowlabocus, S., \& Wood, R. (2015). Introduction: audiences and consumers of porn. Porn Studies, 2(2-3), 118-122. doi:10.1080/23268743.2015.1056465

Mulholland, M. (2013). Young people and pornography: negotiating pornification. New York, USA: Palgrave Macmillan.

Nash, V., Adler, J. R., Horvath, M. A. H., Livingstone, S., Marston, C., Owen, G., \& Wright, J. (2015). Identifying the routes by which children view pornography online: implications for future policy-makers seeking to limit viewing. Retrieved from Department for Culture, Media and Sport:

Neville, L. (2018). Girls who like boys who like boys: women and gay male pornography and erotica. Cham, Switzerland: Springer Nature Switzerland AG.

New Zealand Herald. (2018). Children's Minister Tracey Martin wants online pornography to be regulated. Retrieved from https://www.nzherald.co.nz/nz/news/article.cfm?c id=1\&objectid=12104188

No Fap. (2018). No Fap - Porn Addiction Recovery and Sexual Health Platform. Retrieved from https://www.nofap.com/

Office of Film and Literature Classification. (2018). NZ Youth and Porn: Research findings of a survey on how and why young New Zealanders view online pornography. Wellington, NZ: Office of Film and Literature Classification

Olmstead, S. B., Negash, S., Pasley, K., \& Fincham, F. D. (2013). Emerging adults' expectations for pornography use in the context of future committed romantic relationships: a qualitative study. Archives of Sexual Behavior, 42(625-635).

Owens, E. W., Behun, R. J., Manning, J. C., \& Reid, R. C. (2012). The Impact of Internet Pornography on Adolescents: A Review of the Research. Sexual Addiction \& Compulsivity, 19(1-2), 99-122. doi:10.1080/10720162.2012.660431

Paasonen, S. (2006). Email from Nancy Nutsucker: Representation and gendered address in online pornography. European Journal of Cultural Studies, 9(4), 403-420. doi:10.1177/1367549406069065

Paasonen, S. (2010). Good amateurs: erotica writing and notions of quality. In F. Attwood (Ed.), Porn.com: Making sense of online pornography (pp. 138-154). New York, NY: Peter Lang Publishing, Inc.

Paasonen, S. (2011). Carnal resonance: affect and online pornography. Cambridge: Massachusetts Institute of Technology Press.

Paasonen, S. (2013). Repetition and hyperbole: the gendered choreographies of heteroporn. In K. Boyle (Ed.), Everyday Pornography. New York: Routledge.

Paasonen, S. (2014). Between meaning and mattering: on affect and porn studies. Porn Studies, 1(1-2), 136-142.

Paasonen, S., Kyrölä, K., Nikunen, K., \& Saarenmaa, L. (2015). 'We hid porn magazines in the nearby woods': Memory-work and pornography consumption in Finland. Sexualities, 18(4), 394-412. doi:10.1177/1363460714550911

Parvez, Z. F. (2006). The labor of pleasure: how perceptions of emotional labor impact women's enjoyment of pornography. Gender \& Society, 20(5), 605-631. doi:10.1177/0891243206291109

Paul, P. (2005). Pornified: How pornography is transforming our lives, our relationships, and our families. New York: Times Books.

Peakman, J. (20003). Mighty lewd books: the development of pornography in eighteenthcentury England. Basingstoke, Hampshire: Palgrave Macmillan. 
Peter, J., \& Valkenburg, P. M. (2016). Adolescents and Pornography: A Review of 20 Years of Research. The Journal of Sex Research, 53(4-5), 509-531. doi:10.1080/00224499.2016.1143441

Peters, E. M., Morrison, T., McDermott, D., Bishop, C. J., \& Kiss, M. (2014). Age is in the eye of the beholder: examining the cues employed to construct the illusion of youth in teen pornography. Sexuality \& Culture, 18(3), 527-546. doi:10.1007/s12119-0139210-5

Phillips, L. (2000). Flirting with danger: young women's reflections on sexuality and domination. New York, NY: New York University.

Pornhub. (2015). Pornhub \& New Zealand. Retrieved from https://www.pornhub.com/insights/pornhub-new-zealand

Pornhub. (2018a). 2018 Year in Review - Pornhub Insights. Retrieved from https://www.pornhub.com/insights/2018-year-in-review

Pornhub. (2018b). Extreme category insights. Retrieved from https://www.pornhub.com/insights/extreme-categories

Potts, A. (2002). The science/fiction of sex: feminist deconstruction and the vocabularies of heterosex. New York, NY: Psychology Press.

Purcell, N. (2012). Violence and the pornographic imaginary: the politics of sex, gender, and aggression in hardcore pornography. New York: Routledge.

r/NoFap. (2018). Get a new grip on life - the official Reddit-forum. Retrieved from https://www.reddit.com/r/NoFap/

Rasmussen, E. E., Ortiz, R. R., \& White, S. R. (2015). Emerging adults' responses to active mediation of pornography during adolescence. Journal of Children and Media, 9(2), 160-176. doi:10.1080/17482798.2014.997769

Rasmussen, K. R., Millar, D., \& Trenchuk, J. (2018). Relationships and infidelity in pornography: an analysis of pornography streaming websites. Sexuality \& Culture, $1-14$.

Ray, J. V., Kimonis, E. R., \& Donoghue, C. (2010). Legal, ethical, and methodological considerations in the Internet-based study of child pornography offenders. Behav Sci Law, 28(1), 84-105. doi:10.1002/bsl.906

Reinharz, S. (1992). Feminist methods in social research. New York: Oxford University Press.

Renzetti, C. M. (2013). Feminist criminology. Abingdon, Oxon: Routledge.

Resch, M. N., \& Alderson, K. G. (2014). Female partners of men who use pornography: are honesty and mutual use associated with relationship satisfaction? Journal of Sex \& Marital Therapy, 40(5), 410-424. doi:10.1080/0092623X.2012.751077

Richards, L. (1999). Using NVIVO in qualitative research. London, UK: Sage Publications Ltd.

Rotherham, N. (2018). Porn: all you need to know about the UK's porn block for under 18s. Retrieved from https://www.bbc.com/news/newsbeat-43795806

Rothman, E. F., Kaczmarsky, C., Burke, N., Jansen, E., \& Baughman, A. (2015). "Without porn ... I wouldn't know half the things I know now": a qualitative study of pornography use among a sample of urban, low-income, Black and Hispanic youth. The Journal of Sex Research, 52(7), 736-746. doi:10.1080/00224499.2014.960908

Rubin, A., \& Babbie, E. (2010). Essential research methods for social work (2nd ed.). Belmont, CA: Brooks/Cole, Cengage Learning.

Rubin, G. (1993). Misguided, dangerous and wrong: an analysis of anti-pornography politics. In A. Assiter \& C. Avedon (Eds.), Bad girls and dirty pictures: the challenge to reclaim feminism (pp. 18-40). London: Pluto Press. 
Saldana, J. (2011). Fundamentals of qualitative research. New York, NY: Oxford University Press.

Scarcelli, C. M. (2015). 'It is disgusting, but ...': adolescent girls' relationship to internet pornography as gender performance. Porn Studies, 2(2-3), 237-249. doi:10.1080/23268743.2015.1051914

Schneider, J. P. (2000). Effects of cybersex addiction on the family: Results of a survey. Sexual Addiction \& Compulsivity, 7(1-2), 31-58. doi:10.1080/10720160008400206

Scott, J. E., \& Cuvelier, S. J. (1987). Violence in Playboy magazine: a longitudinal analysis. Archives of Sexual Behavior, 16(4), 279-288.

Scott, J. E., \& Cuvelier, S. J. (1993). Violence and sexual violence in pornography: is it really increasing? Archives of Sexual Behavior, 22(4), 357-371.

Segal, L. (1998). Only the literal: the contradictions of anti-pornography feminism. Sexualities, 1(1), 43-62.

Seguin, L. J., Rodrigue, C., \& Lavigne, J. (2018). Consuming ecstasy: representations of male and female orgasm in mainstream pornography. The Journal of Sex Research, 55(3), 348-356. doi:10.1080/00224499.2017.1332152

Senn, C. Y. (1993). Women's Multiple Perspectives and Experiences with Pornography. Psychology of Women Quarterly, 17(3), 319-341. doi:10.1111/j.14716402.1993.tb00490.x

Shaw, S. M. (1999). Men's leisure and women's lives: the impact of pornography on women. Leisure Studies, 18(3), 197-212. doi:10.1080/026143699374925

Shope, J. H. (2004). When Words Are Not Enough: The Search for the Effect of Pornography on Abused Women. Violence Against Women, 10(1), 56-72. doi: $10.1177 / 1077801203256003$

Shor, E., \& Golriz, G. (2018). Gender, race, and aggression in mainstream pornography. Archives of Sexual Behavior. doi:10.1007/s10508-018-1304-6

Shor, E., \& Seida, K. (2018). "Harder and harder"? is mainstream pornography becoming increasingly violence and do viewers prefer violent content? The Journal of Sex Research, 1-13. doi:10.1080/00224499.2018.1451476

Simon, W., \& Gagnon, J. H. (1986). Sexual scripts: permanence and change. Arch Sex Behav, 15(2), 97-120.

Smith, C. (2010). Pornographication: A discourse for all seasons. International Journal of Media and Cultural Politics, 6(1), 103-108.

Smith, C., \& Attwood, F. (2014). Anti/pro/critical porn studies. Porn Studies, 1(1-2), 7-23. doi:10.1080/23268743.2014.887364

Smith, C., Barker, M., \& Attwood, F. (2015). Why do people watch porn? Results from PornResearch.Org. In L. T. Comella, Shira (Ed.), New views on pornography: sexuality, politics, and the law (pp. 277-296). Santa Barbara: ABC-CLIO, LLC.

Smith, M. (2012). Youth viewing sexually explicit material online: addressing the elephant on the screen. Sexuality Research and Social Policy, 10(1), 62-75. doi:10.1007/s13178-012-0103-4

Sniewski, L., Farvid, P., \& Carter, P. (2018). The assessment and treatment of adult heterosexual men with self-perceived problematic pornography use: A review. Addict Behav, 77, 217-224. doi:10.1016/j.addbeh.2017.10.010

Sostar, T., \& Sullivan, R. (2015). The money shot in feminist queer and mainstream pornographies. In T. Miller (Ed.), The routledge companion to global popular culture. New York, NY: Routledge. 
Spaulding, C. (1988). Anti-pornography laws as a claim for equal respect: feminism, leberalism. Berkeley Women's Law Journal, 4(1), 128-165.

Stanley, N., Barter, C., Wood, M., Aghtaie, N., Larkins, C., Lanau, A., \& Overlien, C. (2018). Pornography, sexual coercion and abuse and sexting in young people's intimate relationships: a European study. Journal of Interpersonal Violence, 33(19), 29192944. doi:10.1177/0886260516633204

Stappenbeck, C. A., George, W. H., Staples, J., Nguyen, H., Davis, K. C., Kaysen, D., . . . Kajumulo, K. F. (2016). In-the-moment dissociation, emotional numbing, and sexual risk: the influence of sexual trauma history, trauma symptoms, and alcohol intoxication. Psychology of violence, 6(4), 586-595. doi:10.1037/a0039978

Stewart, D. N., \& Szymanski, D. M. (2012). Young adult women's reports of their male romantic partner's pornography use as a correlate of their self-esteem, relationship quality, and sexual satisfaction. Sex Roles, 67(5), 257-271. doi:10.1007/s11199-012-0164-0

Strossen, N. (2000). Defending pornography: free speech, sex, and the fight for women's rights (Vol. New York University Press): New York, NY.

Struthers, W. M. (2008). Wired for intimacy: how pornography hijacks the male brain: Accessible Publishing Systems PTY, Ltd.

Sun, C., Bridges, A., Johnson, J. A., \& Ezzell, M. B. (2016). Pornography and the male sexual script: an analysis of consumption and sexual relations. Archives of Sexual Behavior, 45(4), 983-994. doi:10.1007/s10508-014-0391-2

Sun, C., Bridges, A., Wosnitzer, R., Scharrer, E., \& Liberman, R. (2008). A comparison of male and female directors in popular pornography: what happens when women are at the helm? Psychology of Women Quarterly, 32(3), 312-325. doi:10.1111/j.1471-6402.2008.00439.x

Sun, C., Ezzell, M., \& Kendall, O. (2017). Naked aggression: the meaning and practice of ejaculation on a woman's face. Violence Against Women, 23(14), 1710-1729.

Sweeney, B. N. (2017). Slut shaming. In K. L. Nadal (Ed.), The SAGE encylopedia of psychology and gender (pp. 1578-1580). Thousand Oaks, CA: SAGE Publications, Inc.

Szabo, T. (2010). Strange love, or" how I learned to stop worrying and love porn. In D. Monroe (Ed.), Porn - Philosophy for everyone: How to think with kink (pp. 81-92). United Kingdom: John Wiley \& Sons Ltd.

Szymanski, D. M., \& Stewart-Richardson, D. N. (2014). Psychological, relational, and sexual correlates of pornography use on young adult heterosexual men in romantic relationships. The Journal of Men's Studies, 22(1), 64-82. doi:10.3149/jms.2201.64

Taormino, T., Shimizu, C. P., Penley, C., \& Miller-Young, M. (2013). The feminist porn book: the politics of producing pleasure. New York: The Feminist Press.

Tarrant, S. (2016). The pornography industry: what everyone needs to know. New York: Oxford University Press.

Taylor, K., \& Jackson, S. (2018). 'I want that power back': Discourses of masculinity within an online pornography abstinence forum. Sexualities, 21(4), 621-639. doi:10.1177/1363460717740248

Thomas, J. N., \& Williams, D. J. (2016). Getting off on sex research: A methodological commentary on the sexual desires of sex researchers. Sexualities, 19(1-2), 83-97. doi:10.1177/1363460715583610

Thompson, L., \& Donaghue, N. (2014). The confidence trick: Competing constructions of confidence and self-esteem in young Australian women's discussions of the 
sexualisation of culture. Women's Studies International Forum, 47, 23-35. doi:https://doi.org/10.1016/j.wsif.2014.07.007

Tibbals, C. A. (2014). Gonzo, trannys, and teens - current trends in US adult content production, distribution, and consumption. Porn Studies, 1(1-2), 127-135. doi:10.1080/23268743.2013.863659

Tolman, D. L. (2002). Dilemmas of desire: teenage girls talk about sexuality. Cambridge, MA: Harvard University Press.

Tyler, M. (2010). 'Now that's pornography!' Violence and domination in Adult Video News. In K. Boyle (Ed.), Everyday Pornography (pp. 50-62). Abingdon, Oxon: Routledge.

Tyler, M. (2015). Harms of production: theorising pornography as a form of prostitution. Women's Studies International Forum, 48, 114-123. doi:http://dx.doi.org/10.1016/j.wsif.2014.11.014

Tylka, T. (2015). No harm in looking, right? Men's pornography consumption, body image, and well-being. Psychology of Men and Masculinity, 16(1), 97-107.

Tylka, T., \& Kroon Van Diest, A. M. (2015). You looking at her "hot" body may not be "cool" for me: integrating male partners' pornography use into objectification theory for women. Psychology of Women Quarterly, 39(1), 67-84. doi:10.1177/0361684314521784

van Doorn, N. (2010). Keeping it real: user-generated pornography, gender reification, and visual pleasure. Convergence: The International Journal of Research into New Media Technologies, 16(4), 411-430. doi:10.1177/1354856510375144

Vance, C. S. (1984). Pleasure and danger: towards a politics of sexuality. In C. S. Vance (Ed.), Pleasure and danger: exploring female sexuality (pp. 1-27). London: Routledge.

Vannier, S. A., Currie, A. B., \& O'Sullivan, L. F. (2014). Schoolgirls and soccer moms: a content analysis of free "teen" and "MILF" online pornography. J Sex Res, 51(3), 253-264. doi:10.1080/00224499.2013.829795

Vares, T., Potts, A., Gavey, N., \& M. Grace, V. (2007). Reconceptualizing cultural narratives of mature women's sexuality in the Viagra era. Journal of Aging Studies, 21(2), 153164. doi:https://doi.org/10.1016/j.jaging.2006.08.002

Voros, F. (2009). The invention of addiction to pornography. Sexologies, 18, 243-246.

Voss, G. (2015). Stigma and the shaping of the pornography industry. Abingdon, Oxon: Routledge.

Walker, S., Temple-Smith, M., Higgs, P., \& Sanci, L. (2015). 'It's always just there in your face': young people's views on porn. Sexual Health, 12(3), 200-206. doi:http://dx.doi.org/10.1071/SH14225

Webber, V., \& Brunger, F. (2018). Assessing risk to researchers: using the case of sexuality research to inform research ethics board guidelines. Forum: Qualitative Social Research, 19(3). doi:dx.doi.org/10.17169/fqs-19.3.3062.

Weiss, M. (2011). Techniques of pleasure: BDSM and the circuits of sexuality. Durham, NC: Duke University Press.

Weitzer, R. (2017). Resistance to sex work stigma. Sexualities, 21(5-6), 717-729. doi:10.1177/1363460716684509

Wertz, F. J., Charmaz, K., McMullen, L. M., Josselson, R., Anderson, R., \& McSpadden, E. (2011). Five ways of doing qualitative analysis: phenomenological psychology, grounded theory, discourse analysis, narrative research, and intuitive inquiry. New York, NY: The Guildford Press. 
West, R. (1987). The feminist-conservative anti-pornography alliance and the 1986 Attorney General's Commission on Pornography Report. American Bar Foundation Research Journal, 12(4), 681-711.

Whisnant, R. (2004). Confronting pornography: some conceptual basics. In R. Whisnant \& C. Stark (Eds.), Not for sale: feminists resisting prostitution and pornography. Melbourne, Victoria: Spinifix Press Pty Ltd.

Whisnant, R. (2010). From Jekyll to Hyde: the grooming of male pornography consumers. In K. Boyle (Ed.), Everyday Pornography (pp. 114-133). Abingdon, Oxon: Routledge.

Whisnant, R. (2016a). "But what about Feminist porn?": Examining the work of Tristan Taormino. Sexualization, Media, \& Society, 2(2).

Whisnant, R. (2016b). Pornography, humiliation, and consent. Sexualization, Media, and Society, 2(3). doi:10.1177/2374623816662876

Wiederman, W. M. (2015). Sexual script theory: past, present and future. In J. DeLamater \& F. R. Plante (Eds.), Handbook of the Sociology of Sexualities (pp. 7-22). Cham: Springer International Publishing.

Wiles, R. (2013). What are qualitative research ethics? London: Boomsbury Academic.

Williams, D. J. (2016). The framing of frequent sexual behavior and/or pornography viewing as addiction: some concerns for social work. Journal of Social Work, 17(5), 616-623.

Williams, L. (1989). Hard core: power, pleasure, and the "frenzy of the visible". Los Angeles, California: University of California Press.

Williams, L. (2014). Pornography, porno, porn: thoughts on a weedy field. Porn Studies, 1(1-2), 24-40. doi:10.1080/23268743.2013.863662

Willis, E. (1993). Feminism, moralism and pornography. New York Law School Law Review, 38, 351-358.

Willoughby, B. J., Carroll, J. S., Busby, D. M., \& Brown, C. C. (2016). Differences in pornography use among couples: Associations with satisfaction, stability, and relationship processes. Archives of Sexual Behavior, 45(1), 145-158. doi:10.1007/s10508-015-0562-9

Wilson, G. (2015). Your brain on porn: internet pornography and the emerging science of addiction. Kent: Commonwealth Publishing.

Wodda, A., \& Panfil, V. R. (2018). Insert sexy title here: Moving toward a sex-positive criminology. Feminist Criminology, 13(5), 583-608. doi:10.1177/1557085117693088

Wong, H.-w., \& Yau, H.-y. (2014). "I don't like watching Japanese adult videos because you like it": the politics of pornography consumption in Taiwan. SAGE Open, April-June, $1-11$.

Wright, P. J., Sun, C., Steffen, N. J., \& Tokunaga, R. S. (2015). Pornography, Alcohol, and Male Sexual Dominance. Communication Monographs, 82(2), 252-270. doi:10.1080/03637751.2014.981558

Ybarra, M. L., \& Mitchell, K. J. (2005). Exposure to internet pornography among children and adolescents: a national survey. Cyberpsychology \& Behvior, 8(5), 473-486.

Young, M. (2014). Authenticity and its role within feminist pornography. Porn Studies, 1(1-2), 186-188. doi:10.1080/23268743.2014.888250

Zhou, Y., \& Paul, B. (2016). Lotus Blossom or Dragon Lady: A content analysis of 'Asian women' online pornography. Sexuality \& Culture, 20(4), 1083-1100. doi:10.1007/s12119-016-9375-9 
Zitzman, S. T., \& Butler, M. H. (2009). Wives' experience of husbands' pornography use and concomitant deception as an attachment threat in the adult pair-bond relationship. Sexual Addiction \& Compulsivity, 16(3), 210-240. doi:10.1080/10720160903202679 